\title{
Impact of New-generation Wide-base Tires on Pavement Structure and Fuel Consumption
}

\author{
Prepared By \\ Imad L. Al-Qadi \\ University of Illinois at Urbana-Champaign \\ Izak M. Said \\ University of Illinois at Urbana-Champaign \\ Jaime Hernandez \\ Marquette University \\ Egemen Okte \\ University of Illinois at Urbana-Champaign
}

Research Report No. ICT-20-001

https://doi.org/10.36501/0197-9191/20-001

Illinois Center for Transportation

March 2020 

TECHNICAL REPORT DOCUMENTATION PAGE

\begin{tabular}{|l|l|}
\hline $\begin{array}{l}\text { 1. Report No. } \\
\text { ICT-20-001 }\end{array}$ & $\begin{array}{l}\text { 2. Government Accession No. } \\
\text { N/A }\end{array}$ \\
\hline
\end{tabular}

\section{Title and Subtitle}

Impact of New-generation Wide-base Tires on Pavement Structure and Fuel Consumption

3. Recipient's Catalog No.

N/A

\section{Report Date}

March 2020

6. Performing Organization Code N/A

\section{Authors}

Imad L. Al-Qadi (https://orcid.org/0000-0002-5824-103X), Izak M. Said

(https://orcid.org/0000-0002-1796-0337), Jaime Hernandez

(https://orcid.org/0000-0002-9665-0408), and Egemen Okte

\section{Performing Organization Name and Address}

Illinois Center for Transportation

Department of Civil and Environmental Engineering

University of Illinois at Urbana-Champaign

205 North Mathews Avenue, MC-250

Urbana, IL 61801

\section{Sponsoring Agency Name and Address}

Department of Transportation \& Infrastructure / Ministères des Transports et de

I'Infrastructure

New Brunswick Department of Transportation \& Infrastructure (NBDTI)

Fredericton, New Brunswick / Nouveau Brunswick

Canada

\section{Supplementary Notes}

Conducted in cooperation with the New Brunswick Department of Transportation \& Infrastructure (NBDTI).

https://doi.org/10.36501/0197-9191/20-001

\section{Abstract}

This study combined multiple approaches to evaluate the structural and economic impact of using new-generation wide-base tires (NG-WBT) in New Brunswick, Canada. A three-dimensional finite-element model of a typical pavement structure was used to predict critical pavement responses. The model included measured tire-pavement contact forces among other variables overlooked in conventional flexible pavement analysis approaches. Using the model output, regression analysis was used to predict the responses under various loadings without performing finite-element analysis. Eight-year weight-in-motion data and critical pavement responses were used in transfer functions to predict pavement damage and the corresponding progression of international roughness index (IRI) over an analysis period of 60 years. Most pavement responses from NG-WBT compared to dual-tire assembly (DTA) were between $20 \%$ and $30 \%$ higher. The smallest difference was the vertical strain on top of subgrade. The life cycle cost analysis (LCCA) considered reduction of fuel consumption because of the use of NG-WBTs. Two scenarios were analyzed: (1) Case A, where maintenance was performed periodically and independent of IRI values, and (2) Case B, where IRI threshold triggered maintenance. A reduction in fuel costs was significant in both cases. Maintaining a low pavement IRI would increase savings in vehicle and truck fuel costs. The results show that the agency cost to maintain pavement used by NG-WBT is expected to be between Can\$7,703 to $\$ 8,840$ (2019 dollars) for $10 \%$ and $20 \%$ of all tandem axles using NG-WBT per 1 kilometer for a 60-year analysis period. The annual worth of such savings would be Can\$298 and $\$ 342$ (2019 dollars), respectively. On the other hand, the fuel savings per truck-km is expected to be between Can\$30,471 to $\$ 60,119$ (2019 dollars) for $10 \%$ and $20 \%$ of all tandem axles using NG-WBT per 1 kilometer for the same analysis period. The annual worth of such savings would be Can\$1,100 and $\$ 2,172$ (2019 dollars) per 1 kilometer, respectively. Additionally, the trucks would save 0.42 and 0.107 CAD annually per ton transported per 1 kilometer for $10 \%$ and $20 \%$ MG-WBT market penetrations, respectively.

\section{Key Words}

Flexible Pavement, Wide-base Tires, Life Cycle Cost Analysis, Life Cycle Assessment, Economic Impact, Environmental Impact, Finite Element

19. Security Classif. (of this report) Unclassified.
20. Security Classif. (of this page) Unclassified.

\section{Distribution Statement}

No restrictions.
21. No. of Pages
22. Price
$25+$ appendices
N/A 



\section{ACKNOWLEDGMENT, DISCLAIMER, MANUFACTURERS' NAMES}

This project was conducted in cooperation with the Illinois Center for Transportation (ICT) and the New Brunswick Department of Transportation \& Infrastructure (NBDTI). Assistance by Corey White and Matt Illsley of NBDTI is greatly appreciated.

The contents of this report reflect the view of the authors, who are responsible for the facts and the accuracy of the data presented herein. The contents do not necessarily reflect the official views or policies of the Illinois Center for Transportation or the New Brunswick Department of Transportation. This report does not constitute a standard, specification, or regulation.

This work used the Extreme Science and Engineering Discovery Environment (XSEDE) at the San Diego Supercomputer Center, which is supported by National Science Foundation grant number $\mathrm{ACl}$ 1548562. 


\section{EXECUTIVE SUMMARY}

This study combined multiple approaches to evaluate the structural and economic impact of using new-generation wide-base tires (NG-WBT) in New Brunswick, Canada. A three-dimensional finiteelement model of a typical pavement structure was used to predict critical pavement responses. The model included measured tire-pavement contact forces among other variables overlooked in conventional flexible pavement analysis approaches. Using the model output, regression analysis was used to predict the responses under various loadings without performing finite-element analysis.

Eight-year weight-in-motion data and critical pavement responses were used in transfer functions to predict pavement damage and the corresponding progression of international roughness index (IRI) over an analysis period of 60 years. Most pavement responses from NG-WBT compared to dual-tire assembly (DTA) were between $20 \%$ and $30 \%$ higher. The smallest difference was the vertical strain on top of subgrade. The life cycle cost analysis (LCCA) considered reduction of fuel consumption because of the use of NG-WBTs. Two scenarios were analyzed: (1) Case A, where maintenance was performed periodically and independent of IRI values, and (2) Case B, where IRI threshold triggered maintenance. A reduction in fuel costs was significant in both cases. Maintaining a low pavement IRI would increase savings in vehicle and truck fuel costs. The results show that the agency cost to maintain pavement used by NG-WBT is expected to be between Can $\$ 7,703$ to $\$ 8,840$ (2019 dollars) for $10 \%$ and $20 \%$ of all tandem axles using NG-WBT per one kilometer for a 60 -year analysis period. The annual worth of such savings would be Can\$298 and \$342 (2019 dollars), respectively. On the other hand, the fuel savings per truck-km is expected to be between Can\$30,471 to $\$ 60,119$ (2019 dollars) for $10 \%$ and $20 \%$ of all tandem axles using NG-WBT per one kilometer for the same analysis period. The annual worth of such savings would be Can\$1,100 and \$2,172 (2019 dollars) per one kilometer, respectively. Additionally, the trucks would save 0.42 and 0.107 CAD annually per ton transported per one kilometer for $10 \%$ and $20 \%$ MG-WBT market penetrations, respectively. 


\section{TABLE OF CONTENTS}

CHAPTER 1: INTRODUCTION .......................................................................1

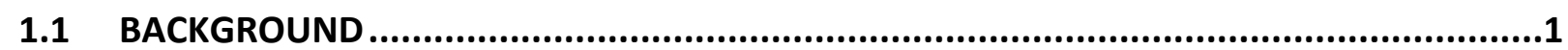

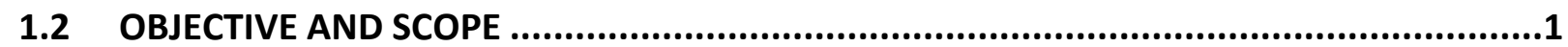

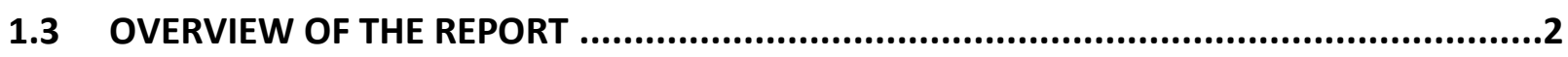

CHAPTER 2: CURRENT STATE OF KNOWLEDGE...........................................................3

2.1 NEW-GENERATION WIDE-BASE TIRES .................................................................3

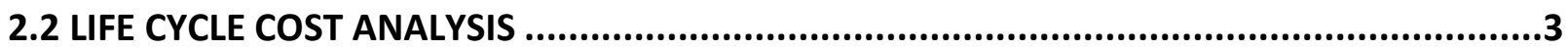

CHAPTER 3: FINITE-ELEMENT MODEL ...............................................................5

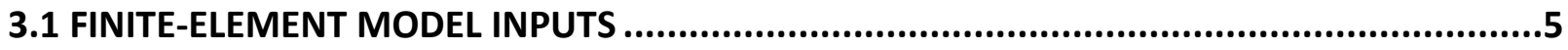

3.2 CRITICAL PAVEMENT RESPONSES-SINGLE AXLE...............................................7

3.3 CRITICAL PAVEMENT RESPONSES-TANDEM AND TRIDEM AXLE...............................8

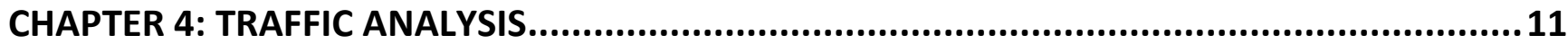

4.1 WEIGHT-IN-MOTION DATA ANALYSIS .........................................................11

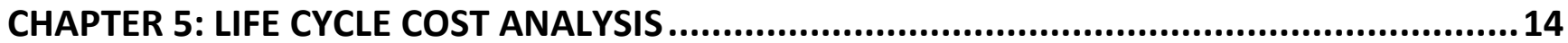

5.1 PAVEMENT LIFE CYCLE COST ANALYSIS TERMINOLOGIES ......................................14

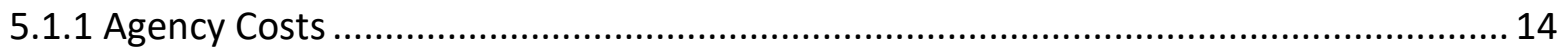

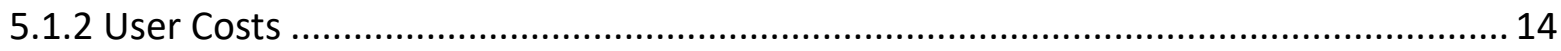

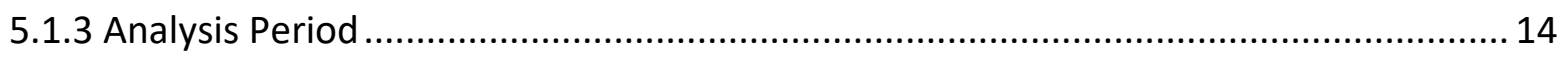

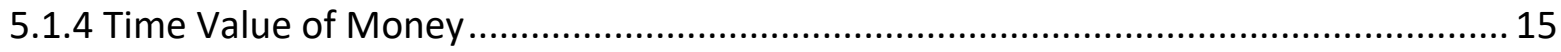

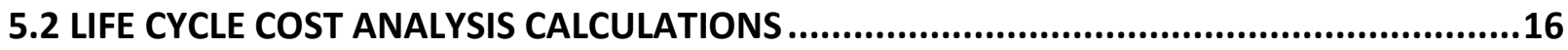

5.2.1 Pavement Damage and IRI Progression ............................................................ 16

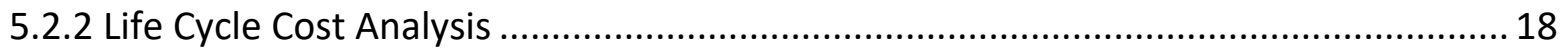

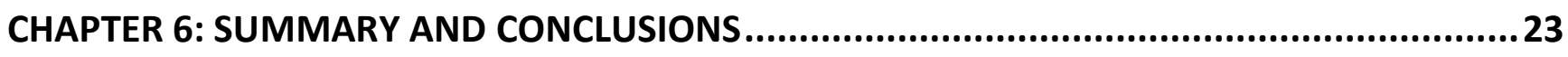

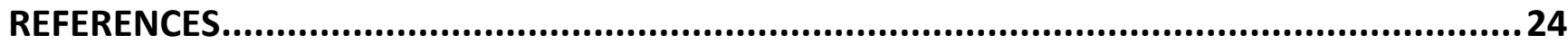

APPENDIX A: FINITE-ELEMENT MODEL .................................................................26

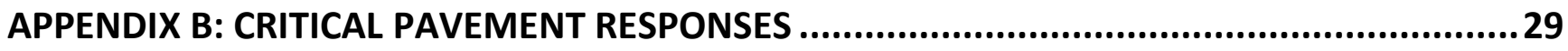


APPENDIX C: WEIGHT-IN-MOTION ANALYSIS

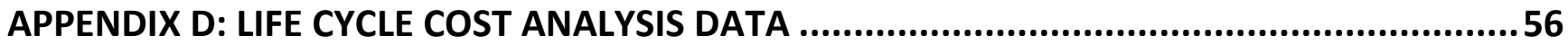




\section{LIST OF FIGURES}

Figure 1.1. Summary of procedure to perform LCCA.............................................................. 2

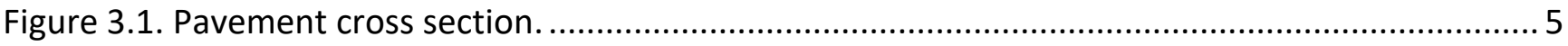

Figure 3.2. Comparison of critical pavement responses between DTA and NG-WBT at 36 kN............ 9

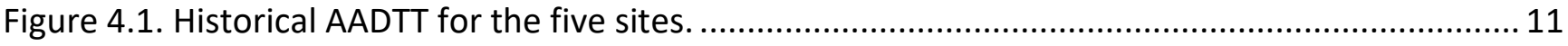

Figure 4.2. Yearly and average class distribution as the percent of AADTT................................... 12

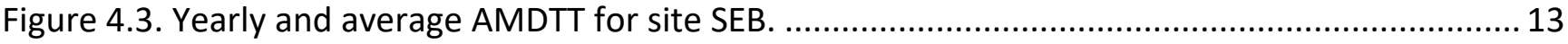

Figure 4.4. Average normalized axle load spectra for single, tandem, and tridem axles. .................. 13

Figure 5.1. Area of thermal cracking for a duration of 15 years $(1 \mathrm{~m} / \mathrm{km}=5.28 \mathrm{ft} / \mathrm{mi}) \ldots \ldots \ldots \ldots \ldots \ldots \ldots \ldots$

Figure 5.2. IRI progressions for cases A and B for various market penetrations. .............................. 20

Figure 5.3. Market penetration vs lifetime costs (present cost) in Can\$ per km............................. 22

Figure A.1. Pavement layers configuration. ................................................................................. 26

Figure A.2. Variation of vertical, transverse, and longitudinal contact forces along contact length..... 27

Figure A.3. Asphalt layer temperature distribution. .................................................................. 27

Figure A.4. Pavement model using ABAQUS (left) and geometric configuration in plan view (right)... 28

Figure B.1. Tensile strain at the bottom of the AC layer. ............................................................... 30

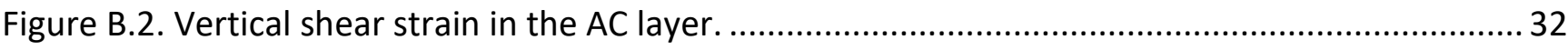

Figure B.3. Transverse strain at the surface of the AC layer. .......................................................... 34

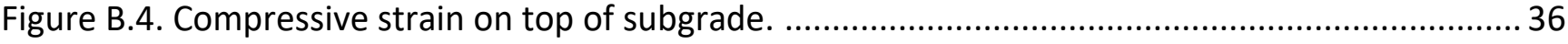




\section{LIST OF TABLES}

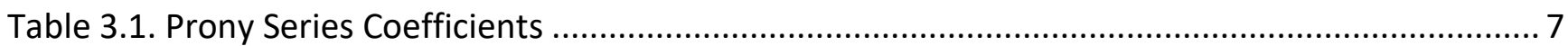

Table 3.2. Resilient Modulus of Borrow A and Glacial Till and Corresponding Yearly Distribution ......... 7

Table 3.3. Linear Regression Models for Critical Pavement Responses at 8 km/h........................... 10

Table 5.1. Truck Distribution and Average Number of Tandem Axles per Class ................................ 19

Table 5.2. Maintenance Schedule of the Two Scenarios................................................................. 20

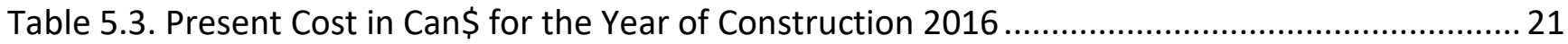

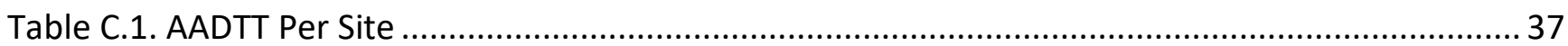

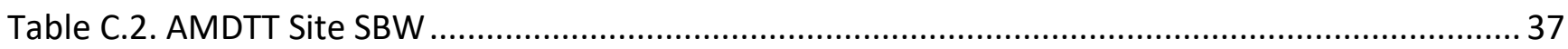

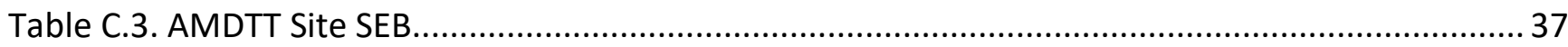

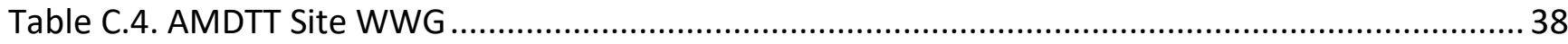

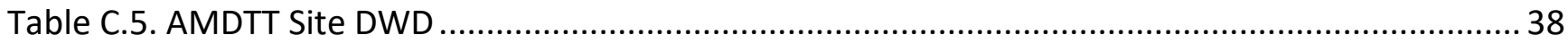

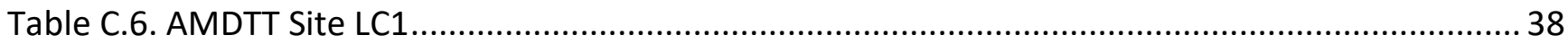

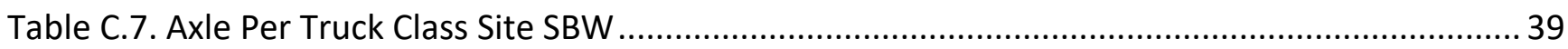

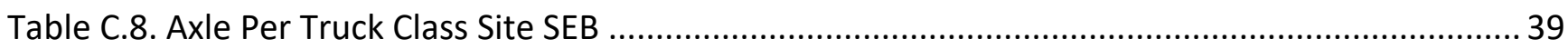

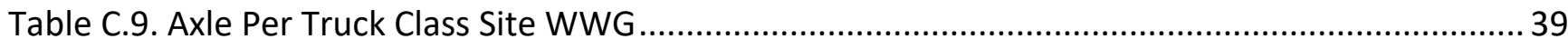

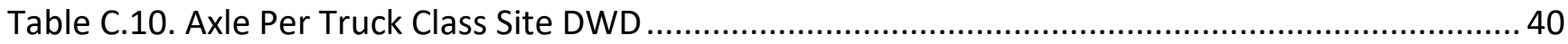

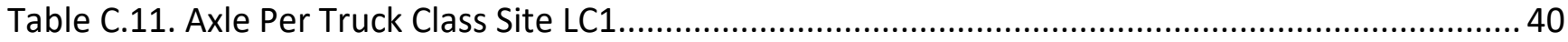

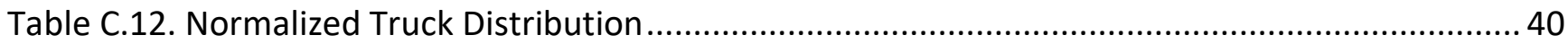

Table C.13. Normalized Single Axle Load Distribution Per Class for Site SBW ................................... 41

Table C.14. Normalized Single Axle Load Distribution Per Class for Site SEB.................................... 42

Table C.15. Normalized Single Axle Load Distribution Per Class for Site WWG ................................. 43

Table C.16. Normalized Single Axle Load Distribution Per Class for Site DWD ................................ 44

Table C.17. Normalized Single Axle Load Distribution Per Class for Site LC1 .................................... 45

Table C.18. Normalized Tandem Axle Load Distribution Per Class for Site SBW ............................... 46

Table C.19. Normalized Tandem Axle Load Distribution Per Class for Site SEB ................................ 47

Table C.20. Normalized Tandem Axle Load Distribution Per Class for Site WWG ............................. 48

Table C.21. Normalized Tandem Axle Load Distribution Per Class for Site DWD ............................... 49

Table C.22. Normalized Tandem Axle Load Distribution Per Class for Site LC1 ...............................50

Table C.23. Normalized Tridem Axle Load Distribution Per Class for Site SBW ................................ 51

Table C.24. Normalized Tridem Axle Load Distribution Per Class for Site SEB .................................. 52

Table C.25. Normalized Tridem Axle Load Distribution Per Class for Site WWG ............................... 53 
Table C.26. Normalized Tridem Axle Load Distribution Per Class for Site DWD ................................ 54

Table C.27. Normalized Tridem Axle Load Distribution Per Class for Site LC1 ................................ 55

Table D.1. Pay Items for Case A-0\% Penetration .........................................................................5 56

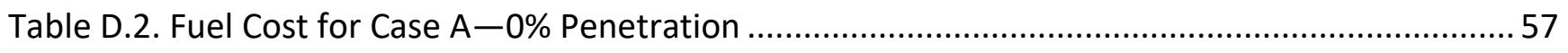

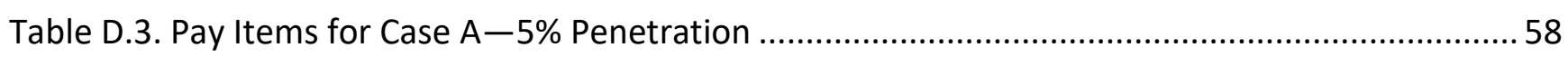

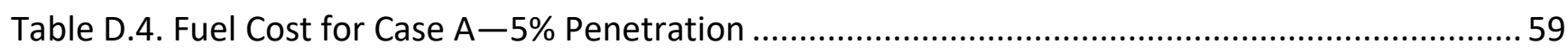

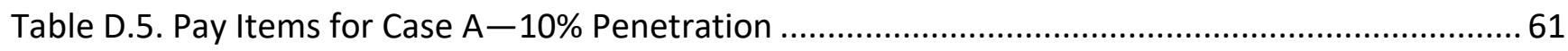

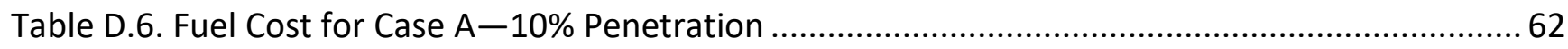

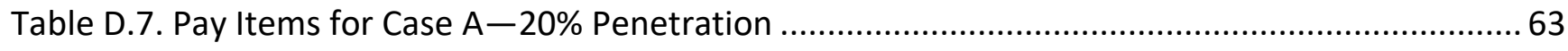

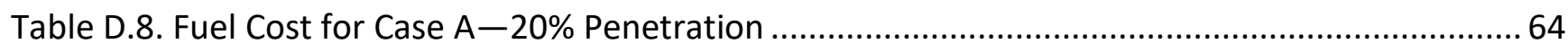

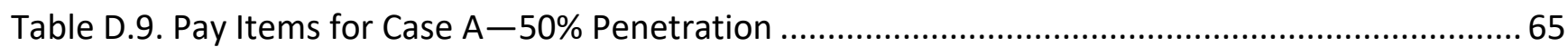

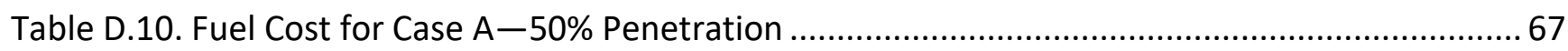

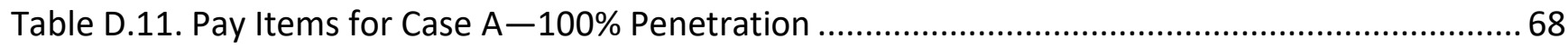

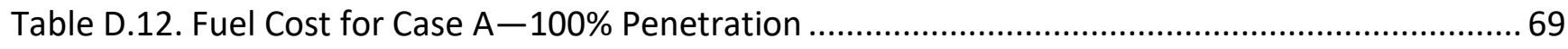

Table D.13. Pay Items for Case B-0\% Penetration .................................................................... 70

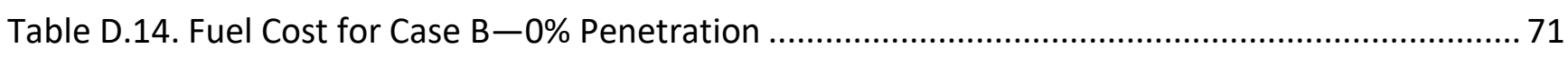

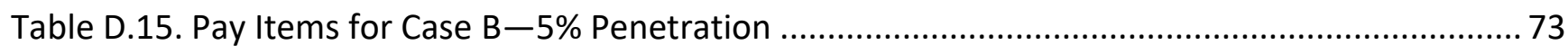

Table D.16. Fuel Cost for Case B-5\% Penetration .................................................................... 74

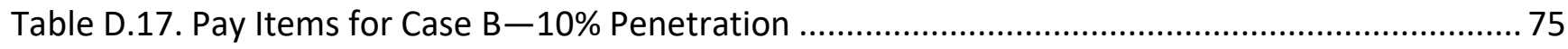

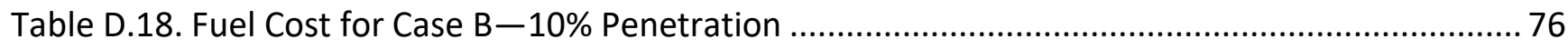

Table D.19. Pay Items for Case B-20\% Penetration ................................................................... 78

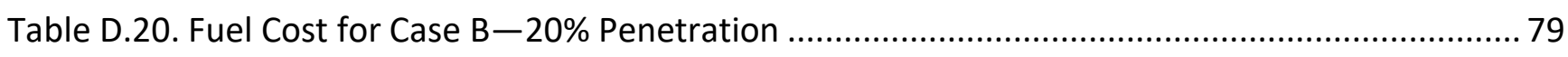

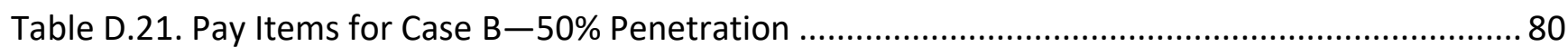

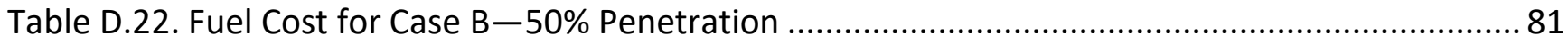

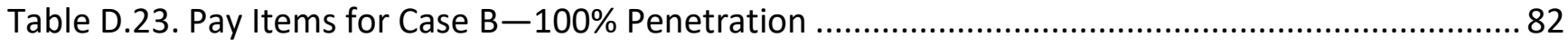

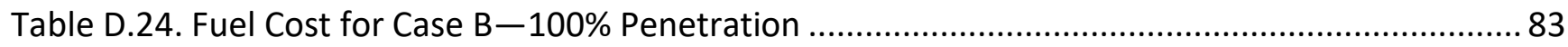





\section{CHAPTER 1: INTRODUCTION}

\subsection{BACKGROUND}

Replacing trucks' dual-tire assembly (DTA) with wide-base tires (WBT) is one of the options to reduce environmental impact in transportation. In addition to improved fuel efficiency, WBTs reduce gross truck weight, require less frequent replacement, and have lower maintenance costs (Al-Qadi and Elseifi 2007). Despite the benefits, studies in the 1980s and 1990s reported that WBTs caused more pavement damage than DTA. This drawback motivated the tire industry to produce the so-called new-generation WBT (NG-WBT) in the early 2000s. Since then, studies have shown that NG-WBT caused similar (Al-Qadi et al. 2002) or slightly more (Al-Qadi et al. 2018) damage than DTA, depending on NG-WBT and loaded pavements.

However, current pavement structural evaluation excludes NG-WBT's economic benefits, such as less money spent on fuel and higher truck payload. Consequently, a methodology such as life cycle cost analysis (LCCA) is needed to assess the long-term economic feasibility of pavement infrastructure subjected to NG-WBT. The main two pillars of LCCA are agency and user costs. Agency costs are associated with constructing and rehabilitating the pavement structure during its analysis period. User costs are incurred by the user for travelling on the pavement. These costs are work zone delays, excessive fuel consumption because of pavement condition, tire and maintenance costs, crash costs, and emission costs. Studies have shown that WBTs could reduce user costs by up to $1.5 \%$ per axle and increase the carrying capacity by $1.5 \%$ per axle (Kang et al. 2019). At the same time, an increase in pavement roughness because of potential greater pavement damage would increase fuel consumption (Chatti and Zaabar 2012).

\subsection{OBJECTIVE AND SCOPE}

The objective of this study is to perform LCCA to quantify the trade-off between NG-WBT's economic advantages and disadvantages in New Brunswick, Canada. The quantification combined analytical (finite-element method and regression analysis), experimental (measured tire-pavement contact stresses), field (weight-in-motion [WIM] data), and empirical (pavement-damage estimation using transfer functions) tools to assess the impacts of NG-WBT market penetration. Figure 1.1 summarizes the procedure to perform LCCA. The procedure combines the finite-element (FE) method, WIM data, regression analysis, pavement-damage calculation, and prediction of international roughness index (IRI) progression. Finite-element (FE) analysis provided critical pavement responses for four load magnitudes. Based on FE results, regression analyses were performed to predict critical pavement responses for any axle type (i.e., single, tandem, and tridem) and load magnitude. Pavement damage, which utilizes critical pavement responses as input, was estimated using transfer functions, while IRI progression was predicted using the mechanistic-empirical pavement design guide (MEPDG) (AASHTO 2008). Finally, pavement damage and IRI progression were used in LCCA to determine the economic impact of using NG-WBT. The remainder of the report provides further details on the main blocks in Figure 1.1. 


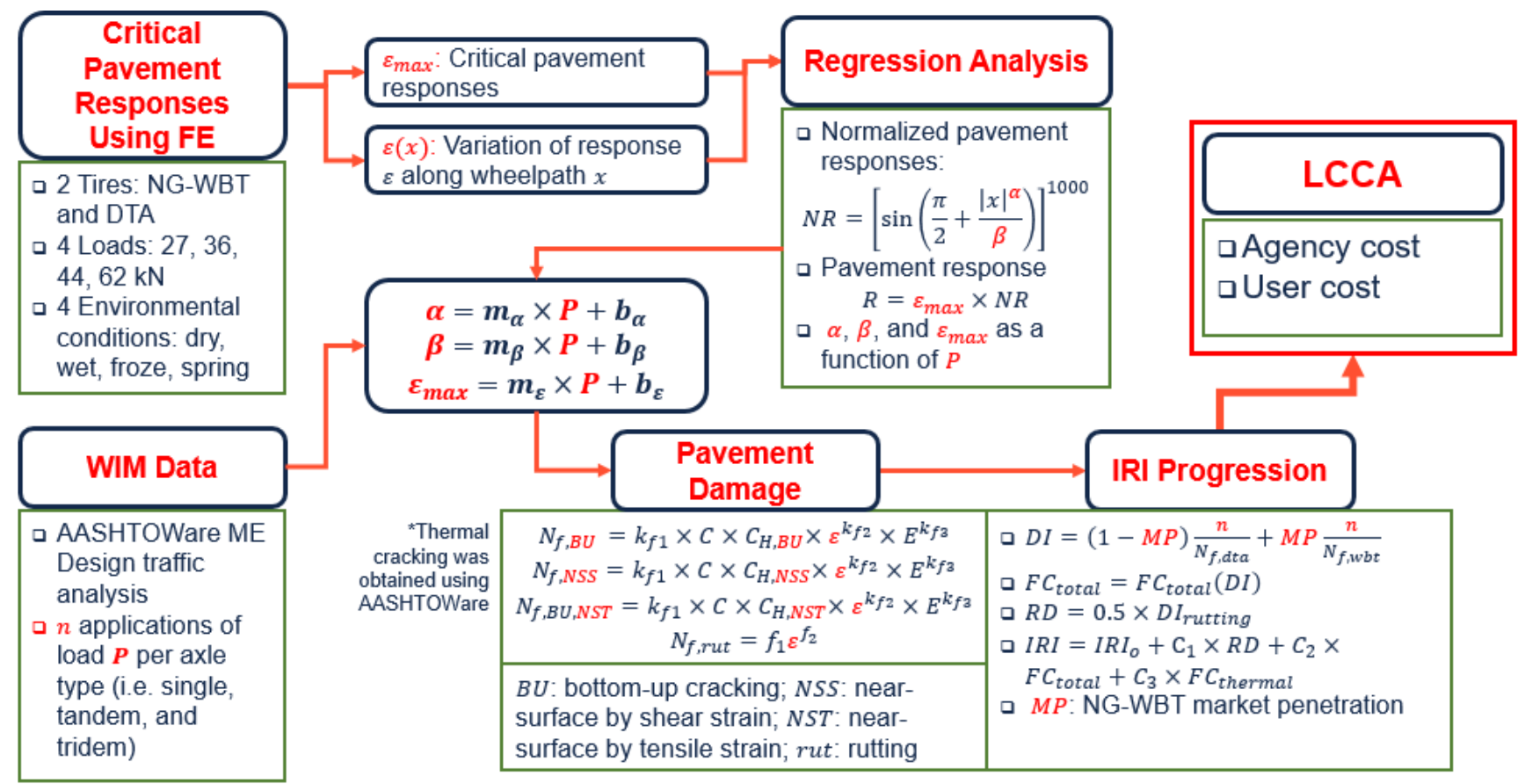

Figure 1.1. Summary of procedure to perform LCCA.

\subsection{OVERVIEW OF THE REPORT}

This report consists of six chapters. Chapter 2 provides a literature review on existing research regarding the effect of WBTs on pavements and presents the LCCA of pavement structures. Chapter 3 details the pavement sections and structural model considered in addition to material characterization, environmental factors, seasonal temperature variation, and definitions of threedimensional contact loads for NG-WBT and DTA. Chapter 4 focuses on WIM data and traffic calculation, while Chapter 5 presents the damage calculation and LCCA results. Finally, Chapter 6 presents the findings of the project. 


\section{CHAPTER 2: CURRENT STATE OF KNOWLEDGE}

This chapter summarizes research efforts in quantifying the impact of NG-WBTs on pavements and determining the life cycle cost of pavement structures in the United States and Canada.

\subsection{NEW-GENERATION WIDE-BASE TIRES}

Since the 1980s, the transportation sector has made attempts to replace dual-tire assembly (DTA) with wide-base tires (WBT) to reduce environmental impacts. In addition to improved fuel efficiency, WBTs were reported to introduce several other advantages such as better handling and braking, reduced gross weight, less frequent tire replacement, and lower maintenance costs (Al-Qadi and Elseifi 2007). However, the studies conducted between the 1980 s and 2000 suggested that WBTs caused more damage to pavement than DTA. This motivated the tire industry to produce the newgeneration of WBT (NG-WBT) with a wider tread than its predecessors and a change in the tire design. While the first-generation WBT had a width of 385 or $425 \mathrm{~mm}$, the width was increased to $445 \mathrm{~mm}$ and $455 \mathrm{~mm}$ (in the United States) or up to $495 \mathrm{~mm}$ (in Europe) for NG-WBTs (Al-Qadi and Elseifi 2017).

Illinois Center for Transportation (ICT) project 17-018 (Al-Qadi et al. 2017), sponsored by the New Brunswick Department of Transportation and Infrastructure (NBDTI), discussed impacts of NG-WBT (445/50R22.5) and DTA (275/80R22.5) on typical pavement sections in New Brunswick. Finiteelement models were developed based on accurate loading conditions and material properties. The results showed that NG-WBT developed greater critical pavement responses than DTA, especially near the pavement surface. The vertical compressive strain on top of the subgrade was similar for the two tire configurations. Moreover, the study concluded that the increase in NG-WBT market penetration may result in an increase in pavement damage. For example, for a specific set of variables, a $6 \%$ increase in damage was associated with a $20 \%$ NG-WBT market penetration.

\subsection{LIFE CYCLE COST ANALYSIS}

There are multiple ways to quantify the long-term costs and environmental impacts of a pavement project. Life cycle assessment (LCA) quantifies the environmental impacts of a roadway project. In pavement LCA's cradle-to-grave analysis, every decision that goes into planning a section, from the production of the asphalt binder to removal of the pavement surface from the roadway, is considered, and the corresponding environmental impacts are analyzed. Similarly, cost-benefit analysis (CBA) is another type of analysis in which the costs and benefits of a decision are compared from cradle to grave. Cost-benefit analysis is used widely for making decisions about constructing new pavement sections. Life cycle cost analysis (LCCA), in which the costs of alternatives are compared, assumes the benefits of each alternative are comparable (Walls and Smith 1998). Life cycle cost analysis is used widely for making maintenance and rehabilitation decisions. Because most road construction is focused on maintenance and rehabilitation and not on new construction, LCCA is a common method for analyzing long-term costs of a pavement project. In this study, LCCA will be used to quantify the economic impacts of NG-WBT. 
There are two main costs that affect decision-making for pavement LCCA: agency and user. Agency costs are associated with constructing and maintaining a pavement section. These costs are easy to estimate if rehabilitation strategies are known. User costs, on the other hand, are incurred by the roadway user. These costs could be due to fuel consumption, tire wear and tear, vehicle maintenance and repair, traffic delay, crashes, and emissions. User costs are generally difficult to estimate because of inherit uncertainty in traffic and their association with pavement condition.

Life cycle cost analysis was first introduced to US agencies by the American Association of State Highway Officials (AASHTO) "Red Book" in 1960. In 1969, available data were combined to be used in a systematic life cycle costing approach (Winfrey 1969). In 1972, LCCA was first recommended to the agencies by AASHTO as part of the 1972 Pavement Design Guide. However, it was not adopted because there was no clear framework for agencies to follow. The Federal Highway Administration (FHWA) released "Life Cycle Cost Analysis in Pavement Design" in 1998, which includes user and agency costs. In 2004, FHWA released "RealCost," an LCCA tool. In 2011, the National Cooperative Highway Research Program developed a process for pavement selection based on LCCA, NCHRP 703. However, the exact methodology of LCCA is left to each individual agency, which makes the results of LCCA difficult to compare. In 2014, Caltrans explored 17 agencies nationwide and reported that the range of parameters used by agencies for LCCA analysis were not consistent. Although all explored agencies supported LCCA, only 60\% applied LCCA regularly (ASCE 2014).

In Canada, a recent study investigated provinces' selection of LCCA parameters. Like the United States, there was a wide variation of LCCA parameters and methodologies that make the comparison of LCCA difficult (Moges et al. 2017). The discount rate varied from $4 \%$ to $6 \%$, whereas the analysis period varied from 15 to 30 years for different provinces. Moreover, some provinces included user costs whereas other provinces did not. Note that having different LCCA assumptions, while problematic, is unavoidable because of the time and resource constraints of agencies and the wide ranges of acceptable LCCA parameters.

Several other calculation models have also been used by agencies to conduct LCCA (e.g., QUEWZ in Australia and COMPARE in Great Britain). A common model used by many countries, including the United States, is Highway Design and Management (HDM), which was developed by the World Bank and has several versions (Huvstig 1998). Although the models are powerful, they have not been used to their designed extent (Chatti and Zaabar 2012).

Although LCCA is a good tool for decision-making, it requires several assumptions and prediction models. These assumptions include inflation and discount rates, traffic conditions, and performance of the roadway for the next few decades. It is crucial for an agency to be transparent about these assumptions so that analyses can be duplicated and compared. 


\section{CHAPTER 3: FINITE-ELEMENT MODEL}

Finite-element analysis provided critical pavement responses, which are one of the main inputs in damage prediction. The three-dimensional (3D) pavement model includes variables usually overlooked in conventional analyses of flexible pavement, such as dynamic analysis (Yoo and Al-Qadi 2007), moving load (Yoo et al. 2006), linear viscoelastic asphalt concrete (AC), nonlinear granular materials, 3D contact loads (Al-Qadi and Yoo 2007), nonuniform temperature distribution in the AC layer, and interaction between pavement layers (Yoo et al. 2006). Comprehensive details of the FE model may be found elsewhere (Said et al. 2019; Hernandez et al. 2016). Thirty-two cases were considered in the FE model in this study. The cases result from combining four environmental conditions (wet, dry, spring-thaw, and frozen), four tire loads (27, 36, 44, and $62 \mathrm{kN})$, and two tire configurations (DTA and NG-WBT).

\subsection{FINITE-ELEMENT MODEL INPUTS}

Four inputs are used in the model: layer configuration, material properties, loading, and environmental conditions. For layer configuration, the pavement structure is a typical pavement section in New Brunswick, Canada. It is composed of a 140-mm AC layer, 150-mm granular base, and 450-mm subbase on top of a 600-mm layer of Borrow A material and a glacial till (Figure 3.1).

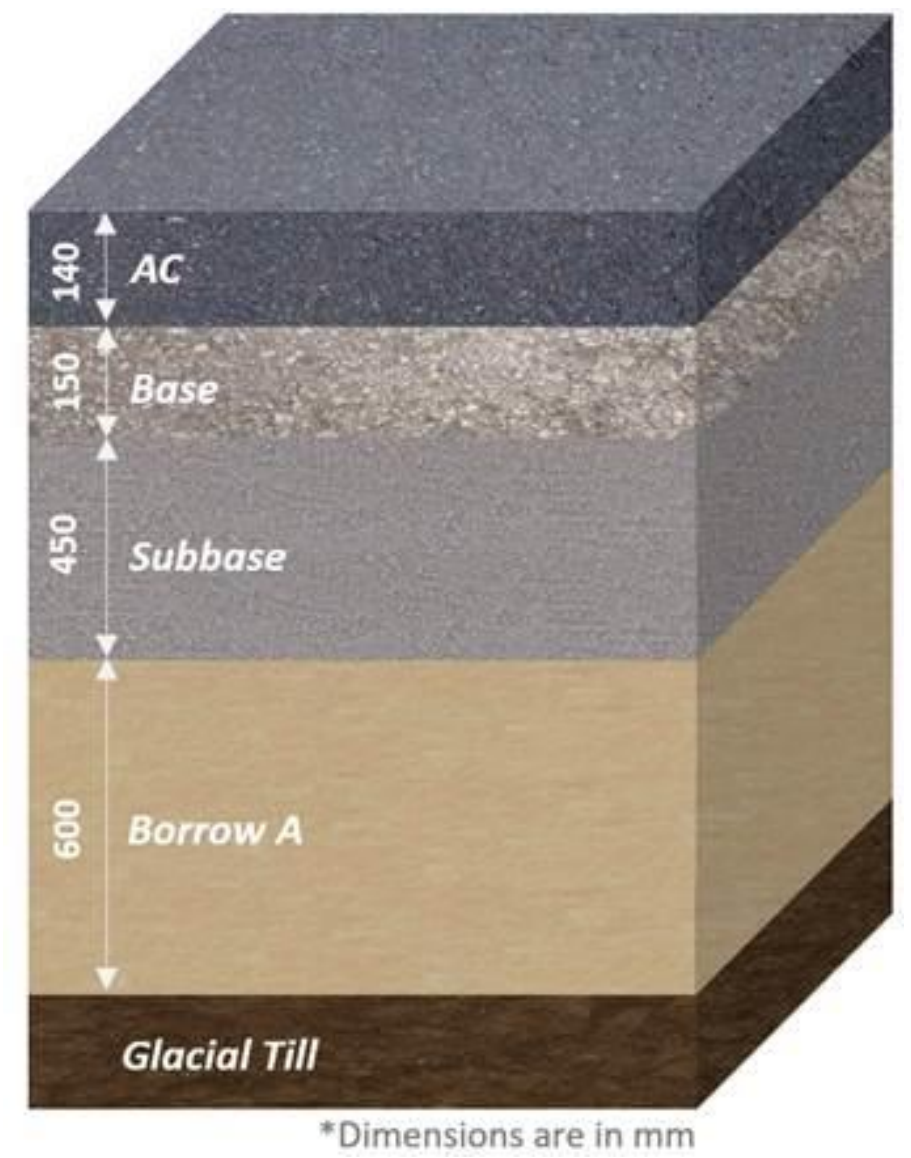

Figure 3.1. Pavement cross section. 
Three material models were considered: linear viscoelastic, nonlinear stress-dependent, and linear elastic. Asphalt concrete was assumed to be linear viscoelastic, with Prony's series terms determined from the Long-Term Pavement Performance (LTPP) database for New Brunswick (Appendix A). The terms in the Prony series in equation (1) were obtained by fitting a generalized Maxwell model to the dynamic modulus in LTPP. The generalized Maxwell model has the following form:

$$
E(t)=E_{\infty}+\sum_{i=1}^{N} E_{i} \exp \left(-\frac{t}{\tau_{i}}\right)
$$

where $E(t)$ is relaxation modulus at time $t ; E_{\infty}$ is residual relaxation modulus; $N$ is number of dashpot-spring elements; $E_{i}$ is spring constant; and $\tau_{i}$ is relaxation time. Table 3.1 summarizes the generalized Maxwell coefficients.

The granular base was modeled as nonlinear stress-dependent, and the constants were obtained from test results in an ICT database (Tutumluer 2009). This material model is appropriate for the relatively thin AC pavement section at hand. Thin AC causes high stresses in the granular base, thus triggering nonlinear behavior. From the database, $k$-values for the model in equation (2) can be determined:

$$
M_{r}=k_{1} p_{a}\left(\frac{\theta}{p_{a}}\right)^{k_{2}}\left(\frac{\tau_{o c t}}{2}+1\right)^{k_{3}}
$$

where $M_{r}$ is resilient modulus; $k_{1}, k_{2}$, and $k_{3}$ are regression coefficients; $\theta=\sigma_{1}+\sigma_{2}+\sigma_{3}$ is bulk stresses; $\tau_{o c t}$ is octahedral shear stress $=\sqrt{2} / 3\left(\sigma_{1}-\sigma_{3}\right)$; and $p_{a}$ is atmospheric pressure. The $k$ values, $k_{1}=4272.4, k_{2}=0.631$, and $k_{3}=-0.134$, were considered for the base layer. Finally, subbase and subgrade were assumed linear elastic. The New Brunswick Department of Transportation provided resilient modulus of $76 \mathrm{MPa}$ and a Poison's ratio of 0.40 for the subbase. Subgrade's resilient modulus is seasonally dependent, and Table 3.1 presents the values.

Variations in subgrade's resilient modulus and temperature profile in the AC accounted for environmental conditions. Because there is no distinction between the "Borrow $A$ " layer and the underlying "Glacial Till" in New Brunswick, the resilient moduli of these two layers were adjusted to the same values. Table 3.2 presents the yearly distribution of effective resilient modulus. The temperature distribution along the depth of the AC layer was determined using an analytical onedimensional temperature distribution model for the AC layer (Wang et al. 2009; Hernandez et al. 2016). The surface temperature, a defining factor for the temperature distribution, corresponded to the quarterly average temperature in New Brunswick.

The loading consisted of measured 3D contact forces for DTA (275/80R22.5) and NG-WBT (DTA445/50R22.5) loaded at 27, 36, 44, and $62 \mathrm{kN}$, with a tire inflation pressure of $690 \mathrm{kPa}$ (Hernandez et al. 2013). Using experimentally measured contact forces would improve the accuracy of calculated critical pavement responses, especially those near the pavement surface (Al-Qadi and Yoo 2007). 
Table 3.1. Prony Series Coefficients

\begin{tabular}{|c|c|}
\hline $\boldsymbol{E}_{\boldsymbol{i}}$ & $\boldsymbol{\tau}_{\boldsymbol{i}}$ \\
\hline 1439.24 & $1.00 \mathrm{E}-06$ \\
\hline 2803.27 & $1.00 \mathrm{E}-05$ \\
\hline 3841.67 & 0.0001 \\
\hline 3302.01 & 0.001 \\
\hline 4335.10 & 0.01 \\
\hline 3208.31 & 0.1 \\
\hline 2186.80 & 1 \\
\hline 1103.99 & 10 \\
\hline 398.68 & 100 \\
\hline 252.29 & 1000 \\
\hline 78.10 & 10000 \\
\hline
\end{tabular}

Table 3.2. Resilient Modulus of Borrow A and Glacial Till and Corresponding Yearly Distribution

\begin{tabular}{|c|c|c|c|}
\hline Moisture Condition & $\begin{array}{c}\boldsymbol{M}_{\boldsymbol{r}} \\
(\mathbf{M P a})\end{array}$ & $\begin{array}{c}\text { Duration } \\
\text { (months) }\end{array}$ & $\begin{array}{c}\text { Surface Temp. } \\
\left({ }^{\circ} \mathbf{C}\right)\end{array}$ \\
\hline Wet & 34.5 & 5 & 7.0 \\
\hline Dry & 44.8 & 5 & 17.0 \\
\hline Spring-Thaw & 27.6 & 1 & 3.3 \\
\hline Frozen & 138 & 1 & -8.3 \\
\hline
\end{tabular}

\subsection{CRITICAL PAVEMENT RESPONSES-SINGLE AXLE}

Critical pavement responses are linked to pavement distresses through transfer functions. The critical pavement responses of interest in this study are tensile strain at the bottom of the $A C\left(\varepsilon_{11, b o t ~ a c}\right)$, vertical strain on the top of the subgrade $\left(\varepsilon_{22}\right.$,subgrade $)$, transverse tensile strain on the surface of the $\operatorname{AC}\left(\varepsilon_{33, t o p ~ a c}\right)$, and vertical shear strain in the $A C$ layer $\left(\varepsilon_{23, a c}\right)$. Each critical pavement response is linked to a distress. Tensile strain at the bottom of the $A C$ is associated with bottom-up fatigue cracking. Vertical shear strain in the AC layer and transverse tensile strain on AC's surface are related to near-surface fatigue cracking. Subgrade rutting highly correlates with the vertical strains on top of the subgrade.

Figure 3.2 compares the critical pavement responses for the four environmental conditions and two tires considered at a $36 \mathrm{kN}$ load. NG-WBT generated $9 \mu \varepsilon$ higher $\varepsilon_{11, b o t ~ a c}$ than DTA. The NG-WBT configuration has a smaller contact area than the DTA (Hernandez et al. 2013), which leads to higher loads at the tire-pavement interface and, hence, critical responses, especially near the surface. Concerning the environmental effect, $A C$ temperature was the main factor affecting $\varepsilon_{11, b o t ~ a c}$. Because of AC's viscoelastic nature, its modulus decreases with temperature increase, thus escalating critical pavement responses. The relatively high contact stresses of NG-WBT would intensify AC layer deformation and, consequently, higher distortion and shear strain. The $\varepsilon_{23, a c}$ from NG-WBT was $3 \mu \varepsilon$ higher than those of DTA. The transverse strain at the surface of the AC $\left(\varepsilon_{33, \text { top ac }}\right)$ was slightly lower 
for the NG-WBT configuration than that of DTA. The vertical strain on top of the borrow material and subgrade $\left(\varepsilon_{22, \text { subgrade }}\right)$ were comparable between NG-WBT and DTA. The maximum difference in $\varepsilon_{22, \text { subgrade }}$ between tires was $3.6 \mu \varepsilon$. The impact of load distribution diminishes with depth, and after a certain depth, pavement responses are affected mainly by total tire load rather than its distribution on the surface. Similar trends were observed for other considered loads (i.e., 27, 44, and $62 \mathrm{kN}$ ) (Appendix B).

The results showed a linear relationship between critical pavement responses and tire load for a specific tire configuration and environmental condition. Table 3.3 presents the equations that relate load and critical strains with the corresponding coefficients of correlation $\left(R^{2}\right)$. The equations are valid for the structure presented in this study and axle loading between 27 and $62 \mathrm{kN}$ at the corresponding environmental condition and at a speed of $8 \mathrm{~km} / \mathrm{h}$.

\subsection{CRITICAL PAVEMENT RESPONSES-TANDEM AND TRIDEM AXLE}

Tandem and tridem axles in the model require a model geometry that significantly increases the already high computational cost. To overcome this limitation, the approach proposed by Fakhri and Ghanizadeh (2014) was extended. In the approach, the variation of critical pavement responses with distance is given as follows in equation (3):

$$
Y=\left[\sin \left(\frac{\pi}{2}+\frac{|x|^{\alpha}}{\beta}\right)\right]^{1000}
$$

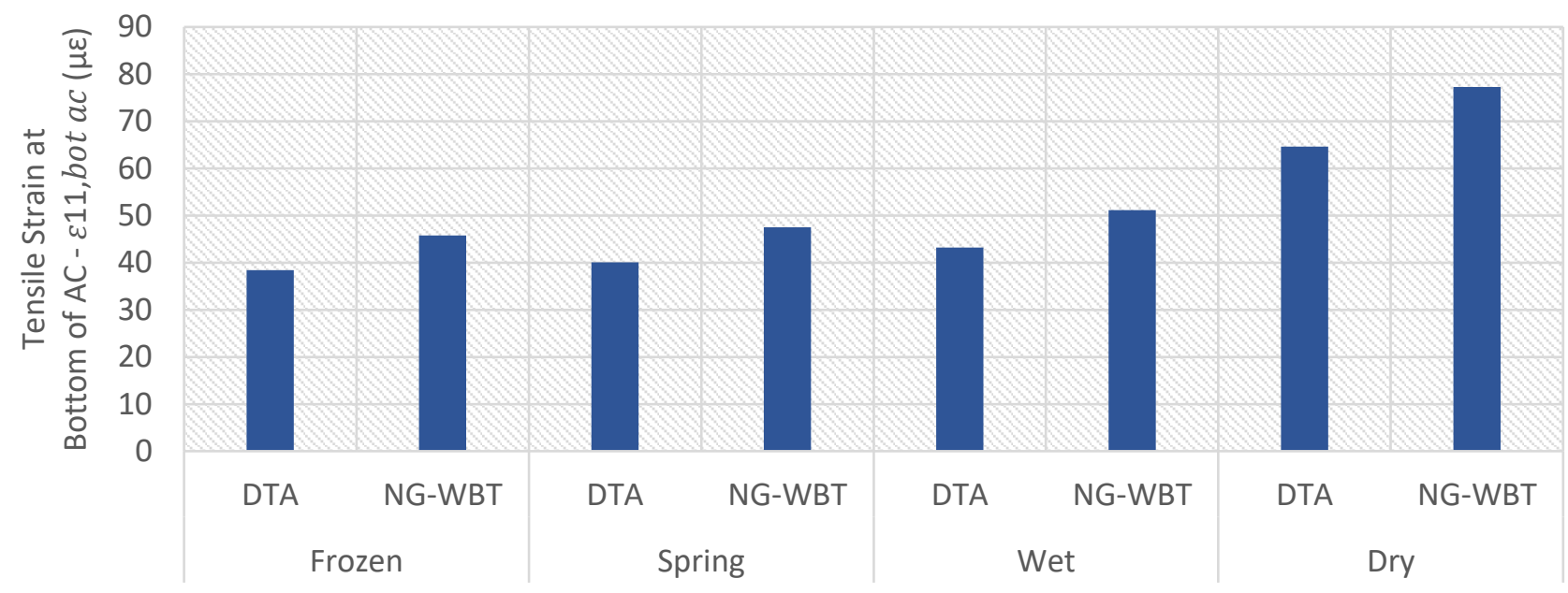



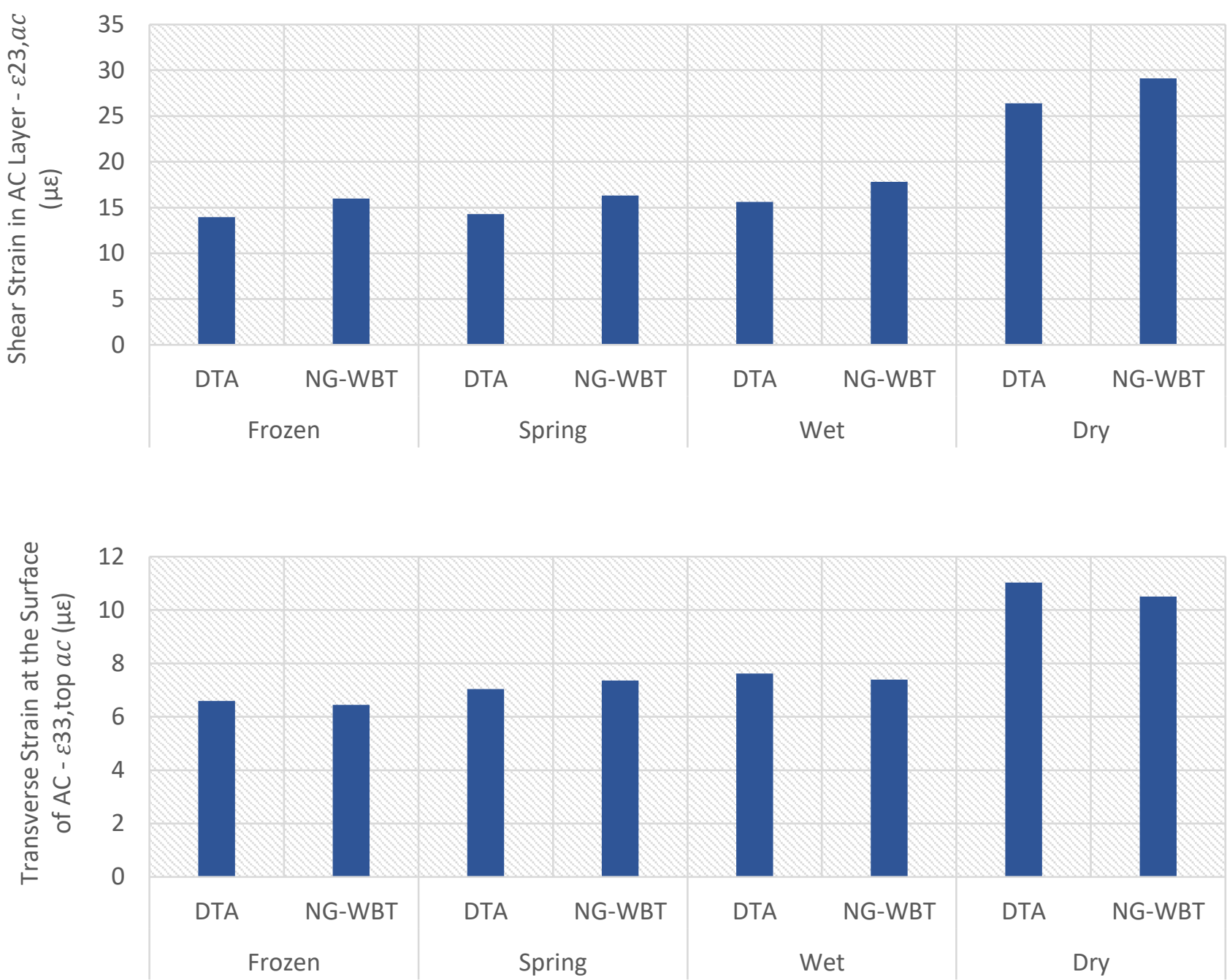

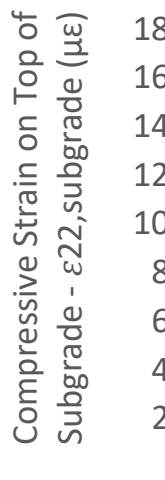

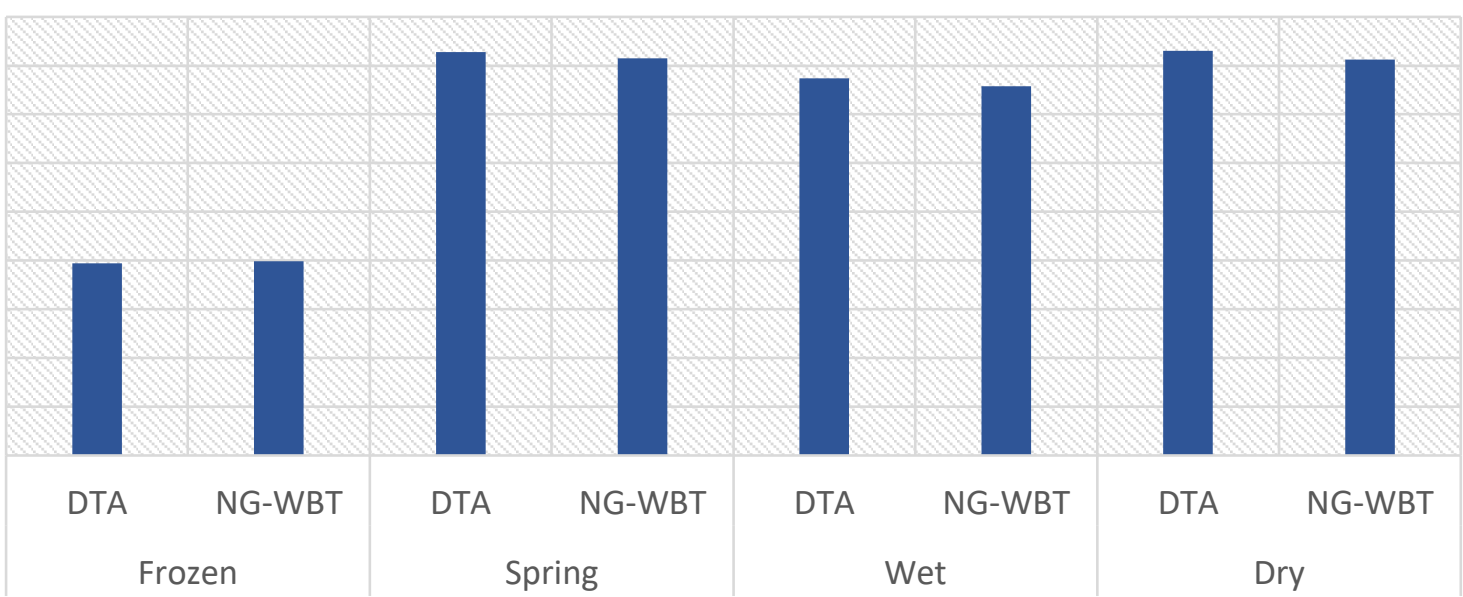

Figure 3.2. Comparison of critical pavement responses between DTA and NG-WBT at 36 kN. 
where $x$ is distance from the loading center; $Y$ is the normalized stress or strain pulse; and $\alpha$ and $\beta$ are model parameters that define the shape of the pulse. As presented in Table 3.3, the parameters $\alpha$ and $\beta$ were found to vary linearly with tire load. This allows the generation of the strain pulse for any load, even the ones not included in the FE analysis. The strain pulse was shifted based on tire speed and axle spacing after it was generated. The original and shifted pulses were superposed to determine critical strains for the tandem and tridem axles. A similar procedure was applied to calculate the load duration, relevant in the calculation of $A C^{\prime}$ 's dynamic modulus.

Table 3.3. Linear Regression Models for Critical Pavement Responses at 8 km/h.

\begin{tabular}{|c|c|c|c|c|c|c|}
\hline & Tire & Equation & $R^{2}$ & Tire & Equation & $R^{2}$ \\
\hline \multicolumn{7}{|c|}{ Tensile Strain at the bottom of AC } \\
\hline Dry & \multirow{4}{*}{ DTA } & $\varepsilon=1.5154 \mathrm{P}+10.0971$ & 0.998 & \multirow{4}{*}{$\begin{array}{l}\text { NG- } \\
\text { WBT }\end{array}$} & $\varepsilon=1.6180 \mathrm{P}+18.9998$ & 0.992 \\
\hline Frozen & & $\varepsilon=0.9281 \mathrm{P}+4.9728$ & 0.998 & & $\varepsilon=0.9859 \mathrm{P}+10.2714$ & 0.995 \\
\hline Spring & & $\varepsilon=0.9781 \mathrm{P}+4.8797$ & 0.998 & & $\varepsilon=1.0370 \mathrm{P}+10.1633$ & 0.995 \\
\hline Wet & & $\varepsilon=1.0544 \mathrm{P}+5.2495$ & 0.998 & & $\varepsilon=1.1206 \mathrm{P}+10.8307$ & 0.995 \\
\hline \multicolumn{7}{|c|}{ Shear Strain in AC } \\
\hline Dry & \multirow{4}{*}{ DTA } & $\varepsilon=0.4694 \mathrm{P}+9.5076$ & 0.998 & \multirow{4}{*}{$\begin{array}{l}\text { NG- } \\
\text { WBT }\end{array}$} & $\varepsilon=0.5455 \mathrm{P}+9.4729$ & 0.987 \\
\hline Frozen & & $\varepsilon=0.2508 \mathrm{P}+4.9336$ & 0.998 & & $\varepsilon=0.2837 \mathrm{P}+5.7771$ & 0.998 \\
\hline Spring & & $\varepsilon=0.2605 \mathrm{P}+4.9123$ & 0.998 & & $\varepsilon=0.2908 \mathrm{P}+5.8359$ & 0.998 \\
\hline Wet & & $\varepsilon=0.2873 \mathrm{P}+5.2745$ & 0.998 & & $\varepsilon=0.3366 \mathrm{P}+5.6804$ & 0.994 \\
\hline \multicolumn{7}{|c|}{ Transverse Strain on the AC Surface } \\
\hline Dry & \multirow{4}{*}{ DTA } & $\varepsilon=0.3146 \mathrm{P}-0.2974$ & 0.999 & \multirow{4}{*}{$\begin{array}{l}\text { NG- } \\
\text { WBT }\end{array}$} & $\varepsilon=0.3071 P-0.5517$ & 0.999 \\
\hline Frozen & & $\varepsilon=0.1861 \mathrm{P}-0.1032$ & 0.999 & & $\varepsilon=0.1828 \mathrm{P}-0.1323$ & 0.999 \\
\hline Spring & & $\varepsilon=0.2001 \mathrm{P}-0.1632$ & 0.999 & & $\varepsilon=0.1801 \mathrm{P}+0.8794$ & 0.917 \\
\hline Wet & & $\varepsilon=0.2163 P-0.1689$ & 0.999 & & $\varepsilon=0.2124 \mathrm{P}-0.2592$ & 0.999 \\
\hline \multicolumn{7}{|c|}{ Vertical Strain on top of Borrow A } \\
\hline Dry & \multirow{4}{*}{ DTA } & $\varepsilon=-5.4304 P+29.4660$ & 0.997 & \multirow{4}{*}{$\begin{array}{l}\text { NG- } \\
\text { WBT }\end{array}$} & $\varepsilon=-5.2364 \mathrm{P}+26.0729$ & 0.999 \\
\hline Frozen & & $\varepsilon=-1.9757 \mathrm{P}-7.7804$ & 0.999 & & $\varepsilon=-1.9850 P-8.3377$ & 0.999 \\
\hline Spring & & $\varepsilon=-5.2574 P+23.7073$ & 0.998 & & $\varepsilon=-5.2253 P+25.0464$ & 1.000 \\
\hline Wet & & $\varepsilon=-4.9843 P+25.6326$ & 0.999 & & $\varepsilon=-4.8952 P+24.6954$ & 0.999 \\
\hline
\end{tabular}

*Strains in microstrains and load in kilo-Newtons. 


\section{CHAPTER 4: TRAFFIC ANALYSIS}

Weight-in-motion data collected over eight years in New Brunswick was processed following the MEPDG procedure to determine traffic characteristics. The characteristics included average annual daily truck traffic (AADTT), AADTT in the base year, and normalized truck traffic distribution based on FHWA vehicle classes. The average vehicle class distribution was determined by averaging the number of trucks per class for all years with measurements. The analysis also computed the monthly adjustment factor. Finally, the load on each axle allowed the calculation of the normalized axle load spectra.

\subsection{WEIGHT-IN-MOTION DATA ANALYSIS}

Weight-in-motion data, in a CSV format, for multiple years and five sites were provided to the research team. The sites are identified as DWD, LC1, SBW, SEB, and WWG. A Python script was developed to process the WIM data for suitable input in MEPDG Pavement M-E. The WIM data were processed following the MEPDG procedure to determine traffic characteristics, which were used in subsequent stages to determine pavement damage over the analysis period. The data included vehicles for lane one and two, but the gross vehicle weight (GVW) in lane two was reported as zero. Consequently, only data in lane one was processed. This also guarantees that the processed data corresponds to the vehicles in the design lane (Appendix C).

AADTT was calculated as the number of trucks in a given year divided by the number of days in that year. Figure 4.1 presents the yearly variation of AADTT in the design lane for the five sites. Only days having measurements were considered in this calculation. Historic AADTT were used to determine the AADTT in the base year, which is the average of the AADTT in previous years. Measurements outside the general trend were excluded in base year AADTT calculations. For instance, AADTT for years 5,6 , and 7 were excluded in the calculation of base year AADTT for site SBW.

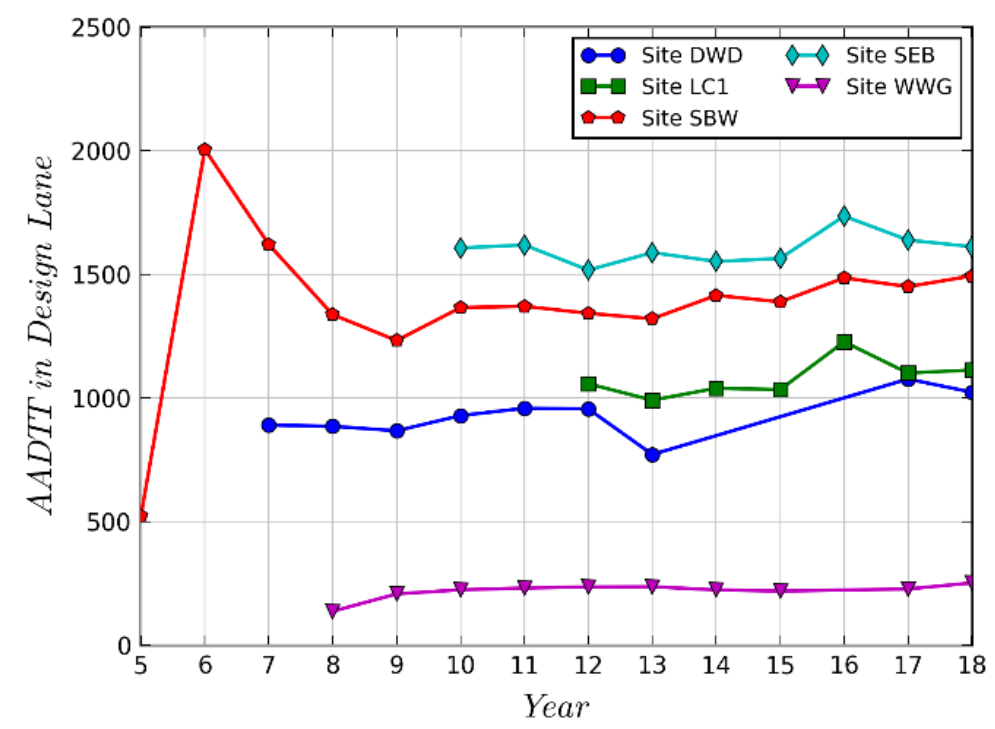

Figure 4.1. Historical AADTT for the five sites. 
Only vehicles in Classes 4 to 13 per AASHTO's truck classification were considered in the analysis. These are the vehicles that cause relevant pavement damage. The number of vehicles in each class was added. The class distribution is the percentage of trucks in each class in one year with respect to the AADTT. This distribution was calculated for each year and averaged over all years. Figure 4.2 shows the yearly and average class distribution as the percent of AADTT for site SEB.
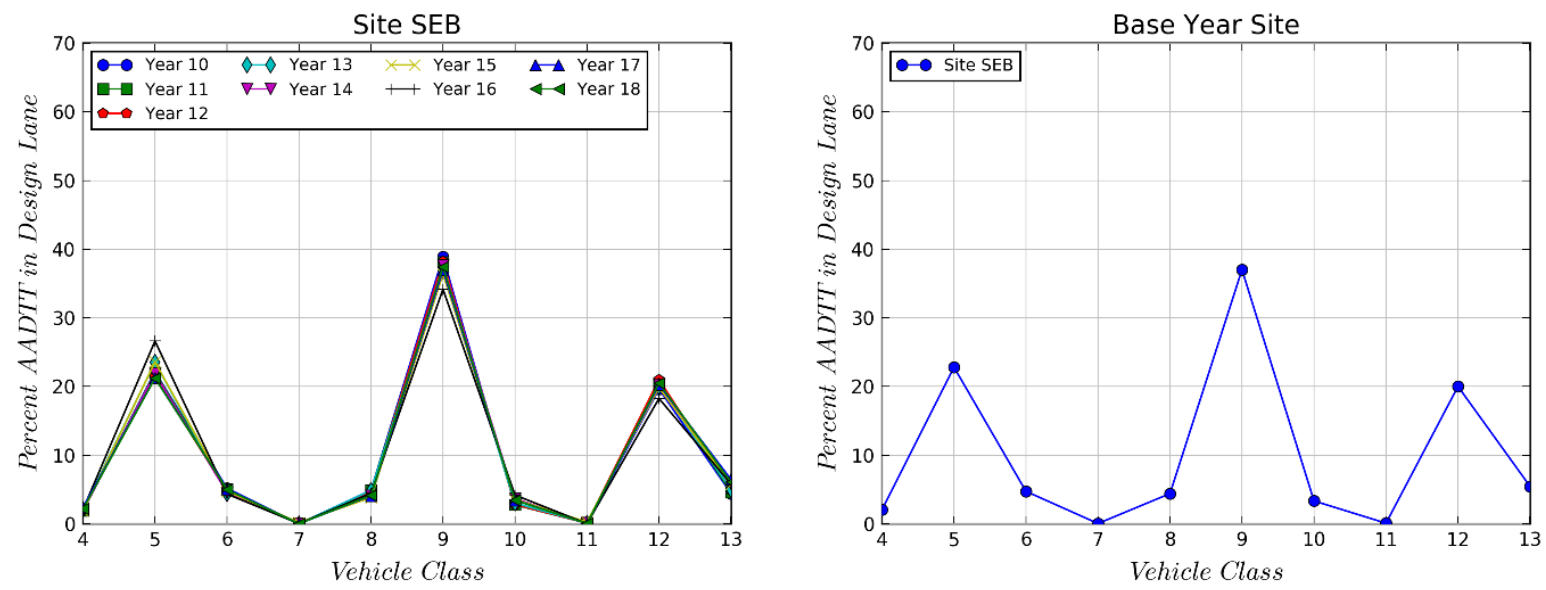

Figure 4.2. Yearly and average class distribution as the percent of AADTT.

Once the traffic is separated per vehicle class, the weights of single, tandem, and tridem axles in each class were calculated. After this, the calculated axle weight for each axle type was presented in a histogram. The weight range depends on the type of axle. For single axles, the weight changed from 0 to $20,000 \mathrm{kgf}$ with a $500 \mathrm{kgf}$ increment. For tandem axles, the range was from 0 to 40,000 kgf in 1,000 $\mathrm{kgf}$ increments. For tridem, the range was from 0 to 121,000 with an increment of 1,500 kgf.

The number of trucks in each month and each class was determined. For a truck count to be considered for a full month, it must be performed for at least 27 days. The average monthly truck traffic (AMDTT) was calculated as the number of trucks in one class in a month over the number of days in that month.

The monthly adjustment factor represents the portion of the annual traffic that occurs in a given month. It is calculated as 12 times the ratio between the average monthly daily truck traffic (AMDTT) and the summation of AMDTT in one year. Figure 4.3 presents the yearly and average AMDTT for site SEB.

The normalized truck traffic distribution was calculated as percentage of AADTT of each FHWA vehicle class in one year. The average class distribution was determined by averaging the number of trucks per class of all the years. Figure 4.4 presents the normalized axle load spectra. The first column corresponds to the single axle, while the second and third columns represent tandem and tridem axles, respectively. Within each class and axle type, the normalized load spectra represents the percentages of axles in each load interval. 
The AADTT for the base year and the growth rate were used to determine the traffic during every year of the analysis period. By multiplying the AADTT for a given year by the class distribution, the number of trucks in one year is obtained per class. The result is multiplied by the AMDTT to obtain the number of trucks in a given class and month.
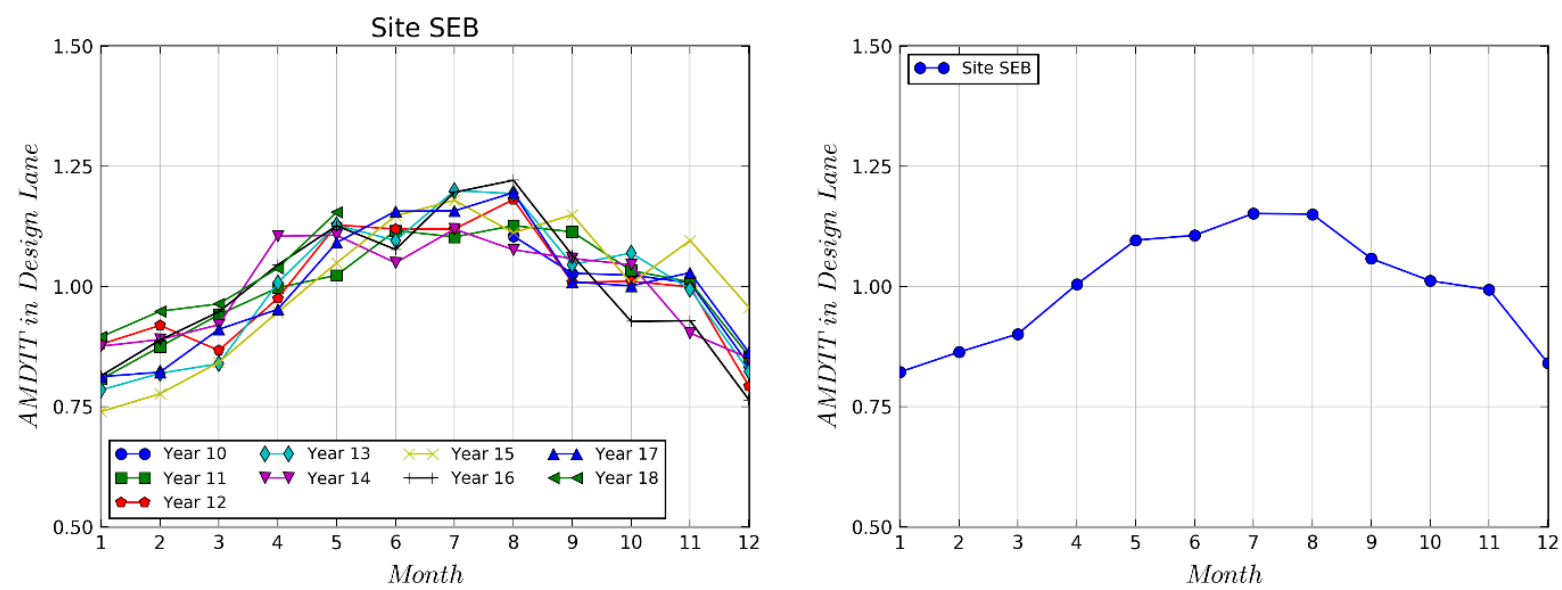

Figure 4.3. Yearly and average AMDTT for site SEB.
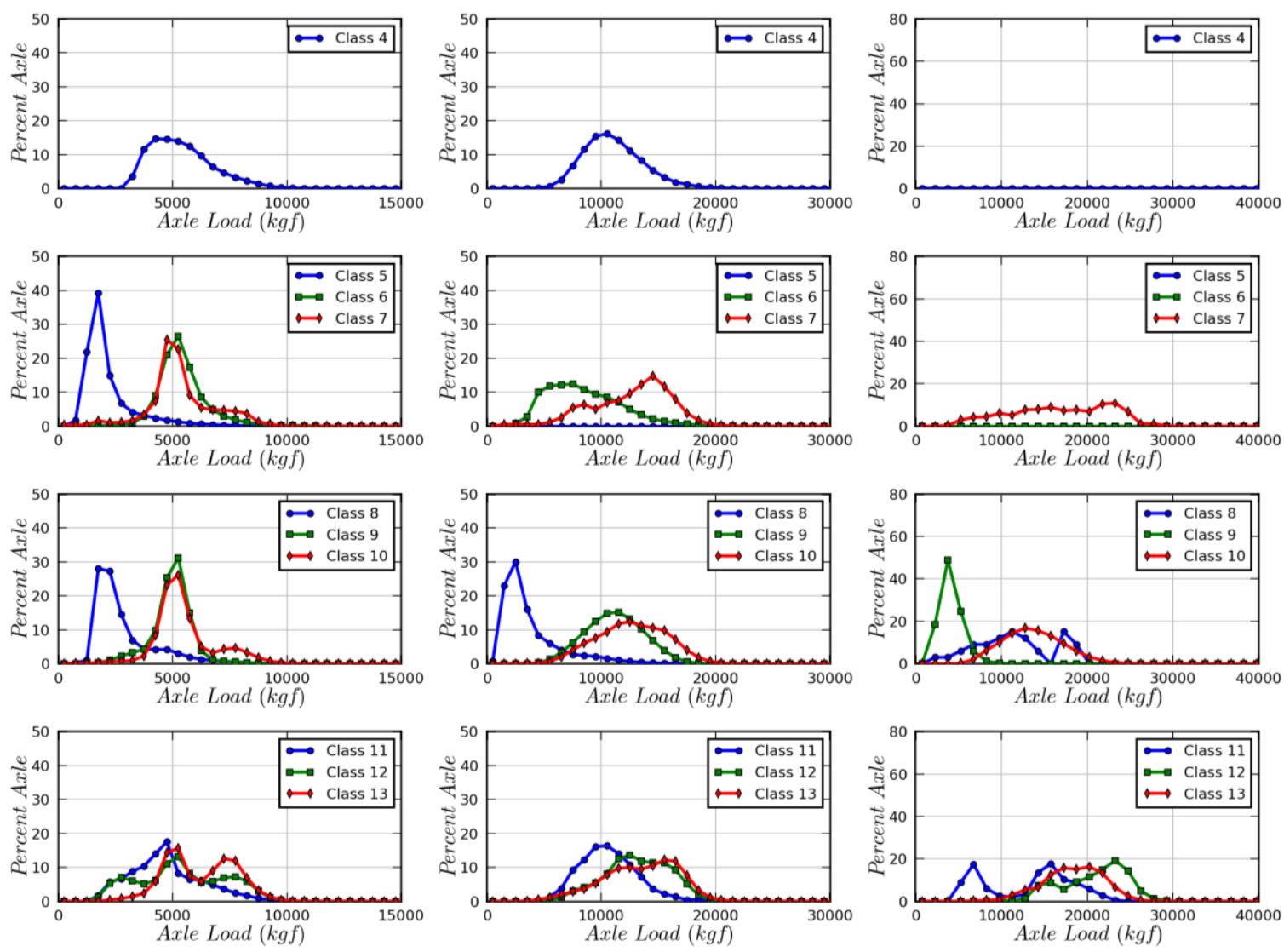

Figure 4.4. Average normalized axle load spectra for single, tandem, and tridem axles. 


\section{CHAPTER 5: LIFE CYCLE COST ANALYSIS}

Life cycle cost analysis (LCCA) is used to evaluate the long-term costs of different alternatives (Walls and Smith 1998). For pavement LCCA, there are two types of costs: agency and user. Agency costs are associated with materials, construction, rehabilitation, and maintenance stages of a project. User costs, on the other hand, are incurred by the roadway user. These costs could be due to fuel consumption, tire wear and tear, vehicle maintenance and repair, traffic delay, crashes, and emissions.

\subsection{PAVEMENT LIFE CYCLE COST ANALYSIS TERMINOLOGIES}

\subsubsection{Agency Costs}

Agency costs consist of the initial construction, material, equipment, and labor costs, as well as the operation and safety costs associated with maintenance activities. There are also terminal values associated with agency costs. These include salvage value, which is the net value of recycled materials after a project's lifetime, and remaining service life, which is the residual value of a project. When agencies bid for a project, they usually use pay items in their contracts to bid prices for unit items or unit processes. This makes agency cost calculations easier because it lowers the uncertainty involved in price determination.

\subsubsection{User Costs}

User costs consist of two main parts: those due to normal operating conditions, where the cost is mainly a function of pavement condition, and those due to a maintenance activity, where there is a work zone present that restricts traffic flow. When the term "user cost" is used, it usually refers to monetized user costs. There are also user costs that are difficult to monetize, such as the comfort of the user, local economic impacts of a specific project, and noise pollution. These costs are usually ignored because they are difficult to quantify. In this study, only the monetary user costs related to the operating conditions are considered. The user delay costs are neglected and assumed to be similar between different alternatives.

\subsubsection{Analysis Period}

Every LCCA includes at least two alternatives, because LCCA is a comparative analysis method. It would be ideal for the alternatives to have the same service life to make analysis straightforward. In practice, however, alternatives rarely have the same service life. Therefore, an analysis period is needed to provide a baseline. For instance, if alternatives $A$ and $B$ are being compared and $A$ has a service life of 50 years while $B$ has 45 , then the minimum of the two (45) would be selected as the analysis period. For an accurate comparison, the remaining five years of $A$ must be accounted for. If an asset still has a useful life after the analysis period, the salvage value/remaining service life must be determined (Ozbay et al. 2003). To determine the salvage value, the price of the final maintenance activity could be reduced proportionally. For instance, if the final maintenance activity for alternative $A$ is on year 35 and it is intended to last until year 50 , the cost at year 35 would be multiplied by (45$35) /(50-35)$ to consider the cost reduction. 


\subsubsection{Time Value of Money}

Changes in the value of money over time must be accounted for by correcting for inflation and discounting rates. While both corrections are necessary for LCCA, inflation and discounting are different processes that are often confused with one another. Inflation captures the change in purchasing power of a currency over time. To capture the variation of prices, goods, or wages because of inflation, Consumer Price Index (CPI) is used to scale the value of money from one year to another. Statistics Canada publishes yearly CPI values for each economic sector and product group.

Equation (4) is usually used to account for inflation. For example, assume that the price of a liter of fuel in Canada in the year 2000 is Can\$0.7. The CPI in 2000 is 172.2, and the CPI in 2015 is 237.07. The price of a liter of fuel in 2015 is then calculated as follows: $0.7 * 237.07 / 172.2=\$ 0.96$ per liter.

$$
\text { Dollars }_{\text {Base Year }}=\text { Dollars }_{\text {Data Year }} * \frac{\text { Price Index }}{\text { Base Year }}
$$

So, $\$ 0.96 / \mathrm{L}$ is considered the fuel price (the amount of money someone would spend at the gas pump) in 2015. This type of money is called "real dollar." Real dollar defines the price of an item that is adjusted with inflation to another year.

On the other hand, current dollars define the price of an item in a given year. In this case, the $\$ 0.7 / \mathrm{L}$ price of gas in $\mathbf{2 0 0 0}$ would be considered "current dollar." Current dollar is useful when the price of an item is known for each year, like fuel. However, the prices of various unit items are not collected every year and conversion to real dollars using inflation correction is necessary.

Once price is adjusted for inflation, it should also be adjusted for discounting. Discounting is also referred to as adjusting for the opportunity value of time (Mallela et al. 2011). This is because a dollar spent in 2000 would have a different purchasing power than a dollar spent in 2015. There are different methods for calculating the present value of an investment, but this study uses present worth calculation. Present worth of any future investment is calculated as follows in equation (5):

$$
\text { Present Value }=\text { Future Value } * \frac{1}{(1+\text { discount value })^{\text {number of years }}}
$$

Continuing with the example, if one would like to determine the amount of money to set aside in 2000 to buy a liter of fuel in 2015, discounting should be used. Assuming a discount rate of $3 \%$, the price of fuel per liter becomes:

$$
0.7 * \frac{1}{(1+0.03)^{(2015-2000)}}=\$ 0.45 / \text { liter. }
$$

Note that the $\$ 0.7 / \mathrm{L}$ that was reported initially as the actual price of fuel in 2000 does not match the $\$ 0.45 / \mathrm{L}$ present cost at year 2000. The money one needs to buy a liter of fuel in 2000 is $\$ 0.7 / \mathrm{L}$. On the other hand, $\$ 0.45$ is the money one needs to save in 2000 to buy a liter of fuel in 2015 . This example illustrates why inflation and discounting are separate concerns. 
In pavement LCCA, adjustment for inflation is only done at the beginning of the calculation, and the unit prices for different items are converted to construction year dollars using discounting. Then, the real discount rate is used to adjust for discounting.

\subsection{LIFE CYCLE COST ANALYSIS CALCULATIONS}

\subsubsection{Pavement Damage and IRI Progression}

Load-related and thermal cracking and rutting define pavement performance and level of deterioration. The number of repetitions to failure for load-related cracking were calculated using the equation presented in the MEPDG's manual of practice, as follows:

$$
N_{f}=k_{f 1} \times C \times C_{H} \times \varepsilon^{-k_{f 2}} \times E^{-k_{f 3}}
$$

where $N_{f}$ is allowable number of applications for load-related cracking; $k_{f 1}, k_{f 2}$, and $k_{f 3}$ are global field calibration coefficients and equal to $0.007566,3.9492,1.281$, respectively; $E$ is $A C^{\prime}$ 's dynamic modulus in psi; $\varepsilon_{t}$ is critical tensile strain; and $C_{H}$ is thickness correction term.

The last two terms, $\varepsilon_{t}$ and $C_{H}$, depend on the type of cracking. For bottom-up fatigue cracking, the critical strain is the maximum tensile strain at the bottom of the AC, while for near-surface cracking, the critical strain is the maximum transverse surface tensile strain. This study also includes another source of near-surface cracking, maximum vertical shear strain in the $A C$, which usually occurs in the upper $100 \mathrm{~mm}$ of the pavement structure (Yoo and Al-Qadi 2008). The thickness correction term for bottom-up $\left(C_{H, B U}\right)$ and near-surface $\left(C_{H, N S}\right)$ cracking are calculated as follows:

$$
\begin{aligned}
C_{H, B U} & =\frac{1}{0.000398+\frac{0.003602}{1+e^{11.02-3.49 H}}} \\
C_{H, N S} & =\frac{1}{0.01+\frac{12.00}{1+e^{15.676-2.8186 H}}}
\end{aligned}
$$

where $\mathrm{H}$ is $\mathrm{AC}$ layer thickness in inches. Because the MEPDG rutting procedure requires variation of vertical strain along the pavement depth, which could not be interpolated from the FE analysis, the Asphalt Institute (AI) equation for rutting was adopted:

$$
N_{f, r}=1.365 \times 10^{-9} \varepsilon_{v}^{-4.477}
$$

where $N_{f, r}$ is number of load repetitions to reach the allowable rutting (12.5 mm rutting) and $\varepsilon_{v}$ is maximum vertical strain on the subgrade.

The allowable number of repetitions from equations (4)-(7) and traffic information were used to calculate the damage index for each distress and various market penetrations of NG-WBT:

$$
D I=(1-M P) \frac{n}{N_{f, d t a}}+M P \frac{n}{N_{f, w b t}}
$$


where $D I$ is damage index; $M P$ is NG-WBT market penetration; $n$ is load applications obtained from traffic analysis; and $N_{f, d t a}$ and $N_{f, w b t}$ are the allowable number of load repetitions for DTA and NGWBT, respectively. The area of alligator cracking $\left(F C_{B U}\right)$ and length of surface cracks $\left(F C_{T D}\right)$ are given by the following equations, respectively:

$$
\begin{gathered}
F C_{B U}=\frac{1}{60} \frac{C_{4}}{1+e^{\mathrm{C}_{1} \times \mathrm{C}_{1}^{*}+\mathrm{C}_{2} \times \mathrm{C}_{2}^{*} \log \left(100 D I_{B U}\right)}} \\
F C_{T D}=10.56 \frac{C_{8}}{1+e^{\mathrm{C}_{5}-\mathrm{C}_{6} \log \left(D I_{T D}\right)}}
\end{gathered}
$$

where $D I_{B U}$ is damage index for bottom-up cracking; $C_{1}, C_{2}$, and $C_{4}$ are transfer regression constants equal to 1.00, 1.00, and 6000, respectively; $D I_{T D}$ is damage index for near-surface cracking; and $C_{5}$, $C_{6}$, and $C_{8}$ are transfer regression constants equal to $7.00,3.5$, and 1000 , respectively. Rut depth was obtained by multiplying the rutting damage index by the allowable rut depth $(12.5 \mathrm{~mm})$.

Thermal cracking is a function of pavement structure, climate condition, and AC mix properties. The area of thermal cracking was obtained using AASHTOWare Pavement M-E Design software. The results are given in Figure 5.1.

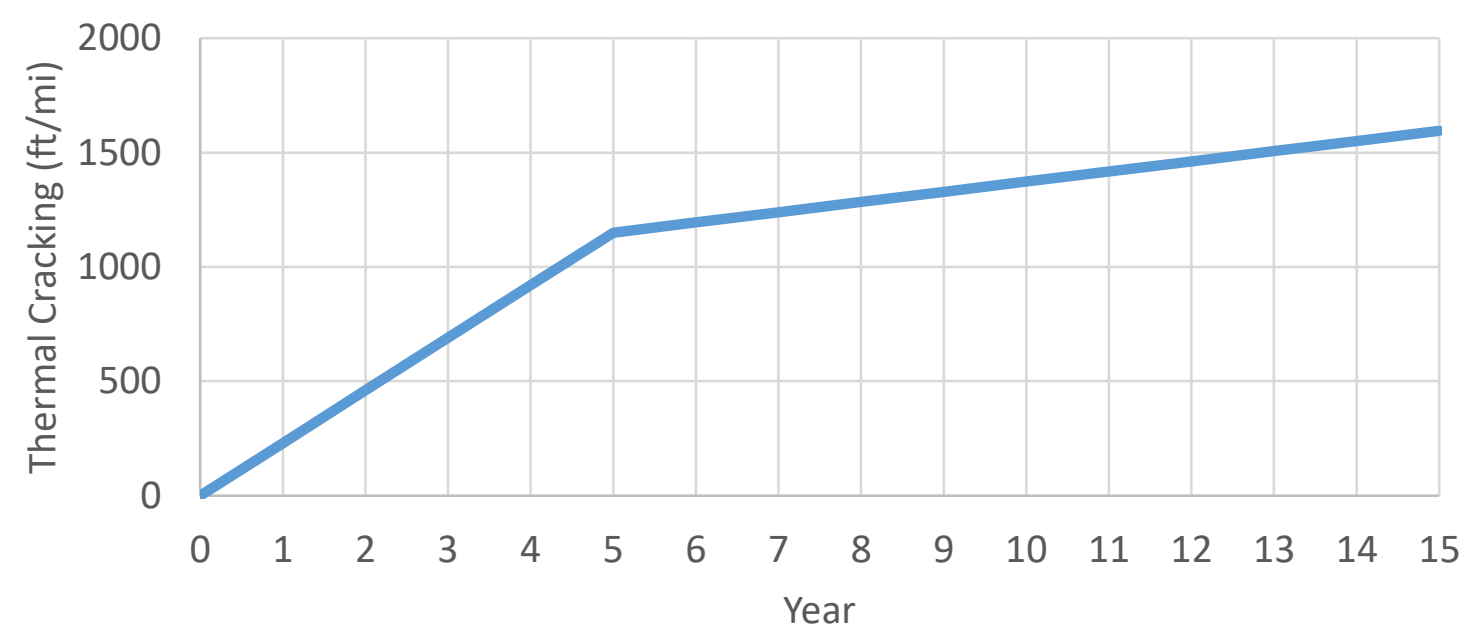

Figure 5.1. Area of thermal cracking for a duration of 15 years $(1 \mathrm{~m} / \mathrm{km}=5.28 \mathrm{ft} / \mathrm{mi})$.

Once the area of cracking and rutting are calculated, the IRI progression was calculated:

$$
I R I=I R I_{o}+40 \times R D+0.40 \times F C_{\text {total }}+0.008 \times F C_{\text {thermal }}
$$

where $I R I_{o}$ is initial $I R I$ (63.6 in/mi); $R D$ is rut depth (in); and $F C_{\text {total }}$ is combined area of loadrelated cracking. The number of single, tandem, and tridem axles in each load interval of the load spectra was calculated for a given month. Afterwards, critical pavement responses were computed using the equations derived in the regression analysis, which were replaced in equations (6)-(13) to obtain the cumulative IRI. The final IRI of a given month becomes the initial IRI for the next month, and the procedure is repeated for the entire analysis period. 


\subsubsection{Life Cycle Cost Analysis}

To perform the analysis, the following assumptions were made:

- The road has two lanes in each direction. The traffic is equally distributed along these directions. The lane width is $3.6 \mathrm{~m}$. Calculations were performed for one direction.

- The pavement length used in the analysis is $1.6 \mathrm{~km}$.

- Based on WIM data, the daily truck traffic is 1,603 vehicles, which is distributed between truck classes, as shown in Table 5.1. The table also presents the average tandem axles in a given class. A 1\% increase in traffic was assumed for vehicles.

- The 10 truck classes were further classified as medium (classes 4 to 8 ) or large trucks (classes 9 to 13), as defined by HDM-4 (Kerali et al. 2000). This further classification was used to estimate roughness-related fuel consumption (Ziyadi et al. 2018).

- Fuel consumption of NG-WBT is $1.5 \%$ less per axle than DTA. Using the information in Table 5.2, at 100\% NG-WBT market penetration (i.e., all tandem axles are equipped with NG-WBT), fuel savings are $0.85 \%$ and $4.75 \%$ for medium and large trucks, respectively.

- Hauling capacity when using NG-WBT is increased by $1.5 \%$ per axle because NG-WBTs are lighter than DTAs. Consequently, for $100 \%$ market penetration, the carrying capacity of each truck would increase by $1.71 \%$. Note that this increase in capacity was not included in the fuel cost computations.

- Additionally, the life cycle costs were computed using the methodology explained in Okte et al. (2019) for both agency and fuel costs.

- The price for unit mill and overlay in New Brunswick was set as US\$105 or Can\$136 per metric ton (Holt et al. 2011).

- The analysis period is 60 years with a $1 \%$ yearly increase in truck traffic. This means that over 60 years, 30.6 million truck-km are expected for a 1-km section.

- The traffic is composed of $10 \%$ trucks and $90 \%$ passenger vehicles.

- The discount rate was assumed to be $3 \%$ for the analysis period.

- Five market penetrations of tandem axles with NG-WBT were considered: $0 \%$ (no tandem axles with NG-WBT), 5\%, 20\%, 50\%, and 100\% (all tandem axles with NG-WBT). No NGWBT was considered in single and tridem axles.

- After each construction/rehabilitation activity, the IRI of the pavement section is returned to $1 \mathrm{~m} / \mathrm{km}$, including the initial year of the analysis.

- The unit cost values for the pay items and fuel were obtained from the life cycle inventory database developed at ICT (Al-Qadi et al. 2015). Although values may differ in New Brunswick, LCCA is comparative in nature and the trends should hold. 
Table 5.1. Truck Distribution and Average Number of Tandem Axles per Class

\begin{tabular}{|c|c|c|c|c|c|}
\hline Class & Classification & $\begin{array}{c}\text { AADTT } \\
\mathbf{( \% )}\end{array}$ & $\begin{array}{c}\text { Average } \\
\text { Tandem Axles } \\
\text { in Class }\end{array}$ & $\begin{array}{c}\text { Savings within } \\
\text { Class (\%) }\end{array}$ & $\begin{array}{c}\text { Saving within } \\
\text { Classification } \\
\text { (\%) }\end{array}$ \\
\hline $\mathbf{4}$ & Medium & 2.1 & 0.41 & 1.23 & 0.08 \\
\hline $\mathbf{5}$ & Medium & 22.8 & 0 & 0 & 0.00 \\
\hline $\mathbf{6}$ & Medium & 4.7 & 1 & 3 & 0.41 \\
\hline $\mathbf{7}$ & Medium & 0.1 & 1.55 & 4.65 & 0.01 \\
\hline $\mathbf{8}$ & Medium & 4.4 & 0.9 & 2.7 & 0.35 \\
\hline $\mathbf{9}$ & Large & 37.0 & 1.89 & 5.67 & 3.18 \\
\hline $\mathbf{1 0}$ & Large & 3.3 & 1.11 & 3.33 & 0.17 \\
\hline $\mathbf{1 1}$ & Large & 0.1 & 0.38 & 1.14 & 0.00 \\
\hline $\mathbf{1 2}$ & Large & 20.0 & 1.03 & 3.09 & 0.94 \\
\hline $\mathbf{1 3}$ & Large & 5.5 & 1.84 & 5.52 & 0.46 \\
\hline
\end{tabular}

Two cases were considered for the 60-year analysis period, Cases A and B. In Case A, the agency decides to mill and overlay $50 \mathrm{~mm}$ of the top surface every 15 years regardless of the pavement condition. This means that there is no threshold set for the IRI progression. As a result, the overall IRI is expected to be higher as the market penetration increases. In Case $B$, the agency sets an IRI threshold of $1.46 \mathrm{~m} / \mathrm{km}$, which corresponds to the IRI at 15 years when there is no NG-WBT. Each time the threshold is reached, the agency performs a $50-\mathrm{mm}$ mill and overlay, similar to the previous case. As a result, maintenance planning is expected to change after increasing traffic and NG-WBT market penetration, because IRI progression triggers the threshold at various times. Table 5.2 presents the schedule summary of these cases. Figure 5.2 gives the IRI progression plots for different market penetrations. If a maintenance activity has a longer expected life than the time remaining to the end of the analysis period, then the cost of that activity was reduced by the ratio of remaining analysis time to expected activity life. For example, if a maintenance activity is performed at the beginning of year 56-five years before the end of the analysis period-and its expected life is 10 years, only $5 / 10$ or $50 \%$ of its cost is considered in the analysis.

Table 5.3 summarizes the LCCA results for both cases in Canadian dollars at the year of construction. In Case A, the agency cost does not change with increasing market penetration. This is due to the stringent maintenance schedule. Even though roughness increases with increasing market penetrations in both cases, NG-WBT's fuel savings overcome the excessive fuel consumption caused by increased IRI. Because of the low traffic, roughness never reaches levels where the passenger vehicles are negatively affected in terms of fuel consumption. 
Table 5.2. Maintenance Schedule of the Two Scenarios

\begin{tabular}{|l|c|c|c|c|c|c|}
\hline \multirow{2}{*}{$\begin{array}{c}\text { Maintenance } \\
\text { Activity }\end{array}$} & $\mathbf{6}$ & $\mathbf{5 \%}$ & $\mathbf{1 0 \%}$ & $\mathbf{2 0 \%}$ & $\mathbf{5 0 \%}$ & $\mathbf{1 0 0 \%}$ \\
\cline { 2 - 7 } & \multicolumn{7}{|c|}{ Case A } \\
\hline $1^{\text {st }}$ & Year 15 & Year 15 & Year 15 & Year 15 & Year 15 & Year 15 \\
\hline $2^{\text {nd }}$ & Year 30 & Year 30 & Year 30 & Year 30 & Year 30 & Year 30 \\
\hline $3^{\text {rd }}$ & Year 45 & Year 45 & Year 45 & Year 45 & Year 45 & Year 45 \\
\hline $4^{\text {th }}$ & Year 60 & Year 60 & Year 60 & Year 60 & Year 60 & Year 60 \\
\hline $5^{\text {th }}$ & - & - & - & - & - & - \\
\hline & Year 15 & Year 15 & Year 15 & Year 15 & Year 14 & Year 13 \\
\hline $1^{\text {st }}$ & Year 27 & Year 27 & Year 27 & Year 27 & Year 26 & Year 24 \\
\hline $2^{\text {nd }}$ & Year 39 & Year 39 & Year 38 & Year 38 & Year 37 & Year 35 \\
\hline $3^{\text {rd }}$ & Year 49 & Year 49 & Year 49 & Year 48 & Year 47 & Year 44 \\
\hline $4^{\text {th }}$ & Year 59 & Year 59 & Year 58 & Year 58 & Year 56 & Year 53 \\
\hline $5^{\text {th }}$ & & \multicolumn{7}{|c|}{} \\
\hline
\end{tabular}

IRI Progression - Case A

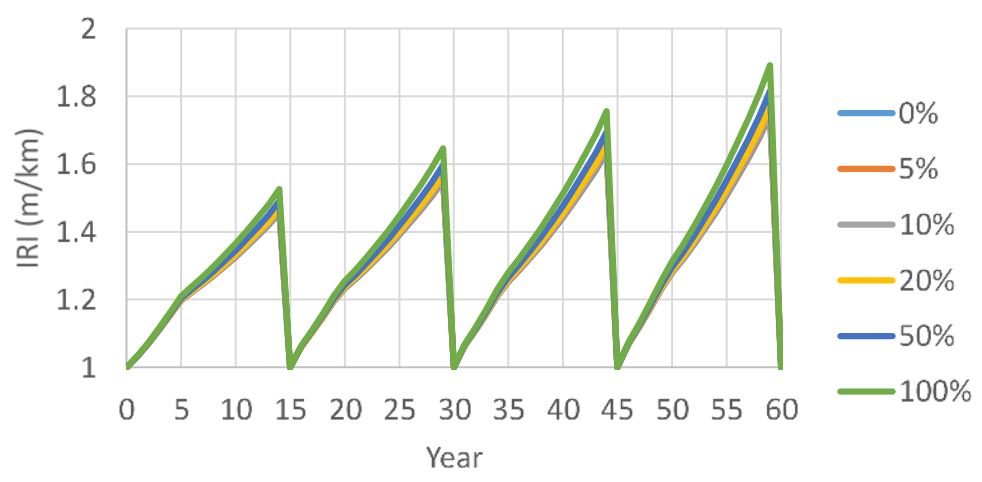

IRI Progression - Case B

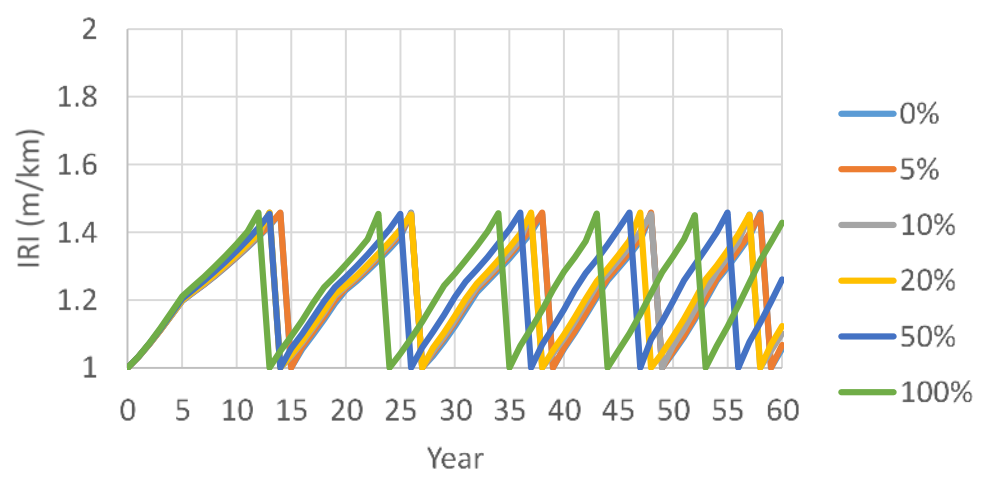

Figure 5.2. IRI progressions for cases A and B for various market penetrations. 
However, there are still savings realized for truck and passenger vehicle fuel costs under all scenarios. This trend may change with increased traffic because IRI progresses faster in Case A and the threshold would be greater with no intervention.

Figure 5.3 shows the difference in agency and truck fuel costs for both cases in Canadian dollars at the year of construction. As expected, the overall agency cost for Case $A$ is lower because of the relatively smaller number of maintenance activities. Note that a fuel consumption database created for the United States was used in this study. The exact values for fuel consumption may differ slightly for other regions, but the trends would remain the same.

Table 5.3. Present Cost in Can\$ for the Year of Construction 2016

\begin{tabular}{|c|c|c|c|c|c|c|}
\hline \multicolumn{7}{|c|}{ Case A } \\
\hline $\begin{array}{c}\text { Market } \\
\text { Penetration }\end{array}$ & $0 \%$ & $5 \%$ & $10 \%$ & $20 \%$ & $50 \%$ & $100 \%$ \\
\hline $\begin{array}{c}\text { Truck Only } \\
\text { Fuel Cost }\end{array}$ & $\$ 6,832,320$ & $\$ 6,818,494$ & $\$ 6,804,669$ & $\$ 6,777,018$ & $\$ 6,694,068$ & $\$ 6,555,815$ \\
\hline $\begin{array}{c}\text { Truck + PV* } \\
\text { Fuel Cost }\end{array}$ & $\$ 21,608,341$ & $\$ 21,595,466$ & $\$ 21,582,595$ & $\$ 21,556,868$ & $\$ 21,479,797$ & $\$ 21,351,697$ \\
\hline Agency Cost & $\$ 361,527$ & $\$ 361,527$ & $\$ 361,527$ & $\$ 361,527$ & $\$ 361,527$ & $\$ 361,527$ \\
\hline \multicolumn{7}{|l|}{ Difference } \\
\hline $\begin{array}{c}\text { Truck Only } \\
\text { Fuel Cost }\end{array}$ & $\$ 0$ & $-\$ 13,826$ & $-\$ 27,651$ & $-\$ 55,302$ & $-\$ 138,252$ & $-\$ 276,504$ \\
\hline $\begin{array}{c}\text { Truck + PV } \\
\text { Fuel Cost }\end{array}$ & $\$ 0$ & $-\$ 12,875$ & $-\$ 25,746$ & $-\$ 51,473$ & $-\$ 128,544$ & $-\$ 256,644$ \\
\hline Agency Cost & $\$ 0$ & $\$ 0$ & $\$ 0$ & $\$ 0$ & $\$ 0$ & $\$ 0$ \\
\hline \multicolumn{7}{|c|}{ Case B } \\
\hline $\begin{array}{c}\text { Market } \\
\text { Penetration }\end{array}$ & $0 \%$ & $5 \%$ & $10 \%$ & $20 \%$ & $50 \%$ & $100 \%$ \\
\hline $\begin{array}{c}\text { Truck Only } \\
\text { Fuel Cost }\end{array}$ & $\$ 6,827,409$ & $\$ 6,813,911$ & $\$ 6,798,975$ & $\$ 6,771,309$ & $\$ 6,688,393$ & $\$ 6,547,625$ \\
\hline $\begin{array}{c}\text { Truck + PV } \\
\text { Fuel Cost }\end{array}$ & $\$ 21,574,275$ & $\$ 21,563,287$ & $\$ 21,543,114$ & $\$ 21,517,141$ & $\$ 21,439,010$ & $\$ 21,294,150$ \\
\hline Agency Cost & $\$ 417,650$ & $\$ 417,650$ & $\$ 425,353$ & $\$ 426,490$ & $\$ 443,146$ & $\$ 466,410$ \\
\hline \multicolumn{7}{|l|}{ Difference } \\
\hline $\begin{array}{c}\text { Truck Only } \\
\text { Fuel Cost }\end{array}$ & $\$ 0$ & $-\$ 13,498$ & $-\$ 28,434$ & $-\$ 56,100$ & $-\$ 139,016$ & $-\$ 279,784$ \\
\hline $\begin{array}{c}\text { Truck + PV } \\
\text { Fuel Cost }\end{array}$ & $\$ 0$ & $-\$ 10,988$ & $-\$ 31,161$ & $-\$ 57,134$ & $-\$ 135,265$ & $-\$ 280,125$ \\
\hline Agency Cost & $\$ 0$ & $\$ 0$ & $\$ 7,704$ & $\$ 8,840$ & $\$ 25,497$ & $\$ 48,760$ \\
\hline
\end{tabular}

* PV: Passenger vehicle 


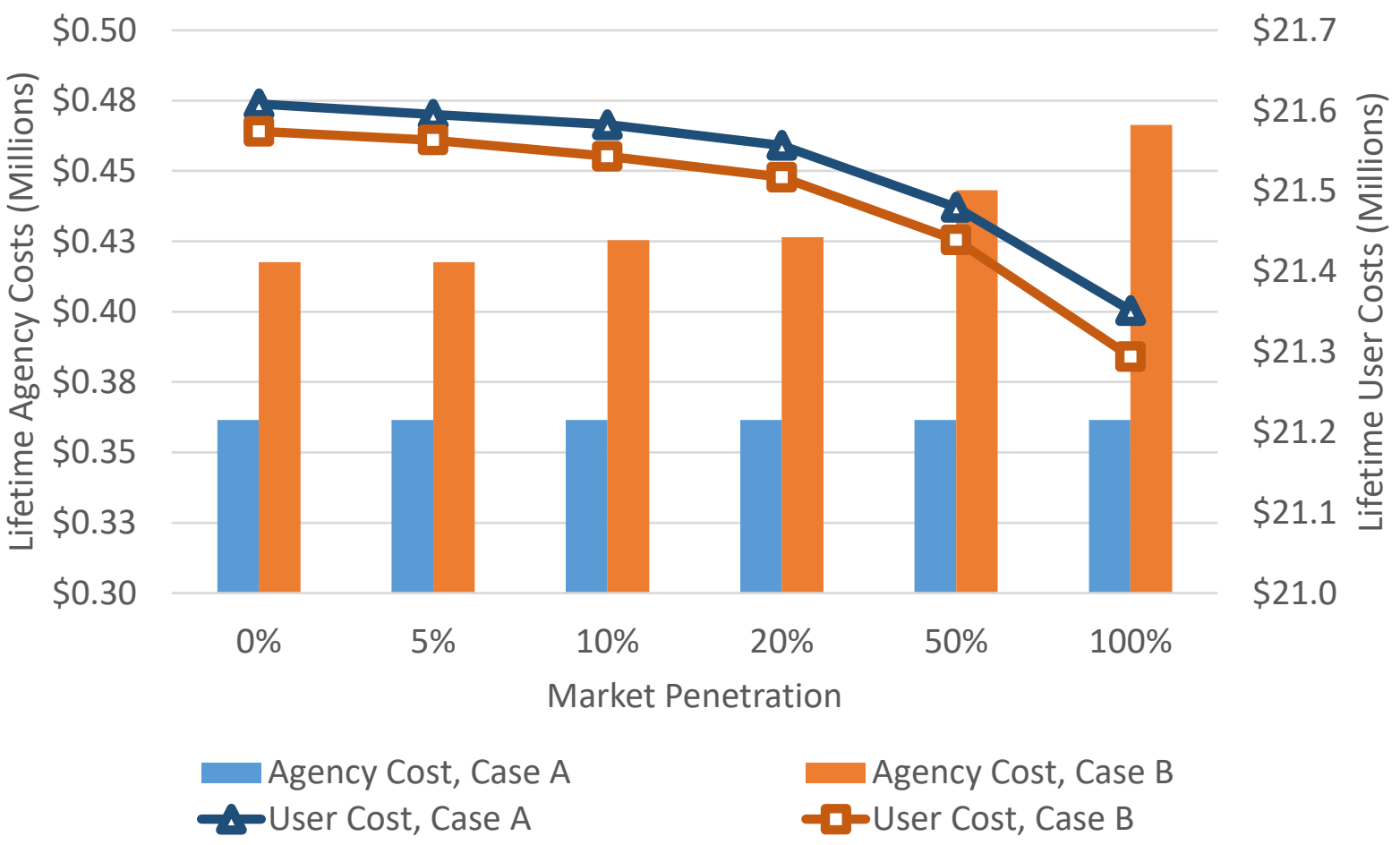

Figure 5.3. Market penetration vs lifetime costs (present cost) in Can\$ per km.

From LCCA, for Case B over an analysis period of 60 years, the agency would pay Can $\$ 8,226, \$ 9,473$, $\$ 27,323, \$ 52,254$ (2019 dollars) extra per kilometer because of the use of NG-WBT at $10 \%, 20 \%, 50 \%$ and $100 \%$ market penetrations, respectively. On the other hand, the trucking industry would save Can $\$ 30,471, \$ 60,119, \$ 148,977, \$ 299,830$ (2019 dollars) in fuel expenses for $10 \%, 20 \%, 50 \%$ and $100 \%$ market penetrations, respectively over the same period and pavement section length. For the analysis period of 60 years, there are expected to be $48 \mathrm{M}$ trucks. Therefore, the savings per truck (in CAD) would be 0.06 cents, 0.13 cents, 0.30 cents, and 0.61 cents ( 2019 dollars) per truck-km for $10 \%$, $20 \%, 50 \%$ and $100 \%$ NG-WBT market penetrations, respectively. Additionally, a metric ton of truck freight costs Can\$12.5 to ship one kilometer in 2019 (Austin 2015). Because the trucks would be able to carry more when using NG-WBT, their shipping cost would be reduced annually by 2.1 cents, 4.2 cents, 10.7 cents, and 21.4 cents (2019 CAD dollars) per truck-km, respectively.

Finally, for passenger vehicles, Case B results in savings because agencies maintain a low overall IRI progression. For passenger vehicles, the annual savings are Can\$2,727, \$1,035, \$3751, \$341 (2019 dollars) for $10 \%, 20 \%, 50 \%$ and $100 \%$ market penetrations, respectively. These savings are considered insignificant per vehicle. A detailed analysis is presented in Appendix D. 


\section{CHAPTER 6: SUMMARY AND CONCLUSIONS}

Life cycle cost analysis was performed to assess the economic impact of NG-WBT usage in New Brunswick, Canada. The procedure combined 3D finite-element models to calculate critical pavement responses, WIM data to determine traffic characteristics, regression analysis to compute critical pavement responses for any axle load, transfer functions to predict pavement damage, and empirical equations to estimate IRI progression.

From the structural evaluation under the specific conditions in this study, NG-WBT (445/50R22.5) resulted in pavement critical responses between 3 and $9 \mu \varepsilon$ greater than DTA (275/80R22.5). Calculated pavement responses include tensile strain at the bottom of the $A C$ and vertical shear strain in the AC. However, the difference was negligible for vertical strain on the subgrade.

For economic evaluation, LCCA, which accounted for fuel savings and greater hauling capacity, resulted in cost savings when NG-WBT is used. Two scenarios were considered: (1) Case A, where maintenance was performed at specific intervals regardless of IRI value, and (2) Case B, where IRI threshold triggers maintenance. There were significant savings in trucking fuel costs under both scenarios.

The agency cost to maintain the pavement used by NG-WBT is expected to be between Can\$7,703 to $\$ 8,840$ (2019 dollars) for $10 \%$ and $20 \%$ of all tandem axles using NG-WBT per one kilometer for a 60 year analysis period. The annual worth of such cost would be Can $\$ 298$ and $\$ 342$ (2019 dollars), respectively. On the other, the fuel savings per truck-km is expected to be between Can\$30,471 to $\$ 60,119$ (2019 dollars) for $10 \%$ and $20 \%$ of all tandem axles using NG-WBT per one kilometer for the same analysis period. The annual worth of such savings per kilometer would be Can $\$ 1,100$ and $\$ 2,172$ (2019 dollars), respectively. In addition, the trucks would save annually 0.42 and 0.107 CAD per ton transported one kilometer when NG-WBT market penetration is $10 \%$ and $20 \%$, respectively. Maintaining a low IRI on the road would also benefit passenger vehicles, which make up most users.

Using NG-WBTs while maintaining pavement conditions at the same level as when only DTAs are used would require additional agency investment. This appears to be justified given the significant savings in fuel by trucks. 


\section{REFERENCES}

AASHTO, 2008. Mechanistic-empirical pavement design guide: A manual of practice. American Association of American Association of State Highway and Transportation Officials.

Al-Qadi, I.L. and Elseifi, M.A., 2007. New generation of wide-base tires: Impact on trucking operations, environment, and pavements. Transportation Research Record, 2008(1), 100-109.

Al-Qadi, I.L., Hernandez, J.A., Gamez, A., Ziyadi, M., Gungor, O.E., and Kang, S., 2018. Impact of widebase tires on pavements: A national study. Transportation Research Record, 2672(40), 186-196.

Al-Qadi, I.L., Loulizi, A., Janajreh, I., and Freeman, T.E., 2002. Pavement response to dual tires and new wide-base tires at same tire pressure. Transportation Research Record, 1806(1), 38-47.

Al-Qadi, I.L., Said, I., Hernandez, J., and Kang, S., 2017. Impact and life cycle assessment of newgeneration wide-base tires in New Brunswick, Canada. Illinois Center for Transportation.

Al-Qadi, I.L., Yang, R., Kang, S., Ozer, H., Ferrebee, E., Roesler, J.R., Salinas, A., Meijer, J., Vavrik, W.R., and Gillen, S.L., 2015. Scenarios developed for improved sustainability of Illinois Tollway: Lifecycle assessment approach. Transportation Research Record, 2523(1), 11-18.

Al-Qadi, I.L., and Yoo, P.J., 2007. Effect of surface tangential contact stresses on flexible pavement response. Journal of the Association of Asphalt Paving Technologists, 76, 663-692.

ASCE, 2014. Maximizing the value of investments using life cycle cost analysis. American Society of Civil Engineers.

Austin, D., 2015. Pricing freight transport to account for external costs. Congressional Budget.

Chatti, K., and Zaabar, I., 2012. Estimating the effects of pavement condition on vehicle operating costs. Transportation Research Board, 720.

Fakhri, M., and Ghanizadeh, A.R., 2014. Modelling of 3D response pulse at the bottom of asphalt layer using a novel function and artificial neural network. International Journal of Pavement Engineering, 15(8), 671-688.

Hernandez, J.A., Al-Qadi, I., and De Beer, M., 2013. Impact of tire loading and tire pressure on measured 3D contact stresses. In Airfield and highway pavement 2013: Sustainable and efficient pavements (pp. 551-560).

Hernandez, J.A., Gamez, A., and Al-Qadi, I.L., 2016. Effect of wide-base tires on nationwide flexible pavement systems: Numerical modeling. Transportation Research Record, 2590(1), 104-112.

Holt, A., Sullivan, S., and Hein, D., 2011, September. Life cycle cost analysis of municipal pavements in southern and eastern Ontario. In 2011 Conference and exhibition of the transportation association of Canada.

Huvstig, A., 1998. Whole life costing. The World Road Association (PIARC), Concrete Roads Committee, Malaysia, Kuala Lumpur. 
Kang, S., Al-Qadi, I.L., Ozer, H., Ziyadi, M., and Harvey, J.T., 2019. Environmental and economic impact of using new-generation wide-base tires. International Journal of Life Cycle Assessment, 24(4), 753-766.

Kerali, H. G., Odoki, J. B., and Stannard, E. E., 2000. Overview of HDM-4. The Highway Development and Management Series, 4.

Mallela, J., and Sadavisam, S., 2011. Work zone road user costs: Concepts and applications (No. FHWA-HOP-12-005). Federal Highway Administration.

Moges, M., Ayed, A., Viecili, G., and Abd El Halim, A., 2017. Review and recommendations for Canadian LCCA guidelines. In TAC 2017: Investing in Transportation: Building Canada's Economy2017 Conference and Exhibition of the Transportation Association of Canada.

Okte, E., Al-Qadi, I.L. and Ozer, H., 2019. Effects of pavement condition on LCCA user costs. Transportation Research Record, 2673(5), 339-350.

Ozbay, K., Parker, N.A., and Jawad, D., 2003. Guidelines for life cycle cost analysis (No. FHWA-NJ2003-012). New Jersey Department of Transportation.

Said, I.M., Hernandez, J., Kang, S., and Al-Qadi, I.L., 2019. Structural and environmental impact of new-generation wide-base tires in New Brunswick, Canada. Road Materials and Pavement Design, 1-17.

Tutumluer, E., 2009. State of the art: Anisotropic characterization of unbound aggregate layers in flexible pavements. In Pavements and materials: Modeling, testing, and performance (pp. 1-16).

Walls III, J., and Smith, M.R., 1998. Life-cycle cost analysis in pavement design-interim technical bulletin (No. FHWA-SA-98-079). Federal Highway Administration.

Wang, D., Roesler, J.R., and Guo, D.Z., 2009. Analytical approach to predicting temperature fields in multilayered pavement systems. Journal of Engineering Mechanics, 135(4), 334-344.

Winfrey, R., 1969. Economic analysis for highways (No. 923 pp).

Yoo, P.J., and Al-Qadi, I.L., 2008. The truth and myth of fatigue cracking potential in hot-mix asphalt: Numerical analysis and validation. Asphalt Paving Technology-Proceedings, 77, 549.

Yoo, P., \& Al-Qadi, I. 2007. Effect of transient dynamic loading on flexible pavements. Transportation Research Record: Journal of the Transportation Research Board, (1990), 129-140.

Yoo, P. J., Al-Qadi, I. L., Elseifi, M. A., and Janajreh, I. 2006. Flexible pavement responses to different loading amplitudes considering layer interface condition and lateral shear forces. International Journal of Pavement Engineering, 7(1), 73-86.

Ziyadi, M., Ozer, H., Kang, S., and Al-Qadi, I.L., 2018. Vehicle energy consumption and an environmental impact calculation model for the transportation infrastructure systems. Journal of Cleaner Production, 174, 424-436. 


\section{APPENDIX A: FINITE-ELEMENT MODEL}

Finite-Element Input

A.1. Structure: The pavement structure considered is a typical pavement section in New Brunswick, composed of a 140-mm asphalt concrete layer, $150-\mathrm{mm}$ granular base, and $450-\mathrm{mm}$ subbase on top of a 600-mm layer of Borrow A material and a glacial till (Figure A.1).

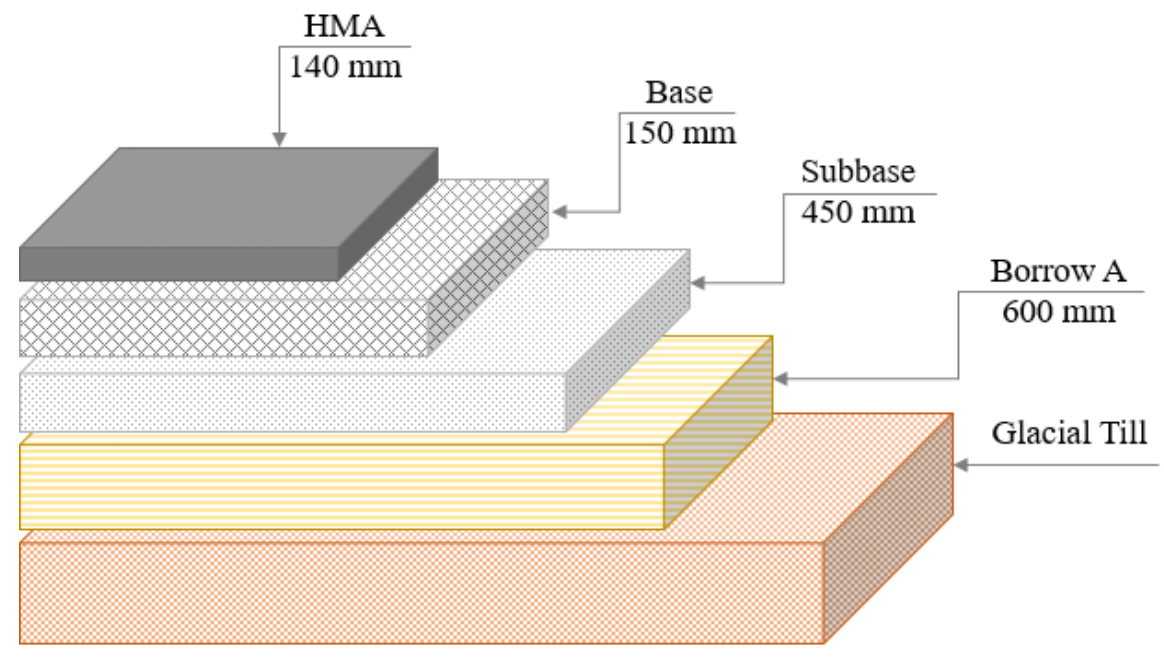

Figure A.1. Pavement layers configuration.

A.2. Loading: The tire configuration consists of NG-WBT loaded at 27, 36, 44, and $62 \mathrm{kN}$, with a tire inflation pressure of $690 \mathrm{kPa}$. The 3D contact forces are based on earlier experimental measurements performed by the Council for Scientific and Industrial Research in South Africa using the Stress-InMotion (SIM) system. Realistic loading characterization allows for an accurate estimation of critical responses, especially those near the pavement surface. Figure A.2 shows a representative variation of the contact loads in the vertical, transverse, and longitudinal directions along the contact length for both tires. The figure only presents values at a specific location across the tire. NG-WBT usually exhibits higher vertical contact stresses. On the other hand, there are no significant differences in the forces in longitudinal and transverse directions (around the tire center for both tires).
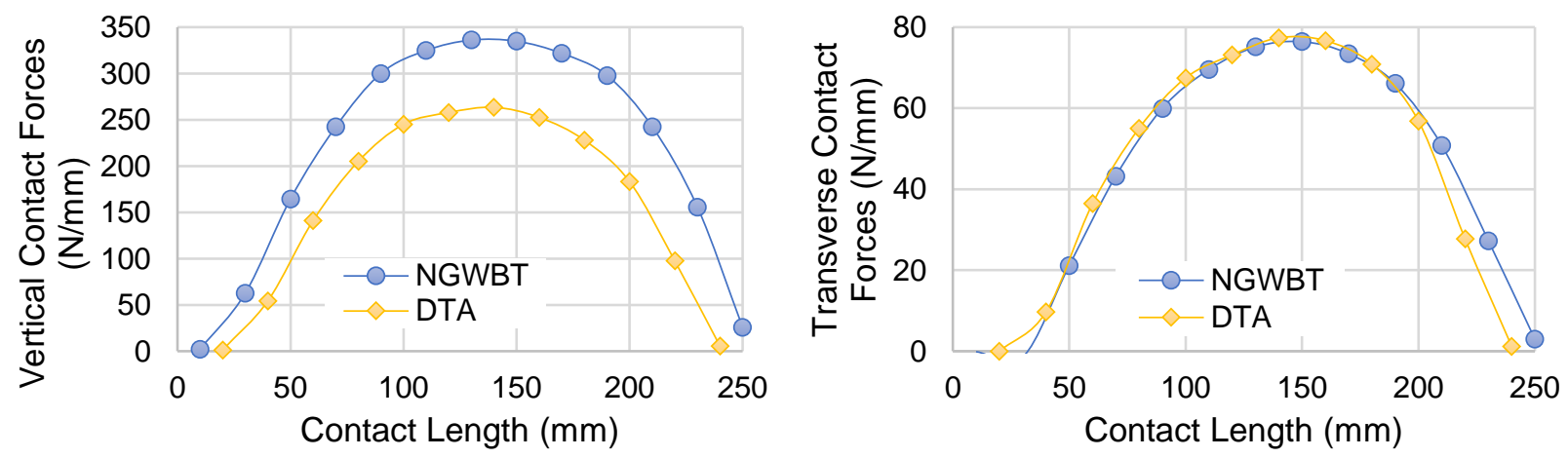


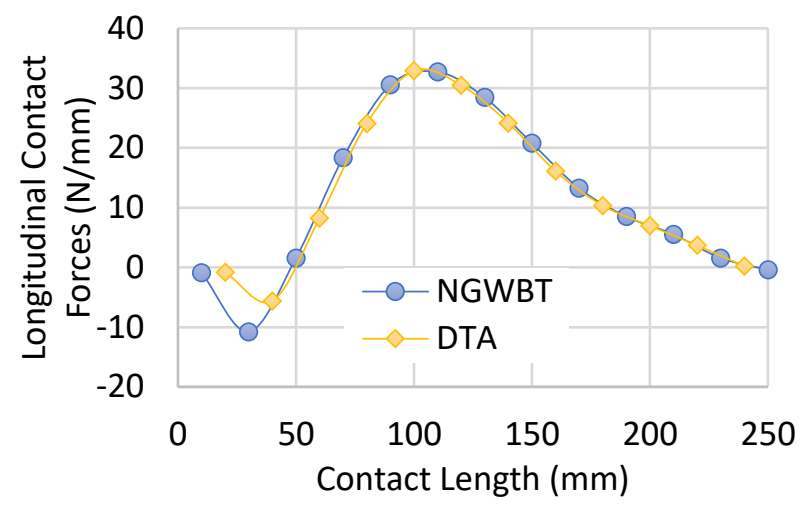

Figure A.2. Variation of vertical, transverse, and longitudinal contact forces along contact length.

A.3. Material Properties: Three material behaviors were incorporated within the developed models. Asphalt concrete (AC) material is assumed to have linear viscoelastic behavior; the granular base is modeled as nonlinear (stress-dependent) cross-anisotropic; and the remaining layers are modeled as linear elastic materials. Material characterization was performed using test results reported in the Long-Term Pavement Performance (LTPP) database for sections in New Brunswick and the ICT database for nonlinear material constants.

A.4. Temperature: The temperature distribution along the depth of the AC layer was determined using an analytical one-dimensional temperature distribution model for the subject region. The temperature considered in the models is defined based on the average temperature per quarter in New Brunswick. The temperature distributions within the asphalt layer are presented in Figure A.3.

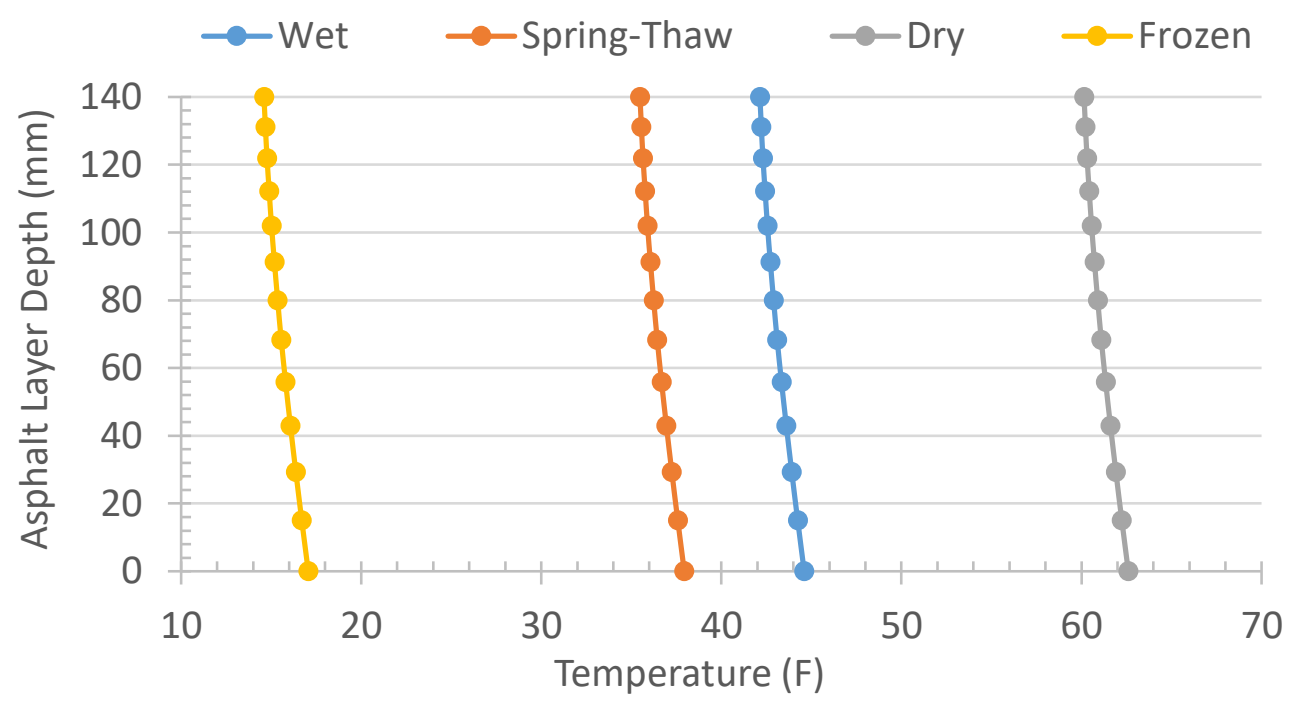

Figure A.3. Asphalt layer temperature distribution.

A.5. Cases: For each tire configuration and loading case, four models were developed to account for the sensitivity of material properties to wet, dry, spring-thaw, and frozen environmental conditions. 
These models have various material properties for the Borrow A layer and subgrade and different temperature distribution within the AC layer. A total of 32 cases were created ( 2 tires $\times 4$ loads $\times 4$ environmental factors).

A.6. Numerical Analysis: The three-dimensional (3D) pavement model used in this study included variables overlooked in conventional analysis of flexible pavement, such as moving three-dimensional contact loads, dynamic analysis, linear viscoelastic asphalt concrete (AC), nonlinear granular materials, nonuniform temperature distribution in the AC layer, and interaction between pavement layers. Figure A.4 shows the pavement model and the geometric configuration. The model geometry consists of a wheel path, two transition zones ( $L 1-B 1$ and $L 2-B 2$ ), and infinite elements. In the transition zone, the size and type of the elements changes from small in the wheel path to coarse in the boundary. The size and type of finite element were determined by a mesh sensitivity analysis, comparing results from a finite element model with a multilinear elastic solution. The main objective of the mesh sensitivity analysis is to identify the coarsest mesh (low computational time) that provides accurate results. Linear brick elements (C3D8) were used for all layers in the model, except subgrade. Brick elements with reduced integration (C3D8R) were selected for the subgrade. Moreover, infinite elements (CIN3D8) were chosen for the outer faces of the model (except surface) to eliminate the need for artificial boundary conditions.
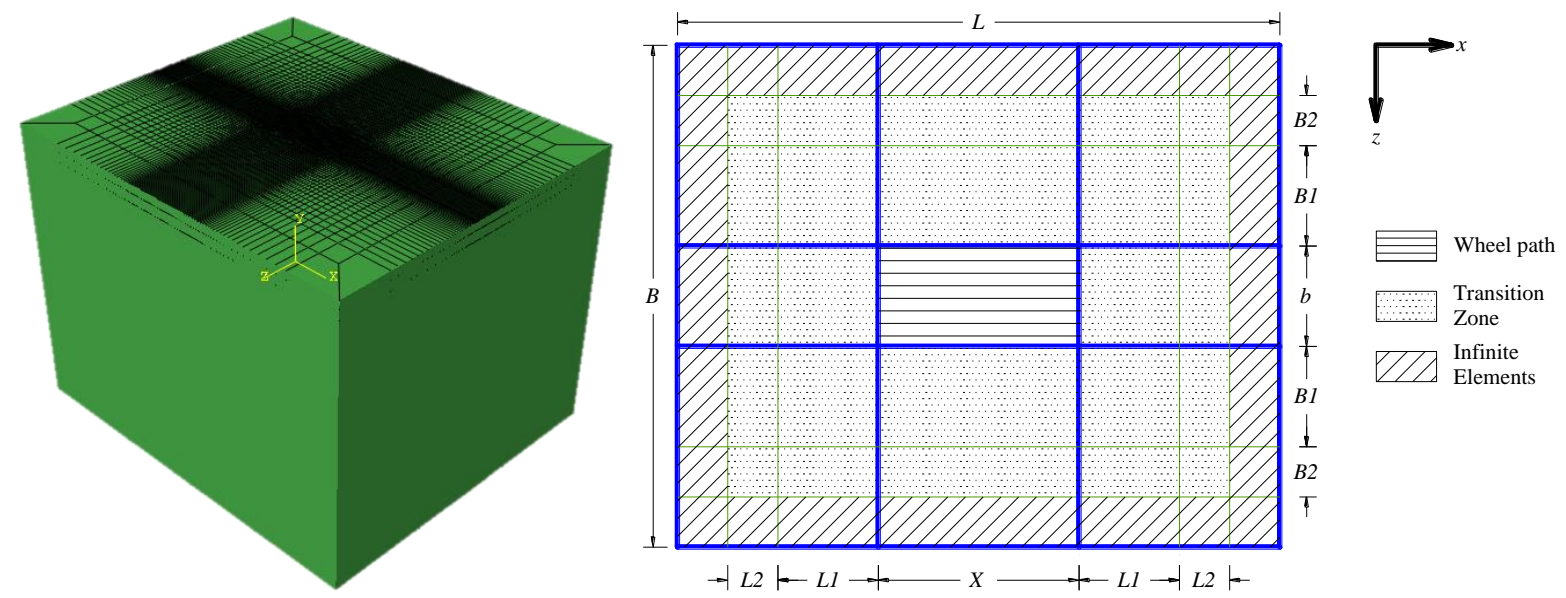

Figure A.4. Pavement model using ABAQUS (left) and geometric configuration in plan view (right). 


\section{APPENDIX B: CRITICAL PAVEMENT RESPONSES}

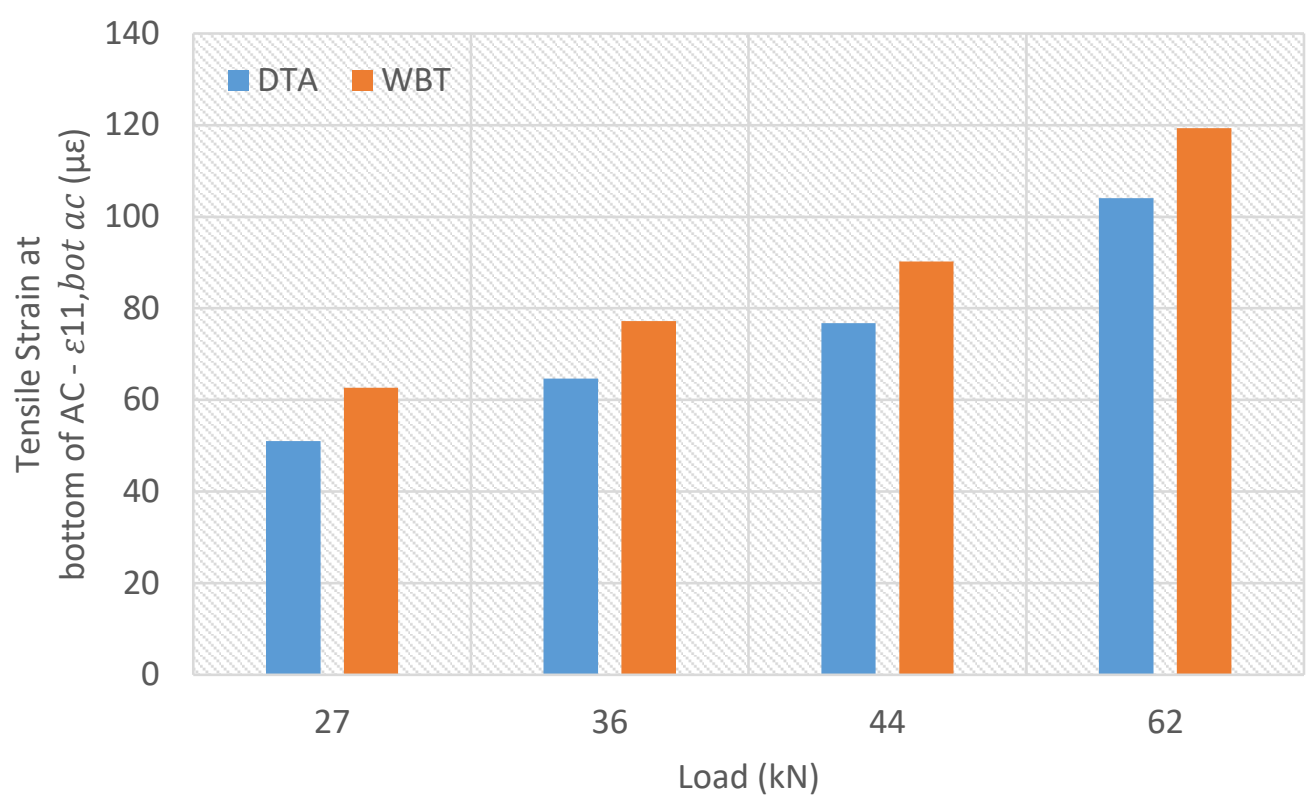

(a) Dry

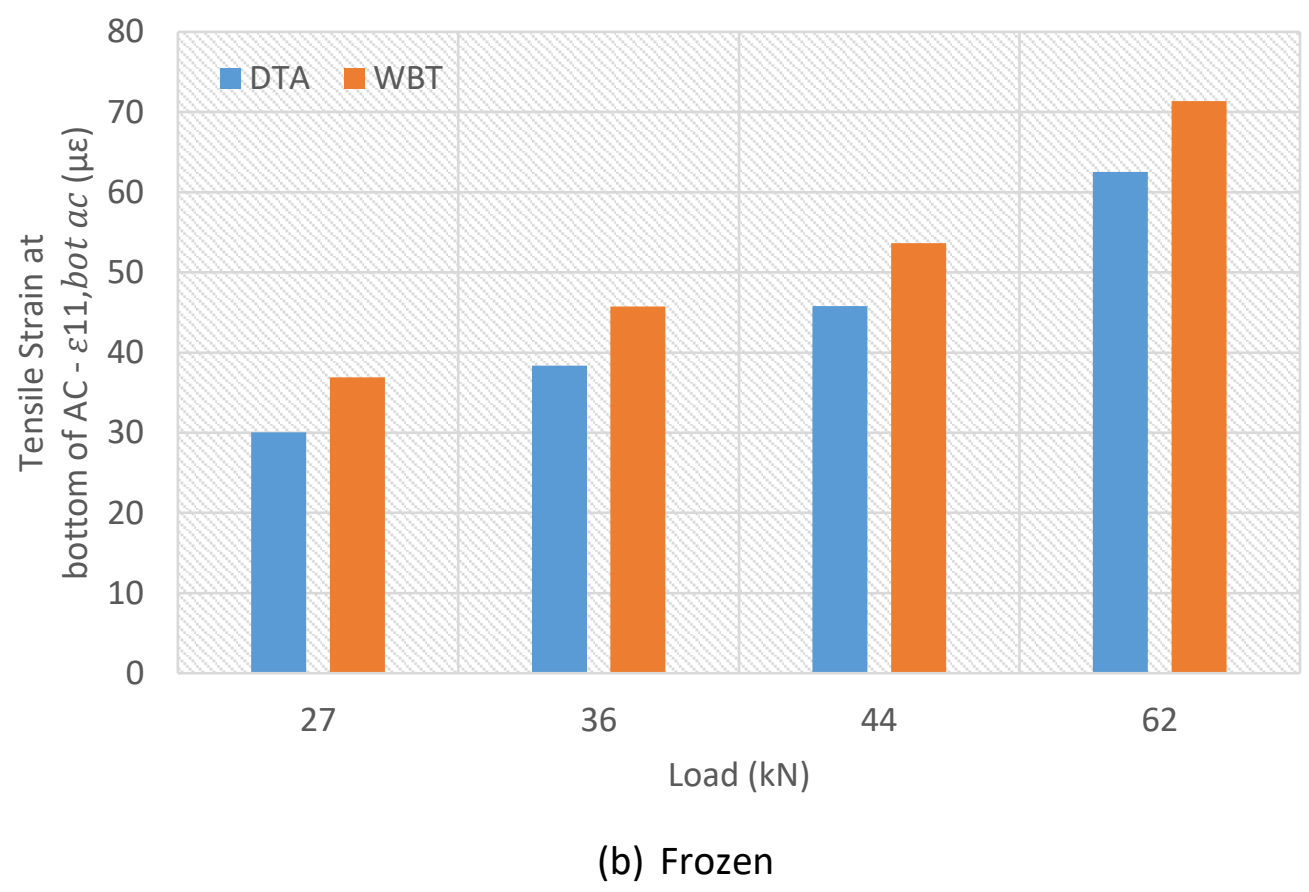



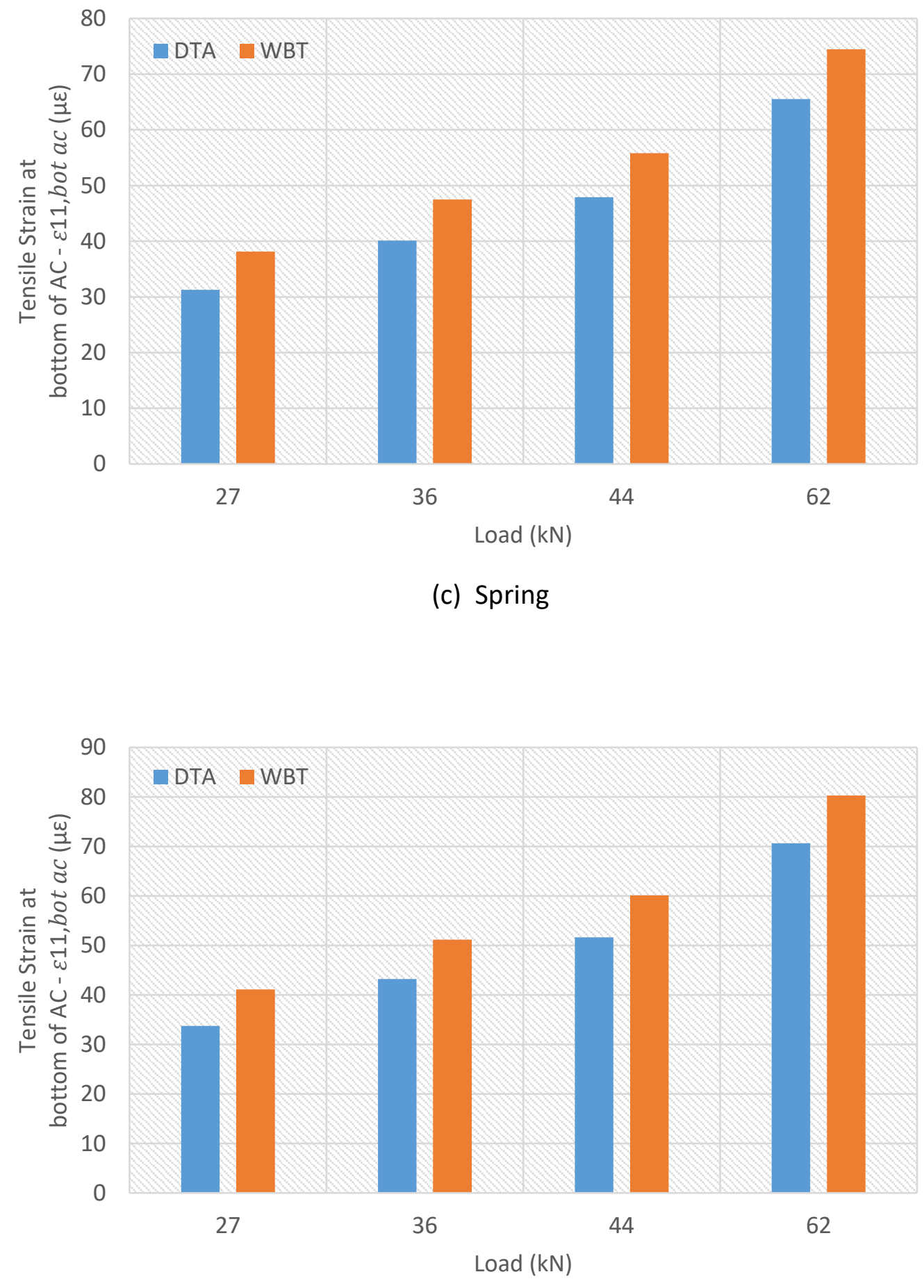

(d) Wet

Figure B.1. Tensile strain at the bottom of the AC layer. 


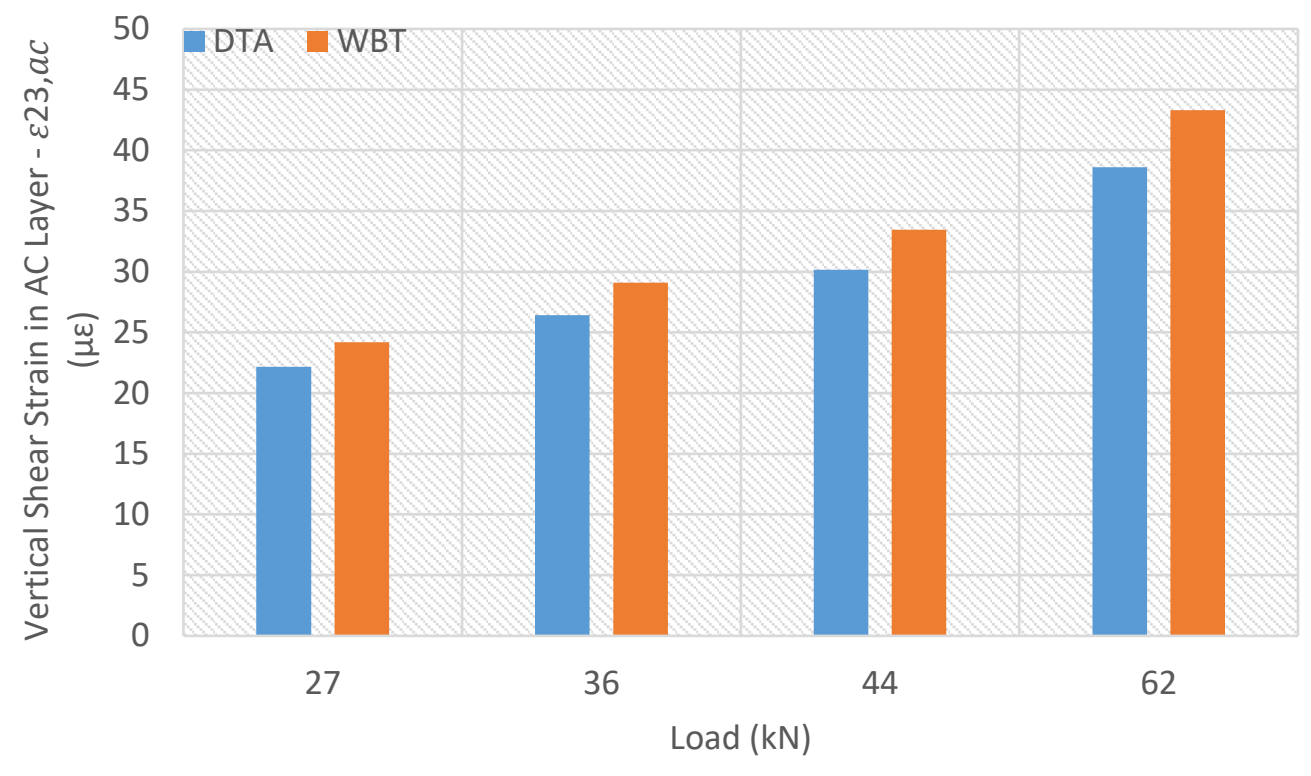

(a) Dry

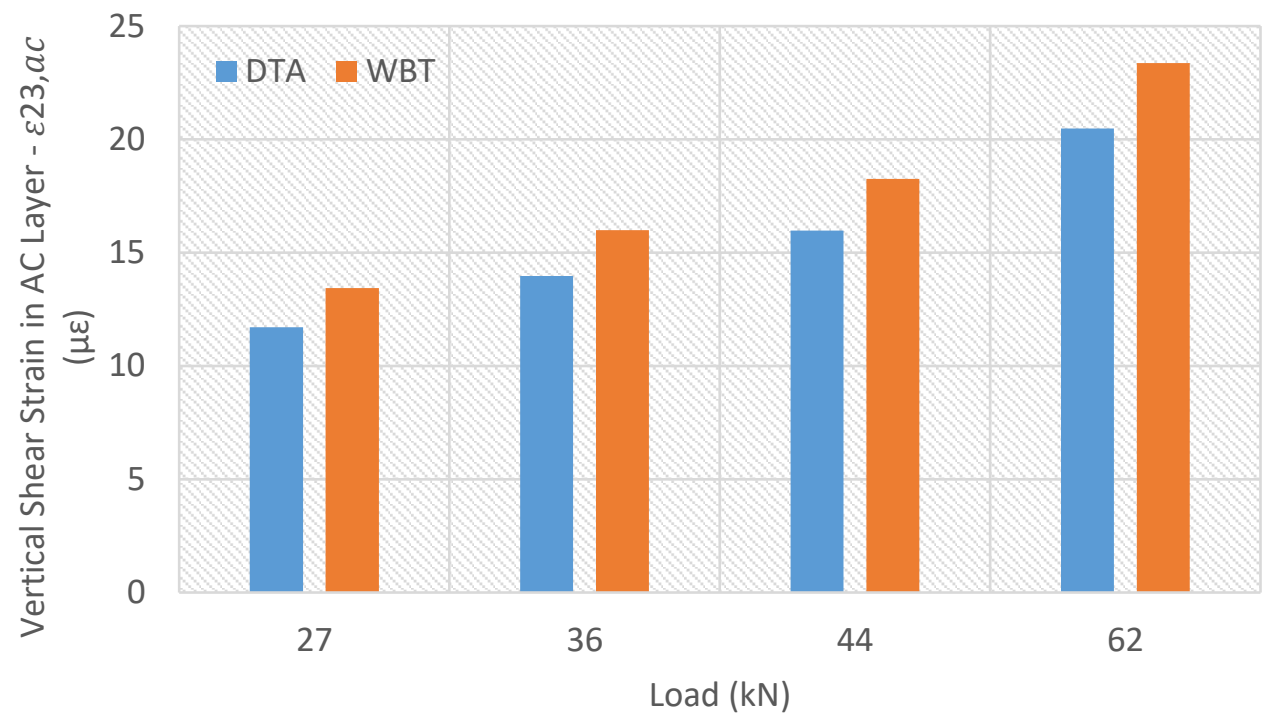

(b) Frozen 

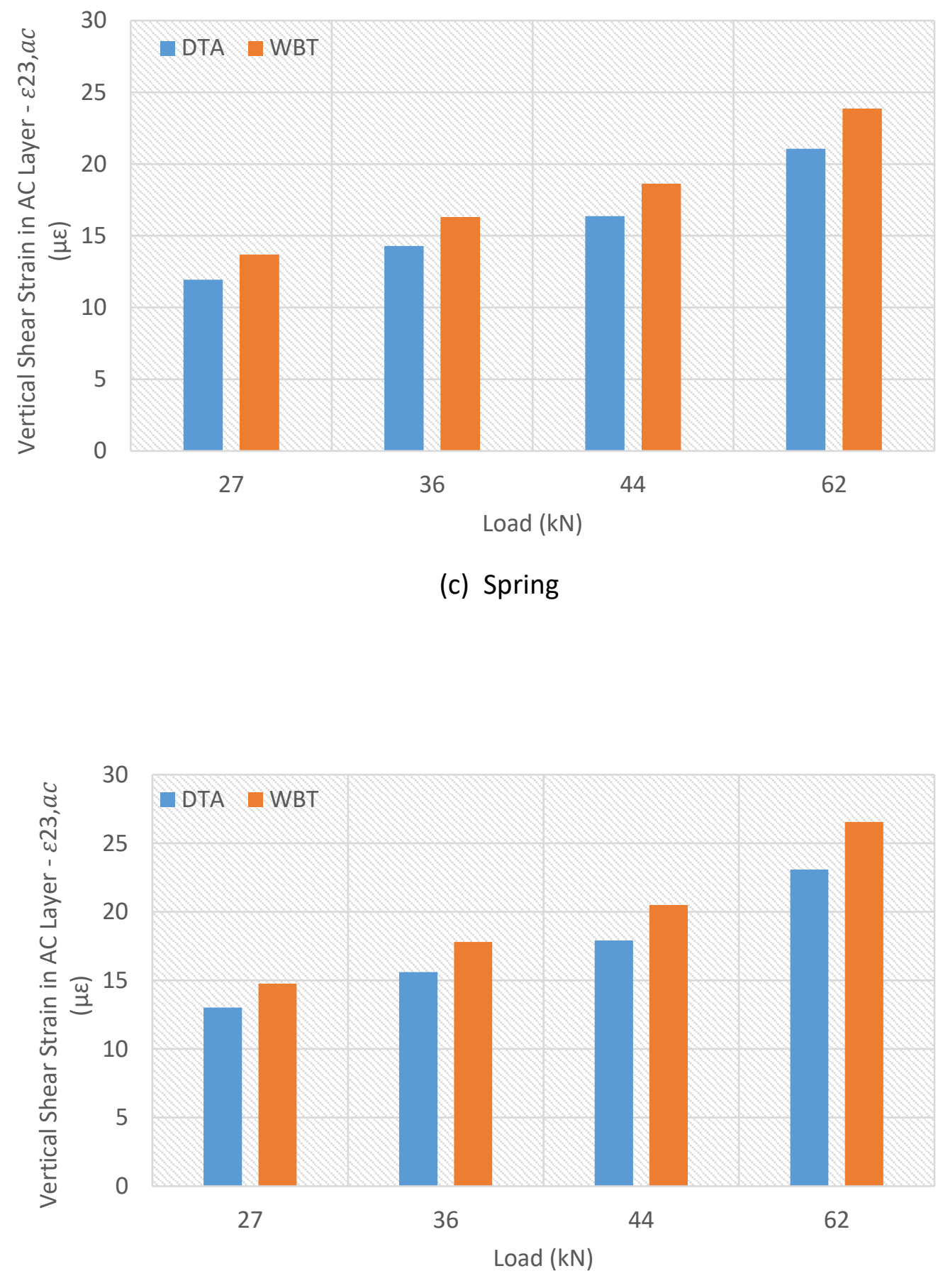

(d) Wet

Figure B.2. Vertical shear strain in the AC layer. 


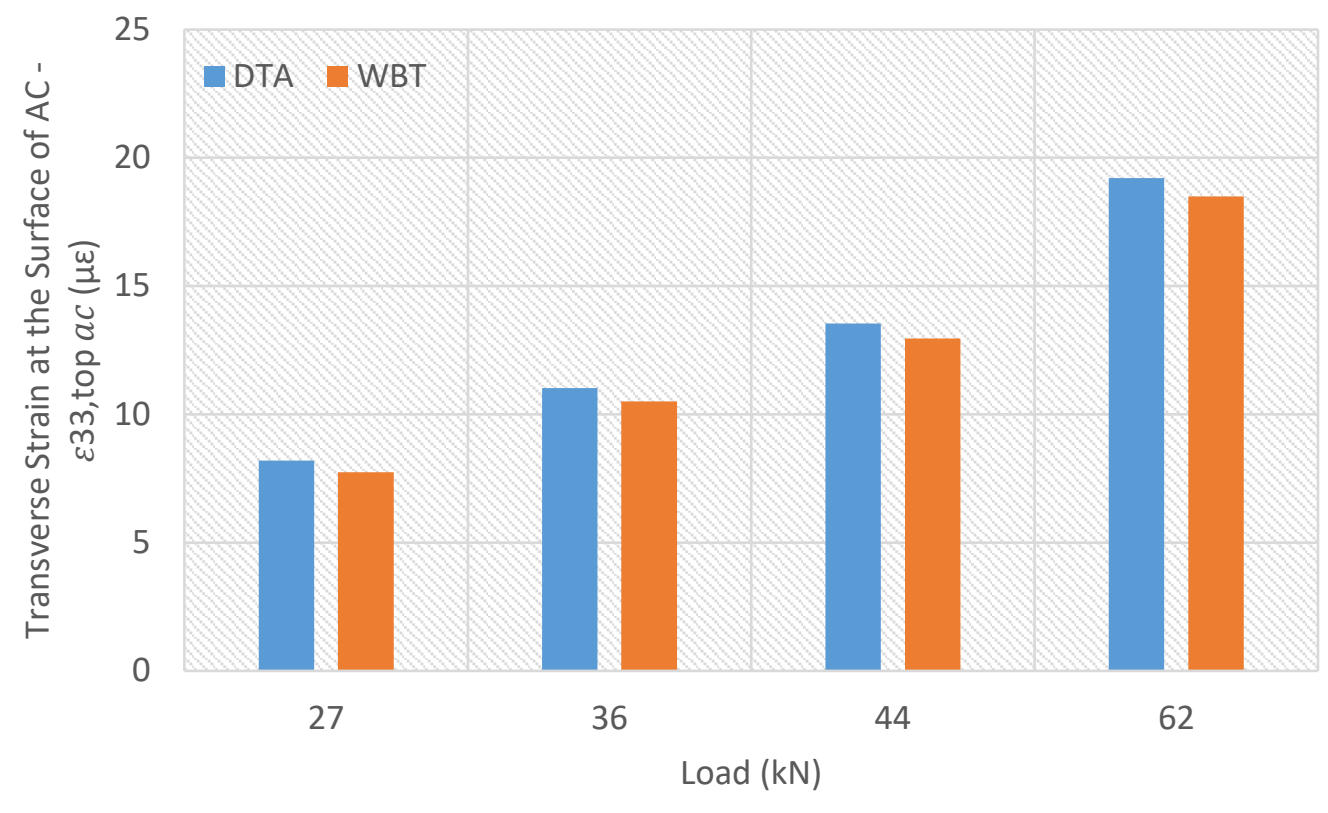

(a) Dry

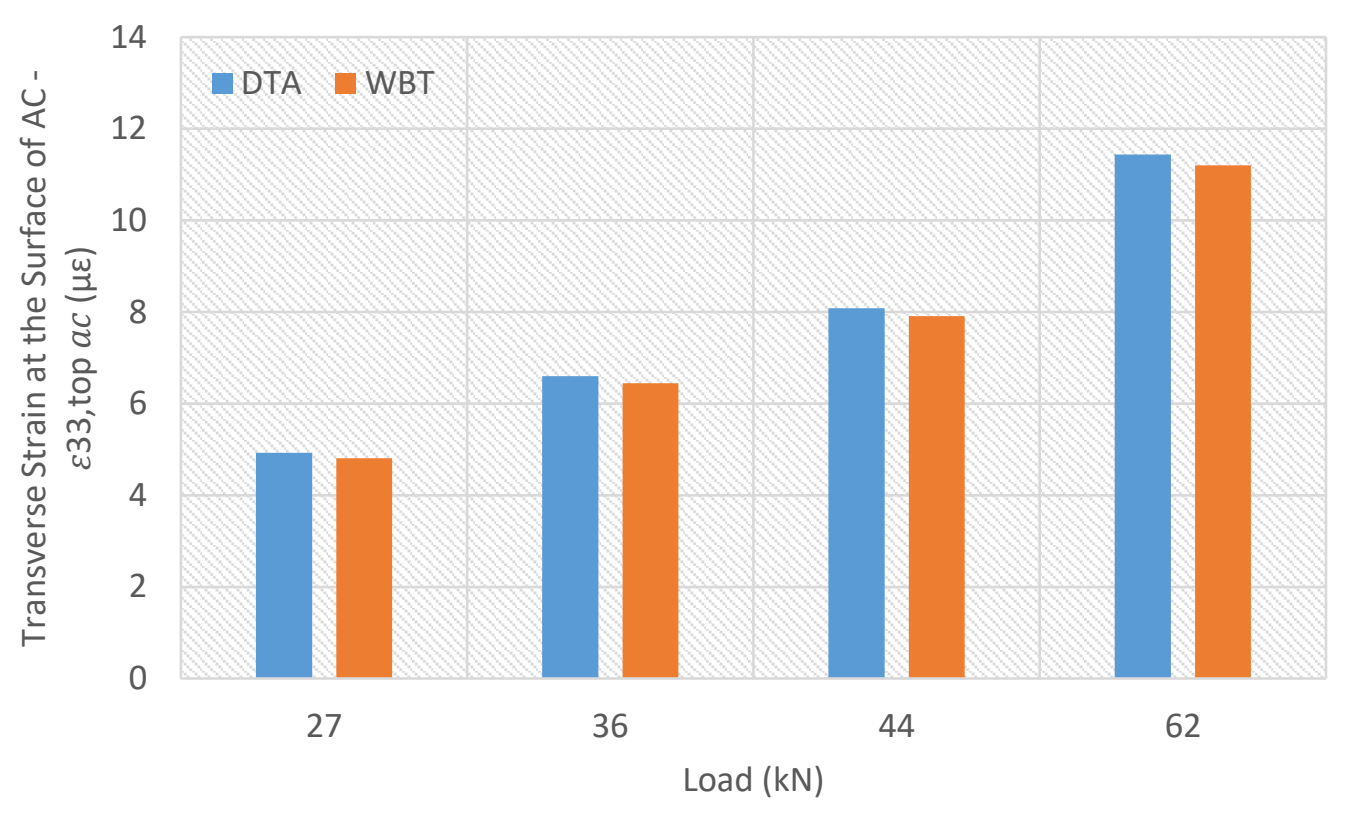

(b) Frozen 

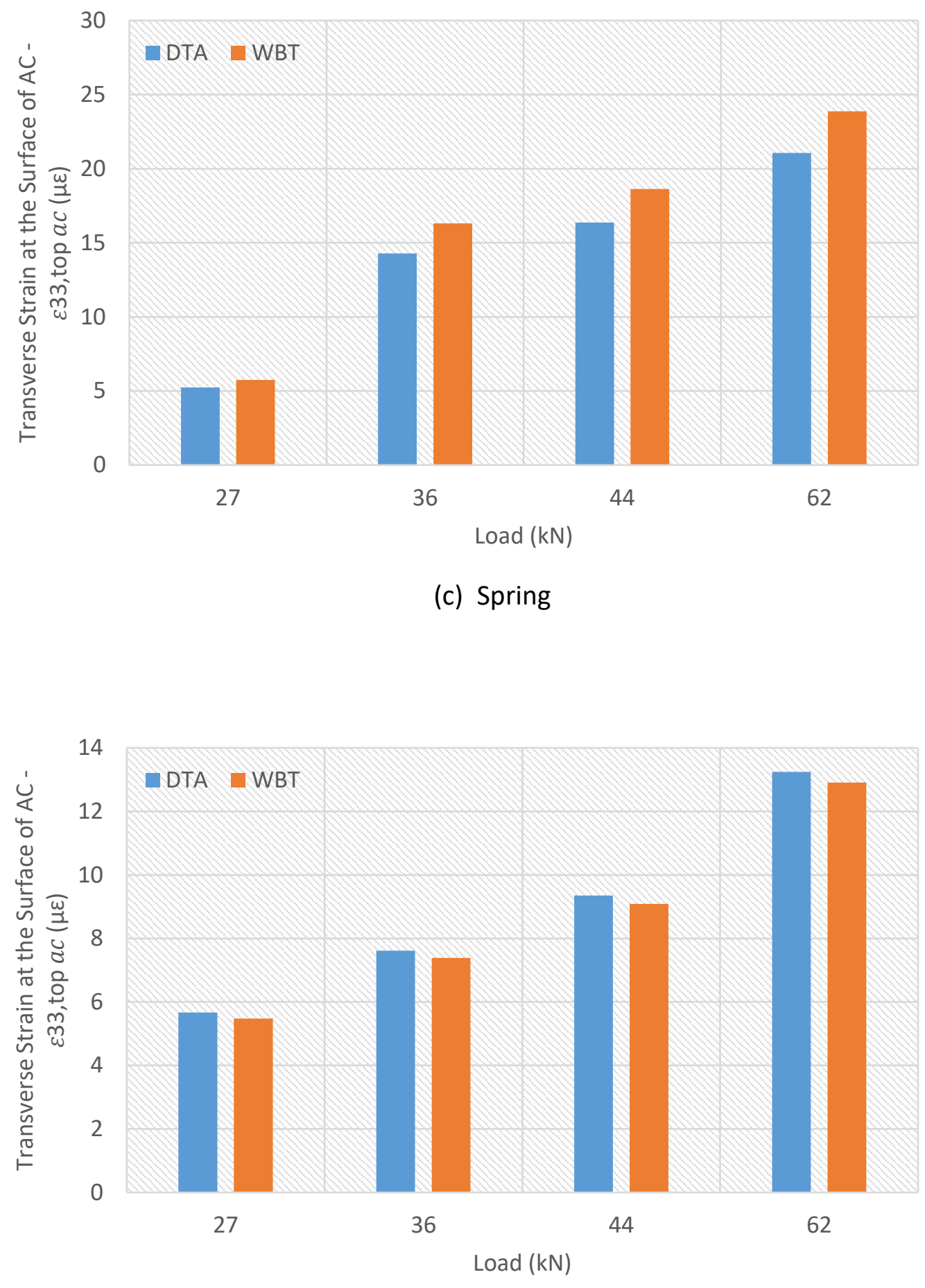

(d) Wet

Figure B.3. Transverse strain at the surface of the AC layer. 


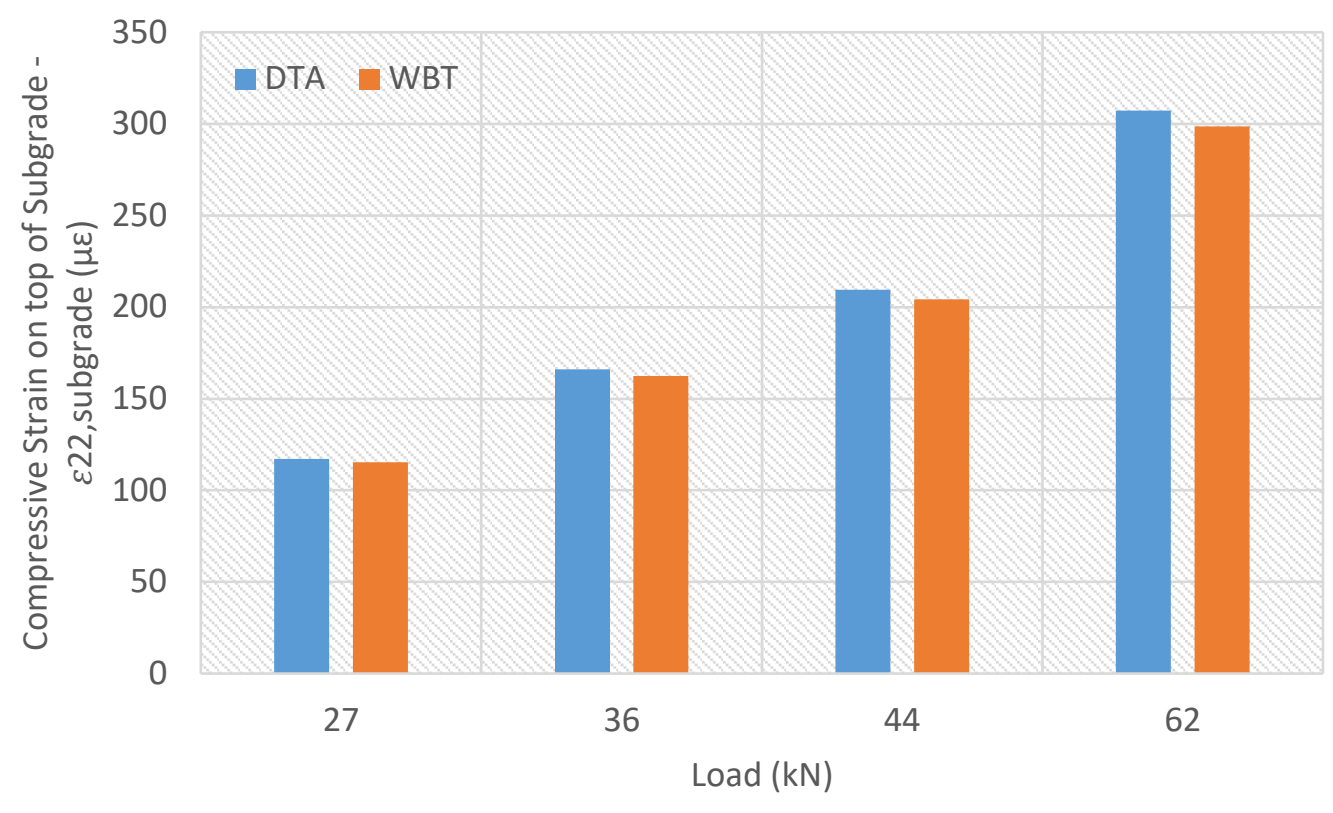

(a) Dry

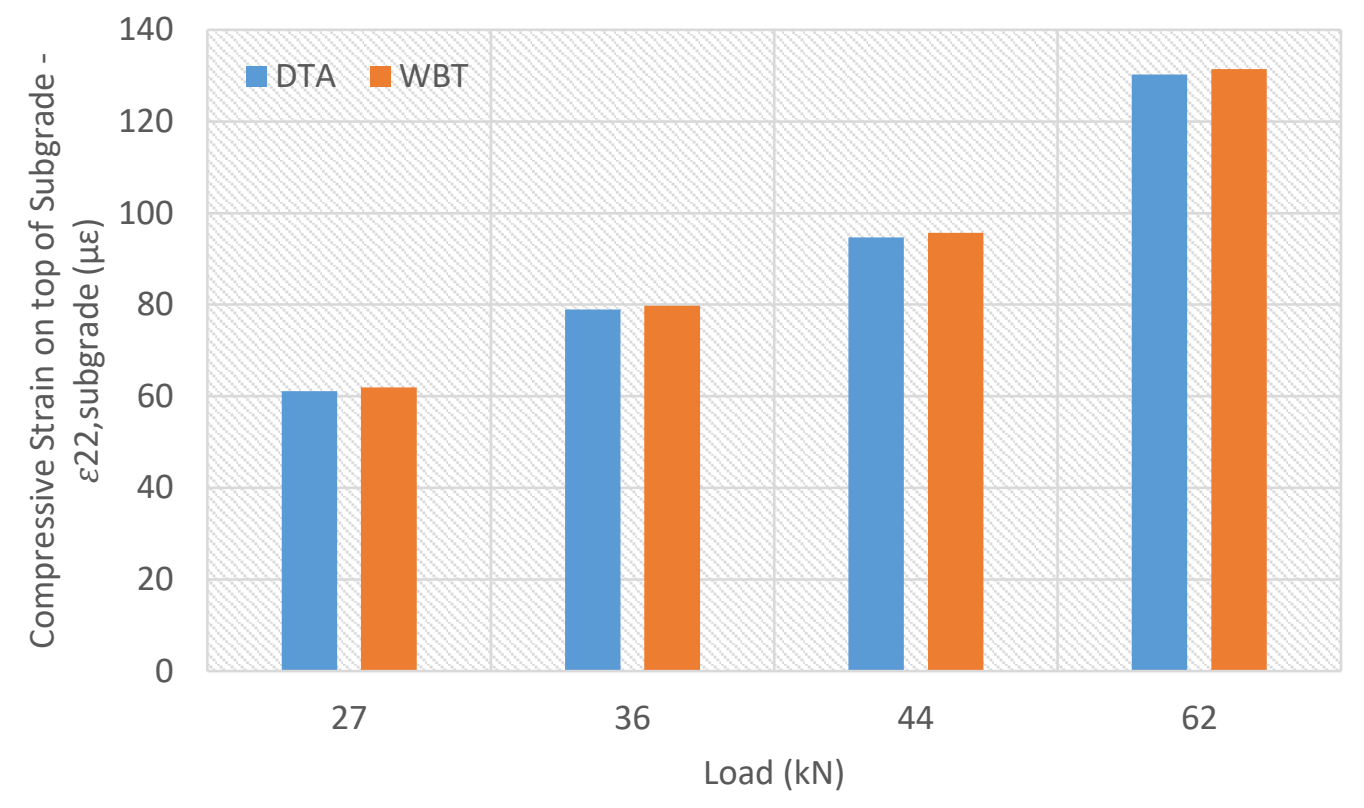

(b) Frozen 


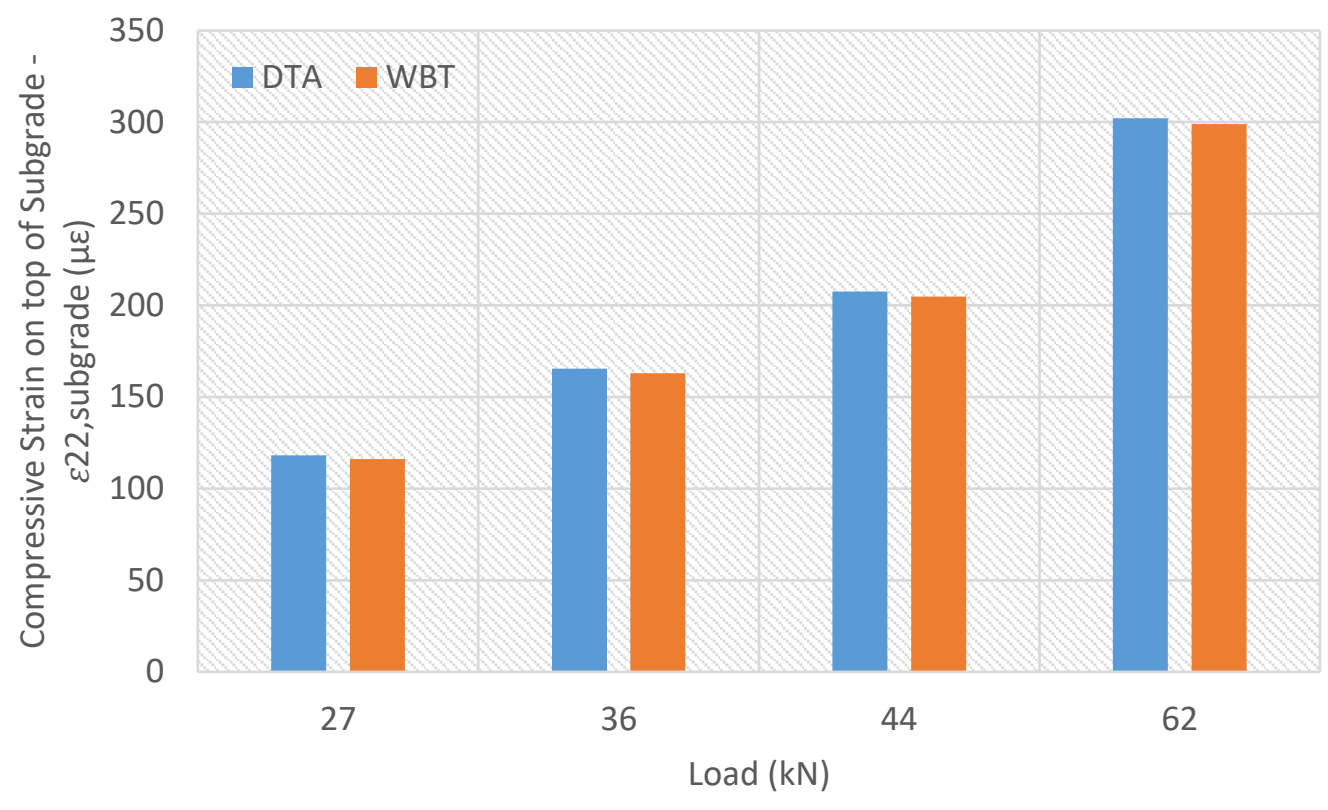

(c) Spring

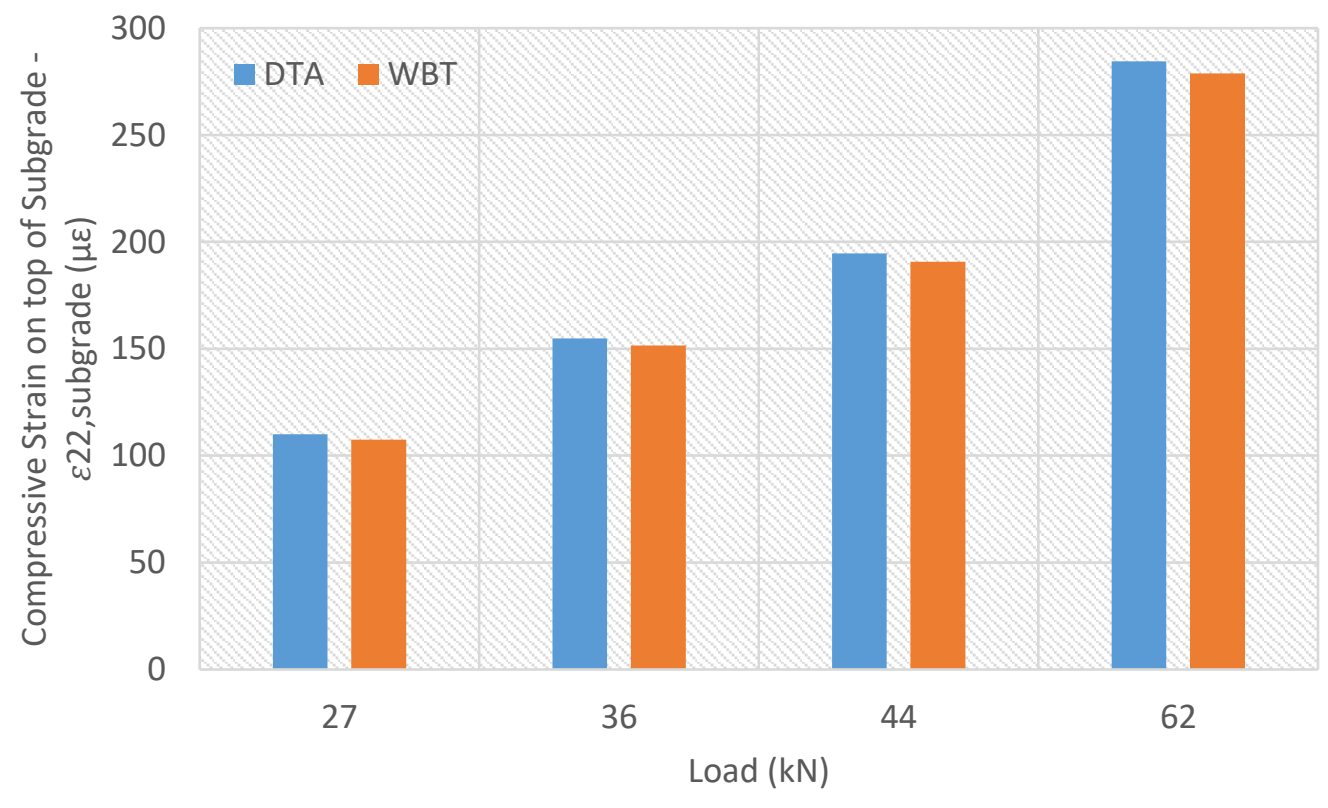

(d) Wet

Figure B.4. Compressive strain on top of subgrade. 


\section{APPENDIX C: WEIGHT-IN-MOTION ANALYSIS}

Table C.3. AADTT Per Site

\begin{tabular}{|c|c|}
\hline Site & AADTT \\
\hline SBW & 1382 \\
\hline SEB & 1604 \\
\hline WWG & 220 \\
\hline DWD & 949 \\
\hline LC1 & 1056 \\
\hline
\end{tabular}

Table C.4. AMDTT Site SBW

\begin{tabular}{|c|c|c|c|c|c|c|c|c|c|c|}
\hline Month & Class 4 & Class 5 & Class 6 & Class 7 & Class 8 & Class 9 & Class 10 & Class 11 & Class 12 & Class 13 \\
\hline 1 & 0.74 & 0.70 & 0.86 & 1.00 & 0.43 & 0.89 & 0.70 & 1.00 & 0.92 & 0.89 \\
\hline 2 & 0.84 & 0.80 & 0.92 & 1.00 & 0.47 & 0.92 & 0.76 & 1.00 & 0.98 & 1.06 \\
\hline 3 & 0.84 & 0.81 & 0.91 & 1.00 & 0.50 & 0.93 & 1.10 & 1.00 & 0.91 & 0.81 \\
\hline 4 & 0.96 & 0.88 & 0.95 & 1.00 & 0.73 & 1.00 & 0.97 & 1.00 & 1.07 & 0.83 \\
\hline 5 & 1.15 & 0.98 & 1.04 & 1.00 & 1.11 & 1.07 & 1.10 & 1.00 & 1.17 & 1.08 \\
\hline 6 & 1.12 & 1.04 & 1.12 & 1.00 & 1.25 & 1.06 & 1.14 & 1.00 & 1.03 & 1.06 \\
\hline 7 & 1.11 & 1.29 & 1.11 & 1.00 & 1.80 & 1.04 & 1.13 & 1.00 & 1.03 & 1.23 \\
\hline 8 & 1.14 & 1.53 & 1.04 & 1.00 & 2.08 & 1.06 & 1.06 & 1.00 & 1.03 & 1.23 \\
\hline 9 & 1.13 & 1.27 & 1.03 & 1.00 & 1.35 & 1.04 & 1.08 & 1.00 & 1.00 & 1.09 \\
\hline 10 & 1.06 & 1.00 & 1.09 & 1.00 & 1.00 & 1.05 & 1.00 & 1.00 & 0.98 & 0.98 \\
\hline 11 & 1.07 & 0.90 & 1.04 & 1.00 & 0.76 & 1.05 & 1.16 & 1.00 & 0.98 & 0.96 \\
\hline 12 & 0.84 & 0.80 & 0.89 & 1.00 & 0.52 & 0.89 & 0.79 & 1.00 & 0.89 & 0.77 \\
\hline
\end{tabular}

Table C.5. AMDTT Site SEB

\begin{tabular}{|c|c|c|c|c|c|c|c|c|c|c|}
\hline Month & Class 4 & Class 5 & Class 6 & Class 7 & Class 8 & Class 9 & Class 10 & Class 11 & Class 12 & Class 13 \\
\hline 1 & 0.76 & 0.71 & 0.87 & 1.00 & 0.40 & 0.88 & 0.74 & 1.00 & 0.93 & 0.89 \\
\hline 2 & 0.87 & 0.77 & 0.91 & 1.00 & 0.45 & 0.92 & 0.80 & 1.00 & 0.94 & 0.92 \\
\hline 3 & 0.87 & 0.91 & 0.88 & 1.00 & 0.55 & 0.94 & 0.89 & 1.00 & 0.91 & 0.93 \\
\hline 4 & 0.99 & 1.08 & 0.91 & 1.00 & 0.87 & 0.97 & 1.03 & 1.00 & 1.01 & 1.03 \\
\hline 5 & 1.19 & 1.10 & 1.00 & 1.00 & 1.19 & 1.06 & 1.12 & 1.00 & 1.13 & 1.12 \\
\hline 6 & 1.21 & 1.13 & 1.08 & 1.00 & 1.42 & 1.06 & 1.10 & 1.00 & 1.09 & 1.10 \\
\hline 7 & 1.06 & 1.30 & 1.11 & 1.00 & 1.96 & 1.05 & 1.17 & 1.00 & 1.02 & 1.07 \\
\hline 8 & 1.07 & 1.28 & 1.13 & 1.00 & 1.80 & 1.08 & 1.11 & 1.00 & 1.03 & 1.05 \\
\hline 9 & 1.09 & 1.06 & 1.13 & 1.00 & 1.25 & 1.04 & 1.08 & 1.00 & 1.04 & 1.03 \\
\hline 10 & 1.07 & 0.95 & 1.07 & 1.00 & 0.93 & 1.04 & 1.06 & 1.00 & 1.03 & 1.03 \\
\hline 11 & 1.04 & 0.91 & 1.04 & 1.00 & 0.72 & 1.04 & 1.03 & 1.00 & 1.03 & 1.02 \\
\hline 12 & 0.79 & 0.80 & 0.87 & 1.00 & 0.48 & 0.91 & 0.86 & 1.00 & 0.85 & 0.80 \\
\hline
\end{tabular}


Table C.6. AMDTT Site WWG

\begin{tabular}{|c|c|c|c|c|c|c|c|c|c|c|}
\hline Month & Class 4 & Class 5 & Class 6 & Class 7 & Class 8 & Class 9 & Class 10 & Class 11 & Class 12 & Class 13 \\
\hline 1 & 0.79 & 0.76 & 0.81 & 1.00 & 0.41 & 0.88 & 0.66 & 1.00 & 0.89 & 1.00 \\
\hline 2 & 0.90 & 0.78 & 0.77 & 1.00 & 0.47 & 0.87 & 0.65 & 1.00 & 0.90 & 1.00 \\
\hline 3 & 0.84 & 0.87 & 0.79 & 1.00 & 0.54 & 0.89 & 0.68 & 1.00 & 0.97 & 1.00 \\
\hline 4 & 1.08 & 0.98 & 0.81 & 1.00 & 0.92 & 0.91 & 1.07 & 1.00 & 0.99 & 1.00 \\
\hline 5 & 1.17 & 1.04 & 0.94 & 1.00 & 1.13 & 1.00 & 1.01 & 1.00 & 1.00 & 1.00 \\
\hline 6 & 1.26 & 1.16 & 1.20 & 1.00 & 1.38 & 1.04 & 1.15 & 1.00 & 1.12 & 1.00 \\
\hline 7 & 0.83 & 1.19 & 1.23 & 1.00 & 1.86 & 1.04 & 1.01 & 1.00 & 0.99 & 1.00 \\
\hline 8 & 0.84 & 1.19 & 1.11 & 1.00 & 1.70 & 1.28 & 1.52 & 1.00 & 1.14 & 1.00 \\
\hline 9 & 1.27 & 1.10 & 1.04 & 1.00 & 1.37 & 1.06 & 1.42 & 1.00 & 1.09 & 1.00 \\
\hline 10 & 1.07 & 1.05 & 1.20 & 1.00 & 0.95 & 1.07 & 1.12 & 1.00 & 1.03 & 1.00 \\
\hline 11 & 1.05 & 0.97 & 1.15 & 1.00 & 0.70 & 1.02 & 0.94 & 1.00 & 0.94 & 1.00 \\
\hline 12 & 0.91 & 0.92 & 0.96 & 1.00 & 0.56 & 0.94 & 0.78 & 1.00 & 0.94 & 1.00 \\
\hline
\end{tabular}

Table C.7. AMDTT Site DWD

\begin{tabular}{|c|c|c|c|c|c|c|c|c|c|c|}
\hline Month & Class 4 & Class 5 & Class 6 & Class 7 & Class 8 & Class 9 & Class 10 & Class 11 & Class 12 & Class 13 \\
\hline 1 & 0.80 & 0.74 & 0.79 & 1.00 & 0.46 & 0.88 & 0.94 & 1.00 & 0.86 & 0.90 \\
\hline 2 & 0.86 & 0.79 & 0.80 & 1.00 & 0.49 & 0.93 & 0.98 & 1.00 & 1.12 & 0.98 \\
\hline 3 & 0.95 & 0.86 & 0.85 & 1.00 & 0.52 & 0.96 & 1.11 & 1.00 & 1.13 & 1.05 \\
\hline 4 & 0.96 & 0.94 & 0.87 & 1.00 & 0.67 & 0.98 & 1.16 & 1.00 & 0.98 & 0.91 \\
\hline 5 & 1.12 & 1.04 & 1.07 & 1.00 & 0.91 & 1.07 & 1.28 & 1.00 & 0.99 & 1.05 \\
\hline 6 & 1.22 & 1.07 & 1.15 & 1.00 & 1.23 & 1.09 & 1.15 & 1.00 & 0.91 & 1.09 \\
\hline 7 & 1.01 & 1.25 & 1.17 & 1.00 & 1.82 & 1.04 & 1.13 & 1.00 & 0.77 & 1.00 \\
\hline 8 & 1.06 & 1.41 & 1.16 & 1.00 & 2.29 & 1.07 & 1.05 & 1.00 & 0.87 & 1.09 \\
\hline 9 & 1.07 & 1.11 & 1.14 & 1.00 & 1.45 & 1.07 & 1.14 & 1.00 & 1.02 & 1.11 \\
\hline 10 & 1.06 & 1.04 & 1.11 & 1.00 & 0.94 & 1.02 & 0.80 & 1.00 & 1.08 & 1.00 \\
\hline 11 & 1.06 & 0.94 & 1.08 & 1.00 & 0.73 & 1.04 & 0.63 & 1.00 & 1.25 & 1.01 \\
\hline 12 & 0.82 & 0.81 & 0.82 & 1.00 & 0.49 & 0.86 & 0.63 & 1.00 & 1.02 & 0.82 \\
\hline
\end{tabular}

Table C.8. AMDTT Site LC1

\begin{tabular}{|c|c|c|c|c|c|c|c|c|c|c|}
\hline Month & Class 4 & Class 5 & Class 6 & Class 7 & Class 8 & Class 9 & Class 10 & Class 11 & Class 12 & Class 13 \\
\hline 1 & 0.78 & 0.72 & 0.96 & 1.00 & 0.40 & 0.90 & 0.97 & 1.00 & 0.90 & 0.87 \\
\hline 2 & 0.81 & 0.75 & 0.97 & 1.00 & 0.45 & 0.94 & 1.03 & 1.00 & 0.92 & 0.97 \\
\hline 3 & 0.85 & 0.80 & 0.92 & 1.00 & 0.55 & 0.96 & 1.18 & 1.00 & 0.95 & 1.06 \\
\hline 4 & 0.96 & 0.89 & 0.81 & 1.00 & 0.83 & 0.97 & 0.80 & 1.00 & 1.14 & 1.05 \\
\hline 5 & 1.15 & 1.00 & 1.02 & 1.00 & 1.15 & 1.08 & 1.00 & 1.00 & 1.16 & 1.04 \\
\hline 6 & 1.26 & 1.15 & 1.10 & 1.00 & 1.32 & 1.07 & 1.10 & 1.00 & 1.06 & 1.11 \\
\hline 7 & 1.07 & 1.33 & 1.19 & 1.00 & 1.93 & 1.03 & 1.02 & 1.00 & 1.04 & 1.09 \\
\hline 8 & 1.08 & 1.30 & 1.10 & 1.00 & 1.75 & 1.04 & 1.02 & 1.00 & 1.00 & 1.03 \\
\hline 9 & 1.08 & 1.11 & 1.06 & 1.00 & 1.21 & 1.04 & 1.24 & 1.00 & 0.92 & 1.12 \\
\hline 10 & 1.03 & 1.01 & 0.96 & 1.00 & 1.02 & 1.03 & 1.03 & 1.00 & 0.98 & 1.00 \\
\hline 11 & 1.07 & 1.05 & 0.99 & 1.00 & 0.85 & 1.05 & 0.87 & 1.00 & 1.04 & 0.93 \\
\hline 12 & 0.86 & 0.89 & 0.93 & 1.00 & 0.54 & 0.89 & 0.74 & 1.00 & 0.88 & 0.72 \\
\hline
\end{tabular}


Table C.9. Axle Per Truck Class Site SBW

\begin{tabular}{|c|c|c|c|}
\hline Class & Single & Tandem & Tridem \\
\hline 4 & 1.53 & 0.47 & 0.00 \\
\hline 5 & 2.00 & 0.00 & 0.00 \\
\hline 6 & 1.00 & 1.00 & 0.00 \\
\hline 7 & 0.91 & 1.56 & 0.07 \\
\hline 8 & 2.08 & 0.92 & 0.00 \\
\hline 9 & 1.28 & 1.85 & 0.00 \\
\hline 10 & 1.42 & 1.20 & 0.73 \\
\hline 11 & 3.69 & 0.14 & 0.34 \\
\hline 12 & 3.87 & 1.07 & 0.00 \\
\hline 13 & 2.48 & 1.87 & 0.49 \\
\hline
\end{tabular}

Table C.10. Axle Per Truck Class Site SEB

\begin{tabular}{|c|c|c|c|}
\hline Class & Single & Tandem & Tridem \\
\hline 4 & 1.59 & 0.41 & 0.00 \\
\hline 5 & 2.00 & 0.00 & 0.00 \\
\hline 6 & 1.00 & 1.00 & 0.00 \\
\hline 7 & 1.02 & 1.55 & 0.21 \\
\hline 8 & 2.10 & 0.90 & 0.00 \\
\hline 9 & 1.20 & 1.89 & 0.00 \\
\hline 10 & 1.32 & 1.11 & 0.82 \\
\hline 11 & 2.39 & 0.38 & 0.61 \\
\hline 12 & 3.93 & 1.03 & 0.00 \\
\hline 13 & 2.60 & 1.84 & 0.47 \\
\hline
\end{tabular}

Table C.11. Axle Per Truck Class Site WWG

\begin{tabular}{|c|c|c|c|}
\hline Class & Single & Tandem & Tridem \\
\hline 4 & 1.70 & 0.30 & 0.00 \\
\hline 5 & 2.00 & 0.00 & 0.00 \\
\hline 6 & 1.00 & 1.00 & 0.00 \\
\hline 7 & 0.68 & 1.55 & 0.22 \\
\hline 8 & 2.03 & 0.97 & 0.00 \\
\hline 9 & 1.43 & 1.78 & 0.00 \\
\hline 10 & 1.11 & 1.05 & 0.93 \\
\hline 11 & 4.33 & 0.13 & 0.14 \\
\hline 12 & 3.98 & 1.01 & 0.00 \\
\hline 13 & 2.00 & 1.70 & 0.76 \\
\hline
\end{tabular}


Table C.12. Axle Per Truck Class Site DWD

\begin{tabular}{|c|c|c|c|}
\hline Class & Single & Tandem & Tridem \\
\hline 4 & 1.56 & 0.44 & 0.00 \\
\hline 5 & 2.00 & 0.00 & 0.00 \\
\hline 6 & 1.00 & 1.00 & 0.00 \\
\hline 7 & 0.97 & 1.74 & 0.15 \\
\hline 8 & 2.05 & 0.95 & 0.00 \\
\hline 9 & 1.20 & 1.89 & 0.00 \\
\hline 10 & 1.76 & 1.58 & 0.36 \\
\hline 11 & 2.18 & 0.56 & 0.57 \\
\hline 12 & 3.85 & 1.06 & 0.01 \\
\hline 13 & 2.19 & 1.91 & 0.57 \\
\hline
\end{tabular}

Table C.13. Axle Per Truck Class Site LC1

\begin{tabular}{|c|c|c|c|}
\hline Class & Single & Tandem & Tridem \\
\hline 4 & 1.61 & 0.39 & 0.00 \\
\hline 5 & 2.00 & 0.00 & 0.00 \\
\hline 6 & 1.00 & 1.00 & 0.00 \\
\hline 7 & 0.47 & 1.71 & 0.10 \\
\hline 8 & 2.08 & 0.92 & 0.00 \\
\hline 9 & 1.20 & 1.90 & 0.00 \\
\hline 10 & 2.02 & 1.40 & 0.40 \\
\hline 11 & 1.83 & 0.37 & 0.81 \\
\hline 12 & 3.89 & 1.05 & 0.00 \\
\hline 13 & 2.65 & 1.84 & 0.46 \\
\hline
\end{tabular}

Table C.14. Normalized Truck Distribution

\begin{tabular}{|c|c|c|c|c|c|}
\hline \multirow{2}{*}{ Class } & \multicolumn{5}{|c|}{ Percent AADTT } \\
\cline { 2 - 6 } & SBW & SEB & WWG & DWD & LC1 \\
\hline 4 & 2.3 & 2.1 & 2.6 & 1.5 & 1.4 \\
\hline 5 & 18.7 & 22.8 & 29.7 & 12.8 & 12.8 \\
\hline 6 & 5.6 & 4.7 & 6.7 & 3.7 & 0.2 \\
\hline 7 & 0.1 & 0.1 & 0.1 & 3.3 & 0.0 \\
\hline 8 & 3.8 & 4.4 & 4.9 & 46.6 & 4.0 \\
\hline 9 & 42.9 & 37.0 & 39.6 & 12.5 & 45.0 \\
\hline 10 & 4.1 & 3.3 & 2.9 & 0.2 & 8.3 \\
\hline 11 & 0.1 & 0.1 & 0.4 & 13.9 & 0.0 \\
\hline 12 & 18.1 & 20.0 & 12.5 & 5.3 & 18.8 \\
\hline 13 & 4.3 & 5.5 & 0.7 & 6.7 \\
\hline
\end{tabular}


Table C.15. Normalized Single Axle Load Distribution Per Class for Site SBW

\begin{tabular}{|c|c|c|c|c|c|c|c|c|c|c|}
\hline $\begin{array}{l}\text { Load } \\
\text { (kgf) }\end{array}$ & Class 4 & Class 5 & Class 6 & Class 7 & Class 8 & Class 9 & Class 10 & Class 11 & Class 12 & Class 13 \\
\hline 250 & 0.00 & 0.07 & 0.13 & 5.85 & 0.07 & 0.04 & 0.53 & 0.00 & 0.00 & 0.00 \\
\hline 750 & 0.00 & 2.13 & 0.10 & 9.00 & 0.19 & 0.43 & 1.03 & 0.00 & 0.00 & 0.00 \\
\hline 1250 & 0.01 & 19.85 & 0.10 & 9.26 & 1.04 & 1.16 & 1.77 & 0.00 & 0.00 & 0.00 \\
\hline 1750 & 0.00 & 33.06 & 0.16 & 6.68 & 26.10 & 2.08 & 2.15 & 2.07 & 3.68 & 0.41 \\
\hline 2250 & 0.02 & 15.89 & 0.17 & 3.08 & 22.99 & 3.15 & 2.57 & 3.91 & 8.17 & 1.22 \\
\hline 2750 & 0.05 & 7.79 & 0.31 & 1.18 & 12.75 & 3.68 & 2.16 & 6.23 & 7.31 & 1.08 \\
\hline 3250 & 5.35 & 5.16 & 0.88 & 1.21 & 6.73 & 3.70 & 1.81 & 12.40 & 5.23 & 1.11 \\
\hline 3750 & 14.09 & 4.35 & 2.92 & 2.25 & 4.90 & 4.09 & 2.65 & 16.53 & 4.36 & 1.97 \\
\hline 4250 & 14.07 & 3.25 & 12.84 & 11.04 & 5.45 & 12.37 & 10.07 & 20.30 & 6.08 & 6.64 \\
\hline 4750 & 12.07 & 2.24 & 24.79 & 22.67 & 5.10 & 26.69 & 23.78 & 12.15 & 10.77 & 13.06 \\
\hline 5250 & 11.54 & 1.62 & 20.94 & 14.66 & 3.80 & 25.76 & 23.03 & 5.44 & 11.71 & 14.57 \\
\hline 5750 & 11.05 & 1.25 & 11.50 & 4.90 & 2.35 & 11.17 & 11.29 & 4.58 & 8.20 & 10.79 \\
\hline 6250 & 9.00 & 0.93 & 6.75 & 2.01 & 1.79 & 2.88 & 4.25 & 3.83 & 5.93 & 8.77 \\
\hline 6750 & 7.14 & 0.67 & 5.13 & 1.40 & 1.57 & 0.80 & 2.79 & 3.50 & 5.96 & 10.18 \\
\hline 7250 & 5.40 & 0.48 & 4.02 & 1.21 & 1.49 & 0.57 & 2.75 & 2.35 & 6.59 & 11.62 \\
\hline 7750 & 3.92 & 0.37 & 3.13 & 1.66 & 1.19 & 0.51 & 2.73 & 1.97 & 6.27 & 9.66 \\
\hline 8250 & 2.69 & 0.28 & 2.33 & 0.62 & 0.94 & 0.40 & 2.23 & 1.54 & 4.78 & 5.27 \\
\hline 8750 & 1.71 & 0.20 & 1.50 & 0.52 & 0.68 & 0.26 & 1.28 & 1.27 & 2.78 & 2.02 \\
\hline 9250 & 0.93 & 0.14 & 0.85 & 0.33 & 0.45 & 0.14 & 0.54 & 0.82 & 1.23 & 0.80 \\
\hline 9750 & 0.50 & 0.09 & 0.53 & 0.24 & 0.21 & 0.07 & 0.26 & 0.51 & 0.51 & 0.36 \\
\hline 10250 & 0.24 & 0.06 & 0.40 & 0.05 & 0.09 & 0.03 & 0.13 & 0.21 & 0.22 & 0.19 \\
\hline 10750 & 0.12 & 0.04 & 0.25 & 0.02 & 0.05 & 0.02 & 0.07 & 0.13 & 0.12 & 0.12 \\
\hline 11250 & 0.05 & 0.02 & 0.14 & 0.05 & 0.03 & 0.01 & 0.04 & 0.09 & 0.06 & 0.07 \\
\hline 11750 & 0.04 & 0.01 & 0.06 & 0.02 & 0.02 & 0.01 & 0.03 & 0.03 & 0.03 & 0.04 \\
\hline 12250 & 0.02 & 0.01 & 0.04 & 0.00 & 0.01 & 0.00 & 0.02 & 0.04 & 0.01 & 0.02 \\
\hline 12750 & 0.01 & 0.00 & 0.02 & 0.00 & 0.00 & 0.00 & 0.01 & 0.05 & 0.01 & 0.02 \\
\hline 13250 & 0.00 & 0.00 & 0.01 & 0.05 & 0.00 & 0.00 & 0.01 & 0.02 & 0.00 & 0.01 \\
\hline 13750 & 0.00 & 0.00 & 0.01 & 0.02 & 0.00 & 0.00 & 0.01 & 0.01 & 0.00 & 0.01 \\
\hline 14250 & 0.00 & 0.00 & 0.00 & 0.00 & 0.00 & 0.00 & 0.00 & 0.00 & 0.00 & 0.00 \\
\hline 14750 & 0.00 & 0.00 & 0.00 & 0.00 & 0.00 & 0.00 & 0.00 & 0.01 & 0.00 & 0.00 \\
\hline 15250 & 0.00 & 0.00 & 0.00 & 0.00 & 0.00 & 0.00 & 0.00 & 0.01 & 0.00 & 0.00 \\
\hline 15750 & 0.00 & 0.00 & 0.00 & 0.00 & 0.00 & 0.00 & 0.00 & 0.00 & 0.00 & 0.00 \\
\hline 16250 & 0.00 & 0.00 & 0.00 & 0.00 & 0.00 & 0.00 & 0.00 & 0.00 & 0.00 & 0.00 \\
\hline 16750 & 0.00 & 0.00 & 0.00 & 0.00 & 0.00 & 0.00 & 0.00 & 0.01 & 0.00 & 0.00 \\
\hline 17250 & 0.00 & 0.00 & 0.00 & 0.00 & 0.00 & 0.00 & 0.00 & 0.00 & 0.00 & 0.00 \\
\hline 17750 & 0.00 & 0.00 & 0.00 & 0.00 & 0.00 & 0.00 & 0.00 & 0.00 & 0.00 & 0.00 \\
\hline 18250 & 0.00 & 0.00 & 0.00 & 0.00 & 0.00 & 0.00 & 0.00 & 0.00 & 0.00 & 0.00 \\
\hline 18750 & 0.00 & 0.00 & 0.00 & 0.00 & 0.00 & 0.00 & 0.00 & 0.00 & 0.00 & 0.00 \\
\hline 19250 & 0.00 & 0.00 & 0.00 & 0.00 & 0.00 & 0.00 & 0.00 & 0.00 & 0.00 & 0.00 \\
\hline 19750 & 0.00 & 0.00 & 0.00 & 0.00 & 0.00 & 0.00 & 0.00 & 0.00 & 0.00 & 0.00 \\
\hline
\end{tabular}


Table C.16. Normalized Single Axle Load Distribution Per Class for Site SEB

\begin{tabular}{|c|c|c|c|c|c|c|c|c|c|c|}
\hline $\begin{array}{l}\text { Load } \\
\text { (kgf) }\end{array}$ & Class 4 & Class 5 & Class 6 & Class 7 & Class 8 & Class 9 & Class 10 & Class 11 & Class 12 & Class 13 \\
\hline 250 & 0.00 & 0.02 & 0.01 & 0.41 & 0.06 & 0.01 & 0.06 & 0.00 & 0.00 & 0.00 \\
\hline 750 & 0.00 & 1.68 & 0.15 & 0.41 & 0.26 & 0.10 & 0.12 & 0.00 & 0.00 & 0.00 \\
\hline 1250 & 0.00 & 21.87 & 0.07 & 0.45 & 1.05 & 0.15 & 0.16 & 0.00 & 0.00 & 0.00 \\
\hline 1750 & 0.00 & 39.28 & 0.13 & 1.64 & 28.03 & 0.30 & 0.35 & 1.74 & 1.31 & 0.11 \\
\hline 2250 & 0.03 & 14.88 & 0.21 & 1.06 & 27.31 & 1.04 & 0.54 & 5.69 & 5.29 & 0.39 \\
\hline 2750 & 0.06 & 6.73 & 0.39 & 1.19 & 14.55 & 2.28 & 0.72 & 6.68 & 7.10 & 0.85 \\
\hline 3250 & 3.64 & 4.07 & 0.94 & 1.59 & 6.91 & 3.25 & 0.97 & 8.84 & 6.07 & 1.43 \\
\hline 3750 & 11.64 & 3.17 & 2.97 & 3.43 & 4.33 & 4.32 & 2.33 & 10.37 & 5.09 & 2.39 \\
\hline 4250 & 14.70 & 2.36 & 8.98 & 7.40 & 4.20 & 9.85 & 8.31 & 13.99 & 6.19 & 5.93 \\
\hline 4750 & 14.54 & 1.80 & 21.05 & 25.51 & 4.22 & 25.33 & 23.12 & 17.58 & 11.12 & 14.33 \\
\hline 5250 & 13.99 & 1.28 & 26.46 & 22.61 & 3.04 & 31.19 & 26.18 & 8.25 & 13.10 & 15.68 \\
\hline 5750 & 12.42 & 0.89 & 17.25 & 9.08 & 1.93 & 15.01 & 13.40 & 6.55 & 8.22 & 7.52 \\
\hline 6250 & 9.63 & 0.64 & 8.63 & 5.40 & 1.29 & 3.85 & 5.05 & 6.12 & 5.67 & 5.77 \\
\hline 6750 & 6.41 & 0.45 & 4.82 & 4.82 & 1.02 & 1.15 & 3.21 & 4.92 & 5.90 & 8.95 \\
\hline 7250 & 4.61 & 0.32 & 2.96 & 4.74 & 0.71 & 0.77 & 4.27 & 3.60 & 6.91 & 12.61 \\
\hline 7750 & 3.33 & 0.22 & 1.85 & 4.37 & 0.47 & 0.62 & 4.68 & 2.43 & 7.27 & 11.92 \\
\hline 8250 & 2.32 & 0.14 & 1.15 & 3.72 & 0.29 & 0.40 & 3.36 & 1.67 & 5.90 & 6.90 \\
\hline 8750 & 1.42 & 0.08 & 0.71 & 1.23 & 0.16 & 0.20 & 1.82 & 0.94 & 3.08 & 3.18 \\
\hline 9250 & 0.72 & 0.05 & 0.46 & 0.65 & 0.09 & 0.09 & 0.81 & 0.39 & 1.16 & 1.35 \\
\hline 9750 & 0.31 & 0.03 & 0.30 & 0.12 & 0.05 & 0.04 & 0.31 & 0.12 & 0.40 & 0.48 \\
\hline 10250 & 0.12 & 0.01 & 0.21 & 0.04 & 0.02 & 0.02 & 0.14 & 0.06 & 0.14 & 0.14 \\
\hline 10750 & 0.07 & 0.01 & 0.16 & 0.00 & 0.01 & 0.01 & 0.05 & 0.04 & 0.05 & 0.04 \\
\hline 11250 & 0.03 & 0.00 & 0.09 & 0.00 & 0.00 & 0.01 & 0.02 & 0.02 & 0.02 & 0.02 \\
\hline 11750 & 0.01 & 0.00 & 0.03 & 0.08 & 0.00 & 0.00 & 0.01 & 0.00 & 0.01 & 0.01 \\
\hline 12250 & 0.01 & 0.00 & 0.01 & 0.00 & 0.00 & 0.00 & 0.01 & 0.00 & 0.00 & 0.00 \\
\hline 12750 & 0.01 & 0.00 & 0.00 & 0.00 & 0.00 & 0.00 & 0.01 & 0.00 & 0.00 & 0.00 \\
\hline 13250 & 0.00 & 0.00 & 0.00 & 0.04 & 0.00 & 0.00 & 0.01 & 0.00 & 0.00 & 0.00 \\
\hline 13750 & 0.00 & 0.00 & 0.00 & 0.00 & 0.00 & 0.00 & 0.00 & 0.00 & 0.00 & 0.00 \\
\hline 14250 & 0.00 & 0.00 & 0.00 & 0.00 & 0.00 & 0.00 & 0.00 & 0.00 & 0.00 & 0.00 \\
\hline 14750 & 0.00 & 0.00 & 0.00 & 0.00 & 0.00 & 0.00 & 0.00 & 0.00 & 0.00 & 0.00 \\
\hline 15250 & 0.00 & 0.00 & 0.00 & 0.00 & 0.00 & 0.00 & 0.00 & 0.00 & 0.00 & 0.00 \\
\hline 15750 & 0.00 & 0.00 & 0.00 & 0.00 & 0.00 & 0.00 & 0.00 & 0.00 & 0.00 & 0.00 \\
\hline 16250 & 0.00 & 0.00 & 0.00 & 0.00 & 0.00 & 0.00 & 0.00 & 0.00 & 0.00 & 0.00 \\
\hline 16750 & 0.00 & 0.00 & 0.00 & 0.00 & 0.00 & 0.00 & 0.00 & 0.00 & 0.00 & 0.00 \\
\hline 17250 & 0.00 & 0.00 & 0.00 & 0.00 & 0.00 & 0.00 & 0.00 & 0.00 & 0.00 & 0.00 \\
\hline 17750 & 0.00 & 0.00 & 0.00 & 0.00 & 0.00 & 0.00 & 0.00 & 0.00 & 0.00 & 0.00 \\
\hline 18250 & 0.00 & 0.00 & 0.00 & 0.00 & 0.00 & 0.00 & 0.00 & 0.00 & 0.00 & 0.00 \\
\hline 18750 & 0.00 & 0.00 & 0.00 & 0.00 & 0.00 & 0.00 & 0.00 & 0.00 & 0.00 & 0.00 \\
\hline 19250 & 0.00 & 0.00 & 0.00 & 0.00 & 0.00 & 0.00 & 0.00 & 0.00 & 0.00 & 0.00 \\
\hline 19750 & 0.00 & 0.00 & 0.00 & 0.00 & 0.00 & 0.00 & 0.00 & 0.00 & 0.00 & 0.00 \\
\hline
\end{tabular}


Table C.17. Normalized Single Axle Load Distribution Per Class for Site WWG

\begin{tabular}{|c|c|c|c|c|c|c|c|c|c|c|}
\hline $\begin{array}{l}\text { Load } \\
\text { (kgf) }\end{array}$ & Class 4 & Class 5 & Class 6 & Class 7 & Class 8 & Class 9 & Class 10 & Class 11 & Class 12 & Class 13 \\
\hline 250 & 0.00 & 0.00 & 0.00 & 0.00 & 0.02 & 0.01 & 0.01 & 0.00 & 0.00 & 0.00 \\
\hline 750 & 0.00 & 0.84 & 0.29 & 0.89 & 0.41 & 0.13 & 0.05 & 0.00 & 0.00 & 0.00 \\
\hline 1250 & 0.00 & 18.08 & 0.06 & 0.00 & 1.58 & 0.24 & 0.20 & 0.00 & 0.00 & 0.00 \\
\hline 1750 & 0.00 & 40.05 & 0.17 & 2.23 & 30.16 & 0.30 & 0.38 & 0.49 & 1.20 & 0.62 \\
\hline 2250 & 0.00 & 17.62 & 0.20 & 0.00 & 30.67 & 1.09 & 1.20 & 2.31 & 9.48 & 1.21 \\
\hline 2750 & 0.04 & 7.07 & 0.28 & 0.89 & 11.19 & 7.17 & 1.72 & 2.20 & 16.87 & 0.89 \\
\hline 3250 & 4.00 & 3.77 & 0.37 & 1.34 & 4.54 & 9.06 & 1.04 & 3.66 & 8.10 & 1.20 \\
\hline 3750 & 17.23 & 3.42 & 0.95 & 2.68 & 3.35 & 4.29 & 1.05 & 4.42 & 3.90 & 1.23 \\
\hline 4250 & 15.89 & 2.36 & 4.71 & 12.05 & 3.25 & 6.02 & 6.51 & 10.98 & 4.25 & 4.55 \\
\hline 4750 & 9.09 & 1.94 & 16.15 & 25.00 & 4.52 & 24.38 & 30.13 & 18.71 & 11.73 & 16.68 \\
\hline 5250 & 13.96 & 1.49 & 21.20 & 21.88 & 3.55 & 33.56 & 39.93 & 10.35 & 12.99 & 22.22 \\
\hline 5750 & 13.44 & 1.13 & 12.20 & 7.59 & 1.97 & 8.08 & 11.74 & 10.93 & 5.60 & 8.94 \\
\hline 6250 & 8.77 & 0.79 & 8.98 & 6.70 & 1.38 & 1.13 & 1.98 & 10.38 & 4.42 & 4.94 \\
\hline 6750 & 7.44 & 0.47 & 8.47 & 2.68 & 1.33 & 1.01 & 1.30 & 9.13 & 6.36 & 8.78 \\
\hline 7250 & 4.08 & 0.33 & 7.81 & 6.25 & 0.99 & 1.26 & 1.27 & 6.65 & 7.75 & 13.24 \\
\hline 7750 & 1.99 & 0.23 & 7.30 & 4.46 & 0.47 & 1.15 & 0.75 & 4.75 & 4.79 & 9.37 \\
\hline 8250 & 1.19 & 0.20 & 5.46 & 1.79 & 0.25 & 0.65 & 0.35 & 2.91 & 1.85 & 3.88 \\
\hline 8750 & 1.54 & 0.12 & 2.84 & 3.13 & 0.20 & 0.30 & 0.20 & 1.48 & 0.53 & 1.31 \\
\hline 9250 & 0.97 & 0.04 & 1.42 & 0.45 & 0.09 & 0.11 & 0.08 & 0.44 & 0.13 & 0.52 \\
\hline 9750 & 0.25 & 0.02 & 0.70 & 0.00 & 0.05 & 0.03 & 0.04 & 0.11 & 0.03 & 0.15 \\
\hline 10250 & 0.06 & 0.01 & 0.29 & 0.00 & 0.02 & 0.02 & 0.03 & 0.07 & 0.01 & 0.13 \\
\hline 10750 & 0.02 & 0.01 & 0.10 & 0.00 & 0.01 & 0.01 & 0.02 & 0.01 & 0.00 & 0.05 \\
\hline 11250 & 0.00 & 0.00 & 0.02 & 0.00 & 0.00 & 0.00 & 0.00 & 0.00 & 0.00 & 0.09 \\
\hline 11750 & 0.00 & 0.00 & 0.01 & 0.00 & 0.00 & 0.00 & 0.01 & 0.00 & 0.00 & 0.00 \\
\hline 12250 & 0.00 & 0.00 & 0.01 & 0.00 & 0.00 & 0.00 & 0.01 & 0.00 & 0.00 & 0.01 \\
\hline 12750 & 0.00 & 0.00 & 0.01 & 0.00 & 0.00 & 0.00 & 0.00 & 0.00 & 0.00 & 0.00 \\
\hline 13250 & 0.01 & 0.00 & 0.00 & 0.00 & 0.00 & 0.00 & 0.00 & 0.00 & 0.00 & 0.00 \\
\hline 13750 & 0.00 & 0.00 & 0.00 & 0.00 & 0.00 & 0.00 & 0.00 & 0.00 & 0.00 & 0.00 \\
\hline 14250 & 0.00 & 0.00 & 0.00 & 0.00 & 0.00 & 0.00 & 0.00 & 0.00 & 0.00 & 0.00 \\
\hline 14750 & 0.00 & 0.00 & 0.00 & 0.00 & 0.00 & 0.00 & 0.00 & 0.00 & 0.00 & 0.00 \\
\hline 15250 & 0.00 & 0.00 & 0.00 & 0.00 & 0.00 & 0.00 & 0.01 & 0.00 & 0.00 & 0.00 \\
\hline 15750 & 0.00 & 0.00 & 0.00 & 0.00 & 0.00 & 0.00 & 0.00 & 0.00 & 0.00 & 0.00 \\
\hline 16250 & 0.00 & 0.00 & 0.00 & 0.00 & 0.00 & 0.00 & 0.00 & 0.00 & 0.00 & 0.00 \\
\hline 16750 & 0.00 & 0.00 & 0.00 & 0.00 & 0.00 & 0.00 & 0.00 & 0.00 & 0.00 & 0.00 \\
\hline 17250 & 0.00 & 0.00 & 0.00 & 0.00 & 0.00 & 0.00 & 0.00 & 0.00 & 0.00 & 0.00 \\
\hline 17750 & 0.00 & 0.00 & 0.00 & 0.00 & 0.00 & 0.00 & 0.00 & 0.00 & 0.00 & 0.00 \\
\hline 18250 & 0.00 & 0.00 & 0.00 & 0.00 & 0.00 & 0.00 & 0.00 & 0.00 & 0.00 & 0.00 \\
\hline 18750 & 0.00 & 0.00 & 0.00 & 0.00 & 0.00 & 0.00 & 0.00 & 0.00 & 0.00 & 0.00 \\
\hline 19250 & 0.00 & 0.00 & 0.00 & 0.00 & 0.00 & 0.00 & 0.00 & 0.00 & 0.00 & 0.00 \\
\hline 19750 & 0.00 & 0.00 & 0.00 & 0.00 & 0.00 & 0.00 & 0.00 & 0.00 & 0.00 & 0.00 \\
\hline
\end{tabular}


Table C.18. Normalized Single Axle Load Distribution Per Class for Site DWD

\begin{tabular}{|c|c|c|c|c|c|c|c|c|c|c|}
\hline $\begin{array}{l}\text { Load } \\
\text { (kgf) }\end{array}$ & Class 4 & Class 5 & Class 6 & Class 7 & Class 8 & Class 9 & Class 10 & Class 11 & Class 12 & Class 13 \\
\hline 250 & 0.00 & 1.48 & 0.04 & 0.45 & 0.09 & 0.02 & 0.11 & 0.00 & 0.00 & 0.00 \\
\hline 750 & 0.00 & 1.99 & 0.08 & 0.16 & 0.20 & 0.17 & 0.18 & 0.00 & 0.00 & 0.00 \\
\hline 1250 & 0.00 & 17.59 & 0.07 & 0.14 & 1.40 & 0.71 & 1.07 & 0.00 & 0.00 & 0.00 \\
\hline 1750 & 0.02 & 33.18 & 0.22 & 0.74 & 28.72 & 1.66 & 3.29 & 4.50 & 2.88 & 0.16 \\
\hline 2250 & 0.02 & 16.25 & 0.24 & 0.62 & 25.45 & 1.74 & 5.06 & 7.34 & 4.40 & 0.42 \\
\hline 2750 & 0.06 & 6.58 & 0.33 & 0.74 & 11.03 & 2.12 & 4.42 & 8.14 & 5.67 & 0.91 \\
\hline 3250 & 5.77 & 4.59 & 0.60 & 1.44 & 6.11 & 2.11 & 2.81 & 9.72 & 6.81 & 1.37 \\
\hline 3750 & 14.76 & 4.55 & 2.32 & 1.42 & 4.86 & 2.17 & 2.06 & 8.82 & 4.59 & 1.37 \\
\hline 4250 & 12.33 & 3.94 & 9.05 & 3.39 & 4.66 & 6.56 & 3.82 & 10.89 & 4.38 & 2.81 \\
\hline 4750 & 10.97 & 2.77 & 22.40 & 13.27 & 5.04 & 23.58 & 13.32 & 12.51 & 10.28 & 10.99 \\
\hline 5250 & 12.57 & 1.92 & 22.11 & 38.70 & 3.33 & 36.52 & 25.95 & 6.72 & 14.81 & 22.89 \\
\hline 5750 & 11.91 & 1.43 & 12.79 & 26.55 & 2.16 & 16.16 & 15.87 & 5.26 & 8.90 & 13.13 \\
\hline 6250 & 9.93 & 1.04 & 8.53 & 4.78 & 1.69 & 2.73 & 5.49 & 5.04 & 5.49 & 6.06 \\
\hline 6750 & 7.03 & 0.71 & 6.12 & 2.11 & 1.37 & 0.90 & 3.44 & 4.48 & 6.34 & 8.24 \\
\hline 7250 & 5.08 & 0.55 & 4.97 & 2.38 & 1.12 & 0.91 & 3.80 & 4.70 & 7.75 & 11.62 \\
\hline 7750 & 3.61 & 0.42 & 3.57 & 1.58 & 0.98 & 0.86 & 3.84 & 4.10 & 7.90 & 11.23 \\
\hline 8250 & 2.45 & 0.34 & 2.30 & 0.88 & 0.66 & 0.56 & 3.02 & 3.15 & 5.63 & 6.06 \\
\hline 8750 & 1.57 & 0.25 & 1.42 & 0.23 & 0.45 & 0.27 & 1.60 & 1.95 & 2.57 & 1.92 \\
\hline 9250 & 0.92 & 0.16 & 0.95 & 0.18 & 0.30 & 0.12 & 0.54 & 1.50 & 0.89 & 0.47 \\
\hline 9750 & 0.43 & 0.10 & 0.73 & 0.08 & 0.17 & 0.05 & 0.16 & 0.68 & 0.33 & 0.16 \\
\hline 10250 & 0.28 & 0.07 & 0.58 & 0.04 & 0.09 & 0.03 & 0.06 & 0.27 & 0.16 & 0.09 \\
\hline 10750 & 0.14 & 0.04 & 0.29 & 0.08 & 0.04 & 0.02 & 0.03 & 0.11 & 0.09 & 0.04 \\
\hline 11250 & 0.07 & 0.03 & 0.16 & 0.02 & 0.03 & 0.01 & 0.02 & 0.06 & 0.05 & 0.02 \\
\hline 11750 & 0.04 & 0.02 & 0.08 & 0.00 & 0.02 & 0.01 & 0.01 & 0.02 & 0.03 & 0.01 \\
\hline 12250 & 0.01 & 0.01 & 0.02 & 0.00 & 0.01 & 0.00 & 0.01 & 0.04 & 0.01 & 0.01 \\
\hline 12750 & 0.01 & 0.00 & 0.00 & 0.00 & 0.00 & 0.00 & 0.00 & 0.00 & 0.01 & 0.00 \\
\hline 13250 & 0.01 & 0.00 & 0.00 & 0.00 & 0.00 & 0.00 & 0.00 & 0.00 & 0.00 & 0.00 \\
\hline 13750 & 0.01 & 0.00 & 0.00 & 0.00 & 0.00 & 0.00 & 0.00 & 0.00 & 0.00 & 0.00 \\
\hline 14250 & 0.00 & 0.00 & 0.00 & 0.00 & 0.00 & 0.00 & 0.00 & 0.00 & 0.00 & 0.00 \\
\hline 14750 & 0.00 & 0.00 & 0.00 & 0.02 & 0.00 & 0.00 & 0.00 & 0.00 & 0.00 & 0.00 \\
\hline 15250 & 0.00 & 0.00 & 0.00 & 0.00 & 0.00 & 0.00 & 0.00 & 0.00 & 0.00 & 0.00 \\
\hline 15750 & 0.00 & 0.00 & 0.00 & 0.00 & 0.00 & 0.00 & 0.00 & 0.00 & 0.00 & 0.00 \\
\hline 16250 & 0.00 & 0.00 & 0.00 & 0.00 & 0.00 & 0.00 & 0.00 & 0.00 & 0.00 & 0.00 \\
\hline 16750 & 0.00 & 0.00 & 0.00 & 0.00 & 0.00 & 0.00 & 0.00 & 0.00 & 0.00 & 0.00 \\
\hline 17250 & 0.00 & 0.00 & 0.00 & 0.00 & 0.00 & 0.00 & 0.00 & 0.00 & 0.00 & 0.00 \\
\hline 17750 & 0.00 & 0.00 & 0.00 & 0.00 & 0.00 & 0.00 & 0.00 & 0.00 & 0.00 & 0.00 \\
\hline 18250 & 0.00 & 0.00 & 0.00 & 0.00 & 0.00 & 0.00 & 0.00 & 0.00 & 0.00 & 0.00 \\
\hline 18750 & 0.00 & 0.00 & 0.00 & 0.00 & 0.00 & 0.00 & 0.00 & 0.00 & 0.00 & 0.00 \\
\hline 19250 & 0.00 & 0.00 & 0.00 & 0.00 & 0.00 & 0.00 & 0.00 & 0.00 & 0.00 & 0.00 \\
\hline 19750 & 0.00 & 0.00 & 0.00 & 0.00 & 0.00 & 0.00 & 0.00 & 0.00 & 0.00 & 0.00 \\
\hline
\end{tabular}


Table C.19. Normalized Single Axle Load Distribution Per Class for Site LC1

\begin{tabular}{|c|c|c|c|c|c|c|c|c|c|c|}
\hline $\begin{array}{l}\text { Load } \\
\text { (kgf) }\end{array}$ & Class 4 & Class 5 & Class 6 & Class 7 & Class 8 & Class 9 & Class 10 & Class 11 & Class 12 & Class 13 \\
\hline 250 & 0.00 & 0.01 & 0.00 & 10.96 & 0.04 & 0.02 & 0.48 & 0.00 & 0.00 & 0.00 \\
\hline 750 & 0.00 & 0.48 & 0.27 & 2.19 & 0.17 & 0.09 & 0.05 & 0.00 & 0.00 & 0.00 \\
\hline 1250 & 0.00 & 11.64 & 0.04 & 1.10 & 0.30 & 0.13 & 0.04 & 0.00 & 0.00 & 0.00 \\
\hline 1750 & 0.00 & 34.46 & 0.17 & 1.10 & 25.23 & 0.17 & 0.18 & 3.81 & 0.14 & 0.04 \\
\hline 2250 & 0.00 & 17.00 & 0.13 & 0.88 & 21.00 & 0.32 & 0.72 & 13.16 & 0.72 & 0.11 \\
\hline 2750 & 0.01 & 10.39 & 0.23 & 0.88 & 18.30 & 0.76 & 2.15 & 14.41 & 2.20 & 0.29 \\
\hline 3250 & 2.86 & 6.75 & 0.48 & 2.19 & 10.76 & 1.72 & 3.77 & 14.19 & 4.62 & 0.59 \\
\hline 3750 & 9.27 & 4.62 & 2.31 & 4.61 & 5.41 & 4.21 & 5.01 & 11.04 & 6.51 & 1.41 \\
\hline 4250 & 13.71 & 3.80 & 7.05 & 6.58 & 3.66 & 10.73 & 7.53 & 9.30 & 8.60 & 4.54 \\
\hline 4750 & 11.10 & 2.73 & 14.69 & 7.68 & 3.54 & 19.28 & 12.41 & 8.16 & 11.13 & 7.67 \\
\hline 5250 & 10.52 & 1.97 & 22.80 & 11.62 & 3.39 & 37.57 & 24.13 & 6.31 & 16.20 & 16.85 \\
\hline 5750 & 10.97 & 1.39 & 15.62 & 19.74 & 2.59 & 17.64 & 18.32 & 2.50 & 12.18 & 14.72 \\
\hline 6250 & 12.02 & 1.16 & 10.74 & 9.65 & 1.83 & 3.87 & 8.12 & 3.10 & 8.68 & 9.68 \\
\hline 6750 & 9.96 & 0.97 & 8.78 & 6.58 & 1.29 & 1.40 & 6.19 & 3.37 & 8.55 & 11.34 \\
\hline 7250 & 6.96 & 0.77 & 6.45 & 3.95 & 0.88 & 0.93 & 5.05 & 2.56 & 8.13 & 13.12 \\
\hline 7750 & 5.22 & 0.60 & 3.62 & 1.10 & 0.57 & 0.61 & 3.28 & 2.72 & 6.32 & 10.84 \\
\hline 8250 & 3.36 & 0.49 & 1.83 & 2.41 & 0.40 & 0.32 & 1.63 & 2.07 & 3.80 & 5.74 \\
\hline 8750 & 1.92 & 0.34 & 1.26 & 1.32 & 0.24 & 0.13 & 0.63 & 1.41 & 1.61 & 2.17 \\
\hline 9250 & 1.07 & 0.19 & 0.88 & 2.19 & 0.16 & 0.05 & 0.22 & 1.20 & 0.45 & 0.61 \\
\hline 9750 & 0.60 & 0.12 & 0.74 & 1.10 & 0.11 & 0.02 & 0.06 & 0.38 & 0.11 & 0.16 \\
\hline 10250 & 0.27 & 0.06 & 0.68 & 0.66 & 0.06 & 0.01 & 0.03 & 0.11 & 0.03 & 0.06 \\
\hline 10750 & 0.10 & 0.03 & 0.50 & 0.22 & 0.03 & 0.01 & 0.01 & 0.05 & 0.01 & 0.02 \\
\hline 11250 & 0.05 & 0.02 & 0.34 & 0.66 & 0.01 & 0.00 & 0.01 & 0.00 & 0.00 & 0.01 \\
\hline 11750 & 0.02 & 0.01 & 0.14 & 0.00 & 0.00 & 0.00 & 0.00 & 0.16 & 0.00 & 0.01 \\
\hline 12250 & 0.01 & 0.00 & 0.09 & 0.22 & 0.00 & 0.00 & 0.00 & 0.00 & 0.00 & 0.01 \\
\hline 12750 & 0.00 & 0.00 & 0.10 & 0.00 & 0.00 & 0.00 & 0.00 & 0.00 & 0.00 & 0.00 \\
\hline 13250 & 0.00 & 0.00 & 0.02 & 0.00 & 0.00 & 0.00 & 0.00 & 0.00 & 0.00 & 0.00 \\
\hline 13750 & 0.00 & 0.00 & 0.01 & 0.00 & 0.00 & 0.00 & 0.00 & 0.00 & 0.00 & 0.00 \\
\hline 14250 & 0.00 & 0.00 & 0.00 & 0.00 & 0.00 & 0.00 & 0.00 & 0.00 & 0.00 & 0.00 \\
\hline 14750 & 0.00 & 0.00 & 0.00 & 0.00 & 0.00 & 0.00 & 0.00 & 0.00 & 0.00 & 0.00 \\
\hline 15250 & 0.00 & 0.00 & 0.00 & 0.00 & 0.00 & 0.00 & 0.00 & 0.00 & 0.00 & 0.00 \\
\hline 15750 & 0.00 & 0.00 & 0.00 & 0.00 & 0.00 & 0.00 & 0.00 & 0.00 & 0.00 & 0.00 \\
\hline 16250 & 0.00 & 0.00 & 0.00 & 0.00 & 0.00 & 0.00 & 0.00 & 0.00 & 0.00 & 0.00 \\
\hline 16750 & 0.00 & 0.00 & 0.00 & 0.00 & 0.00 & 0.00 & 0.00 & 0.00 & 0.00 & 0.00 \\
\hline 17250 & 0.00 & 0.00 & 0.00 & 0.22 & 0.00 & 0.00 & 0.00 & 0.00 & 0.00 & 0.00 \\
\hline 17750 & 0.00 & 0.00 & 0.00 & 0.22 & 0.00 & 0.00 & 0.00 & 0.00 & 0.00 & 0.00 \\
\hline 18250 & 0.00 & 0.00 & 0.00 & 0.00 & 0.00 & 0.00 & 0.00 & 0.00 & 0.00 & 0.00 \\
\hline 18750 & 0.00 & 0.00 & 0.00 & 0.00 & 0.00 & 0.00 & 0.00 & 0.00 & 0.00 & 0.00 \\
\hline 19250 & 0.00 & 0.00 & 0.00 & 0.00 & 0.00 & 0.00 & 0.00 & 0.00 & 0.00 & 0.00 \\
\hline 19750 & 0.00 & 0.00 & 0.00 & 0.00 & 0.00 & 0.00 & 0.00 & 0.00 & 0.00 & 0.00 \\
\hline
\end{tabular}


Table C.20. Normalized Tandem Axle Load Distribution Per Class for Site SBW

\begin{tabular}{|c|c|c|c|c|c|c|c|c|c|c|}
\hline $\begin{array}{l}\text { Load } \\
\text { (kgf) }\end{array}$ & Class 4 & Class 5 & Class 6 & Class 7 & Class 8 & Class 9 & Class 10 & Class 11 & Class 12 & Class 13 \\
\hline 500 & 0.00 & 0.00 & 0.01 & 0.04 & 1.08 & 0.00 & 0.01 & 0.00 & 0.00 & 0.00 \\
\hline 1500 & 0.01 & 0.00 & 1.28 & 2.81 & 20.72 & 0.01 & 0.21 & 0.00 & 0.00 & 0.00 \\
\hline 2500 & 0.06 & 0.00 & 2.89 & 2.94 & 17.94 & 0.21 & 0.44 & 0.00 & 0.00 & 0.00 \\
\hline 3500 & 0.18 & 0.00 & 5.42 & 9.18 & 16.12 & 0.85 & 0.73 & 0.45 & 0.00 & 1.41 \\
\hline 4500 & 0.63 & 0.00 & 7.83 & 6.52 & 12.08 & 1.96 & 1.09 & 4.09 & 0.06 & 4.01 \\
\hline 5500 & 1.33 & 0.00 & 10.32 & 4.28 & 8.17 & 3.51 & 1.68 & 4.70 & 0.43 & 4.28 \\
\hline 6500 & 3.32 & 0.00 & 9.34 & 3.39 & 5.44 & 5.04 & 2.61 & 5.91 & 1.73 & 5.68 \\
\hline 7500 & 6.60 & 0.00 & 9.50 & 3.79 & 4.30 & 7.12 & 4.01 & 5.30 & 3.74 & 5.74 \\
\hline 8500 & 10.42 & 0.00 & 8.78 & 4.53 & 3.80 & 9.36 & 5.64 & 6.36 & 4.55 & 6.24 \\
\hline 9500 & 12.88 & 0.00 & 8.51 & 5.32 & 3.35 & 11.90 & 7.33 & 10.30 & 5.62 & 7.79 \\
\hline 10500 & 13.62 & 0.00 & 8.12 & 5.58 & 2.55 & 13.12 & 9.23 & 12.58 & 8.19 & 8.63 \\
\hline 11500 & 13.05 & 0.00 & 7.16 & 5.86 & 1.64 & 12.46 & 10.95 & 8.33 & 11.75 & 8.96 \\
\hline 12500 & 11.25 & 0.00 & 5.71 & 6.36 & 1.09 & 10.75 & 11.95 & 8.03 & 13.07 & 8.79 \\
\hline 13500 & 8.47 & 0.00 & 4.50 & 7.59 & 0.67 & 9.02 & 11.32 & 8.48 & 11.51 & 7.91 \\
\hline 14500 & 6.12 & 0.00 & 3.31 & 8.21 & 0.38 & 7.19 & 10.32 & 6.67 & 10.55 & 7.13 \\
\hline 15500 & 4.30 & 0.00 & 2.44 & 6.74 & 0.25 & 4.60 & 9.15 & 5.15 & 10.88 & 7.28 \\
\hline 16500 & 2.79 & 0.00 & 1.79 & 6.00 & 0.19 & 1.93 & 6.97 & 2.88 & 9.39 & 7.24 \\
\hline 17500 & 1.98 & 0.00 & 1.27 & 4.58 & 0.11 & 0.64 & 3.80 & 4.39 & 5.28 & 5.08 \\
\hline 18500 & 1.17 & 0.00 & 0.78 & 2.59 & 0.05 & 0.22 & 1.56 & 1.82 & 2.10 & 2.26 \\
\hline 19500 & 0.75 & 0.00 & 0.48 & 1.47 & 0.03 & 0.07 & 0.61 & 0.91 & 0.76 & 0.95 \\
\hline 20500 & 0.49 & 0.00 & 0.27 & 1.33 & 0.01 & 0.03 & 0.24 & 1.52 & 0.26 & 0.40 \\
\hline 21500 & 0.25 & 0.00 & 0.15 & 0.44 & 0.01 & 0.01 & 0.08 & 0.91 & 0.07 & 0.13 \\
\hline 22500 & 0.16 & 0.00 & 0.08 & 0.28 & 0.00 & 0.01 & 0.03 & 0.45 & 0.03 & 0.04 \\
\hline 23500 & 0.11 & 0.00 & 0.03 & 0.10 & 0.00 & 0.00 & 0.02 & 0.30 & 0.02 & 0.03 \\
\hline 24500 & 0.04 & 0.00 & 0.02 & 0.03 & 0.00 & 0.00 & 0.01 & 0.15 & 0.01 & 0.02 \\
\hline 25500 & 0.02 & 0.00 & 0.01 & 0.01 & 0.00 & 0.00 & 0.01 & 0.00 & 0.00 & 0.01 \\
\hline 26500 & 0.02 & 0.00 & 0.00 & 0.01 & 0.00 & 0.00 & 0.00 & 0.00 & 0.00 & 0.00 \\
\hline 27500 & 0.00 & 0.00 & 0.00 & 0.00 & 0.00 & 0.00 & 0.00 & 0.15 & 0.00 & 0.00 \\
\hline 28500 & 0.00 & 0.00 & 0.00 & 0.00 & 0.00 & 0.00 & 0.00 & 0.00 & 0.00 & 0.00 \\
\hline 29500 & 0.00 & 0.00 & 0.00 & 0.01 & 0.00 & 0.00 & 0.00 & 0.15 & 0.00 & 0.00 \\
\hline 30500 & 0.00 & 0.00 & 0.00 & 0.00 & 0.00 & 0.00 & 0.00 & 0.00 & 0.00 & 0.00 \\
\hline 31500 & 0.00 & 0.00 & 0.00 & 0.00 & 0.00 & 0.00 & 0.00 & 0.00 & 0.00 & 0.00 \\
\hline 32500 & 0.00 & 0.00 & 0.00 & 0.00 & 0.00 & 0.00 & 0.00 & 0.00 & 0.00 & 0.00 \\
\hline 33500 & 0.00 & 0.00 & 0.00 & 0.00 & 0.00 & 0.00 & 0.00 & 0.00 & 0.00 & 0.00 \\
\hline 34500 & 0.00 & 0.00 & 0.00 & 0.00 & 0.00 & 0.00 & 0.00 & 0.00 & 0.00 & 0.00 \\
\hline 35500 & 0.00 & 0.00 & 0.00 & 0.00 & 0.00 & 0.00 & 0.00 & 0.00 & 0.00 & 0.00 \\
\hline 36500 & 0.00 & 0.00 & 0.00 & 0.00 & 0.00 & 0.00 & 0.00 & 0.00 & 0.00 & 0.00 \\
\hline 37500 & 0.00 & 0.00 & 0.00 & 0.00 & 0.00 & 0.00 & 0.00 & 0.00 & 0.00 & 0.00 \\
\hline 38500 & 0.00 & 0.00 & 0.00 & 0.00 & 0.00 & 0.00 & 0.00 & 0.00 & 0.00 & 0.00 \\
\hline 39500 & 0.00 & 0.00 & 0.00 & 0.00 & 0.00 & 0.00 & 0.00 & 0.00 & 0.00 & 0.00 \\
\hline
\end{tabular}


Table C.21. Normalized Tandem Axle Load Distribution Per Class for Site SEB

\begin{tabular}{|c|c|c|c|c|c|c|c|c|c|c|}
\hline $\begin{array}{l}\text { Load } \\
\text { (kgf) }\end{array}$ & Class 4 & Class 5 & Class 6 & Class 7 & Class 8 & Class 9 & Class 10 & Class 11 & Class 12 & Class 13 \\
\hline 500 & 0.00 & 0.00 & 0.00 & 0.00 & 0.78 & 0.00 & 0.00 & 0.00 & 0.00 & 0.00 \\
\hline 1500 & 0.00 & 0.00 & 0.03 & 0.51 & 22.98 & 0.00 & 0.02 & 0.00 & 0.00 & 0.00 \\
\hline 2500 & 0.00 & 0.00 & 0.80 & 0.59 & 30.03 & 0.00 & 0.06 & 0.00 & 0.00 & 0.00 \\
\hline 3500 & 0.03 & 0.00 & 2.75 & 0.54 & 16.08 & 0.04 & 0.13 & 0.00 & 0.00 & 0.12 \\
\hline 4500 & 0.13 & 0.00 & 10.03 & 0.54 & 8.30 & 0.29 & 0.22 & 0.28 & 0.02 & 0.57 \\
\hline 5500 & 0.66 & 0.00 & 11.85 & 1.21 & 5.93 & 1.30 & 0.67 & 1.34 & 0.24 & 1.19 \\
\hline 6500 & 2.63 & 0.00 & 12.18 & 2.54 & 4.09 & 3.34 & 2.03 & 3.86 & 1.31 & 2.04 \\
\hline 7500 & 6.77 & 0.00 & 12.40 & 5.44 & 2.76 & 6.16 & 4.06 & 9.29 & 3.04 & 2.90 \\
\hline 8500 & 11.54 & 0.00 & 10.75 & 6.40 & 2.43 & 9.39 & 6.04 & 12.21 & 4.17 & 3.68 \\
\hline 9500 & 15.40 & 0.00 & 9.40 & 4.95 & 2.17 & 12.48 & 7.61 & 16.13 & 5.40 & 5.30 \\
\hline 10500 & 16.14 & 0.00 & 8.55 & 6.86 & 1.59 & 14.84 & 9.43 & 16.41 & 8.17 & 7.88 \\
\hline 11500 & 14.31 & 0.00 & 7.04 & 7.50 & 1.06 & 15.18 & 11.79 & 14.05 & 12.51 & 9.79 \\
\hline 12500 & 11.12 & 0.00 & 4.95 & 9.59 & 0.71 & 13.28 & 12.34 & 10.81 & 13.66 & 9.92 \\
\hline 13500 & 8.28 & 0.00 & 3.30 & 12.29 & 0.44 & 10.23 & 11.24 & 7.22 & 11.86 & 9.51 \\
\hline 14500 & 5.37 & 0.00 & 2.14 & 14.78 & 0.28 & 6.92 & 10.61 & 3.70 & 11.39 & 10.53 \\
\hline 15500 & 3.33 & 0.00 & 1.46 & 11.70 & 0.17 & 3.95 & 9.76 & 2.18 & 11.33 & 12.19 \\
\hline 16500 & 1.87 & 0.00 & 1.01 & 7.90 & 0.11 & 1.75 & 7.13 & 1.40 & 9.25 & 11.79 \\
\hline 17500 & 1.24 & 0.00 & 0.65 & 3.78 & 0.05 & 0.60 & 3.97 & 0.39 & 5.08 & 7.60 \\
\hline 18500 & 0.61 & 0.00 & 0.37 & 1.79 & 0.02 & 0.18 & 1.86 & 0.56 & 1.82 & 3.25 \\
\hline 19500 & 0.35 & 0.00 & 0.18 & 0.67 & 0.01 & 0.05 & 0.72 & 0.11 & 0.56 & 1.17 \\
\hline 20500 & 0.17 & 0.00 & 0.08 & 0.29 & 0.00 & 0.01 & 0.24 & 0.06 & 0.16 & 0.46 \\
\hline 21500 & 0.03 & 0.00 & 0.04 & 0.11 & 0.00 & 0.00 & 0.05 & 0.00 & 0.03 & 0.08 \\
\hline 22500 & 0.01 & 0.00 & 0.01 & 0.00 & 0.00 & 0.00 & 0.01 & 0.00 & 0.00 & 0.01 \\
\hline 23500 & 0.00 & 0.00 & 0.01 & 0.03 & 0.00 & 0.00 & 0.01 & 0.00 & 0.00 & 0.00 \\
\hline 24500 & 0.00 & 0.00 & 0.00 & 0.00 & 0.00 & 0.00 & 0.00 & 0.00 & 0.00 & 0.00 \\
\hline 25500 & 0.00 & 0.00 & 0.00 & 0.00 & 0.00 & 0.00 & 0.00 & 0.00 & 0.00 & 0.00 \\
\hline 26500 & 0.00 & 0.00 & 0.00 & 0.00 & 0.00 & 0.00 & 0.00 & 0.00 & 0.00 & 0.00 \\
\hline 27500 & 0.00 & 0.00 & 0.00 & 0.00 & 0.00 & 0.00 & 0.00 & 0.00 & 0.00 & 0.00 \\
\hline 28500 & 0.00 & 0.00 & 0.00 & 0.00 & 0.00 & 0.00 & 0.00 & 0.00 & 0.00 & 0.00 \\
\hline 29500 & 0.00 & 0.00 & 0.00 & 0.00 & 0.00 & 0.00 & 0.00 & 0.00 & 0.00 & 0.00 \\
\hline 30500 & 0.00 & 0.00 & 0.00 & 0.00 & 0.00 & 0.00 & 0.00 & 0.00 & 0.00 & 0.00 \\
\hline 31500 & 0.00 & 0.00 & 0.00 & 0.00 & 0.00 & 0.00 & 0.00 & 0.00 & 0.00 & 0.00 \\
\hline 32500 & 0.00 & 0.00 & 0.00 & 0.00 & 0.00 & 0.00 & 0.00 & 0.00 & 0.00 & 0.00 \\
\hline 33500 & 0.00 & 0.00 & 0.00 & 0.00 & 0.00 & 0.00 & 0.00 & 0.00 & 0.00 & 0.00 \\
\hline 34500 & 0.00 & 0.00 & 0.00 & 0.00 & 0.00 & 0.00 & 0.00 & 0.00 & 0.00 & 0.00 \\
\hline 35500 & 0.00 & 0.00 & 0.00 & 0.00 & 0.00 & 0.00 & 0.00 & 0.00 & 0.00 & 0.00 \\
\hline 36500 & 0.00 & 0.00 & 0.00 & 0.00 & 0.00 & 0.00 & 0.00 & 0.00 & 0.00 & 0.00 \\
\hline 37500 & 0.00 & 0.00 & 0.00 & 0.00 & 0.00 & 0.00 & 0.00 & 0.00 & 0.00 & 0.00 \\
\hline 38500 & 0.00 & 0.00 & 0.00 & 0.00 & 0.00 & 0.00 & 0.00 & 0.00 & 0.00 & 0.00 \\
\hline 39500 & 0.00 & 0.00 & 0.00 & 0.00 & 0.00 & 0.00 & 0.00 & 0.00 & 0.00 & 0.00 \\
\hline
\end{tabular}


Table C.22. Normalized Tandem Axle Load Distribution Per Class for Site WWG

\begin{tabular}{|c|c|c|c|c|c|c|c|c|c|c|}
\hline $\begin{array}{l}\text { Load } \\
\text { (kgf) }\end{array}$ & Class 4 & Class 5 & Class 6 & Class 7 & Class 8 & Class 9 & Class 10 & Class 11 & Class 12 & Class 13 \\
\hline 500 & 0.00 & 0.00 & 0.01 & 0.00 & 0.31 & 0.00 & 0.00 & 0.00 & 0.00 & 0.00 \\
\hline 1500 & 0.00 & 0.00 & 0.02 & 0.78 & 18.15 & 0.00 & 0.00 & 0.00 & 0.00 & 0.00 \\
\hline 2500 & 0.00 & 0.00 & 0.02 & 0.78 & 30.93 & 0.01 & 0.03 & 0.00 & 0.00 & 0.00 \\
\hline 3500 & 0.00 & 0.00 & 0.20 & 0.59 & 20.30 & 0.03 & 0.05 & 2.24 & 0.00 & 0.50 \\
\hline 4500 & 0.05 & 0.00 & 1.27 & 0.98 & 10.09 & 0.28 & 0.81 & 8.21 & 0.02 & 21.19 \\
\hline 5500 & 0.20 & 0.00 & 4.79 & 2.55 & 6.12 & 2.72 & 0.59 & 4.85 & 0.10 & 6.66 \\
\hline 6500 & 1.09 & 0.00 & 7.67 & 4.71 & 4.19 & 5.19 & 2.11 & 6.72 & 2.03 & 9.40 \\
\hline 7500 & 3.57 & 0.00 & 8.97 & 17.45 & 2.48 & 7.74 & 5.31 & 9.33 & 9.00 & 12.37 \\
\hline 8500 & 9.00 & 0.00 & 9.87 & 11.18 & 2.36 & 10.31 & 5.43 & 11.94 & 11.79 & 5.82 \\
\hline 9500 & 15.58 & 0.00 & 10.48 & 6.86 & 1.99 & 12.59 & 5.17 & 10.07 & 8.88 & 7.54 \\
\hline 10500 & 19.28 & 0.00 & 11.43 & 5.88 & 1.23 & 14.93 & 6.13 & 11.57 & 9.78 & 6.71 \\
\hline 11500 & 18.83 & 0.00 & 11.81 & 5.49 & 0.79 & 14.72 & 13.69 & 6.72 & 16.70 & 9.33 \\
\hline 12500 & 11.51 & 0.00 & 8.90 & 9.61 & 0.54 & 11.07 & 14.78 & 5.60 & 14.66 & 5.85 \\
\hline 13500 & 6.96 & 0.00 & 6.78 & 5.49 & 0.19 & 8.42 & 9.66 & 5.97 & 7.66 & 2.73 \\
\hline 14500 & 5.46 & 0.00 & 5.35 & 8.82 & 0.08 & 7.23 & 7.54 & 8.21 & 6.90 & 2.21 \\
\hline 15500 & 3.21 & 0.00 & 4.86 & 9.41 & 0.07 & 3.62 & 11.60 & 3.73 & 7.20 & 3.08 \\
\hline 16500 & 1.71 & 0.00 & 3.90 & 3.73 & 0.06 & 0.95 & 12.37 & 2.61 & 4.06 & 3.72 \\
\hline 17500 & 1.41 & 0.00 & 2.32 & 1.96 & 0.07 & 0.17 & 4.01 & 1.49 & 1.04 & 2.04 \\
\hline 18500 & 1.46 & 0.00 & 0.94 & 1.76 & 0.02 & 0.02 & 0.48 & 0.37 & 0.14 & 0.70 \\
\hline 19500 & 0.59 & 0.00 & 0.32 & 0.78 & 0.01 & 0.01 & 0.14 & 0.00 & 0.03 & 0.12 \\
\hline 20500 & 0.09 & 0.00 & 0.07 & 0.59 & 0.01 & 0.00 & 0.03 & 0.37 & 0.00 & 0.03 \\
\hline 21500 & 0.02 & 0.00 & 0.02 & 0.59 & 0.01 & 0.00 & 0.04 & 0.00 & 0.00 & 0.00 \\
\hline 22500 & 0.00 & 0.00 & 0.01 & 0.00 & 0.00 & 0.00 & 0.01 & 0.00 & 0.00 & 0.00 \\
\hline 23500 & 0.00 & 0.00 & 0.00 & 0.00 & 0.00 & 0.00 & 0.00 & 0.00 & 0.00 & 0.00 \\
\hline 24500 & 0.00 & 0.00 & 0.00 & 0.00 & 0.00 & 0.00 & 0.00 & 0.00 & 0.00 & 0.00 \\
\hline 25500 & 0.00 & 0.00 & 0.00 & 0.00 & 0.00 & 0.00 & 0.01 & 0.00 & 0.00 & 0.00 \\
\hline 26500 & 0.00 & 0.00 & 0.00 & 0.00 & 0.00 & 0.00 & 0.01 & 0.00 & 0.00 & 0.00 \\
\hline 27500 & 0.00 & 0.00 & 0.00 & 0.00 & 0.00 & 0.00 & 0.00 & 0.00 & 0.00 & 0.00 \\
\hline 28500 & 0.00 & 0.00 & 0.00 & 0.00 & 0.00 & 0.00 & 0.00 & 0.00 & 0.00 & 0.00 \\
\hline 29500 & 0.00 & 0.00 & 0.00 & 0.00 & 0.00 & 0.00 & 0.00 & 0.00 & 0.00 & 0.00 \\
\hline 30500 & 0.00 & 0.00 & 0.00 & 0.00 & 0.00 & 0.00 & 0.00 & 0.00 & 0.00 & 0.00 \\
\hline 31500 & 0.00 & 0.00 & 0.00 & 0.00 & 0.00 & 0.00 & 0.00 & 0.00 & 0.00 & 0.00 \\
\hline 32500 & 0.00 & 0.00 & 0.00 & 0.00 & 0.00 & 0.00 & 0.00 & 0.00 & 0.00 & 0.00 \\
\hline 33500 & 0.00 & 0.00 & 0.00 & 0.00 & 0.00 & 0.00 & 0.00 & 0.00 & 0.00 & 0.00 \\
\hline 34500 & 0.00 & 0.00 & 0.00 & 0.00 & 0.00 & 0.00 & 0.00 & 0.00 & 0.00 & 0.00 \\
\hline 35500 & 0.00 & 0.00 & 0.00 & 0.00 & 0.00 & 0.00 & 0.00 & 0.00 & 0.00 & 0.00 \\
\hline 36500 & 0.00 & 0.00 & 0.00 & 0.00 & 0.00 & 0.00 & 0.00 & 0.00 & 0.00 & 0.00 \\
\hline 37500 & 0.00 & 0.00 & 0.00 & 0.00 & 0.00 & 0.00 & 0.00 & 0.00 & 0.00 & 0.00 \\
\hline 38500 & 0.00 & 0.00 & 0.00 & 0.00 & 0.00 & 0.00 & 0.00 & 0.00 & 0.00 & 0.00 \\
\hline 39500 & 0.00 & 0.00 & 0.00 & 0.00 & 0.00 & 0.00 & 0.00 & 0.00 & 0.00 & 0.00 \\
\hline
\end{tabular}


Table C.23. Normalized Tandem Axle Load Distribution Per Class for Site DWD

\begin{tabular}{|c|c|c|c|c|c|c|c|c|c|c|}
\hline $\begin{array}{l}\text { Load } \\
\text { (kgf) }\end{array}$ & Class 4 & Class 5 & Class 6 & Class 7 & Class 8 & Class 9 & Class 10 & Class 11 & Class 12 & Class 13 \\
\hline 500 & 0.00 & 0.00 & 0.00 & 0.00 & 1.29 & 0.00 & 0.00 & 0.00 & 0.00 & 0.00 \\
\hline 1500 & 0.00 & 0.00 & 0.01 & 0.08 & 16.92 & 0.00 & 0.03 & 0.00 & 0.00 & 0.00 \\
\hline 2500 & 0.01 & 0.00 & 0.88 & 0.18 & 21.55 & 0.05 & 0.52 & 0.00 & 0.00 & 0.00 \\
\hline 3500 & 0.08 & 0.00 & 3.73 & 0.56 & 21.32 & 0.60 & 1.60 & 0.63 & 0.05 & 0.36 \\
\hline 4500 & 0.14 & 0.00 & 6.89 & 0.57 & 13.74 & 1.60 & 2.94 & 2.67 & 0.19 & 0.95 \\
\hline 5500 & 0.77 & 0.00 & 8.83 & 0.83 & 7.69 & 2.58 & 2.73 & 2.19 & 0.47 & 1.86 \\
\hline 6500 & 1.99 & 0.00 & 11.19 & 2.16 & 4.96 & 4.30 & 4.28 & 2.58 & 1.20 & 2.18 \\
\hline 7500 & 4.89 & 0.00 & 10.63 & 3.13 & 3.48 & 5.98 & 5.71 & 3.94 & 2.24 & 2.62 \\
\hline 8500 & 10.15 & 0.00 & 9.84 & 4.02 & 2.68 & 8.24 & 6.66 & 6.66 & 4.22 & 3.29 \\
\hline 9500 & 14.51 & 0.00 & 8.86 & 4.86 & 2.10 & 10.72 & 8.99 & 11.04 & 4.93 & 5.26 \\
\hline 10500 & 14.33 & 0.00 & 8.87 & 6.50 & 1.59 & 12.59 & 10.12 & 16.38 & 5.88 & 7.08 \\
\hline 11500 & 12.09 & 0.00 & 8.21 & 8.49 & 1.04 & 12.88 & 10.25 & 12.40 & 8.84 & 7.38 \\
\hline 12500 & 9.47 & 0.00 & 6.55 & 11.32 & 0.62 & 11.51 & 9.83 & 9.82 & 12.43 & 8.09 \\
\hline 13500 & 8.07 & 0.00 & 4.72 & 15.06 & 0.44 & 10.24 & 9.40 & 10.45 & 12.14 & 8.65 \\
\hline 14500 & 6.76 & 0.00 & 3.28 & 16.95 & 0.27 & 8.96 & 8.33 & 10.50 & 10.41 & 10.19 \\
\hline 15500 & 5.13 & 0.00 & 2.32 & 12.45 & 0.13 & 6.16 & 6.97 & 5.74 & 10.65 & 12.64 \\
\hline 16500 & 3.43 & 0.00 & 1.76 & 6.57 & 0.07 & 2.73 & 5.07 & 2.82 & 11.02 & 11.98 \\
\hline 17500 & 2.90 & 0.00 & 1.33 & 2.82 & 0.04 & 0.69 & 3.33 & 1.02 & 8.92 & 10.21 \\
\hline 18500 & 2.23 & 0.00 & 0.89 & 1.34 & 0.02 & 0.13 & 2.09 & 0.53 & 4.65 & 5.69 \\
\hline 19500 & 1.61 & 0.00 & 0.58 & 0.78 & 0.03 & 0.03 & 0.87 & 0.24 & 1.43 & 1.33 \\
\hline 20500 & 0.86 & 0.00 & 0.30 & 0.55 & 0.01 & 0.01 & 0.24 & 0.10 & 0.27 & 0.17 \\
\hline 21500 & 0.36 & 0.00 & 0.14 & 0.26 & 0.01 & 0.00 & 0.04 & 0.15 & 0.04 & 0.03 \\
\hline 22500 & 0.14 & 0.00 & 0.09 & 0.13 & 0.00 & 0.00 & 0.01 & 0.00 & 0.01 & 0.00 \\
\hline 23500 & 0.04 & 0.00 & 0.04 & 0.14 & 0.00 & 0.00 & 0.00 & 0.00 & 0.00 & 0.00 \\
\hline 24500 & 0.02 & 0.00 & 0.03 & 0.09 & 0.00 & 0.00 & 0.00 & 0.05 & 0.00 & 0.00 \\
\hline 25500 & 0.02 & 0.00 & 0.01 & 0.07 & 0.00 & 0.00 & 0.00 & 0.10 & 0.00 & 0.00 \\
\hline 26500 & 0.00 & 0.00 & 0.00 & 0.06 & 0.00 & 0.00 & 0.00 & 0.00 & 0.00 & 0.00 \\
\hline 27500 & 0.00 & 0.00 & 0.00 & 0.02 & 0.00 & 0.00 & 0.00 & 0.00 & 0.00 & 0.00 \\
\hline 28500 & 0.00 & 0.00 & 0.00 & 0.01 & 0.00 & 0.00 & 0.00 & 0.00 & 0.00 & 0.00 \\
\hline 29500 & 0.00 & 0.00 & 0.00 & 0.00 & 0.00 & 0.00 & 0.00 & 0.00 & 0.00 & 0.00 \\
\hline 30500 & 0.00 & 0.00 & 0.00 & 0.01 & 0.00 & 0.00 & 0.00 & 0.00 & 0.00 & 0.00 \\
\hline 31500 & 0.00 & 0.00 & 0.00 & 0.00 & 0.00 & 0.00 & 0.00 & 0.00 & 0.00 & 0.00 \\
\hline 32500 & 0.00 & 0.00 & 0.00 & 0.00 & 0.00 & 0.00 & 0.00 & 0.00 & 0.00 & 0.00 \\
\hline 33500 & 0.00 & 0.00 & 0.00 & 0.00 & 0.00 & 0.00 & 0.00 & 0.00 & 0.00 & 0.00 \\
\hline 34500 & 0.00 & 0.00 & 0.00 & 0.00 & 0.00 & 0.00 & 0.00 & 0.00 & 0.00 & 0.00 \\
\hline 35500 & 0.00 & 0.00 & 0.00 & 0.00 & 0.00 & 0.00 & 0.00 & 0.00 & 0.00 & 0.00 \\
\hline 36500 & 0.00 & 0.00 & 0.00 & 0.00 & 0.00 & 0.00 & 0.00 & 0.00 & 0.00 & 0.00 \\
\hline 37500 & 0.00 & 0.00 & 0.00 & 0.00 & 0.00 & 0.00 & 0.00 & 0.00 & 0.00 & 0.00 \\
\hline 38500 & 0.00 & 0.00 & 0.00 & 0.00 & 0.00 & 0.00 & 0.00 & 0.00 & 0.00 & 0.00 \\
\hline 39500 & 0.00 & 0.00 & 0.00 & 0.00 & 0.00 & 0.00 & 0.00 & 0.00 & 0.00 & 0.00 \\
\hline
\end{tabular}


Table C.24. Normalized Tandem Axle Load Distribution Per Class for Site LC1

\begin{tabular}{|c|c|c|c|c|c|c|c|c|c|c|}
\hline $\begin{array}{l}\text { Load } \\
\text { (kgf) }\end{array}$ & Class 4 & Class 5 & Class 6 & Class 7 & Class 8 & Class 9 & Class 10 & Class 11 & Class 12 & Class 13 \\
\hline 500 & 0.00 & 0.00 & 0.00 & 0.24 & 0.45 & 0.00 & 0.04 & 0.00 & 0.00 & 0.00 \\
\hline 1500 & 0.00 & 0.00 & 0.06 & 0.18 & 18.68 & 0.00 & 0.01 & 0.00 & 0.00 & 0.00 \\
\hline 2500 & 0.00 & 0.00 & 0.02 & 0.18 & 34.48 & 0.00 & 0.01 & 0.00 & 0.00 & 0.00 \\
\hline 3500 & 0.00 & 0.00 & 0.04 & 0.43 & 19.00 & 0.01 & 0.02 & 0.27 & 0.00 & 0.00 \\
\hline 4500 & 0.04 & 0.00 & 0.27 & 2.55 & 7.06 & 0.04 & 0.13 & 0.00 & 0.03 & 0.12 \\
\hline 5500 & 0.05 & 0.00 & 0.81 & 7.11 & 4.65 & 0.19 & 0.49 & 0.82 & 0.15 & 0.95 \\
\hline 6500 & 0.23 & 0.00 & 3.06 & 15.62 & 3.77 & 0.73 & 1.30 & 1.63 & 0.44 & 2.32 \\
\hline 7500 & 0.98 & 0.00 & 7.87 & 13.07 & 2.51 & 2.14 & 2.27 & 2.72 & 0.91 & 3.26 \\
\hline 8500 & 3.24 & 0.00 & 11.20 & 8.88 & 1.95 & 4.78 & 3.62 & 4.36 & 1.62 & 4.64 \\
\hline 9500 & 7.30 & 0.00 & 12.15 & 5.41 & 1.74 & 8.49 & 5.99 & 8.45 & 3.24 & 6.92 \\
\hline 10500 & 11.98 & 0.00 & 11.69 & 5.35 & 1.65 & 12.72 & 8.54 & 15.26 & 5.59 & 8.52 \\
\hline 11500 & 14.04 & 0.00 & 11.23 & 5.35 & 1.38 & 15.78 & 10.82 & 21.53 & 8.10 & 8.85 \\
\hline 12500 & 14.16 & 0.00 & 10.08 & 7.42 & 0.96 & 16.84 & 12.62 & 16.89 & 11.16 & 9.52 \\
\hline 13500 & 13.11 & 0.00 & 8.41 & 6.50 & 0.71 & 15.21 & 13.46 & 11.72 & 14.21 & 10.58 \\
\hline 14500 & 10.14 & 0.00 & 6.88 & 5.35 & 0.43 & 11.07 & 12.59 & 8.45 & 14.76 & 10.20 \\
\hline 15500 & 8.49 & 0.00 & 5.00 & 5.05 & 0.26 & 6.83 & 10.62 & 3.81 & 13.67 & 9.09 \\
\hline 16500 & 5.95 & 0.00 & 3.62 & 3.65 & 0.15 & 3.42 & 7.90 & 1.09 & 11.77 & 8.81 \\
\hline 17500 & 3.92 & 0.00 & 2.49 & 2.31 & 0.08 & 1.33 & 5.15 & 1.63 & 8.45 & 7.85 \\
\hline 18500 & 2.74 & 0.00 & 1.74 & 1.16 & 0.04 & 0.36 & 2.80 & 0.27 & 4.11 & 5.02 \\
\hline 19500 & 1.78 & 0.00 & 1.35 & 1.03 & 0.02 & 0.07 & 1.14 & 0.54 & 1.40 & 2.33 \\
\hline 20500 & 0.97 & 0.00 & 1.00 & 1.34 & 0.01 & 0.01 & 0.35 & 0.00 & 0.34 & 0.77 \\
\hline 21500 & 0.45 & 0.00 & 0.63 & 0.79 & 0.01 & 0.00 & 0.09 & 0.00 & 0.05 & 0.19 \\
\hline 22500 & 0.26 & 0.00 & 0.25 & 0.12 & 0.01 & 0.00 & 0.03 & 0.00 & 0.01 & 0.04 \\
\hline 23500 & 0.08 & 0.00 & 0.09 & 0.24 & 0.00 & 0.00 & 0.01 & 0.27 & 0.00 & 0.01 \\
\hline 24500 & 0.04 & 0.00 & 0.03 & 0.00 & 0.00 & 0.00 & 0.00 & 0.00 & 0.00 & 0.00 \\
\hline 25500 & 0.03 & 0.00 & 0.01 & 0.18 & 0.00 & 0.00 & 0.00 & 0.27 & 0.00 & 0.00 \\
\hline 26500 & 0.01 & 0.00 & 0.00 & 0.12 & 0.00 & 0.00 & 0.00 & 0.00 & 0.00 & 0.00 \\
\hline 27500 & 0.00 & 0.00 & 0.00 & 0.06 & 0.00 & 0.00 & 0.00 & 0.00 & 0.00 & 0.00 \\
\hline 28500 & 0.00 & 0.00 & 0.00 & 0.06 & 0.00 & 0.00 & 0.00 & 0.00 & 0.00 & 0.00 \\
\hline 29500 & 0.00 & 0.00 & 0.00 & 0.06 & 0.00 & 0.00 & 0.00 & 0.00 & 0.00 & 0.00 \\
\hline 30500 & 0.00 & 0.00 & 0.00 & 0.00 & 0.00 & 0.00 & 0.00 & 0.00 & 0.00 & 0.00 \\
\hline 31500 & 0.00 & 0.00 & 0.00 & 0.00 & 0.00 & 0.00 & 0.00 & 0.00 & 0.00 & 0.00 \\
\hline 32500 & 0.00 & 0.00 & 0.00 & 0.06 & 0.00 & 0.00 & 0.00 & 0.00 & 0.00 & 0.00 \\
\hline 33500 & 0.00 & 0.00 & 0.00 & 0.06 & 0.00 & 0.00 & 0.00 & 0.00 & 0.00 & 0.00 \\
\hline 34500 & 0.00 & 0.00 & 0.00 & 0.00 & 0.00 & 0.00 & 0.00 & 0.00 & 0.00 & 0.00 \\
\hline 35500 & 0.00 & 0.00 & 0.00 & 0.06 & 0.00 & 0.00 & 0.00 & 0.00 & 0.00 & 0.00 \\
\hline 36500 & 0.00 & 0.00 & 0.00 & 0.00 & 0.00 & 0.00 & 0.00 & 0.00 & 0.00 & 0.00 \\
\hline 37500 & 0.00 & 0.00 & 0.00 & 0.00 & 0.00 & 0.00 & 0.00 & 0.00 & 0.00 & 0.00 \\
\hline 38500 & 0.00 & 0.00 & 0.00 & 0.00 & 0.00 & 0.00 & 0.00 & 0.00 & 0.00 & 0.00 \\
\hline 39500 & 0.00 & 0.00 & 0.00 & 0.00 & 0.00 & 0.00 & 0.00 & 0.00 & 0.00 & 0.00 \\
\hline
\end{tabular}


Table C.25. Normalized Tridem Axle Load Distribution Per Class for Site SBW

\begin{tabular}{|c|c|c|c|c|c|c|c|c|c|c|}
\hline $\begin{array}{l}\text { Load } \\
\text { (kgf) }\end{array}$ & Class 4 & Class 5 & Class 6 & Class 7 & Class 8 & Class 9 & Class 10 & Class 11 & Class 12 & Class 13 \\
\hline 750 & 0.00 & 0.00 & 0.00 & 0.00 & 0.00 & 0.69 & 0.02 & 0.00 & 0.00 & 0.00 \\
\hline 2250 & 0.00 & 0.00 & 0.00 & 2.61 & 4.04 & 30.04 & 0.08 & 0.00 & 0.00 & 0.00 \\
\hline 3750 & 0.00 & 0.00 & 0.00 & 2.61 & 4.04 & 29.84 & 0.46 & 0.00 & 0.00 & 0.00 \\
\hline 5250 & 0.00 & 0.00 & 0.00 & 3.58 & 4.04 & 21.81 & 1.60 & 5.89 & 0.00 & 0.20 \\
\hline 6750 & 0.00 & 0.00 & 0.00 & 4.56 & 2.02 & 11.58 & 3.43 & 23.93 & 1.37 & 5.34 \\
\hline 8250 & 0.00 & 0.00 & 0.00 & 4.56 & 9.09 & 3.78 & 6.01 & 19.17 & 1.60 & 5.98 \\
\hline 9750 & 0.00 & 0.00 & 0.00 & 4.56 & 6.06 & 1.27 & 9.02 & 13.35 & 1.37 & 6.53 \\
\hline 11250 & 0.00 & 0.00 & 0.00 & 6.84 & 1.01 & 0.52 & 12.66 & 10.96 & 2.97 & 11.20 \\
\hline 12750 & 0.00 & 0.00 & 0.00 & 4.56 & 2.02 & 0.26 & 14.43 & 7.52 & 5.02 & 12.74 \\
\hline 14250 & 0.00 & 0.00 & 0.00 & 7.17 & 7.07 & 0.12 & 14.64 & 8.65 & 12.79 & 9.96 \\
\hline 15750 & 0.00 & 0.00 & 0.00 & 11.07 & 15.15 & 0.03 & 12.90 & 4.14 & 8.22 & 11.43 \\
\hline 17250 & 0.00 & 0.00 & 0.00 & 9.77 & 12.12 & 0.00 & 10.22 & 2.63 & 6.85 & 11.49 \\
\hline 18750 & 0.00 & 0.00 & 0.00 & 8.79 & 8.08 & 0.04 & 6.71 & 1.38 & 12.33 & 7.84 \\
\hline 20250 & 0.00 & 0.00 & 0.00 & 9.45 & 8.08 & 0.03 & 4.11 & 1.75 & 11.64 & 6.94 \\
\hline 21750 & 0.00 & 0.00 & 0.00 & 7.82 & 9.09 & 0.00 & 2.06 & 0.50 & 11.42 & 5.50 \\
\hline 23250 & 0.00 & 0.00 & 0.00 & 6.51 & 2.02 & 0.00 & 0.97 & 0.06 & 11.42 & 2.84 \\
\hline 24750 & 0.00 & 0.00 & 0.00 & 1.63 & 1.01 & 0.00 & 0.38 & 0.00 & 3.42 & 1.12 \\
\hline 26250 & 0.00 & 0.00 & 0.00 & 1.95 & 3.03 & 0.00 & 0.17 & 0.06 & 5.02 & 0.44 \\
\hline 27750 & 0.00 & 0.00 & 0.00 & 0.98 & 2.02 & 0.00 & 0.07 & 0.00 & 3.42 & 0.23 \\
\hline 29250 & 0.00 & 0.00 & 0.00 & 0.33 & 0.00 & 0.00 & 0.03 & 0.00 & 0.91 & 0.12 \\
\hline 30750 & 0.00 & 0.00 & 0.00 & 0.33 & 0.00 & 0.00 & 0.01 & 0.00 & 0.23 & 0.07 \\
\hline 32250 & 0.00 & 0.00 & 0.00 & 0.33 & 0.00 & 0.00 & 0.00 & 0.00 & 0.00 & 0.02 \\
\hline 33750 & 0.00 & 0.00 & 0.00 & 0.00 & 0.00 & 0.00 & 0.00 & 0.00 & 0.00 & 0.01 \\
\hline 35250 & 0.00 & 0.00 & 0.00 & 0.00 & 0.00 & 0.00 & 0.00 & 0.00 & 0.00 & 0.01 \\
\hline 36750 & 0.00 & 0.00 & 0.00 & 0.00 & 0.00 & 0.00 & 0.00 & 0.00 & 0.00 & 0.00 \\
\hline 38250 & 0.00 & 0.00 & 0.00 & 0.00 & 0.00 & 0.00 & 0.00 & 0.00 & 0.00 & 0.00 \\
\hline 39750 & 0.00 & 0.00 & 0.00 & 0.00 & 0.00 & 0.00 & 0.00 & 0.00 & 0.00 & 0.00 \\
\hline 41250 & 0.00 & 0.00 & 0.00 & 0.00 & 0.00 & 0.00 & 0.00 & 0.00 & 0.00 & 0.00 \\
\hline 42750 & 0.00 & 0.00 & 0.00 & 0.00 & 0.00 & 0.00 & 0.00 & 0.00 & 0.00 & 0.00 \\
\hline 44250 & 0.00 & 0.00 & 0.00 & 0.00 & 0.00 & 0.00 & 0.00 & 0.00 & 0.00 & 0.00 \\
\hline 45750 & 0.00 & 0.00 & 0.00 & 0.00 & 0.00 & 0.00 & 0.00 & 0.00 & 0.00 & 0.00 \\
\hline 47250 & 0.00 & 0.00 & 0.00 & 0.00 & 0.00 & 0.00 & 0.00 & 0.00 & 0.00 & 0.00 \\
\hline 48750 & 0.00 & 0.00 & 0.00 & 0.00 & 0.00 & 0.00 & 0.00 & 0.00 & 0.00 & 0.00 \\
\hline 50250 & 0.00 & 0.00 & 0.00 & 0.00 & 0.00 & 0.00 & 0.00 & 0.00 & 0.00 & 0.00 \\
\hline 51750 & 0.00 & 0.00 & 0.00 & 0.00 & 0.00 & 0.00 & 0.00 & 0.00 & 0.00 & 0.00 \\
\hline 53250 & 0.00 & 0.00 & 0.00 & 0.00 & 0.00 & 0.00 & 0.00 & 0.00 & 0.00 & 0.00 \\
\hline 54750 & 0.00 & 0.00 & 0.00 & 0.00 & 0.00 & 0.00 & 0.00 & 0.00 & 0.00 & 0.00 \\
\hline 56250 & 0.00 & 0.00 & 0.00 & 0.00 & 0.00 & 0.00 & 0.00 & 0.00 & 0.00 & 0.00 \\
\hline 57750 & 0.00 & 0.00 & 0.00 & 0.00 & 0.00 & 0.00 & 0.00 & 0.00 & 0.00 & 0.00 \\
\hline 59250 & 0.00 & 0.00 & 0.00 & 0.00 & 0.00 & 0.00 & 0.00 & 0.00 & 0.00 & 0.00 \\
\hline
\end{tabular}


Table C.26. Normalized Tridem Axle Load Distribution Per Class for Site SEB

\begin{tabular}{|c|c|c|c|c|c|c|c|c|c|c|}
\hline $\begin{array}{l}\text { Load } \\
\text { (kgf) }\end{array}$ & Class 4 & Class 5 & Class 6 & Class 7 & Class 8 & Class 9 & Class 10 & Class 11 & Class 12 & Class 13 \\
\hline 750 & 0.00 & 0.00 & 0.00 & 0.00 & 0.00 & 0.04 & 0.00 & 0.00 & 0.00 & 0.00 \\
\hline 2250 & 0.00 & 0.00 & 0.00 & 0.00 & 3.03 & 18.52 & 0.00 & 0.00 & 0.00 & 0.00 \\
\hline 3750 & 0.00 & 0.00 & 0.00 & 0.39 & 3.03 & 48.93 & 0.01 & 0.00 & 0.00 & 0.00 \\
\hline 5250 & 0.00 & 0.00 & 0.00 & 2.96 & 6.06 & 24.73 & 0.24 & 8.93 & 0.00 & 0.02 \\
\hline 6750 & 0.00 & 0.00 & 0.00 & 4.14 & 9.09 & 6.05 & 2.09 & 17.47 & 0.11 & 0.31 \\
\hline 8250 & 0.00 & 0.00 & 0.00 & 4.34 & 9.09 & 1.21 & 6.33 & 6.10 & 0.18 & 0.55 \\
\hline 9750 & 0.00 & 0.00 & 0.00 & 6.11 & 12.12 & 0.27 & 10.11 & 2.51 & 0.39 & 0.83 \\
\hline 11250 & 0.00 & 0.00 & 0.00 & 5.13 & 15.15 & 0.15 & 14.39 & 2.23 & 0.25 & 2.99 \\
\hline 12750 & 0.00 & 0.00 & 0.00 & 7.69 & 12.12 & 0.03 & 16.79 & 3.14 & 1.29 & 5.46 \\
\hline 14250 & 0.00 & 0.00 & 0.00 & 7.89 & 6.06 & 0.01 & 15.63 & 13.50 & 7.53 & 6.57 \\
\hline 15750 & 0.00 & 0.00 & 0.00 & 8.88 & 0.00 & 0.00 & 13.20 & 17.75 & 8.72 & 12.60 \\
\hline 17250 & 0.00 & 0.00 & 0.00 & 7.30 & 15.15 & 0.00 & 9.52 & 10.32 & 5.74 & 15.75 \\
\hline 18750 & 0.00 & 0.00 & 0.00 & 7.69 & 9.09 & 0.01 & 5.91 & 8.65 & 9.08 & 15.17 \\
\hline 20250 & 0.00 & 0.00 & 0.00 & 6.90 & 0.00 & 0.03 & 3.24 & 5.79 & 11.52 & 16.34 \\
\hline 21750 & 0.00 & 0.00 & 0.00 & 10.45 & 0.00 & 0.00 & 1.57 & 2.90 & 14.93 & 13.40 \\
\hline 23250 & 0.00 & 0.00 & 0.00 & 10.85 & 0.00 & 0.03 & 0.57 & 0.59 & 19.20 & 6.64 \\
\hline 24750 & 0.00 & 0.00 & 0.00 & 6.71 & 0.00 & 0.00 & 0.24 & 0.07 & 14.46 & 2.46 \\
\hline 26250 & 0.00 & 0.00 & 0.00 & 1.18 & 0.00 & 0.00 & 0.11 & 0.03 & 4.88 & 0.64 \\
\hline 27750 & 0.00 & 0.00 & 0.00 & 1.18 & 0.00 & 0.00 & 0.04 & 0.00 & 1.36 & 0.15 \\
\hline 29250 & 0.00 & 0.00 & 0.00 & 0.20 & 0.00 & 0.00 & 0.02 & 0.00 & 0.32 & 0.07 \\
\hline 30750 & 0.00 & 0.00 & 0.00 & 0.00 & 0.00 & 0.00 & 0.01 & 0.00 & 0.04 & 0.03 \\
\hline 32250 & 0.00 & 0.00 & 0.00 & 0.00 & 0.00 & 0.00 & 0.00 & 0.00 & 0.00 & 0.01 \\
\hline 33750 & 0.00 & 0.00 & 0.00 & 0.00 & 0.00 & 0.00 & 0.00 & 0.00 & 0.00 & 0.01 \\
\hline 35250 & 0.00 & 0.00 & 0.00 & 0.00 & 0.00 & 0.00 & 0.00 & 0.00 & 0.00 & 0.00 \\
\hline 36750 & 0.00 & 0.00 & 0.00 & 0.00 & 0.00 & 0.00 & 0.00 & 0.00 & 0.00 & 0.00 \\
\hline 38250 & 0.00 & 0.00 & 0.00 & 0.00 & 0.00 & 0.00 & 0.00 & 0.00 & 0.00 & 0.00 \\
\hline 39750 & 0.00 & 0.00 & 0.00 & 0.00 & 0.00 & 0.00 & 0.00 & 0.00 & 0.00 & 0.00 \\
\hline 41250 & 0.00 & 0.00 & 0.00 & 0.00 & 0.00 & 0.00 & 0.00 & 0.00 & 0.00 & 0.00 \\
\hline 42750 & 0.00 & 0.00 & 0.00 & 0.00 & 0.00 & 0.00 & 0.00 & 0.00 & 0.00 & 0.00 \\
\hline 44250 & 0.00 & 0.00 & 0.00 & 0.00 & 0.00 & 0.00 & 0.00 & 0.00 & 0.00 & 0.00 \\
\hline 45750 & 0.00 & 0.00 & 0.00 & 0.00 & 0.00 & 0.00 & 0.00 & 0.00 & 0.00 & 0.00 \\
\hline 47250 & 0.00 & 0.00 & 0.00 & 0.00 & 0.00 & 0.00 & 0.00 & 0.00 & 0.00 & 0.00 \\
\hline 48750 & 0.00 & 0.00 & 0.00 & 0.00 & 0.00 & 0.00 & 0.00 & 0.00 & 0.00 & 0.00 \\
\hline 50250 & 0.00 & 0.00 & 0.00 & 0.00 & 0.00 & 0.00 & 0.00 & 0.00 & 0.00 & 0.00 \\
\hline 51750 & 0.00 & 0.00 & 0.00 & 0.00 & 0.00 & 0.00 & 0.00 & 0.00 & 0.00 & 0.00 \\
\hline 53250 & 0.00 & 0.00 & 0.00 & 0.00 & 0.00 & 0.00 & 0.00 & 0.00 & 0.00 & 0.00 \\
\hline 54750 & 0.00 & 0.00 & 0.00 & 0.00 & 0.00 & 0.00 & 0.00 & 0.00 & 0.00 & 0.00 \\
\hline 56250 & 0.00 & 0.00 & 0.00 & 0.00 & 0.00 & 0.00 & 0.00 & 0.00 & 0.00 & 0.00 \\
\hline 57750 & 0.00 & 0.00 & 0.00 & 0.00 & 0.00 & 0.00 & 0.00 & 0.00 & 0.00 & 0.00 \\
\hline 59250 & 0.00 & 0.00 & 0.00 & 0.00 & 0.00 & 0.00 & 0.00 & 0.00 & 0.00 & 0.00 \\
\hline
\end{tabular}


Table C.27. Normalized Tridem Axle Load Distribution Per Class for Site WWG

\begin{tabular}{|c|c|c|c|c|c|c|c|c|c|c|}
\hline $\begin{array}{l}\text { Load } \\
\text { (kgf) }\end{array}$ & Class 4 & Class 5 & Class 6 & Class 7 & Class 8 & Class 9 & Class 10 & Class 11 & Class 12 & Class 13 \\
\hline 750 & 0.00 & 0.00 & 0.00 & 0.00 & 0.00 & 0.00 & 0.00 & 0.00 & 0.00 & 0.00 \\
\hline 2250 & 0.00 & 0.00 & 0.00 & 0.00 & 0.00 & 13.42 & 0.00 & 0.00 & 0.00 & 0.00 \\
\hline 3750 & 0.00 & 0.00 & 0.00 & 0.00 & 0.00 & 47.94 & 0.00 & 0.00 & 0.00 & 0.00 \\
\hline 5250 & 0.00 & 0.00 & 0.00 & 0.00 & 10.00 & 29.59 & 0.26 & 37.32 & 2.67 & 0.00 \\
\hline 6750 & 0.00 & 0.00 & 0.00 & 0.00 & 10.00 & 7.00 & 2.85 & 38.41 & 2.67 & 9.51 \\
\hline 8250 & 0.00 & 0.00 & 0.00 & 0.00 & 0.00 & 1.72 & 4.30 & 7.97 & 5.33 & 35.07 \\
\hline 9750 & 0.00 & 0.00 & 0.00 & 4.23 & 10.00 & 0.34 & 4.38 & 1.09 & 6.67 & 8.65 \\
\hline 11250 & 0.00 & 0.00 & 0.00 & 1.41 & 0.00 & 0.00 & 9.65 & 1.81 & 5.33 & 17.07 \\
\hline 12750 & 0.00 & 0.00 & 0.00 & 0.00 & 10.00 & 0.00 & 13.46 & 2.54 & 2.67 & 9.78 \\
\hline 14250 & 0.00 & 0.00 & 0.00 & 4.23 & 20.00 & 0.00 & 10.23 & 1.81 & 2.67 & 6.51 \\
\hline 15750 & 0.00 & 0.00 & 0.00 & 33.80 & 10.00 & 0.00 & 15.24 & 3.26 & 12.00 & 4.95 \\
\hline 17250 & 0.00 & 0.00 & 0.00 & 38.03 & 20.00 & 0.00 & 14.88 & 1.45 & 4.00 & 2.21 \\
\hline 18750 & 0.00 & 0.00 & 0.00 & 2.82 & 0.00 & 0.00 & 8.57 & 1.09 & 6.67 & 1.78 \\
\hline 20250 & 0.00 & 0.00 & 0.00 & 7.04 & 10.00 & 0.00 & 8.92 & 1.45 & 9.33 & 1.19 \\
\hline 21750 & 0.00 & 0.00 & 0.00 & 4.23 & 0.00 & 0.00 & 5.54 & 1.09 & 20.00 & 1.22 \\
\hline 23250 & 0.00 & 0.00 & 0.00 & 2.82 & 0.00 & 0.00 & 1.42 & 0.00 & 13.33 & 0.79 \\
\hline 24750 & 0.00 & 0.00 & 0.00 & 1.41 & 0.00 & 0.00 & 0.26 & 0.72 & 4.00 & 0.50 \\
\hline 26250 & 0.00 & 0.00 & 0.00 & 0.00 & 0.00 & 0.00 & 0.03 & 0.00 & 2.67 & 0.43 \\
\hline 27750 & 0.00 & 0.00 & 0.00 & 0.00 & 0.00 & 0.00 & 0.01 & 0.00 & 0.00 & 0.17 \\
\hline 29250 & 0.00 & 0.00 & 0.00 & 0.00 & 0.00 & 0.00 & 0.00 & 0.00 & 0.00 & 0.07 \\
\hline 30750 & 0.00 & 0.00 & 0.00 & 0.00 & 0.00 & 0.00 & 0.00 & 0.00 & 0.00 & 0.10 \\
\hline 32250 & 0.00 & 0.00 & 0.00 & 0.00 & 0.00 & 0.00 & 0.00 & 0.00 & 0.00 & 0.00 \\
\hline 33750 & 0.00 & 0.00 & 0.00 & 0.00 & 0.00 & 0.00 & 0.00 & 0.00 & 0.00 & 0.00 \\
\hline 35250 & 0.00 & 0.00 & 0.00 & 0.00 & 0.00 & 0.00 & 0.00 & 0.00 & 0.00 & 0.00 \\
\hline 36750 & 0.00 & 0.00 & 0.00 & 0.00 & 0.00 & 0.00 & 0.00 & 0.00 & 0.00 & 0.00 \\
\hline 38250 & 0.00 & 0.00 & 0.00 & 0.00 & 0.00 & 0.00 & 0.00 & 0.00 & 0.00 & 0.00 \\
\hline 39750 & 0.00 & 0.00 & 0.00 & 0.00 & 0.00 & 0.00 & 0.00 & 0.00 & 0.00 & 0.00 \\
\hline 41250 & 0.00 & 0.00 & 0.00 & 0.00 & 0.00 & 0.00 & 0.00 & 0.00 & 0.00 & 0.00 \\
\hline 42750 & 0.00 & 0.00 & 0.00 & 0.00 & 0.00 & 0.00 & 0.00 & 0.00 & 0.00 & 0.00 \\
\hline 44250 & 0.00 & 0.00 & 0.00 & 0.00 & 0.00 & 0.00 & 0.00 & 0.00 & 0.00 & 0.00 \\
\hline 45750 & 0.00 & 0.00 & 0.00 & 0.00 & 0.00 & 0.00 & 0.00 & 0.00 & 0.00 & 0.00 \\
\hline 47250 & 0.00 & 0.00 & 0.00 & 0.00 & 0.00 & 0.00 & 0.00 & 0.00 & 0.00 & 0.00 \\
\hline 48750 & 0.00 & 0.00 & 0.00 & 0.00 & 0.00 & 0.00 & 0.00 & 0.00 & 0.00 & 0.00 \\
\hline 50250 & 0.00 & 0.00 & 0.00 & 0.00 & 0.00 & 0.00 & 0.00 & 0.00 & 0.00 & 0.00 \\
\hline 51750 & 0.00 & 0.00 & 0.00 & 0.00 & 0.00 & 0.00 & 0.00 & 0.00 & 0.00 & 0.00 \\
\hline 53250 & 0.00 & 0.00 & 0.00 & 0.00 & 0.00 & 0.00 & 0.00 & 0.00 & 0.00 & 0.00 \\
\hline 54750 & 0.00 & 0.00 & 0.00 & 0.00 & 0.00 & 0.00 & 0.00 & 0.00 & 0.00 & 0.00 \\
\hline 56250 & 0.00 & 0.00 & 0.00 & 0.00 & 0.00 & 0.00 & 0.00 & 0.00 & 0.00 & 0.00 \\
\hline 57750 & 0.00 & 0.00 & 0.00 & 0.00 & 0.00 & 0.00 & 0.00 & 0.00 & 0.00 & 0.00 \\
\hline 59250 & 0.00 & 0.00 & 0.00 & 0.00 & 0.00 & 0.00 & 0.00 & 0.00 & 0.00 & 0.00 \\
\hline
\end{tabular}


Table C.28. Normalized Tridem Axle Load Distribution Per Class for Site DWD

\begin{tabular}{|c|c|c|c|c|c|c|c|c|c|c|}
\hline $\begin{array}{l}\text { Load } \\
\text { (kgf) }\end{array}$ & Class 4 & Class 5 & Class 6 & Class 7 & Class 8 & Class 9 & Class 10 & Class 11 & Class 12 & Class 13 \\
\hline 750 & 0.00 & 0.00 & 0.00 & 0.00 & 0.00 & 0.32 & 0.00 & 0.00 & 0.00 & 0.00 \\
\hline 2250 & 0.00 & 0.00 & 0.00 & 0.00 & 0.00 & 26.65 & 0.01 & 0.00 & 0.00 & 0.00 \\
\hline 3750 & 0.00 & 0.00 & 0.00 & 0.00 & 0.00 & 42.24 & 0.25 & 0.00 & 0.00 & 0.00 \\
\hline 5250 & 0.00 & 0.00 & 0.00 & 0.13 & 11.11 & 22.67 & 1.32 & 6.55 & 0.00 & 0.12 \\
\hline 6750 & 0.00 & 0.00 & 0.00 & 0.39 & 11.11 & 5.23 & 2.56 & 24.07 & 0.24 & 0.60 \\
\hline 8250 & 0.00 & 0.00 & 0.00 & 0.26 & 0.00 & 1.47 & 4.19 & 10.73 & 0.12 & 1.13 \\
\hline 9750 & 0.00 & 0.00 & 0.00 & 1.82 & 0.00 & 0.71 & 6.74 & 6.60 & 0.43 & 2.01 \\
\hline 11250 & 0.00 & 0.00 & 0.00 & 1.95 & 11.11 & 0.32 & 9.69 & 3.89 & 0.28 & 3.52 \\
\hline 12750 & 0.00 & 0.00 & 0.00 & 2.20 & 11.11 & 0.07 & 12.53 & 3.66 & 0.67 & 5.40 \\
\hline 14250 & 0.00 & 0.00 & 0.00 & 5.06 & 0.00 & 0.07 & 13.76 & 4.23 & 1.06 & 7.06 \\
\hline 15750 & 0.00 & 0.00 & 0.00 & 8.43 & 22.22 & 0.09 & 14.06 & 12.44 & 5.04 & 10.48 \\
\hline 17250 & 0.00 & 0.00 & 0.00 & 10.77 & 22.22 & 0.09 & 12.62 & 8.64 & 6.10 & 14.28 \\
\hline 18750 & 0.00 & 0.00 & 0.00 & 13.23 & 0.00 & 0.06 & 9.20 & 5.41 & 6.26 & 14.12 \\
\hline 20250 & 0.00 & 0.00 & 0.00 & 18.03 & 0.00 & 0.00 & 5.82 & 5.46 & 7.33 & 17.12 \\
\hline 21750 & 0.00 & 0.00 & 0.00 & 13.10 & 11.11 & 0.00 & 3.72 & 4.13 & 9.89 & 15.19 \\
\hline 23250 & 0.00 & 0.00 & 0.00 & 11.80 & 0.00 & 0.00 & 2.10 & 2.85 & 13.90 & 6.32 \\
\hline 24750 & 0.00 & 0.00 & 0.00 & 8.69 & 0.00 & 0.00 & 1.02 & 1.28 & 12.37 & 1.77 \\
\hline 26250 & 0.00 & 0.00 & 0.00 & 2.59 & 0.00 & 0.00 & 0.31 & 0.05 & 14.42 & 0.57 \\
\hline 27750 & 0.00 & 0.00 & 0.00 & 1.17 & 0.00 & 0.00 & 0.08 & 0.00 & 14.93 & 0.20 \\
\hline 29250 & 0.00 & 0.00 & 0.00 & 0.39 & 0.00 & 0.00 & 0.02 & 0.00 & 6.10 & 0.06 \\
\hline 30750 & 0.00 & 0.00 & 0.00 & 0.00 & 0.00 & 0.00 & 0.01 & 0.00 & 0.79 & 0.03 \\
\hline 32250 & 0.00 & 0.00 & 0.00 & 0.00 & 0.00 & 0.00 & 0.00 & 0.00 & 0.08 & 0.02 \\
\hline 33750 & 0.00 & 0.00 & 0.00 & 0.00 & 0.00 & 0.00 & 0.00 & 0.00 & 0.00 & 0.00 \\
\hline 35250 & 0.00 & 0.00 & 0.00 & 0.00 & 0.00 & 0.00 & 0.00 & 0.00 & 0.00 & 0.00 \\
\hline 36750 & 0.00 & 0.00 & 0.00 & 0.00 & 0.00 & 0.00 & 0.00 & 0.00 & 0.00 & 0.00 \\
\hline 38250 & 0.00 & 0.00 & 0.00 & 0.00 & 0.00 & 0.00 & 0.00 & 0.00 & 0.00 & 0.00 \\
\hline 39750 & 0.00 & 0.00 & 0.00 & 0.00 & 0.00 & 0.00 & 0.00 & 0.00 & 0.00 & 0.00 \\
\hline 41250 & 0.00 & 0.00 & 0.00 & 0.00 & 0.00 & 0.00 & 0.00 & 0.00 & 0.00 & 0.00 \\
\hline 42750 & 0.00 & 0.00 & 0.00 & 0.00 & 0.00 & 0.00 & 0.00 & 0.00 & 0.00 & 0.00 \\
\hline 44250 & 0.00 & 0.00 & 0.00 & 0.00 & 0.00 & 0.00 & 0.00 & 0.00 & 0.00 & 0.00 \\
\hline 45750 & 0.00 & 0.00 & 0.00 & 0.00 & 0.00 & 0.00 & 0.00 & 0.00 & 0.00 & 0.00 \\
\hline 47250 & 0.00 & 0.00 & 0.00 & 0.00 & 0.00 & 0.00 & 0.00 & 0.00 & 0.00 & 0.00 \\
\hline 48750 & 0.00 & 0.00 & 0.00 & 0.00 & 0.00 & 0.00 & 0.00 & 0.00 & 0.00 & 0.00 \\
\hline 50250 & 0.00 & 0.00 & 0.00 & 0.00 & 0.00 & 0.00 & 0.00 & 0.00 & 0.00 & 0.00 \\
\hline 51750 & 0.00 & 0.00 & 0.00 & 0.00 & 0.00 & 0.00 & 0.00 & 0.00 & 0.00 & 0.00 \\
\hline 53250 & 0.00 & 0.00 & 0.00 & 0.00 & 0.00 & 0.00 & 0.00 & 0.00 & 0.00 & 0.00 \\
\hline 54750 & 0.00 & 0.00 & 0.00 & 0.00 & 0.00 & 0.00 & 0.00 & 0.00 & 0.00 & 0.00 \\
\hline 56250 & 0.00 & 0.00 & 0.00 & 0.00 & 0.00 & 0.00 & 0.00 & 0.00 & 0.00 & 0.00 \\
\hline 57750 & 0.00 & 0.00 & 0.00 & 0.00 & 0.00 & 0.00 & 0.00 & 0.00 & 0.00 & 0.00 \\
\hline 59250 & 0.00 & 0.00 & 0.00 & 0.00 & 0.00 & 0.00 & 0.00 & 0.00 & 0.00 & 0.00 \\
\hline
\end{tabular}


Table C.29. Normalized Tridem Axle Load Distribution Per Class for Site LC1

\begin{tabular}{|c|c|c|c|c|c|c|c|c|c|c|}
\hline $\begin{array}{l}\text { Load } \\
\text { (kgf) }\end{array}$ & Class 4 & Class 5 & Class 6 & Class 7 & Class 8 & Class 9 & Class 10 & Class 11 & Class 12 & Class 13 \\
\hline 750 & 0.00 & 0.00 & 0.00 & 0.00 & 0.00 & 0.21 & 0.00 & 0.00 & 0.00 & 0.00 \\
\hline 2250 & 0.00 & 0.00 & 0.00 & 0.00 & 0.00 & 7.10 & 0.00 & 0.00 & 0.00 & 0.00 \\
\hline 3750 & 0.00 & 0.00 & 0.00 & 0.00 & 0.00 & 52.95 & 0.00 & 0.00 & 0.00 & 0.00 \\
\hline 5250 & 0.00 & 0.00 & 0.00 & 0.00 & 0.00 & 31.96 & 0.01 & 25.18 & 0.00 & 0.00 \\
\hline 6750 & 0.00 & 0.00 & 0.00 & 0.00 & 0.00 & 6.00 & 0.11 & 37.47 & 0.00 & 0.02 \\
\hline 8250 & 0.00 & 0.00 & 0.00 & 4.35 & 40.00 & 1.27 & 0.81 & 7.13 & 0.00 & 0.40 \\
\hline 9750 & 0.00 & 0.00 & 0.00 & 7.61 & 20.00 & 0.17 & 3.45 & 1.60 & 0.00 & 2.11 \\
\hline 11250 & 0.00 & 0.00 & 0.00 & 6.52 & 0.00 & 0.24 & 8.04 & 1.23 & 1.06 & 4.55 \\
\hline 12750 & 0.00 & 0.00 & 0.00 & 5.43 & 0.00 & 0.00 & 14.27 & 1.47 & 1.59 & 9.63 \\
\hline 14250 & 0.00 & 0.00 & 0.00 & 5.43 & 0.00 & 0.03 & 18.94 & 1.60 & 3.17 & 13.79 \\
\hline 15750 & 0.00 & 0.00 & 0.00 & 8.70 & 0.00 & 0.00 & 19.89 & 2.70 & 8.99 & 17.43 \\
\hline 17250 & 0.00 & 0.00 & 0.00 & 9.78 & 0.00 & 0.00 & 15.74 & 6.51 & 17.46 & 18.80 \\
\hline 18750 & 0.00 & 0.00 & 0.00 & 5.43 & 0.00 & 0.03 & 10.03 & 4.30 & 9.52 & 15.22 \\
\hline 20250 & 0.00 & 0.00 & 0.00 & 14.13 & 0.00 & 0.00 & 5.50 & 3.44 & 6.35 & 10.68 \\
\hline 21750 & 0.00 & 0.00 & 0.00 & 14.13 & 0.00 & 0.03 & 2.34 & 2.83 & 11.11 & 4.89 \\
\hline 23250 & 0.00 & 0.00 & 0.00 & 9.78 & 20.00 & 0.00 & 0.66 & 3.32 & 15.34 & 1.58 \\
\hline 24750 & 0.00 & 0.00 & 0.00 & 5.43 & 0.00 & 0.00 & 0.13 & 0.86 & 14.81 & 0.43 \\
\hline 26250 & 0.00 & 0.00 & 0.00 & 2.17 & 0.00 & 0.00 & 0.02 & 0.37 & 7.41 & 0.17 \\
\hline 27750 & 0.00 & 0.00 & 0.00 & 1.09 & 20.00 & 0.00 & 0.01 & 0.00 & 2.65 & 0.12 \\
\hline 29250 & 0.00 & 0.00 & 0.00 & 0.00 & 0.00 & 0.00 & 0.02 & 0.00 & 0.00 & 0.07 \\
\hline 30750 & 0.00 & 0.00 & 0.00 & 0.00 & 0.00 & 0.00 & 0.01 & 0.00 & 0.53 & 0.06 \\
\hline 32250 & 0.00 & 0.00 & 0.00 & 0.00 & 0.00 & 0.00 & 0.00 & 0.00 & 0.00 & 0.03 \\
\hline 33750 & 0.00 & 0.00 & 0.00 & 0.00 & 0.00 & 0.00 & 0.00 & 0.00 & 0.00 & 0.01 \\
\hline 35250 & 0.00 & 0.00 & 0.00 & 0.00 & 0.00 & 0.00 & 0.00 & 0.00 & 0.00 & 0.00 \\
\hline 36750 & 0.00 & 0.00 & 0.00 & 0.00 & 0.00 & 0.00 & 0.00 & 0.00 & 0.00 & 0.00 \\
\hline 38250 & 0.00 & 0.00 & 0.00 & 0.00 & 0.00 & 0.00 & 0.00 & 0.00 & 0.00 & 0.00 \\
\hline 39750 & 0.00 & 0.00 & 0.00 & 0.00 & 0.00 & 0.00 & 0.00 & 0.00 & 0.00 & 0.00 \\
\hline 41250 & 0.00 & 0.00 & 0.00 & 0.00 & 0.00 & 0.00 & 0.00 & 0.00 & 0.00 & 0.00 \\
\hline 42750 & 0.00 & 0.00 & 0.00 & 0.00 & 0.00 & 0.00 & 0.00 & 0.00 & 0.00 & 0.00 \\
\hline 44250 & 0.00 & 0.00 & 0.00 & 0.00 & 0.00 & 0.00 & 0.00 & 0.00 & 0.00 & 0.00 \\
\hline 45750 & 0.00 & 0.00 & 0.00 & 0.00 & 0.00 & 0.00 & 0.00 & 0.00 & 0.00 & 0.00 \\
\hline 47250 & 0.00 & 0.00 & 0.00 & 0.00 & 0.00 & 0.00 & 0.00 & 0.00 & 0.00 & 0.00 \\
\hline 48750 & 0.00 & 0.00 & 0.00 & 0.00 & 0.00 & 0.00 & 0.00 & 0.00 & 0.00 & 0.00 \\
\hline 50250 & 0.00 & 0.00 & 0.00 & 0.00 & 0.00 & 0.00 & 0.00 & 0.00 & 0.00 & 0.00 \\
\hline 51750 & 0.00 & 0.00 & 0.00 & 0.00 & 0.00 & 0.00 & 0.00 & 0.00 & 0.00 & 0.00 \\
\hline 53250 & 0.00 & 0.00 & 0.00 & 0.00 & 0.00 & 0.00 & 0.00 & 0.00 & 0.00 & 0.00 \\
\hline 54750 & 0.00 & 0.00 & 0.00 & 0.00 & 0.00 & 0.00 & 0.00 & 0.00 & 0.00 & 0.00 \\
\hline 56250 & 0.00 & 0.00 & 0.00 & 0.00 & 0.00 & 0.00 & 0.00 & 0.00 & 0.00 & 0.00 \\
\hline 57750 & 0.00 & 0.00 & 0.00 & 0.00 & 0.00 & 0.00 & 0.00 & 0.00 & 0.00 & 0.00 \\
\hline 59250 & 0.00 & 0.00 & 0.00 & 0.00 & 0.00 & 0.00 & 0.00 & 0.00 & 0.00 & 0.00 \\
\hline
\end{tabular}




\section{APPENDIX D: LIFE CYCLE COST ANALYSIS DATA}

Table D.30. Pay Items for Case A-0\% Penetration

\begin{tabular}{|c|c|c|c|c|c|}
\hline Number & Stage & Description & Unit & Quantity & Present Cost (\$) \\
\hline 1 & Material \& Construction & $\begin{array}{l}\text { HOT-MIX ASPHALT } \\
\text { SURFACE COURSE }\end{array}$ & TON & 1531.00 & $\$ 179,417.81$ \\
\hline 2 & $\begin{array}{l}\text { Maintenance \& } \\
\text { Rehabilitation }\end{array}$ & $\begin{array}{l}\text { HOT-MIX ASPHALT } \\
\text { SURFACE COURSE } \\
\text { REPLACEMENT OVER } \\
\text { PATCHES }\end{array}$ & TON & 1530.92 & $\$ 115,155.33$ \\
\hline 3 & $\begin{array}{l}\text { Maintenance \& } \\
\text { Rehabilitation }\end{array}$ & $\begin{array}{l}\text { HOT-MIX ASPHALT } \\
\text { SURFACE COURSE } \\
\text { REPLACEMENT OVER } \\
\text { PATCHES }\end{array}$ & TON & 1530.92 & $\$ 73,913.82$ \\
\hline 4 & $\begin{array}{l}\text { Maintenance \& } \\
\text { Rehabilitation }\end{array}$ & $\begin{array}{l}\text { HOT-MIX ASPHALT } \\
\text { SURFACE COURSE } \\
\text { REPLACEMENT OVER } \\
\text { PATCHES }\end{array}$ & TON & 1530.92 & $\$ 47,442.47$ \\
\hline 5 & $\begin{array}{c}\text { Maintenance \& } \\
\text { Rehabilitation }\end{array}$ & EPOXY PVT MK LINE 6 & FOOT & 10560.00 & $\$ 7,000.84$ \\
\hline 6 & $\begin{array}{c}\text { Maintenance \& } \\
\text { Rehabilitation }\end{array}$ & EPOXY PVT MK LINE 6 & FOOT & 10560.00 & $\$ 4,493.57$ \\
\hline 7 & $\begin{array}{c}\text { Maintenance \& } \\
\text { Rehabilitation }\end{array}$ & EPOXY PVT MK LINE 4 & FOOT & 10560.00 & $\$ 3,843.60$ \\
\hline 8 & $\begin{array}{c}\text { Maintenance \& } \\
\text { Rehabilitation }\end{array}$ & EPOXY PVT MK LINE 6 & FOOT & 10560.00 & $\$ 2,884.25$ \\
\hline 9 & $\begin{array}{c}\text { Maintenance \& } \\
\text { Rehabilitation }\end{array}$ & EPOXY PVT MK LINE 4 & FOOT & 10560.00 & $\$ 2,467.06$ \\
\hline 10 & $\begin{array}{l}\text { Maintenance \& } \\
\text { Rehabilitation }\end{array}$ & $\begin{array}{l}\text { HOT-MIX ASPHALT } \\
\text { SURFACE COURSE } \\
\text { REPLACEMENT OVER } \\
\text { PATCHES }\end{array}$ & TON & 102.11 & $\$ 2,031.12$ \\
\hline 11 & $\begin{array}{c}\text { Maintenance \& } \\
\text { Rehabilitation }\end{array}$ & EPOXY PVT MK LINE 4 & FOOT & 10560.00 & $\$ 1,583.51$ \\
\hline 12 & $\begin{array}{l}\text { Maintenance \& } \\
\text { Rehabilitation }\end{array}$ & $\begin{array}{l}\text { BITUMINOUS } \\
\text { MATERIALS } \\
\text { (PRIME COAT) }\end{array}$ & GAL & 234.67 & $\$ 158.62$ \\
\hline 13 & $\begin{array}{c}\text { Maintenance \& } \\
\text { Rehabilitation }\end{array}$ & EPOXY PVT MK LINE 6 & FOOT & 704.35 & $\$ 123.48$ \\
\hline 14 & $\begin{array}{l}\text { Maintenance \& } \\
\text { Rehabilitation }\end{array}$ & $\begin{array}{l}\text { BITUMINOUS } \\
\text { MATERIALS } \\
\text { (PRIME COAT) }\end{array}$ & GAL & 234.67 & $\$ 101.82$ \\
\hline 15 & $\begin{array}{l}\text { Maintenance \& } \\
\text { Rehabilitation }\end{array}$ & EPOXY PVT MK LINE 4 & FOOT & 704.35 & $\$ 67.79$ \\
\hline 16 & $\begin{array}{c}\text { Maintenance \& } \\
\text { Rehabilitation }\end{array}$ & $\begin{array}{l}\text { BITUMINOUS } \\
\text { MATERIALS } \\
\text { (PRIME COAT) }\end{array}$ & GAL & 234.67 & $\$ 65.35$ \\
\hline 17 & $\begin{array}{l}\text { Maintenance \& } \\
\text { Rehabilitation }\end{array}$ & $\begin{array}{l}\text { BITUMINOUS } \\
\text { MATERIALS } \\
\text { (PRIME COAT) }\end{array}$ & GAL & 15.65 & $\$ 2.80$ \\
\hline 18 & Material \& Construction & $\begin{array}{l}\text { HOT-MIX ASPHALT } \\
\text { SURFACE REMOVAL }\end{array}$ & SQ YD & 14080.00 & $\$ 0.00$ \\
\hline
\end{tabular}




\begin{tabular}{|c|c|c|c|c|c|}
\hline Number & Stage & Description & Unit & Quantity & Present Cost (\$) \\
\hline 19 & $\begin{array}{c}\text { Maintenance \& } \\
\text { Rehabilitation }\end{array}$ & $\begin{array}{l}\text { HOT-MIX ASPHALT } \\
\text { REMOVAL OVER } \\
\text { PATCHES, 2" }\end{array}$ & SQ YD & 14080.00 & $\$ 0.00$ \\
\hline 20 & $\begin{array}{c}\text { Maintenance \& } \\
\text { Rehabilitation }\end{array}$ & $\begin{array}{l}\text { HOT-MIX ASPHALT } \\
\text { REMOVAL OVER } \\
\text { PATCHES, 2" }\end{array}$ & SQ YD & 14080.00 & $\$ 0.00$ \\
\hline 21 & $\begin{array}{c}\text { Maintenance \& } \\
\text { Rehabilitation }\end{array}$ & $\begin{array}{l}\text { HOT-MIX ASPHALT } \\
\text { REMOVAL OVER } \\
\text { PATCHES, 2" }\end{array}$ & SQ YD & 14080.00 & $\$ 0.00$ \\
\hline 22 & $\begin{array}{c}\text { Maintenance \& } \\
\text { Rehabilitation }\end{array}$ & $\begin{array}{l}\text { HOT-MIX ASPHALT } \\
\text { REMOVAL OVER } \\
\text { PATCHES, 2" }\end{array}$ & SQ YD & 939.14 & $\$ 0.00$ \\
\hline
\end{tabular}

Table D.31. Fuel Cost for Case A-0\% Penetration

\begin{tabular}{|c|c|c|c|c|c|c|}
\hline \multirow[b]{2}{*}{ Year } & \multicolumn{2}{|c|}{ Passenger } & \multicolumn{2}{|c|}{ Medium Truck } & \multicolumn{2}{|c|}{ Large Truck } \\
\hline & Fuel (gal) & Present Cost (\$) & Fuel (gal) & Present Cost (\$) & Fuel (gal) & Present Cost (\$) \\
\hline 0 & 192886.0 & 496483.0 & 14072.0 & 38573.5 & 70577.7 & 193463.9 \\
\hline 1 & 195043.9 & 487414.8 & 14207.3 & 37810.1 & 71274.7 & 189684.0 \\
\hline 2 & 197267.3 & 478612.8 & 14347.6 & 37071.3 & 72000.6 & 186034.8 \\
\hline 3 & 199532.6 & 470008.6 & 14490.9 & 36351.0 & 72743.0 & 182478.8 \\
\hline 4 & 201837.9 & 461591.2 & 14636.6 & 35647.0 & 73499.2 & 179005.5 \\
\hline 5 & 204182.5 & 453352.5 & 14784.4 & 34958.3 & 74267.8 & 175609.1 \\
\hline 6 & 206405.1 & 444939.4 & 14931.3 & 34277.4 & 75020.4 & 172222.1 \\
\hline 7 & 208648.8 & 436675.7 & 15079.9 & 33610.2 & 75781.5 & 168902.1 \\
\hline 8 & 210928.1 & 428588.4 & 15230.4 & 32956.9 & 76553.2 & 165652.6 \\
\hline 9 & 213243.3 & 420672.4 & 15382.8 & 32317.1 & 77335.6 & 162471.5 \\
\hline 10 & 215594.6 & 412923.3 & 15537.0 & 31690.4 & 78128.6 & 159356.8 \\
\hline 11 & 217982.5 & 405336.6 & 15693.1 & 31076.5 & 78932.2 & 156306.7 \\
\hline 12 & 220407.4 & 397908.4 & 15851.1 & 30475.1 & 79746.6 & 153319.7 \\
\hline 13 & 222869.8 & 390634.8 & 16011.0 & 29885.9 & 80571.6 & 150394.1 \\
\hline 14 & 225402.2 & 383566.5 & 16173.3 & 29309.7 & 81413.1 & 147538.6 \\
\hline 15 & 223934.7 & 369970.1 & 16290.1 & 28661.5 & 81702.5 & 143750.6 \\
\hline 16 & 226666.9 & 363576.8 & 16452.5 & 28104.0 & 82556.4 & 141022.2 \\
\hline 17 & 229289.0 & 357070.6 & 16616.8 & 27557.9 & 83409.3 & 138329.4 \\
\hline 18 & 231961.7 & 350711.4 & 16784.3 & 27025.0 & 84280.9 & 135703.7 \\
\hline 19 & 234683.6 & 344492.1 & 16954.6 & 26504.1 & 85168.4 & 133138.6 \\
\hline 20 & 237353.5 & 338263.3 & 17125.6 & 25991.6 & 86053.1 & 130603.5 \\
\hline 21 & 239968.1 & 332028.6 & 17297.0 & 25487.2 & 86934.0 & 128097.6 \\
\hline 22 & 242627.5 & 325930.3 & 17470.8 & 24993.4 & 87828.1 & 125645.5 \\
\hline 23 & 245331.9 & 319964.3 & 17646.7 & 24509.8 & 88735.0 & 123245.6 \\
\hline 24 & 248081.7 & 314126.8 & 17824.9 & 24036.2 & 89654.9 & 120896.3 \\
\hline 25 & 250877.3 & 308414.3 & 18005.3 & 23572.4 & 90587.6 & 118596.2 \\
\hline 26 & 253719.4 & 302823.4 & 18188.0 & 23118.0 & 91533.3 & 116344.1 \\
\hline 27 & 256608.4 & 297351.1 & 18372.9 & 22672.8 & 92492.1 & 114138.6 \\
\hline 28 & 259545.2 & 291994.3 & 18560.1 & 22236.7 & 93464.1 & 111978.6 \\
\hline 29 & 262572.6 & 286796.3 & 18750.3 & 21810.3 & 94456.6 & 109871.6 \\
\hline 30 & 259981.2 & 275695.0 & 18865.3 & 21304.9 & 94618.1 & 106853.9 \\
\hline 31 & 263189.3 & 270967.9 & 19055.5 & 20892.9 & 95621.0 & 104841.2 \\
\hline 32 & 266265.3 & 266150.3 & 19247.4 & 20488.7 & 96620.0 & 102851.0 \\
\hline
\end{tabular}




\begin{tabular}{|c|c|c|c|c|c|c|}
\hline \multirow[b]{2}{*}{ Year } & \multicolumn{2}{|c|}{ Passenger } & \multicolumn{2}{|c|}{ Medium Truck } & \multicolumn{2}{|c|}{ Large Truck } \\
\hline & Fuel (gal) & Present Cost (\$) & Fuel (gal) & Present Cost (\$) & Fuel (gal) & Present Cost (\$) \\
\hline 33 & 269406.7 & 261447.0 & 19443.1 & 20094.2 & 97640.8 & 100910.3 \\
\hline 34 & 272611.6 & 256851.7 & 19642.0 & 19708.5 & 98680.6 & 99014.5 \\
\hline 35 & 275762.0 & 252252.4 & 19841.7 & 19329.0 & 99718.0 & 97141.1 \\
\hline 36 & 278854.2 & 247651.4 & 20042.1 & 18955.5 & 100751.7 & 95289.4 \\
\hline 37 & 282004.2 & 243154.3 & 20245.1 & 18589.8 & 101801.4 & 93477.9 \\
\hline 38 & 285212.2 & 238757.7 & 20450.8 & 18231.8 & 102867.1 & 91705.3 \\
\hline 39 & 288478.8 & 234458.4 & 20659.2 & 17881.2 & 103948.6 & 89970.4 \\
\hline 40 & 291804.5 & 230253.8 & 20870.3 & 17537.7 & 105046.1 & 88272.1 \\
\hline 41 & 295190.1 & 226140.9 & 21084.1 & 17201.3 & 106159.6 & 86609.6 \\
\hline 42 & 298636.2 & 222117.5 & 21300.6 & 16871.8 & 107289.2 & 84981.7 \\
\hline 43 & 302143.8 & 218180.9 & 21519.8 & 16548.9 & 108435.2 & 83387.7 \\
\hline 44 & 305769.6 & 214368.1 & 21742.8 & 16233.4 & 109607.2 & 81834.0 \\
\hline 45 & 301830.1 & 205442.9 & 21855.0 & 15841.9 & 109612.7 & 79454.5 \\
\hline 46 & 305606.5 & 201954.7 & 22077.8 & 15537.3 & 110791.5 & 77969.9 \\
\hline 47 & 309223.6 & 198393.2 & 22302.2 & 15238.1 & 111962.3 & 76498.9 \\
\hline 48 & 312926.5 & 194921.2 & 22530.8 & 14945.9 & 113159.3 & 75064.8 \\
\hline 49 & 316712.1 & 191533.3 & 22763.3 & 14660.3 & 114379.5 & 73664.2 \\
\hline 50 & 320443.2 & 188145.3 & 22996.7 & 14379.3 & 115597.9 & 72280.6 \\
\hline 51 & 324115.2 & 184758.6 & 23231.1 & 14102.7 & 116813.4 & 70913.2 \\
\hline 52 & 327862.7 & 181451.3 & 23468.7 & 13832.0 & 118048.8 & 69575.9 \\
\hline 53 & 331686.1 & 178220.7 & 23709.5 & 13567.0 & 119304.0 & 68267.6 \\
\hline 54 & 335585.9 & 175064.1 & 23953.6 & 13307.4 & 120579.1 & 66987.6 \\
\hline 55 & 339562.7 & 171979.4 & 24201.0 & 13053.2 & 121874.0 & 65734.9 \\
\hline 56 & 343617.6 & 168964.1 & 24451.6 & 12804.3 & 123188.9 & 64508.9 \\
\hline 57 & 347751.6 & 166016.4 & 24705.5 & 12560.4 & 124523.9 & 63308.7 \\
\hline 58 & 351965.6 & 163134.2 & 24962.7 & 12321.6 & 125879.4 & 62133.9 \\
\hline 59 & 356335.5 & 160349.1 & 25224.7 & 12088.2 & 127268.3 & 60989.7 \\
\hline 60 & 350415.4 & 153092.3 & 25325.9 & 11783.2 & 127021.0 & 59098.3 \\
\hline
\end{tabular}

Table D.32. Pay Items for Case A-5\% Penetration

\begin{tabular}{|c|c|c|c|c|c|}
\hline Number & Stage & Description & Unit & Quantity & Present Cost (\$) \\
\hline 1 & Material \& Construction & $\begin{array}{l}\text { HOT-MIX ASPHALT SURFACE } \\
\text { COURSE }\end{array}$ & TON & 1531.00 & $\$ 179,417.81$ \\
\hline 2 & $\begin{array}{l}\text { Maintenance \& } \\
\text { Rehabilitation }\end{array}$ & $\begin{array}{c}\text { HOT-MIX ASPHALT SURFACE } \\
\text { COURSE REPLACEMENT OVER } \\
\text { PATCHES }\end{array}$ & TON & 1530.92 & $\$ 115,155.33$ \\
\hline 3 & $\begin{array}{l}\text { Maintenance \& } \\
\text { Rehabilitation }\end{array}$ & $\begin{array}{c}\text { HOT-MIX ASPHALT SURFACE } \\
\text { COURSE REPLACEMENT OVER } \\
\text { PATCHES }\end{array}$ & TON & 1530.92 & $\$ 73,913.82$ \\
\hline 4 & $\begin{array}{l}\text { Maintenance \& } \\
\text { Rehabilitation }\end{array}$ & $\begin{array}{c}\text { HOT-MIX ASPHALT SURFACE } \\
\text { COURSE REPLACEMENT OVER } \\
\text { PATCHES }\end{array}$ & TON & 1530.92 & $\$ 47,442.47$ \\
\hline 5 & $\begin{array}{c}\text { Maintenance \& } \\
\text { Rehabilitation }\end{array}$ & EPOXY PVT MK LINE 6 & FOOT & 10560.00 & $\$ 7,000.84$ \\
\hline 6 & $\begin{array}{l}\text { Maintenance \& } \\
\text { Rehabilitation }\end{array}$ & EPOXY PVT MK LINE 6 & FOOT & 10560.00 & $\$ 4,493.57$ \\
\hline 7 & $\begin{array}{l}\text { Maintenance \& } \\
\text { Rehabilitation }\end{array}$ & EPOXY PVT MK LINE 4 & FOOT & 10560.00 & $\$ 3,843.60$ \\
\hline
\end{tabular}




\begin{tabular}{|c|c|c|c|c|c|}
\hline Number & Stage & Description & Unit & Quantity & Present Cost (\$) \\
\hline 8 & $\begin{array}{c}\text { Maintenance \& } \\
\text { Rehabilitation }\end{array}$ & EPOXY PVT MK LINE 6 & FOOT & 10560.00 & $\$ 2,884.25$ \\
\hline 9 & $\begin{array}{l}\text { Maintenance \& } \\
\text { Rehabilitation }\end{array}$ & EPOXY PVT MK LINE 4 & FOOT & 10560.00 & $\$ 2,467.06$ \\
\hline 10 & $\begin{array}{l}\text { Maintenance \& } \\
\text { Rehabilitation }\end{array}$ & $\begin{array}{c}\text { HOT-MIX ASPHALT SURFACE } \\
\text { COURSE REPLACEMENT OVER } \\
\text { PATCHES }\end{array}$ & TON & 102.11 & $\$ 2,031.12$ \\
\hline 11 & $\begin{array}{l}\text { Maintenance \& } \\
\text { Rehabilitation }\end{array}$ & EPOXY PVT MK LINE 4 & FOOT & 10560.00 & $\$ 1,583.51$ \\
\hline 12 & $\begin{array}{l}\text { Maintenance \& } \\
\text { Rehabilitation }\end{array}$ & $\begin{array}{c}\text { BITUMINOUS MATERIALS } \\
\text { (PRIME COAT) }\end{array}$ & GAL & 234.67 & $\$ 158.62$ \\
\hline 13 & $\begin{array}{c}\text { Maintenance \& } \\
\text { Rehabilitation }\end{array}$ & EPOXY PVT MK LINE 6 & FOOT & 704.35 & $\$ 123.48$ \\
\hline 14 & $\begin{array}{l}\text { Maintenance \& } \\
\text { Rehabilitation }\end{array}$ & $\begin{array}{l}\text { BITUMINOUS MATERIALS } \\
\text { (PRIME COAT) }\end{array}$ & GAL & 234.67 & $\$ 101.82$ \\
\hline 15 & $\begin{array}{l}\text { Maintenance \& } \\
\text { Rehabilitation }\end{array}$ & EPOXY PVT MK LINE 4 & FOOT & 704.35 & $\$ 67.79$ \\
\hline 16 & $\begin{array}{l}\text { Maintenance \& } \\
\text { Rehabilitation }\end{array}$ & $\begin{array}{l}\text { BITUMINOUS MATERIALS } \\
\text { (PRIME COAT) }\end{array}$ & GAL & 234.67 & $\$ 65.35$ \\
\hline 17 & $\begin{array}{l}\text { Maintenance \& } \\
\text { Rehabilitation }\end{array}$ & $\begin{array}{c}\text { BITUMINOUS MATERIALS } \\
\text { (PRIME COAT) }\end{array}$ & GAL & 15.65 & $\$ 2.80$ \\
\hline 18 & Material \& Construction & $\begin{array}{c}\text { HOT-MIX ASPHALT SURFACE } \\
\text { REMOVAL }\end{array}$ & SQ YD & 14080.00 & $\$ 0.00$ \\
\hline 19 & $\begin{array}{l}\text { Maintenance \& } \\
\text { Rehabilitation }\end{array}$ & $\begin{array}{c}\text { HOT-MIX ASPHALT REMOVAL } \\
\text { OVER PATCHES, 2" }\end{array}$ & SQ YD & 14080.00 & $\$ 0.00$ \\
\hline 20 & $\begin{array}{l}\text { Maintenance \& } \\
\text { Rehabilitation }\end{array}$ & $\begin{array}{c}\text { HOT-MIX ASPHALT REMOVAL } \\
\text { OVER PATCHES, 2" }\end{array}$ & SQ YD & 14080.00 & $\$ 0.00$ \\
\hline 21 & $\begin{array}{l}\text { Maintenance \& } \\
\text { Rehabilitation }\end{array}$ & $\begin{array}{c}\text { HOT-MIX ASPHALT REMOVAL } \\
\text { OVER PATCHES, 2" }\end{array}$ & SQ YD & 14080.00 & $\$ 0.00$ \\
\hline 22 & $\begin{array}{l}\text { Maintenance \& } \\
\text { Rehabilitation }\end{array}$ & $\begin{array}{c}\text { HOT-MIX ASPHALT REMOVAL } \\
\text { OVER PATCHES, 2" }\end{array}$ & SQ YD & 939.14 & $\$ 0.00$ \\
\hline
\end{tabular}

Table D.33. Fuel Cost for Case A-5\% Penetration

\begin{tabular}{|c|c|c|c|c|c|c|}
\hline \multirow[b]{2}{*}{ Year } & \multicolumn{2}{|c|}{ Passenger } & \multicolumn{2}{|c|}{ Medium Truck } & \multicolumn{2}{|c|}{ Large Truck } \\
\hline & Fuel (gal) & Present Cost (\$) & Fuel (gal) & Present Cost (\$) & Fuel (gal) & Present Cost (\$) \\
\hline 0 & 192886.0 & 496483.0 & 14072.0 & 38557.1 & 70577.7 & 193004.3 \\
\hline 1 & 195044.2 & 487415.8 & 14207.3 & 37794.0 & 71274.7 & 189233.6 \\
\hline 2 & 197268.4 & 478615.4 & 14347.7 & 37055.7 & 72000.8 & 185593.3 \\
\hline 3 & 199534.7 & 470013.5 & 14490.9 & 36335.6 & 72743.4 & 182046.2 \\
\hline 4 & 201841.2 & 461598.7 & 14636.6 & 35632.0 & 73499.8 & 178581.6 \\
\hline 5 & 204187.2 & 453363.0 & 14784.5 & 34943.7 & 74268.6 & 175193.9 \\
\hline 6 & 206411.5 & 444953.1 & 14931.4 & 34263.1 & 75021.5 & 171815.5 \\
\hline 7 & 208657.0 & 436692.9 & 15080.1 & 33596.3 & 75782.9 & 168504.0 \\
\hline 8 & 210938.3 & 428609.1 & 15230.6 & 32943.3 & 76555.0 & 165262.9 \\
\hline 9 & 213255.7 & 420696.9 & 15383.0 & 32303.9 & 77337.8 & 162090.0 \\
\hline 10 & 215609.5 & 412951.7 & 15537.3 & 31677.5 & 78131.2 & 158983.4 \\
\hline 11 & 218000.0 & 405369.2 & 15693.4 & 31064.0 & 78935.3 & 155941.4 \\
\hline 12 & 220427.7 & 397945.1 & 15851.5 & 30462.9 & 79750.1 & 152962.2 \\
\hline 13 & 222893.1 & 390675.7 & 16011.4 & 29874.0 & 80575.7 & 150044.4 \\
\hline 14 & 225429.0 & 383612.2 & 16173.8 & 29298.2 & 81417.7 & 147196.5 \\
\hline
\end{tabular}




\begin{tabular}{|c|c|c|c|c|c|c|}
\hline \multirow[b]{2}{*}{ Year } & \multicolumn{2}{|c|}{ Passenger } & \multicolumn{2}{|c|}{ Medium Truck } & \multicolumn{2}{|c|}{ Large Truck } \\
\hline & Fuel (gal) & Present Cost (\$) & Fuel (gal) & Present Cost (\$) & Fuel (gal) & Present Cost (\$) \\
\hline 15 & 223934.7 & 369970.1 & 16290.1 & 28649.3 & 81702.5 & 143409.1 \\
\hline 16 & 226668.3 & 363579.1 & 16452.5 & 28092.1 & 82556.6 & 140687.7 \\
\hline 17 & 229291.8 & 357075.0 & 16616.8 & 27546.3 & 83409.8 & 138001.6 \\
\hline 18 & 231966.2 & 350718.2 & 16784.4 & 27013.7 & 84281.7 & 135382.6 \\
\hline 19 & 234690.2 & 344501.7 & 16954.7 & 26493.0 & 85169.5 & 132824.1 \\
\hline 20 & 237362.3 & 338275.8 & 17125.7 & 25980.8 & 86054.7 & 130295.6 \\
\hline 21 & 239979.5 & 332044.4 & 17297.2 & 25476.7 & 86936.0 & 127796.2 \\
\hline 22 & 242641.7 & 325949.5 & 17471.0 & 24983.2 & 87830.5 & 125350.6 \\
\hline 23 & 245349.3 & 319987.0 & 17647.0 & 24499.9 & 88738.0 & 122957.0 \\
\hline 24 & 248102.5 & 314153.2 & 17825.3 & 24026.6 & 89658.5 & 120614.0 \\
\hline 25 & 250901.8 & 308444.4 & 18005.8 & 23562.9 & 90591.9 & 118320.0 \\
\hline 26 & 253747.9 & 302857.5 & 18188.5 & 23108.8 & 91538.3 & 116073.9 \\
\hline 27 & 256641.2 & 297389.1 & 18373.5 & 22663.9 & 92497.8 & 113874.4 \\
\hline 28 & 259582.5 & 292036.3 & 18560.7 & 22228.0 & 93470.5 & 111720.3 \\
\hline 29 & 262615.2 & 286842.9 & 18751.1 & 21801.9 & 94464.0 & 109619.1 \\
\hline 30 & 259981.2 & 275695.0 & 18865.3 & 21295.8 & 94618.1 & 106600.0 \\
\hline 31 & 263191.4 & 270970.1 & 19055.5 & 20884.1 & 95621.4 & 104592.6 \\
\hline 32 & 266269.4 & 266154.5 & 19247.5 & 20480.1 & 96620.7 & 102607.4 \\
\hline 33 & 269413.3 & 261453.4 & 19443.3 & 20085.8 & 97641.9 & 100671.7 \\
\hline 34 & 272621.1 & 256860.6 & 19642.2 & 19700.3 & 98682.2 & 98780.9 \\
\hline 35 & 275774.9 & 252264.1 & 19842.0 & 19321.0 & 99720.2 & 96912.5 \\
\hline 36 & 278870.8 & 247666.2 & 20042.4 & 18947.7 & 100754.5 & 95065.8 \\
\hline 37 & 282025.0 & 243172.2 & 20245.5 & 18582.3 & 101805.0 & 93259.2 \\
\hline 38 & 285237.6 & 238778.9 & 20451.3 & 18224.5 & 102871.5 & 91491.4 \\
\hline 39 & 288509.1 & 234483.1 & 20659.8 & 17874.0 & 103953.9 & 89761.2 \\
\hline 40 & 291840.2 & 230281.9 & 20871.0 & 17530.8 & 105052.3 & 88067.6 \\
\hline 41 & 295231.6 & 226172.7 & 21084.9 & 17194.6 & 106166.8 & 86409.6 \\
\hline 42 & 298683.9 & 222152.9 & 21301.5 & 16865.3 & 107297.5 & 84786.3 \\
\hline 43 & 302198.1 & 218220.1 & 21520.8 & 16542.7 & 108444.5 & 83196.8 \\
\hline 44 & 305831.5 & 214411.5 & 21743.9 & 16227.4 & 109617.9 & 81647.6 \\
\hline 45 & 301830.1 & 205442.9 & 21855.0 & 15835.2 & 109612.7 & 79265.8 \\
\hline 46 & 305609.6 & 201956.7 & 22077.9 & 15530.8 & 110792.0 & 77785.0 \\
\hline 47 & 309229.7 & 198397.1 & 22302.3 & 15231.7 & 111963.3 & 76317.8 \\
\hline 48 & 312936.1 & 194927.2 & 22531.0 & 14939.7 & 113161.0 & 74887.6 \\
\hline 49 & 316725.9 & 191541.7 & 22763.5 & 14654.2 & 114381.9 & 73490.8 \\
\hline 50 & 320461.9 & 188156.3 & 22997.1 & 14373.4 & 115601.2 & 72110.9 \\
\hline 51 & 324139.4 & 184772.4 & 23231.5 & 14097.0 & 116817.6 & 70747.3 \\
\hline 52 & 327893.0 & 181468.0 & 23469.2 & 13826.5 & 118054.1 & 69413.7 \\
\hline 53 & 331723.0 & 178240.5 & 23710.2 & 13561.6 & 119310.4 & 68109.1 \\
\hline 54 & 335630.0 & 175087.2 & 23954.5 & 13302.2 & 120586.7 & 66832.7 \\
\hline 55 & 339614.7 & 172005.7 & 24201.9 & 13048.2 & 121882.9 & 65583.6 \\
\hline 56 & 343678.0 & 168993.8 & 24452.7 & 12799.4 & 123199.3 & 64361.1 \\
\hline 57 & 347821.0 & 166049.5 & 24706.8 & 12555.7 & 124535.9 & 63164.4 \\
\hline 58 & 352044.7 & 163170.8 & 24964.2 & 12317.0 & 125893.1 & 61993.0 \\
\hline 59 & 356425.5 & 160389.6 & 25226.3 & 12083.9 & 127283.9 & 60852.3 \\
\hline 60 & 350415.4 & 153092.3 & 25325.9 & 11778.2 & 127021.0 & 58957.9 \\
\hline
\end{tabular}


Table D.34. Pay Items for Case A-10\% Penetration

\begin{tabular}{|c|c|c|c|c|c|}
\hline Number & Stage & Description & Unit & Quantity & Present Cost (\$) \\
\hline 1 & Material \& Construction & $\begin{array}{l}\text { HOT-MIX ASPHALT SURFACE } \\
\text { COURSE }\end{array}$ & TON & 1531.00 & $\$ 179,417.81$ \\
\hline 2 & Maintenance \& Rehabilitation & $\begin{array}{c}\text { HOT-MIX ASPHALT SURFACE } \\
\text { COURSE REPLACEMENT OVER } \\
\text { PATCHES }\end{array}$ & TON & 1530.92 & $\$ 115,155.33$ \\
\hline 3 & Maintenance \& Rehabilitation & $\begin{array}{c}\text { HOT-MIX ASPHALT SURFACE } \\
\text { COURSE REPLACEMENT OVER } \\
\text { PATCHES }\end{array}$ & TON & 1530.92 & $\$ 73,913.82$ \\
\hline 4 & Maintenance \& Rehabilitation & $\begin{array}{c}\text { HOT-MIX ASPHALT SURFACE } \\
\text { COURSE REPLACEMENT OVER } \\
\text { PATCHES }\end{array}$ & TON & 1530.92 & $\$ 47,442.47$ \\
\hline 5 & Maintenance \& Rehabilitation & EPOXY PVT MK LINE 6 & FOOT & 10560.00 & $\$ 7,000.84$ \\
\hline 6 & Maintenance \& Rehabilitation & EPOXY PVT MK LINE 6 & FOOT & 10560.00 & $\$ 4,493.57$ \\
\hline 7 & Maintenance \& Rehabilitation & EPOXY PVT MK LINE 4 & FOOT & 10560.00 & $\$ 3,843.60$ \\
\hline 8 & Maintenance \& Rehabilitation & EPOXY PVT MK LINE 6 & FOOT & 10560.00 & $\$ 2,884.25$ \\
\hline 9 & Maintenance \& Rehabilitation & EPOXY PVT MK LINE 4 & FOOT & 10560.00 & $\$ 2,467.06$ \\
\hline 10 & Maintenance \& Rehabilitation & $\begin{array}{c}\text { HOT-MIX ASPHALT SURFACE } \\
\text { COURSE REPLACEMENT OVER } \\
\text { PATCHES }\end{array}$ & TON & 102.11 & $\$ 2,031.12$ \\
\hline 11 & Maintenance \& Rehabilitation & EPOXY PVT MK LINE 4 & FOOT & 10560.00 & $\$ 1,583.51$ \\
\hline 12 & Maintenance \& Rehabilitation & $\begin{array}{l}\text { BITUMINOUS MATERIALS } \\
\text { (PRIME COAT) }\end{array}$ & GAL & 234.67 & $\$ 158.62$ \\
\hline 13 & Maintenance \& Rehabilitation & EPOXY PVT MK LINE 6 & FOOT & 704.35 & $\$ 123.48$ \\
\hline 14 & Maintenance \& Rehabilitation & $\begin{array}{l}\text { BITUMINOUS MATERIALS } \\
\text { (PRIME COAT) }\end{array}$ & GAL & 234.67 & $\$ 101.82$ \\
\hline 15 & Maintenance \& Rehabilitation & EPOXY PVT MK LINE 4 & FOOT & 704.35 & $\$ 67.79$ \\
\hline 16 & Maintenance \& Rehabilitation & $\begin{array}{l}\text { BITUMINOUS MATERIALS } \\
\text { (PRIME COAT) }\end{array}$ & GAL & 234.67 & $\$ 65.35$ \\
\hline 17 & Maintenance \& Rehabilitation & $\begin{array}{l}\text { BITUMINOUS MATERIALS } \\
\text { (PRIME COAT) }\end{array}$ & GAL & 15.65 & $\$ 2.80$ \\
\hline 18 & Material \& Construction & $\begin{array}{l}\text { HOT-MIX ASPHALT SURFACE } \\
\text { REMOVAL }\end{array}$ & SQ YD & 14080.00 & $\$ 0.00$ \\
\hline 19 & Maintenance \& Rehabilitation & $\begin{array}{c}\text { HOT-MIX ASPHALT REMOVAL } \\
\text { OVER PATCHES, 2" }\end{array}$ & SQ YD & 14080.00 & $\$ 0.00$ \\
\hline 20 & Maintenance \& Rehabilitation & $\begin{array}{c}\text { HOT-MIX ASPHALT REMOVAL } \\
\text { OVER PATCHES, 2" }\end{array}$ & SQ YD & 14080.00 & $\$ 0.00$ \\
\hline 21 & Maintenance \& Rehabilitation & $\begin{array}{l}\text { HOT-MIX ASPHALT REMOVAL } \\
\text { OVER PATCHES, 2" }\end{array}$ & SQ YD & 14080.00 & $\$ 0.00$ \\
\hline 22 & Maintenance \& Rehabilitation & $\begin{array}{c}\text { HOT-MIX ASPHALT REMOVAL } \\
\text { OVER PATCHES, 2" }\end{array}$ & SQ YD & 939.14 & $\$ 0.00$ \\
\hline
\end{tabular}


Table D.35. Fuel Cost for Case A-10\% Penetration

\begin{tabular}{|c|c|c|c|c|c|c|}
\hline Year & Fuel (gal) & Present Cost (\$) & Fuel (gal) & Present Cost (\$) & Fuel (gal) & Present Cost (\$) \\
\hline 0 & 192886.0 & 496483.0 & 14072.0 & 38540.7 & 70577.7 & 192544.7 \\
\hline 1 & 195044.6 & 487416.7 & 14207.3 & 37778.0 & 71274.8 & 188783.2 \\
\hline 2 & 197269.5 & 478618.1 & 14347.7 & 37040.0 & 72000.9 & 185151.9 \\
\hline 3 & 199536.8 & 470018.5 & 14491.0 & 36320.3 & 72743.7 & 181613.6 \\
\hline 4 & 201844.5 & 461606.3 & 14636.7 & 35617.0 & 73500.3 & 178157.8 \\
\hline 5 & 204192.0 & 453373.6 & 14784.6 & 34929.0 & 74269.4 & 174778.7 \\
\hline 6 & 206417.9 & 444966.9 & 14931.6 & 34248.8 & 75022.6 & 171408.9 \\
\hline 7 & 208665.2 & 436710.1 & 15080.2 & 33582.3 & 75784.3 & 168106.0 \\
\hline 8 & 210948.6 & 428630.0 & 15230.8 & 32929.7 & 76556.8 & 164873.2 \\
\hline 9 & 213268.2 & 420721.6 & 15383.2 & 32290.6 & 77339.9 & 161708.6 \\
\hline 10 & 215624.4 & 412980.4 & 15537.6 & 31664.6 & 78133.8 & 158610.1 \\
\hline 11 & 218017.6 & 405401.9 & 15693.8 & 31051.4 & 78938.3 & 155576.0 \\
\hline 12 & 220448.1 & 397982.0 & 15851.9 & 30450.7 & 79753.6 & 152604.7 \\
\hline 13 & 222916.6 & 390716.8 & 16011.8 & 29862.1 & 80579.7 & 149694.6 \\
\hline 14 & 225456.0 & 383658.0 & 16174.3 & 29286.6 & 81422.4 & 146854.4 \\
\hline 15 & 223934.7 & 369970.1 & 16290.1 & 28637.1 & 81702.5 & 143067.6 \\
\hline 16 & 226669.8 & 363581.4 & 16452.5 & 28080.2 & 82556.9 & 140353.1 \\
\hline 17 & 229294.7 & 357079.4 & 16616.9 & 27534.7 & 83410.3 & 137673.8 \\
\hline 18 & 231970.7 & 350725.1 & 16784.5 & 27002.3 & 84282.5 & 135061.5 \\
\hline 19 & 234696.7 & 344511.3 & 16954.9 & 26482.0 & 85170.7 & 132509.5 \\
\hline 20 & 237371.2 & 338288.5 & 17125.9 & 25970.0 & 86056.2 & 129987.7 \\
\hline 21 & 239991.0 & 332060.2 & 17297.4 & 25466.2 & 86938.0 & 127494.8 \\
\hline 22 & 242656.1 & 325968.7 & 17471.3 & 24972.9 & 87833.0 & 125055.6 \\
\hline 23 & 245366.8 & 320009.8 & 17647.4 & 24489.9 & 88741.0 & 122668.4 \\
\hline 24 & 248123.4 & 314179.6 & 17825.7 & 24016.9 & 89662.1 & 120331.6 \\
\hline 25 & 250926.5 & 308474.7 & 18006.2 & 23553.5 & 90596.1 & 118043.9 \\
\hline 26 & 253776.5 & 302891.7 & 18189.0 & 23099.7 & 91543.2 & 115803.8 \\
\hline 27 & 256674.2 & 297427.3 & 18374.1 & 22655.0 & 92503.5 & 113610.2 \\
\hline 28 & 259620.1 & 292078.6 & 18561.4 & 22219.4 & 93477.0 & 111462.0 \\
\hline 29 & 262658.0 & 286889.6 & 18751.8 & 21793.6 & 94471.3 & 109366.7 \\
\hline 30 & 259981.2 & 275695.0 & 18865.3 & 21286.8 & 94618.1 & 106346.2 \\
\hline 31 & 263193.5 & 270972.3 & 19055.6 & 20875.3 & 95621.8 & 104343.9 \\
\hline 32 & 266273.5 & 266158.6 & 19247.6 & 20471.5 & 96621.4 & 102363.8 \\
\hline 33 & 269419.9 & 261459.8 & 19443.4 & 20077.4 & 97643.0 & 100433.2 \\
\hline 34 & 272630.7 & 256869.6 & 19642.4 & 19692.1 & 98683.9 & 98547.4 \\
\hline 35 & 275787.8 & 252276.0 & 19842.2 & 19313.0 & 99722.4 & 96683.9 \\
\hline 36 & 278887.5 & 247681.0 & 20042.7 & 18940.0 & 100757.4 & 94842.1 \\
\hline 37 & 282045.8 & 243190.2 & 20245.9 & 18574.7 & 101808.6 & 93040.4 \\
\hline 38 & 285263.0 & 238800.2 & 20451.8 & 18217.1 & 102875.9 & 91277.4 \\
\hline 39 & 288539.6 & 234507.8 & 20660.4 & 17866.9 & 103959.1 & 89552.0 \\
\hline 40 & 291876.1 & 230310.2 & 20871.7 & 17523.9 & 105058.5 & 87863.1 \\
\hline 41 & 295273.3 & 226204.7 & 21085.6 & 17188.0 & 106174.0 & 86209.7 \\
\hline 42 & 298731.9 & 222188.6 & 21302.4 & 16858.8 & 107305.8 & 84591.0 \\
\hline 43 & 302252.8 & 218259.6 & 21521.8 & 16536.4 & 108454.0 & 83006.0 \\
\hline 44 & 305893.8 & 214455.1 & 21745.1 & 16221.3 & 109628.6 & 81461.1 \\
\hline 45 & 301830.1 & 205442.9 & 21855.0 & 15828.5 & 109612.7 & 79077.0 \\
\hline 46 & 305612.7 & 201958.8 & 22077.9 & 15524.2 & 110792.6 & 77600.2 \\
\hline 47 & 309235.7 & 198400.9 & 22302.4 & 15225.3 & 111964.4 & 76136.8 \\
\hline 48 & 312945.7 & 194933.3 & 22531.2 & 14933.5 & 113162.6 & 74710.3 \\
\hline
\end{tabular}




\begin{tabular}{|c|c|c|c|c|c|c|}
\hline Year & Fuel (gal) & Present Cost (\$) & Fuel (gal) & Present Cost (\$) & Fuel (gal) & Present Cost (\$) \\
\hline 49 & 316739.9 & 191550.1 & 22763.8 & 14648.2 & 114384.3 & 73317.3 \\
\hline 50 & 320480.7 & 188167.4 & 22997.4 & 14367.5 & 115604.4 & 71941.2 \\
\hline 51 & 324163.7 & 184786.2 & 23232.0 & 14091.3 & 116821.8 & 70581.3 \\
\hline 52 & 327923.4 & 181484.9 & 23469.8 & 13820.9 & 118059.3 & 69251.5 \\
\hline 53 & 331760.1 & 178260.4 & 23710.9 & 13556.2 & 119316.8 & 67950.6 \\
\hline 54 & 335674.3 & 175110.3 & 23955.3 & 13297.0 & 120594.3 & 66677.8 \\
\hline 55 & 339666.9 & 172032.1 & 24202.9 & 13043.2 & 121892.0 & 65432.3 \\
\hline 56 & 343738.7 & 169023.7 & 24453.8 & 12794.6 & 123209.8 & 64213.3 \\
\hline 57 & 347890.7 & 166082.8 & 24708.1 & 12551.1 & 124548.0 & 63020.1 \\
\hline 58 & 352124.1 & 163207.6 & 24965.7 & 12312.5 & 125906.8 & 61852.1 \\
\hline 59 & 356516.0 & 160430.3 & 25228.0 & 12079.5 & 127299.5 & 60714.8 \\
\hline 60 & 350415.4 & 153092.3 & 25325.9 & 11773.2 & 127021.0 & 58817.5 \\
\hline
\end{tabular}

Table D.36. Pay Items for Case A-20\% Penetration

\begin{tabular}{|c|c|c|c|c|c|}
\hline Number & Stage & Description & Unit & Quantity & Present Cost (\$) \\
\hline 1 & Material \& Construction & $\begin{array}{c}\text { HOT-MIX ASPHALT SURFACE } \\
\text { COURSE }\end{array}$ & TON & 1531.00 & $\$ 179,417.81$ \\
\hline 2 & $\begin{array}{c}\text { Maintenance \& } \\
\text { Rehabilitation }\end{array}$ & $\begin{array}{c}\text { HOT-MIX ASPHALT SURFACE } \\
\text { COURSE REPLACEMENT } \\
\text { OVER PATCHES }\end{array}$ & TON & 1530.92 & $\$ 115,155.33$ \\
\hline 3 & $\begin{array}{l}\text { Maintenance \& } \\
\text { Rehabilitation }\end{array}$ & $\begin{array}{c}\text { HOT-MIX ASPHALT SURFACE } \\
\text { COURSE REPLACEMENT } \\
\text { OVER PATCHES }\end{array}$ & TON & 1530.92 & $\$ 73,913.82$ \\
\hline 4 & $\begin{array}{c}\text { Maintenance \& } \\
\text { Rehabilitation }\end{array}$ & $\begin{array}{c}\text { HOT-MIX ASPHALT SURFACE } \\
\text { COURSE REPLACEMENT } \\
\text { OVER PATCHES }\end{array}$ & TON & 1530.92 & $\$ 47,442.47$ \\
\hline 5 & $\begin{array}{l}\text { Maintenance \& } \\
\text { Rehabilitation }\end{array}$ & EPOXY PVT MK LINE 6 & FOOT & 10560.00 & $\$ 7,000.84$ \\
\hline 6 & $\begin{array}{l}\text { Maintenance \& } \\
\text { Rehabilitation }\end{array}$ & EPOXY PVT MK LINE 6 & FOOT & 10560.00 & $\$ 4,493.57$ \\
\hline 7 & $\begin{array}{l}\text { Maintenance \& } \\
\text { Rehabilitation }\end{array}$ & EPOXY PVT MK LINE 4 & FOOT & 10560.00 & $\$ 3,843.60$ \\
\hline 8 & $\begin{array}{l}\text { Maintenance \& } \\
\text { Rehabilitation }\end{array}$ & EPOXY PVT MK LINE 6 & FOOT & 10560.00 & $\$ 2,884.25$ \\
\hline 9 & $\begin{array}{l}\text { Maintenance \& } \\
\text { Rehabilitation }\end{array}$ & EPOXY PVT MK LINE 4 & FOOT & 10560.00 & $\$ 2,467.06$ \\
\hline 10 & $\begin{array}{c}\text { Maintenance \& } \\
\text { Rehabilitation }\end{array}$ & $\begin{array}{c}\text { HOT-MIX ASPHALT SURFACE } \\
\text { COURSE REPLACEMENT } \\
\text { OVER PATCHES }\end{array}$ & TON & 102.11 & $\$ 2,031.12$ \\
\hline 11 & $\begin{array}{l}\text { Maintenance \& } \\
\text { Rehabilitation }\end{array}$ & EPOXY PVT MK LINE 4 & FOOT & 10560.00 & $\$ 1,583.51$ \\
\hline 12 & $\begin{array}{l}\text { Maintenance \& } \\
\text { Rehabilitation }\end{array}$ & $\begin{array}{l}\text { BITUMINOUS MATERIALS } \\
\text { (PRIME COAT) }\end{array}$ & GAL & 234.67 & $\$ 158.62$ \\
\hline 13 & $\begin{array}{l}\text { Maintenance \& } \\
\text { Rehabilitation }\end{array}$ & EPOXY PVT MK LINE 6 & FOOT & 704.35 & $\$ 123.48$ \\
\hline 14 & $\begin{array}{l}\text { Maintenance \& } \\
\text { Rehabilitation }\end{array}$ & $\begin{array}{c}\text { BITUMINOUS MATERIALS } \\
\text { (PRIME COAT) }\end{array}$ & GAL & 234.67 & $\$ 101.82$ \\
\hline 15 & $\begin{array}{l}\text { Maintenance \& } \\
\text { Rehabilitation }\end{array}$ & EPOXY PVT MK LINE 4 & FOOT & 704.35 & $\$ 67.79$ \\
\hline 16 & $\begin{array}{l}\text { Maintenance \& } \\
\text { Rehabilitation }\end{array}$ & $\begin{array}{l}\text { BITUMINOUS MATERIALS } \\
\text { (PRIME COAT) }\end{array}$ & GAL & 234.67 & $\$ 65.35$ \\
\hline
\end{tabular}




\begin{tabular}{|c|c|c|c|c|c|}
\hline Number & Stage & Description & Unit & Quantity & Present Cost (\$) \\
\hline 17 & $\begin{array}{l}\text { Maintenance \& } \\
\text { Rehabilitation }\end{array}$ & $\begin{array}{l}\text { BITUMINOUS MATERIALS } \\
\text { (PRIME COAT) }\end{array}$ & GAL & 15.65 & $\$ 2.80$ \\
\hline 18 & Material \& Construction & $\begin{array}{c}\text { HOT-MIX ASPHALT SURFACE } \\
\text { REMOVAL }\end{array}$ & SQ YD & 14080.00 & $\$ 0.00$ \\
\hline 19 & $\begin{array}{l}\text { Maintenance \& } \\
\text { Rehabilitation }\end{array}$ & $\begin{array}{c}\text { HOT-MIX ASPHALT } \\
\text { REMOVAL OVER PATCHES, } \\
2^{\prime \prime}\end{array}$ & SQ YD & 14080.00 & $\$ 0.00$ \\
\hline 20 & $\begin{array}{l}\text { Maintenance \& } \\
\text { Rehabilitation }\end{array}$ & $\begin{array}{c}\text { HOT-MIX ASPHALT } \\
\text { REMOVAL OVER PATCHES, } \\
2^{\prime \prime} \\
\end{array}$ & SQ YD & 14080.00 & $\$ 0.00$ \\
\hline 21 & $\begin{array}{l}\text { Maintenance \& } \\
\text { Rehabilitation }\end{array}$ & $\begin{array}{c}\text { HOT-MIX ASPHALT } \\
\text { REMOVAL OVER PATCHES, } \\
2^{"}\end{array}$ & SQ YD & 14080.00 & $\$ 0.00$ \\
\hline 22 & $\begin{array}{l}\text { Maintenance \& } \\
\text { Rehabilitation }\end{array}$ & $\begin{array}{c}\text { HOT-MIX ASPHALT } \\
\text { REMOVAL OVER PATCHES, } \\
2^{"}\end{array}$ & SQ YD & 939.14 & $\$ 0.00$ \\
\hline
\end{tabular}

Table D.37. Fuel Cost for Case A-20\% Penetration

\begin{tabular}{|c|c|c|c|c|c|c|}
\hline \multirow[b]{2}{*}{ Year } & \multicolumn{2}{|c|}{ Passenger } & \multicolumn{2}{|c|}{ Medium Truck } & \multicolumn{2}{|c|}{ Large Truck } \\
\hline & Fuel (gal) & Present Cost (\$) & Fuel (gal) & Present Cost (\$) & Fuel (gal) & Present Cost (\$) \\
\hline 0 & 192886.0 & 496483.0 & 14072.0 & 38507.9 & 70577.7 & 191625.6 \\
\hline 1 & 195045.4 & 487418.6 & 14207.3 & 37745.9 & 71274.9 & 187882.3 \\
\hline 2 & 197271.7 & 478623.5 & 14347.7 & 37008.6 & 72001.3 & 184269.0 \\
\hline 3 & 199541.0 & 470028.4 & 14491.0 & 36289.6 & 72744.5 & 180748.5 \\
\hline 4 & 201851.2 & 461621.6 & 14636.8 & 35587.0 & 73501.5 & 177310.1 \\
\hline 5 & 204201.5 & 453394.9 & 14784.8 & 34899.7 & 74271.1 & 173948.2 \\
\hline 6 & 206430.8 & 444994.6 & 14931.8 & 34220.2 & 75024.9 & 170595.7 \\
\hline 7 & 208681.8 & 436744.8 & 15080.5 & 33554.5 & 75787.2 & 167309.8 \\
\hline 8 & 210969.3 & 428672.0 & 15231.2 & 32902.6 & 76560.3 & 164093.8 \\
\hline 9 & 213293.4 & 420771.3 & 15383.7 & 32264.1 & 77344.3 & 160945.7 \\
\hline 10 & 215654.5 & 413038.0 & 15538.1 & 31638.8 & 78139.0 & 157863.5 \\
\hline 11 & 218053.0 & 405467.7 & 15694.4 & 31026.3 & 78944.4 & 154845.4 \\
\hline 12 & 220489.3 & 398056.3 & 15852.6 & 30426.2 & 79760.7 & 151889.8 \\
\hline 13 & 222963.9 & 390799.7 & 16012.7 & 29838.4 & 80587.9 & 148995.1 \\
\hline 14 & 225510.3 & 383750.5 & 16175.3 & 29263.5 & 81431.8 & 146170.2 \\
\hline 15 & 223934.7 & 369970.1 & 16290.1 & 28612.8 & 81702.5 & 142384.7 \\
\hline 16 & 226672.7 & 363586.2 & 16452.6 & 28056.4 & 82557.4 & 139683.9 \\
\hline 17 & 229300.4 & 357088.3 & 16617.0 & 27511.4 & 83411.3 & 137018.2 \\
\hline 18 & 231979.9 & 350739.0 & 16784.6 & 26979.7 & 84284.1 & 134419.3 \\
\hline 19 & 234709.9 & 344530.7 & 16955.1 & 26459.8 & 85172.9 & 131880.5 \\
\hline 20 & 237389.0 & 338313.9 & 17126.2 & 25948.4 & 86059.3 & 129371.8 \\
\hline 21 & 240014.0 & 332092.1 & 17297.9 & 25445.2 & 86942.0 & 126892.0 \\
\hline 22 & 242684.9 & 326007.5 & 17471.8 & 24952.4 & 87838.0 & 124465.7 \\
\hline 23 & 245402.0 & 320055.7 & 17648.0 & 24470.0 & 88747.1 & 122091.2 \\
\hline 24 & 248165.5 & 314233.0 & 17826.5 & 23997.5 & 89669.3 & 119766.9 \\
\hline 25 & 250976.1 & 308535.7 & 18007.2 & 23534.7 & 90604.7 & 117491.5 \\
\hline 26 & 253834.3 & 302960.5 & 18190.1 & 23081.4 & 91553.2 & 115263.5 \\
\hline 27 & 256740.6 & 297504.2 & 18375.3 & 22637.3 & 92514.9 & 113081.9 \\
\hline 28 & 259695.7 & 292163.7 & 18562.8 & 22202.2 & 93490.1 & 110945.4 \\
\hline 29 & 262744.2 & 286983.8 & 18753.4 & 21776.9 & 94486.2 & 108861.7 \\
\hline
\end{tabular}




\begin{tabular}{|c|c|c|c|c|c|c|}
\hline \multirow[b]{2}{*}{ Year } & \multicolumn{2}{|c|}{ Passenger } & \multicolumn{2}{|c|}{ Medium Truck } & \multicolumn{2}{|c|}{ Large Truck } \\
\hline & Fuel (gal) & Present Cost (\$) & Fuel (gal) & Present Cost (\$) & Fuel (gal) & Present Cost (\$) \\
\hline 30 & 259981.2 & 275695.0 & 18865.3 & 21268.7 & 94618.1 & 105838.5 \\
\hline 31 & 263197.8 & 270976.7 & 19055.7 & 20857.6 & 95622.5 & 103846.6 \\
\hline 32 & 266281.9 & 266166.9 & 19247.8 & 20454.2 & 96622.8 & 101876.7 \\
\hline 33 & 269433.3 & 261472.8 & 19443.6 & 20060.6 & 97645.4 & 99956.1 \\
\hline 34 & 272649.9 & 256887.8 & 19642.7 & 19675.7 & 98687.2 & 98080.2 \\
\hline 35 & 275813.8 & 252299.8 & 19842.7 & 19297.1 & 99726.9 & 96226.7 \\
\hline 36 & 278921.1 & 247710.8 & 20043.3 & 18924.4 & 100763.2 & 94394.8 \\
\hline 37 & 282087.9 & 243226.4 & 20246.6 & 18559.7 & 101815.9 & 92602.9 \\
\hline 38 & 285314.3 & 238843.1 & 20452.7 & 18202.5 & 102884.7 & 90849.5 \\
\hline 39 & 288601.0 & 234557.7 & 20661.5 & 17852.7 & 103969.7 & 89133.6 \\
\hline 40 & 291948.4 & 230367.2 & 20873.0 & 17510.1 & 105071.0 & 87454.1 \\
\hline 41 & 295357.2 & 226269.0 & 21087.2 & 17174.6 & 106188.5 & 85809.9 \\
\hline 42 & 298828.4 & 222260.4 & 21304.1 & 16845.9 & 107322.5 & 84200.3 \\
\hline 43 & 302362.8 & 218339.0 & 21523.8 & 16523.9 & 108473.0 & 82624.2 \\
\hline 44 & 306019.1 & 214543.0 & 21747.4 & 16209.3 & 109650.3 & 81088.3 \\
\hline 45 & 301830.1 & 205442.9 & 21855.0 & 15815.0 & 109612.7 & 78699.5 \\
\hline 46 & 305619.0 & 201962.9 & 22078.1 & 15511.1 & 110793.6 & 77230.5 \\
\hline 47 & 309247.9 & 198408.8 & 22302.6 & 15212.5 & 111966.5 & 75774.8 \\
\hline 48 & 312965.2 & 194945.4 & 22531.5 & 14921.0 & 113166.0 & 74355.9 \\
\hline 49 & 316768.0 & 191567.1 & 22764.3 & 14636.1 & 114389.1 & 72970.4 \\
\hline 50 & 320518.7 & 188189.7 & 22998.1 & 14355.7 & 115611.0 & 71601.8 \\
\hline 51 & 324212.7 & 184814.2 & 23232.9 & 14079.9 & 116830.3 & 70249.5 \\
\hline 52 & 327984.6 & 181518.7 & 23470.9 & 13809.8 & 118069.9 & 68927.1 \\
\hline 53 & 331834.8 & 178300.5 & 23712.3 & 13545.5 & 119329.7 & 67633.5 \\
\hline 54 & 335763.6 & 175156.9 & 23956.9 & 13286.6 & 120609.8 & 66368.0 \\
\hline 55 & 339772.0 & 172085.4 & 24204.8 & 13033.1 & 121910.1 & 65129.6 \\
\hline 56 & 343860.8 & 169083.7 & 24456.1 & 12784.9 & 123230.9 & 63917.7 \\
\hline 57 & 348031.1 & 166149.9 & 24710.7 & 12541.7 & 124572.2 & 62731.5 \\
\hline 58 & 352284.0 & 163281.7 & 24968.6 & 12303.5 & 125934.4 & 61570.3 \\
\hline 59 & 356698.1 & 160512.3 & 25231.4 & 12070.9 & 127331.0 & 60439.9 \\
\hline 60 & 350415.4 & 153092.3 & 25325.9 & 11763.2 & 127021.0 & 58536.7 \\
\hline
\end{tabular}

Table D.38. Pay Items for Case A-50\% Penetration

\begin{tabular}{|c|c|c|c|c|c|}
\hline Number & Stage & Description & Unit & Quantity & Present Cost (\$) \\
\hline 1 & Material \& Construction & $\begin{array}{l}\text { HOT-MIX ASPHALT } \\
\text { SURFACE COURSE }\end{array}$ & TON & 1531.00 & $\$ 179,417.81$ \\
\hline 2 & Maintenance \& Rehabilitation & $\begin{array}{l}\text { HOT-MIX ASPHALT } \\
\text { SURFACE COURSE } \\
\text { REPLACEMENT OVER } \\
\text { PATCHES }\end{array}$ & TON & 1530.92 & $\$ 115,155.33$ \\
\hline 3 & Maintenance \& Rehabilitation & $\begin{array}{l}\text { HOT-MIX ASPHALT } \\
\text { SURFACE COURSE } \\
\text { REPLACEMENT OVER } \\
\text { PATCHES }\end{array}$ & TON & 1530.92 & $\$ 73,913.82$ \\
\hline 4 & Maintenance \& Rehabilitation & $\begin{array}{l}\text { HOT-MIX ASPHALT } \\
\text { SURFACE COURSE } \\
\text { REPLACEMENT OVER } \\
\text { PATCHES }\end{array}$ & TON & 1530.92 & $\$ 47,442.47$ \\
\hline 5 & Maintenance \& Rehabilitation & EPOXY PVT MK LINE 6 & FOOT & 10560.00 & $\$ 7,000.84$ \\
\hline
\end{tabular}




\begin{tabular}{|c|c|c|c|c|c|}
\hline Number & Stage & Description & Unit & Quantity & Present Cost (\$) \\
\hline 6 & Maintenance \& Rehabilitation & EPOXY PVT MK LINE 6 & FOOT & 10560.00 & $\$ 4,493.57$ \\
\hline 7 & Maintenance \& Rehabilitation & EPOXY PVT MK LINE 4 & FOOT & 10560.00 & $\$ 3,843.60$ \\
\hline 8 & Maintenance \& Rehabilitation & EPOXY PVT MK LINE 6 & FOOT & 10560.00 & $\$ 2,884.25$ \\
\hline 9 & Maintenance \& Rehabilitation & EPOXY PVT MK LINE 4 & FOOT & 10560.00 & $\$ 2,467.06$ \\
\hline 10 & Maintenance \& Rehabilitation & $\begin{array}{l}\text { HOT-MIX ASPHALT } \\
\text { SURFACE COURSE } \\
\text { REPLACEMENT OVER } \\
\text { PATCHES }\end{array}$ & TON & 102.11 & $\$ 2,031.12$ \\
\hline 11 & Maintenance \& Rehabilitation & EPOXY PVT MK LINE 4 & FOOT & 10560.00 & $\$ 1,583.51$ \\
\hline 12 & Maintenance \& Rehabilitation & $\begin{array}{l}\text { BITUMINOUS } \\
\text { MATERIALS } \\
\text { (PRIME COAT) }\end{array}$ & GAL & 234.67 & $\$ 158.62$ \\
\hline 13 & Maintenance \& Rehabilitation & EPOXY PVT MK LINE 6 & FOOT & 704.35 & $\$ 123.48$ \\
\hline 14 & Maintenance \& Rehabilitation & $\begin{array}{l}\text { BITUMINOUS } \\
\text { MATERIALS } \\
\text { (PRIME COAT) }\end{array}$ & GAL & 234.67 & $\$ 101.82$ \\
\hline 15 & Maintenance \& Rehabilitation & EPOXY PVT MK LINE 4 & FOOT & 704.35 & $\$ 67.79$ \\
\hline 16 & Maintenance \& Rehabilitation & $\begin{array}{l}\text { BITUMINOUS } \\
\text { MATERIALS } \\
\text { (PRIME COAT) }\end{array}$ & GAL & 234.67 & $\$ 65.35$ \\
\hline 17 & Maintenance \& Rehabilitation & $\begin{array}{l}\text { BITUMINOUS } \\
\text { MATERIALS } \\
\text { (PRIME COAT) }\end{array}$ & GAL & 15.65 & $\$ 2.80$ \\
\hline 18 & Material \& Construction & $\begin{array}{l}\text { HOT-MIX ASPHALT } \\
\text { SURFACE REMOVAL }\end{array}$ & SQ YD & 14080.00 & $\$ 0.00$ \\
\hline 19 & Maintenance \& Rehabilitation & $\begin{array}{l}\text { HOT-MIX ASPHALT } \\
\text { REMOVAL OVER } \\
\text { PATCHES, 2" }\end{array}$ & SQ YD & 14080.00 & $\$ 0.00$ \\
\hline 20 & Maintenance \& Rehabilitation & $\begin{array}{l}\text { HOT-MIX ASPHALT } \\
\text { REMOVAL OVER } \\
\text { PATCHES, 2" }\end{array}$ & SQ YD & 14080.00 & $\$ 0.00$ \\
\hline 21 & Maintenance \& Rehabilitation & $\begin{array}{l}\text { HOT-MIX ASPHALT } \\
\text { REMOVAL OVER } \\
\text { PATCHES, 2" }\end{array}$ & SQ YD & 14080.00 & $\$ 0.00$ \\
\hline 22 & Maintenance \& Rehabilitation & $\begin{array}{l}\text { HOT-MIX ASPHALT } \\
\text { REMOVAL OVER } \\
\text { PATCHES, 2" }\end{array}$ & SQ YD & 939.14 & $\$ 0.00$ \\
\hline
\end{tabular}


Table D.39. Fuel Cost for Case A-50\% Penetration

\begin{tabular}{|c|c|c|c|c|c|c|}
\hline \multirow[b]{2}{*}{ Year } & \multicolumn{2}{|c|}{ Passenger } & \multicolumn{2}{|c|}{ Medium Truck } & \multicolumn{2}{|c|}{ Large Truck } \\
\hline & Fuel (gal) & Present Cost (\$) & Fuel (gal) & Present Cost (\$) & Fuel (gal) & Present Cost (\$) \\
\hline 0 & 192886.0 & 496483.0 & 14072.0 & 38409.6 & 70577.7 & 188868.2 \\
\hline 1 & 195047.7 & 487424.3 & 14207.4 & 37649.7 & 71275.3 & 185179.8 \\
\hline 2 & 197278.5 & 478640.1 & 14347.8 & 36914.4 & 72002.5 & 181620.4 \\
\hline 3 & 199553.9 & 470058.9 & 14491.3 & 36197.6 & 72746.7 & 178153.0 \\
\hline 4 & 201871.7 & 461668.4 & 14637.2 & 35497.1 & 73505.0 & 174767.0 \\
\hline 5 & 204230.8 & 453459.9 & 14785.3 & 34811.9 & 74276.1 & 171456.8 \\
\hline 6 & 206470.2 & 445079.5 & 14932.5 & 34134.6 & 75031.7 & 168156.1 \\
\hline 7 & 208732.5 & 436850.9 & 15081.5 & 33470.9 & 75795.9 & 164921.3 \\
\hline 8 & 211032.6 & 428800.6 & 15232.3 & 32821.1 & 76571.3 & 161755.7 \\
\hline 9 & 213370.5 & 420923.3 & 15385.1 & 32184.7 & 77357.6 & 158657.0 \\
\hline 10 & 215746.6 & 413214.3 & 15539.8 & 31561.5 & 78154.9 & 155623.5 \\
\hline 11 & 218161.3 & 405669.1 & 15696.4 & 30951.0 & 78963.1 & 152653.3 \\
\hline 12 & 220615.0 & 398283.3 & 15854.9 & 30353.0 & 79782.4 & 149744.9 \\
\hline 13 & 223108.4 & 391053.0 & 16015.4 & 29767.2 & 80612.8 & 146896.6 \\
\hline 14 & 225676.3 & 384033.0 & 16178.4 & 29194.3 & 81460.4 & 144117.6 \\
\hline 15 & 223934.7 & 369970.1 & 16290.1 & 28539.7 & 81702.5 & 140335.8 \\
\hline 16 & 226681.7 & 363600.6 & 16452.7 & 27985.1 & 82558.9 & 137676.5 \\
\hline 17 & 229317.9 & 357115.6 & 16617.3 & 27441.7 & 83414.3 & 135051.4 \\
\hline 18 & 232007.9 & 350781.3 & 16785.2 & 26911.6 & 84288.9 & 132492.7 \\
\hline 19 & 234750.3 & 344590.0 & 16955.8 & 26393.5 & 85179.9 & 129993.4 \\
\hline 20 & 237443.6 & 338391.7 & 17127.2 & 25883.7 & 86068.7 & 127524.1 \\
\hline 21 & 240084.6 & 332189.8 & 17299.2 & 25382.1 & 86954.2 & 125083.5 \\
\hline 22 & 242773.2 & 326126.0 & 17473.4 & 24891.1 & 87853.2 & 122695.9 \\
\hline 23 & 245509.6 & 320196.1 & 17650.0 & 24410.3 & 88765.7 & 120359.5 \\
\hline 24 & 248294.4 & 314396.1 & 17828.8 & 23939.4 & 89691.6 & 118072.8 \\
\hline 25 & 251127.8 & 308722.3 & 18009.9 & 23478.3 & 90630.9 & 115834.3 \\
\hline 26 & 254010.7 & 303171.1 & 18193.4 & 23026.6 & 91583.7 & 113642.7 \\
\hline 27 & 256943.4 & 297739.3 & 18379.1 & 22584.1 & 92550.0 & 111496.9 \\
\hline 28 & 259926.9 & 292423.7 & 18567.1 & 22150.6 & 93530.0 & 109395.7 \\
\hline 29 & 263007.7 & 287271.6 & 18758.3 & 21726.9 & 94531.8 & 107346.9 \\
\hline 30 & 259981.2 & 275695.0 & 18865.3 & 21214.4 & 94618.1 & 104315.5 \\
\hline 31 & 263210.9 & 270990.2 & 19055.9 & 20804.6 & 95624.8 & 102354.7 \\
\hline 32 & 266307.4 & 266192.4 & 19248.2 & 20402.5 & 96627.2 & 100415.3 \\
\hline 33 & 269474.1 & 261512.4 & 19444.4 & 20010.1 & 97652.4 & 98524.9 \\
\hline 34 & 272708.8 & 256943.3 & 19643.8 & 19626.6 & 98697.4 & 96678.9 \\
\hline 35 & 275893.4 & 252372.6 & 19844.1 & 19249.2 & 99740.7 & 94855.1 \\
\hline 36 & 279023.9 & 247802.1 & 20045.2 & 18877.9 & 100781.0 & 93052.9 \\
\hline 37 & 282216.4 & 243337.3 & 20249.0 & 18514.4 & 101838.1 & 91290.2 \\
\hline 38 & 285471.1 & 238974.4 & 20455.6 & 18158.6 & 102911.8 & 89565.8 \\
\hline 39 & 288788.5 & 234710.1 & 20665.0 & 17810.1 & 104002.1 & 87878.4 \\
\hline 40 & 292169.2 & 230541.5 & 20877.1 & 17468.9 & 105109.1 & 86226.9 \\
\hline 41 & 295614.0 & 226465.7 & 21091.9 & 17134.6 & 106232.8 & 84610.5 \\
\hline 42 & 299123.6 & 222480.0 & 21309.6 & 16807.2 & 107373.4 & 83028.1 \\
\hline 43 & 302699.0 & 218581.8 & 21530.0 & 16486.5 & 108531.1 & 81478.9 \\
\hline 44 & 306402.2 & 214811.6 & 21754.4 & 16173.1 & 109716.5 & 79969.7 \\
\hline 45 & 301830.1 & 205442.9 & 21855.0 & 15774.6 & 109612.7 & 77567.1 \\
\hline 46 & 305638.1 & 201975.6 & 22078.4 & 15471.8 & 110796.9 & 76121.4 \\
\hline 47 & 309285.1 & 198432.6 & 22303.3 & 15174.1 & 111972.9 & 74688.7 \\
\hline
\end{tabular}




\begin{tabular}{|c|c|c|c|c|c|c|}
\hline \multirow[b]{2}{*}{ Year } & \multicolumn{2}{|c|}{ Passenger } & \multicolumn{2}{|c|}{ Medium Truck } & \multicolumn{2}{|c|}{ Large Truck } \\
\hline & Fuel (gal) & Present Cost (\$) & Fuel (gal) & Present Cost (\$) & Fuel (gal) & Present Cost (\$) \\
\hline 48 & 313024.8 & 194982.5 & 22532.6 & 14883.6 & 113176.3 & 73292.6 \\
\hline 49 & 316853.8 & 191619.0 & 22765.9 & 14599.7 & 114403.9 & 71929.7 \\
\hline 50 & 320634.6 & 188257.8 & 23000.3 & 14320.4 & 115631.0 & 70583.7 \\
\hline 51 & 324362.4 & 184899.5 & 23235.6 & 14045.6 & 116856.1 & 69253.9 \\
\hline 52 & 328171.8 & 181622.4 & 23474.4 & 13776.6 & 118102.2 & 67953.8 \\
\hline 53 & 332063.0 & 178423.2 & 23716.5 & 13513.3 & 119369.2 & 66682.3 \\
\hline 54 & 336036.6 & 175299.3 & 23961.9 & 13255.5 & 120656.9 & 65438.5 \\
\hline 55 & 340093.4 & 172248.1 & 24210.8 & 13003.1 & 121965.6 & 64221.7 \\
\hline 56 & 344234.2 & 169267.3 & 24463.0 & 12755.8 & 123295.4 & 63030.9 \\
\hline 57 & 348460.2 & 166354.7 & 24718.6 & 12513.7 & 124646.4 & 61865.6 \\
\hline 58 & 352772.7 & 163508.2 & 24977.6 & 12276.5 & 126018.8 & 60725.0 \\
\hline 59 & 357254.7 & 160762.7 & 25241.6 & 12044.9 & 127427.1 & 59615.2 \\
\hline 60 & 350415.4 & 153092.3 & 25325.9 & 11733.2 & 127021.0 & 57694.4 \\
\hline
\end{tabular}

Table D.40. Pay Items for Case A-100\% Penetration

\begin{tabular}{|c|c|c|c|c|c|}
\hline Number & Stage & Description & Unit & Quantity & Present Cost (\$) \\
\hline 1 & Material \& Construction & $\begin{array}{c}\text { HOT-MIX ASPHALT SURFACE } \\
\text { COURSE }\end{array}$ & TON & 1531.00 & $\$ 179,417.81$ \\
\hline 2 & Maintenance \& Rehabilitation & $\begin{array}{c}\text { HOT-MIX ASPHALT SURFACE } \\
\text { COURSE REPLACEMENT OVER } \\
\text { PATCHES }\end{array}$ & TON & 1530.92 & $\$ 115,155.33$ \\
\hline 3 & Maintenance \& Rehabilitation & $\begin{array}{c}\text { HOT-MIX ASPHALT SURFACE } \\
\text { COURSE REPLACEMENT OVER } \\
\text { PATCHES }\end{array}$ & TON & 1530.92 & $\$ 73,913.82$ \\
\hline 4 & Maintenance \& Rehabilitation & $\begin{array}{c}\text { HOT-MIX ASPHALT SURFACE } \\
\text { COURSE REPLACEMENT OVER } \\
\text { PATCHES }\end{array}$ & TON & 1530.92 & $\$ 47,442.47$ \\
\hline 5 & Maintenance \& Rehabilitation & EPOXY PVT MK LINE 6 & FOOT & 10560.00 & $\$ 7,000.84$ \\
\hline 6 & Maintenance \& Rehabilitation & EPOXY PVT MK LINE 6 & FOOT & 10560.00 & $\$ 4,493.57$ \\
\hline 7 & Maintenance \& Rehabilitation & EPOXY PVT MK LINE 4 & FOOT & 10560.00 & $\$ 3,843.60$ \\
\hline 8 & Maintenance \& Rehabilitation & EPOXY PVT MK LINE 6 & FOOT & 10560.00 & $\$ 2,884.25$ \\
\hline 9 & Maintenance \& Rehabilitation & EPOXY PVT MK LINE 4 & FOOT & 10560.00 & $\$ 2,467.06$ \\
\hline 10 & Maintenance \& Rehabilitation & $\begin{array}{c}\text { HOT-MIX ASPHALT SURFACE } \\
\text { COURSE REPLACEMENT OVER } \\
\text { PATCHES }\end{array}$ & TON & 102.11 & $\$ 2,031.12$ \\
\hline 11 & Maintenance \& Rehabilitation & EPOXY PVT MK LINE 4 & FOOT & 10560.00 & $\$ 1,583.51$ \\
\hline 12 & Maintenance \& Rehabilitation & $\begin{array}{l}\text { BITUMINOUS MATERIALS } \\
\text { (PRIME COAT) }\end{array}$ & GAL & 234.67 & $\$ 158.62$ \\
\hline 13 & Maintenance \& Rehabilitation & EPOXY PVT MK LINE 6 & FOOT & 704.35 & $\$ 123.48$ \\
\hline 14 & Maintenance \& Rehabilitation & $\begin{array}{l}\text { BITUMINOUS MATERIALS } \\
\text { (PRIME COAT) }\end{array}$ & GAL & 234.67 & $\$ 101.82$ \\
\hline 15 & Maintenance \& Rehabilitation & EPOXY PVT MK LINE 4 & FOOT & 704.35 & $\$ 67.79$ \\
\hline 16 & Maintenance \& Rehabilitation & $\begin{array}{l}\text { BITUMINOUS MATERIALS } \\
\text { (PRIME COAT) }\end{array}$ & GAL & 234.67 & $\$ 65.35$ \\
\hline 17 & Maintenance \& Rehabilitation & $\begin{array}{l}\text { BITUMINOUS MATERIALS } \\
\text { (PRIME COAT) }\end{array}$ & GAL & 15.65 & $\$ 2.80$ \\
\hline 18 & Material \& Construction & $\begin{array}{c}\text { HOT-MIX ASPHALT SURFACE } \\
\text { REMOVAL }\end{array}$ & SQ YD & 14080.00 & $\$ 0.00$ \\
\hline
\end{tabular}




\begin{tabular}{|cccccc|}
\hline Number & Stage & Description & Unit & Quantity & Present Cost (\$) \\
\hline 19 & Maintenance \& Rehabilitation & $\begin{array}{c}\text { HOT-MIX ASPHALT REMOVAL } \\
\text { OVER PATCHES, 2" }\end{array}$ & SQ YD & 14080.00 & $\$ 0.00$ \\
\hline 20 & Maintenance \& Rehabilitation & $\begin{array}{c}\text { HOT-MIX ASPHALT REMOVAL } \\
\text { OVER PATCHES, 2" }\end{array}$ & SQ YD & 14080.00 & 14080.00 \\
\hline 21 & Maintenance \& Rehabilitation & $\begin{array}{c}\text { HOT-MIX ASPHALT REMOVAL } \\
\text { OVER PATCHES, 2" }\end{array}$ & SQ YD & $\$ 0.00$ \\
\hline 22 & Maintenance \& Rehabilitation & $\begin{array}{c}\text { HOT-MIX ASPHALT REMOVAL } \\
\text { OVER PATCHES, 2" }\end{array}$ & SQ YD & 939.14 \\
\hline
\end{tabular}

Table D.41. Fuel Cost for Case A-100\% Penetration

\begin{tabular}{|c|c|c|c|c|c|c|}
\hline & \multicolumn{2}{|c|}{ Passenger } & \multicolumn{2}{|c|}{ Medium Truck } & \multicolumn{2}{|c|}{ Large Truck } \\
\hline Year & Fuel (gal) & Present Cost (\$) & Fuel (gal) & Present Cost (\$) & Fuel (gal) & Present Cost (\$) \\
\hline 0 & 192927.3 & 496589.2 & 14072.8 & 38247.9 & 70584.8 & 184291.0 \\
\hline 1 & 194903.6 & 487064.4 & 14204.7 & 37482.1 & 71250.5 & 180610.7 \\
\hline 2 & 196932.0 & 477799.3 & 14341.5 & 36740.6 & 71942.7 & 177053.7 \\
\hline 3 & 199003.6 & 468762.5 & 14481.2 & 36018.0 & 72651.6 & 173590.9 \\
\hline 4 & 201115.8 & 459939.8 & 14623.3 & 35312.1 & 73374.4 & 170211.6 \\
\hline 5 & 203267.5 & 451320.9 & 14767.6 & 34621.8 & 74109.7 & 166910.0 \\
\hline 6 & 205458.2 & 442898.0 & 14913.9 & 33946.5 & 74856.9 & 163682.1 \\
\hline 7 & 207687.7 & 434664.2 & 15062.2 & 33285.6 & 75615.4 & 160525.1 \\
\hline 8 & 209956.1 & 426613.3 & 15212.5 & 32638.6 & 76385.3 & 157436.4 \\
\hline 9 & 212263.6 & 418739.8 & 15364.7 & 32005.0 & 77166.4 & 154413.8 \\
\hline 10 & 214610.6 & 411038.6 & 15518.9 & 31384.6 & 77958.6 & 151455.5 \\
\hline 11 & 216997.4 & 403504.8 & 15675.0 & 30776.9 & 78762.1 & 148559.6 \\
\hline 12 & 219424.5 & 396134.0 & 15833.0 & 30181.8 & 79576.8 & 145724.5 \\
\hline 13 & 221892.5 & 388921.8 & 15993.0 & 29598.8 & 80402.8 & 142948.8 \\
\hline 14 & 224401.8 & 381864.2 & 16154.9 & 29027.6 & 81240.3 & 140230.8 \\
\hline 15 & 224036.7 & 370138.7 & 16292.0 & 28421.3 & 81720.1 & 136950.6 \\
\hline 16 & 226385.6 & 363125.7 & 16447.3 & 27856.5 & 82507.8 & 134243.2 \\
\hline 17 & 228791.2 & 356295.4 & 16607.6 & 27308.7 & 83323.3 & 131621.5 \\
\hline 18 & 231249.4 & 349634.5 & 16771.2 & 26774.5 & 84157.9 & 129067.8 \\
\hline 19 & 233758.4 & 343133.9 & 16937.6 & 26252.6 & 85008.6 & 126575.2 \\
\hline 20 & 236317.4 & 336786.7 & 17106.5 & 25742.1 & 85874.2 & 124139.8 \\
\hline 21 & 238926.1 & 330586.9 & 17277.8 & 25242.7 & 86754.1 & 121759.0 \\
\hline 22 & 241584.5 & 324529.2 & 17451.5 & 24753.9 & 87647.9 & 119430.6 \\
\hline 23 & 244292.7 & 318609.0 & 17627.6 & 24275.3 & 88555.5 & 117152.7 \\
\hline 24 & 247051.2 & 312822.0 & 17805.9 & 23806.7 & 89476.9 & 114923.9 \\
\hline 25 & 249860.5 & 307164.3 & 17986.6 & 23347.8 & 90412.0 & 112742.7 \\
\hline 26 & 252721.2 & 301632.1 & 18169.6 & 22898.4 & 91360.9 & 110607.8 \\
\hline 27 & 255633.9 & 296221.8 & 18354.9 & 22458.3 & 92323.8 & 108518.0 \\
\hline 28 & 258599.3 & 290930.2 & 18542.6 & 22027.1 & 93300.7 & 106472.0 \\
\hline 29 & 261618.3 & 285754.0 & 18732.7 & 21604.7 & 94291.7 & 104469.0 \\
\hline 30 & 260114.5 & 275836.4 & 18867.7 & 21126.7 & 94641.1 & 101802.0 \\
\hline 31 & 262872.0 & 270641.3 & 19049.7 & 20709.1 & 95566.2 & 99803.0 \\
\hline 32 & 265705.4 & 265590.7 & 19237.1 & 20303.8 & 96523.2 & 97866.4 \\
\hline 33 & 268608.6 & 260672.5 & 19428.4 & 19908.4 & 97502.9 & 95980.3 \\
\hline 34 & 271579.0 & 255878.7 & 19623.0 & 19522.2 & 98502.2 & 94139.8 \\
\hline 35 & 274615.2 & 251203.4 & 19820.6 & 19144.4 & 99519.9 & 92342.2 \\
\hline 36 & 277716.8 & 246641.3 & 20021.1 & 18774.8 & 100555.2 & 90585.3 \\
\hline
\end{tabular}




\begin{tabular}{|rrr|rr|rr|}
\cline { 2 - 7 } & \multicolumn{2}{c}{ Passenger } & \multicolumn{2}{c|}{ Medium Truck } & \multicolumn{2}{c|}{ Large Truck } \\
\hline Year & Fuel (gal) & Present Cost (\$) & Fuel (gal) & Present Cost (\$) & Fuel (gal) & Present Cost (\$) \\
\hline 37 & 280883.6 & 242188.1 & 20224.5 & 18413.1 & 101607.8 & 88867.5 \\
\hline 38 & 284115.9 & 237839.9 & 20430.7 & 18059.1 & 102677.7 & 87187.6 \\
\hline 39 & 287414.1 & 233593.1 & 20639.6 & 17712.4 & 103764.7 & 85544.3 \\
\hline 40 & 290778.8 & 229444.4 & 20851.5 & 17373.0 & 104868.9 & 83936.5 \\
\hline 41 & 294210.8 & 225390.7 & 21066.1 & 17040.6 & 105990.5 & 82363.3 \\
\hline 42 & 297711.0 & 221429.3 & 21283.6 & 16715.1 & 107129.4 & 80823.6 \\
\hline 43 & 301280.3 & 217557.3 & 21503.9 & 16396.3 & 108286.0 & 79316.7 \\
\hline 44 & 304919.8 & 213772.3 & 21727.2 & 16084.0 & 109460.4 & 77841.7 \\
\hline 45 & 302006.3 & 205562.8 & 21858.2 & 15709.7 & 109643.2 & 75700.6 \\
\hline 46 & 305251.8 & 201720.3 & 22071.3 & 15400.8 & 110730.2 & 74224.4 \\
\hline 47 & 308599.9 & 197993.0 & 22290.7 & 15100.9 & 111854.6 & 72794.3 \\
\hline 48 & 312041.9 & 194370.3 & 22514.5 & 14808.3 & 113006.5 & 71401.9 \\
\hline 49 & 315573.7 & 190844.9 & 22742.3 & 14522.4 & 114182.8 & 70043.8 \\
\hline 50 & 319193.4 & 187411.5 & 22973.7 & 14242.9 & 115382.1 & 68717.9 \\
\hline 51 & 322900.0 & 184065.8 & 23208.7 & 13969.5 & 116603.5 & 67422.7 \\
\hline 52 & 326693.2 & 180804.0 & 23447.2 & 13701.9 & 117846.8 & 66156.9 \\
\hline 53 & 330573.3 & 177622.7 & 23689.1 & 13440.1 & 119111.8 & 64919.5 \\
\hline 54 & 334540.8 & 174519.0 & 23934.4 & 13183.8 & 120398.5 & 63709.5 \\
\hline 55 & 338596.5 & 171490.0 & 24183.2 & 12932.8 & 121707.1 & 62526.1 \\
\hline 56 & 342741.4 & 168533.3 & 24435.5 & 12687.1 & 123037.5 & 61368.6 \\
\hline 57 & 346976.5 & 165646.4 & 24691.2 & 12446.5 & 124390.1 & 60236.1 \\
\hline 58 & 351303.2 & 162827.1 & 24950.5 & 12210.9 & 125765.0 & 59128.1 \\
\hline 59 & 355722.9 & 160073.4 & 25213.4 & 11980.2 & 127162.5 & 58043.8 \\
\hline 60 & 350650.9 & 153195.2 & 25330.2 & 11685.1 & 127061.7 & 56308.5 \\
\hline
\end{tabular}

Table D.42. Pay Items for Case B-0\% Penetration

\begin{tabular}{|c|c|c|c|c|c|}
\hline Number & Stage & Description & Unit & Quantity & Present Cost (\$) \\
\hline 1 & Material \& Construction & $\begin{array}{c}\text { HOT-MIX ASPHALT SURFACE } \\
\text { COURSE }\end{array}$ & TON & 1531.00 & $\$ 179,417.81$ \\
\hline 2 & Maintenance \& Rehabilitation & $\begin{array}{c}\text { HOT-MIX ASPHALT SURFACE } \\
\text { COURSE REPLACEMENT } \\
\text { OVER PATCHES }\end{array}$ & TON & 1530.92 & $\$ 115,155.33$ \\
\hline 3 & Maintenance \& Rehabilitation & $\begin{array}{c}\text { HOT-MIX ASPHALT SURFACE } \\
\text { COURSE REPLACEMENT } \\
\text { OVER PATCHES }\end{array}$ & TON & 1530.92 & $\$ 80,767.63$ \\
\hline 4 & Maintenance \& Rehabilitation & $\begin{array}{l}\text { HOT-MIX ASPHALT SURFACE } \\
\text { COURSE REPLACEMENT } \\
\text { OVER PATCHES }\end{array}$ & TON & 1530.92 & $\$ 56,648.79$ \\
\hline 5 & Maintenance \& Rehabilitation & $\begin{array}{l}\text { HOT-MIX ASPHALT SURFACE } \\
\text { COURSE REPLACEMENT } \\
\text { OVER PATCHES }\end{array}$ & TON & 1530.92 & $\$ 42,152.02$ \\
\hline 6 & Maintenance \& Rehabilitation & EPOXY PVT MK LINE 6 & FOOT & 10560.00 & $\$ 7,000.84$ \\
\hline 7 & Maintenance \& Rehabilitation & $\begin{array}{c}\text { HOT-MIX ASPHALT SURFACE } \\
\text { COURSE REPLACEMENT } \\
\text { OVER PATCHES }\end{array}$ & TON & 306.18 & $\$ 6,273.01$ \\
\hline 8 & Maintenance \& Rehabilitation & EPOXY PVT MK LINE 6 & FOOT & 10560.00 & $\$ 4,910.25$ \\
\hline 9 & Maintenance \& Rehabilitation & EPOXY PVT MK LINE 4 & FOOT & 10560.00 & $\$ 3,843.60$ \\
\hline 10 & Maintenance \& Rehabilitation & EPOXY PVT MK LINE 6 & FOOT & 10560.00 & $\$ 3,443.95$ \\
\hline 11 & Maintenance \& Rehabilitation & EPOXY PVT MK LINE 4 & FOOT & 10560.00 & $\$ 2,695.82$ \\
\hline
\end{tabular}




\begin{tabular}{|c|c|c|c|c|c|}
\hline Number & Stage & Description & Unit & Quantity & Present Cost (\$) \\
\hline 12 & Maintenance \& Rehabilitation & EPOXY PVT MK LINE 6 & FOOT & 10560.00 & $\$ 2,562.62$ \\
\hline 13 & Maintenance \& Rehabilitation & EPOXY PVT MK LINE 4 & FOOT & 10560.00 & $\$ 1,890.80$ \\
\hline 14 & Maintenance \& Rehabilitation & EPOXY PVT MK LINE 4 & FOOT & 10560.00 & $\$ 1,406.93$ \\
\hline 15 & Maintenance \& Rehabilitation & EPOXY PVT MK LINE 6 & FOOT & 2112.00 & $\$ 381.37$ \\
\hline 16 & Maintenance \& Rehabilitation & EPOXY PVT MK LINE 4 & FOOT & 2112.00 & $\$ 209.38$ \\
\hline 17 & Maintenance \& Rehabilitation & $\begin{array}{l}\text { BITUMINOUS MATERIALS } \\
\text { (PRIME COAT) }\end{array}$ & GAL & 234.67 & $\$ 158.62$ \\
\hline 18 & Maintenance \& Rehabilitation & $\begin{array}{l}\text { BITUMINOUS MATERIALS } \\
\text { (PRIME COAT) }\end{array}$ & GAL & 234.67 & $\$ 111.26$ \\
\hline 19 & Maintenance \& Rehabilitation & $\begin{array}{l}\text { BITUMINOUS MATERIALS } \\
\text { (PRIME COAT) }\end{array}$ & GAL & 234.67 & $\$ 78.03$ \\
\hline 20 & Maintenance \& Rehabilitation & $\begin{array}{l}\text { BITUMINOUS MATERIALS } \\
\text { (PRIME COAT) }\end{array}$ & GAL & 234.67 & $\$ 58.06$ \\
\hline 21 & Maintenance \& Rehabilitation & $\begin{array}{l}\text { BITUMINOUS MATERIALS } \\
\text { (PRIME COAT) }\end{array}$ & GAL & 46.93 & $\$ 8.64$ \\
\hline 22 & Material \& Construction & $\begin{array}{c}\text { HOT-MIX ASPHALT SURFACE } \\
\text { REMOVAL }\end{array}$ & SQ YD & 14080.00 & $\$ 0.00$ \\
\hline 23 & Maintenance \& Rehabilitation & $\begin{array}{l}\text { HOT-MIX ASPHALT REMOVAL } \\
\text { OVER PATCHES, 2" }\end{array}$ & SQ YD & 14080.00 & $\$ 0.00$ \\
\hline 24 & Maintenance \& Rehabilitation & $\begin{array}{l}\text { HOT-MIX ASPHALT REMOVAL } \\
\text { OVER PATCHES, 2" }\end{array}$ & SQ YD & 14080.00 & $\$ 0.00$ \\
\hline 25 & Maintenance \& Rehabilitation & $\begin{array}{l}\text { HOT-MIX ASPHALT REMOVAL } \\
\text { OVER PATCHES, 2" }\end{array}$ & SQ YD & 14080.00 & $\$ 0.00$ \\
\hline 26 & Maintenance \& Rehabilitation & $\begin{array}{c}\text { HOT-MIX ASPHALT REMOVAL } \\
\text { OVER PATCHES, } 2 "\end{array}$ & SQ YD & 14080.00 & $\$ 0.00$ \\
\hline 27 & Maintenance \& Rehabilitation & $\begin{array}{l}\text { HOT-MIX ASPHALT REMOVAL } \\
\text { OVER PATCHES, 2" }\end{array}$ & SQ YD & 2816.00 & $\$ 0.00$ \\
\hline
\end{tabular}

Table D.43. Fuel Cost for Case B-0\% Penetration

\begin{tabular}{|c|c|c|c|c|c|c|}
\hline \multirow[b]{2}{*}{ Year } & \multicolumn{2}{|c|}{ Passenger } & \multicolumn{2}{|c|}{ Medium Truck } & \multicolumn{2}{|c|}{ Large Truck } \\
\hline & Fuel (gal) & Present Cost (\$) & Fuel (gal) & Present Cost (\$) & Fuel (gal) & Present Cost (\$) \\
\hline 0 & 192886.0 & 496483.0 & 14073.5 & 38577.6 & 70585.1 & 193484.4 \\
\hline 1 & 195043.9 & 487414.8 & 14208.8 & 37813.9 & 71282.0 & 189703.4 \\
\hline 2 & 197267.3 & 478612.8 & 14349.1 & 37075.1 & 72007.8 & 186053.4 \\
\hline 3 & 199532.6 & 470008.6 & 14492.3 & 36354.5 & 72750.2 & 182496.6 \\
\hline 4 & 201837.9 & 461591.2 & 14638.0 & 35650.4 & 73506.3 & 179022.7 \\
\hline 5 & 204182.5 & 453352.5 & 14785.8 & 34961.6 & 74274.8 & 175625.7 \\
\hline 6 & 206405.1 & 444939.4 & 14932.7 & 34280.6 & 75027.4 & 172238.1 \\
\hline 7 & 208648.8 & 436675.7 & 15081.3 & 33613.3 & 75788.4 & 168917.6 \\
\hline 8 & 210928.1 & 428588.4 & 15231.8 & 32959.9 & 76560.1 & 165667.6 \\
\hline 9 & 213243.3 & 420672.4 & 15384.2 & 32320.0 & 77342.5 & 162486.0 \\
\hline 10 & 215594.6 & 412923.3 & 15538.4 & 31693.2 & 78135.5 & 159370.8 \\
\hline 11 & 217982.5 & 405336.6 & 15694.5 & 31079.2 & 78939.1 & 156320.3 \\
\hline 12 & 220407.4 & 397908.4 & 15852.5 & 30477.7 & 79753.4 & 153332.8 \\
\hline 13 & 222869.8 & 390634.8 & 16012.3 & 29888.5 & 80578.4 & 150406.8 \\
\hline 14 & 225411.9 & 383583.1 & 16174.9 & 29312.5 & 81421.6 & 147554.0 \\
\hline 15 & 223934.7 & 369970.1 & 16291.6 & 28664.1 & 81710.0 & 143763.7 \\
\hline 16 & 226630.5 & 363518.5 & 16453.2 & 28105.3 & 82557.4 & 141024.0 \\
\hline 17 & 229248.5 & 357007.5 & 16617.4 & 27559.0 & 83409.5 & 138329.7 \\
\hline 18 & 231917.6 & 350644.7 & 16784.9 & 27026.0 & 84280.4 & 135702.9 \\
\hline
\end{tabular}




\begin{tabular}{|c|c|c|c|c|c|c|}
\hline & \multicolumn{2}{|c|}{ Passenger } & \multicolumn{2}{|c|}{ Medium Truck } & \multicolumn{2}{|c|}{ Large Truck } \\
\hline Year & Fuel (gal) & Present Cost (\$) & Fuel (gal) & Present Cost (\$) & Fuel (gal) & Present Cost (\$) \\
\hline 19 & 234636.2 & 344422.4 & 16955.1 & 26504.9 & 85167.3 & 133136.8 \\
\hline 20 & 237319.7 & 338215.1 & 17126.4 & 25992.8 & 86054.3 & 130605.4 \\
\hline 21 & 239931.5 & 331978.0 & 17297.7 & 25488.3 & 86934.7 & 128098.5 \\
\hline 22 & 242588.2 & 325877.5 & 17471.4 & 24994.3 & 87828.2 & 125645.8 \\
\hline 23 & 245290.0 & 319909.6 & 17647.3 & 24510.7 & 88734.7 & 123245.2 \\
\hline 24 & 248037.2 & 314070.5 & 17825.5 & 24037.0 & 89654.1 & 120895.3 \\
\hline 25 & 250830.3 & 308356.5 & 18005.8 & 23573.0 & 90586.4 & 118594.6 \\
\hline 26 & 254006.1 & 303165.7 & 18194.6 & 23126.4 & 91589.7 & 116415.7 \\
\hline 27 & 252335.2 & 292399.4 & 18320.5 & 22608.2 & 91886.0 & 113390.6 \\
\hline 28 & 255180.8 & 287084.2 & 18500.0 & 22164.7 & 92811.9 & 111197.3 \\
\hline 29 & 258128.5 & 281942.3 & 18685.5 & 21734.9 & 93774.3 & 109077.9 \\
\hline 30 & 261143.0 & 276927.0 & 18874.7 & 21315.5 & 94758.6 & 107012.5 \\
\hline 31 & 264220.3 & 272029.4 & 19067.0 & 20905.5 & 95761.7 & 104995.5 \\
\hline 32 & 267358.7 & 267243.3 & 19262.3 & 20504.5 & 96782.2 & 103023.7 \\
\hline 33 & 270347.1 & 262359.6 & 19456.4 & 20107.9 & 97783.0 & 101057.3 \\
\hline 34 & 273372.2 & 257568.3 & 19652.9 & 19719.4 & 98796.1 & 99130.4 \\
\hline 35 & 276453.1 & 252884.5 & 19851.9 & 19338.9 & 99824.6 & 97245.0 \\
\hline 36 & 279590.0 & 248304.9 & 20053.5 & 18966.3 & 100868.3 & 95399.8 \\
\hline 37 & 282783.5 & 243826.2 & 20257.7 & 18601.4 & 101927.4 & 93593.7 \\
\hline 38 & 286166.8 & 239556.7 & 20467.0 & 18246.2 & 103024.9 & 91846.0 \\
\hline 39 & 284337.6 & 231092.7 & 20606.8 & 17835.7 & 103352.6 & 89454.5 \\
\hline 40 & 287766.5 & 227067.5 & 20814.0 & 17490.3 & 104438.7 & 87761.7 \\
\hline 41 & 291140.5 & 223038.6 & 21024.4 & 17152.6 & 105534.6 & 86099.6 \\
\hline 42 & 294593.3 & 219110.4 & 21239.0 & 16823.0 & 106655.2 & 84479.5 \\
\hline 43 & 298121.5 & 215276.4 & 21457.1 & 16500.8 & 107797.4 & 82897.3 \\
\hline 44 & 301638.4 & 211471.8 & 21677.0 & 16184.3 & 108945.1 & 81339.7 \\
\hline 45 & 305054.5 & 207637.6 & 21896.9 & 15872.3 & 110082.2 & 79794.8 \\
\hline 46 & 308538.7 & 203892.4 & 22119.8 & 15566.9 & 111237.6 & 78283.8 \\
\hline 47 & 312091.3 & 200233.0 & 22345.7 & 15267.8 & 112411.2 & 76805.6 \\
\hline 48 & 316125.4 & 196913.9 & 22582.2 & 14980.0 & 113674.3 & 75406.4 \\
\hline 49 & 314085.6 & 189944.9 & 22732.0 & 14640.2 & 114011.4 & 73427.2 \\
\hline 50 & 317725.7 & 186549.8 & 22958.8 & 14355.6 & 115189.2 & 72025.0 \\
\hline 51 & 321454.1 & 183241.7 & 23191.7 & 14078.9 & 116402.1 & 70663.5 \\
\hline 52 & 325282.4 & 180023.2 & 23429.3 & 13808.8 & 117643.9 & 69337.2 \\
\hline 53 & 329204.0 & 176887.0 & 23670.9 & 13544.9 & 118910.9 & 68042.7 \\
\hline 54 & 333192.4 & 173815.5 & 23915.9 & 13286.5 & 120197.4 & 66775.6 \\
\hline 55 & 337007.1 & 170685.0 & 24159.7 & 13031.0 & 121461.4 & 65512.4 \\
\hline 56 & 340904.4 & 167630.0 & 24407.0 & 12780.9 & 122746.8 & 64277.4 \\
\hline 57 & 344884.4 & 164647.6 & 24657.7 & 12536.1 & 124053.5 & 63069.6 \\
\hline 58 & 349243.8 & 161872.6 & 24917.3 & 12299.1 & 125432.5 & 61913.3 \\
\hline 59 & 346945.9 & 156123.8 & 25079.5 & 12018.6 & 125785.4 & 60279.1 \\
\hline 60 & 351126.5 & 153403.0 & 25333.7 & 11786.9 & 127117.5 & 59143.2 \\
\hline
\end{tabular}


Table D.44. Pay Items for Case B-5\% Penetration

\begin{tabular}{|c|c|c|c|c|c|}
\hline Number & Stage & Description & Unit & Quantity & $\begin{array}{c}\text { Present Cost } \\
\text { (\$) }\end{array}$ \\
\hline 1 & Material \& Construction & HOT-MIX ASPHALT SURFACE COURSE & TON & 1531.00 & $\$ 179,417.81$ \\
\hline 2 & Maintenance \& Rehabilitation & $\begin{array}{l}\text { HOT-MIX ASPHALT SURFACE COURSE } \\
\text { REPLACEMENT OVER PATCHES }\end{array}$ & TON & 1530.92 & $\$ 115,155.33$ \\
\hline 3 & Maintenance \& Rehabilitation & $\begin{array}{l}\text { HOT-MIX ASPHALT SURFACE COURSE } \\
\text { REPLACEMENT OVER PATCHES }\end{array}$ & TON & 1530.92 & $\$ 80,767.63$ \\
\hline 4 & Maintenance \& Rehabilitation & $\begin{array}{l}\text { HOT-MIX ASPHALT SURFACE COURSE } \\
\text { REPLACEMENT OVER PATCHES }\end{array}$ & TON & 1530.92 & $\$ 56,648.79$ \\
\hline 5 & Maintenance \& Rehabilitation & $\begin{array}{l}\text { HOT-MIX ASPHALT SURFACE COURSE } \\
\text { REPLACEMENT OVER PATCHES }\end{array}$ & TON & 1530.92 & $\$ 42,152.02$ \\
\hline 6 & Maintenance \& Rehabilitation & EPOXY PVT MK LINE 6 & FOOT & 10560.00 & $\$ 7,000.84$ \\
\hline 7 & Maintenance \& Rehabilitation & $\begin{array}{l}\text { HOT-MIX ASPHALT SURFACE COURSE } \\
\text { REPLACEMENT OVER PATCHES }\end{array}$ & TON & 306.18 & $\$ 6,273.01$ \\
\hline 8 & Maintenance \& Rehabilitation & EPOXY PVT MK LINE 6 & FOOT & 10560.00 & $\$ 4,910.25$ \\
\hline 9 & Maintenance \& Rehabilitation & EPOXY PVT MK LINE 4 & FOOT & 10560.00 & $\$ 3,843.60$ \\
\hline 10 & Maintenance \& Rehabilitation & EPOXY PVT MK LINE 6 & FOOT & 10560.00 & $\$ 3,443.95$ \\
\hline 11 & Maintenance \& Rehabilitation & EPOXY PVT MK LINE 4 & FOOT & 10560.00 & $\$ 2,695.82$ \\
\hline 12 & Maintenance \& Rehabilitation & EPOXY PVT MK LINE 6 & FOOT & 10560.00 & $\$ 2,562.62$ \\
\hline 13 & Maintenance \& Rehabilitation & EPOXY PVT MK LINE 4 & FOOT & 10560.00 & $\$ 1,890.80$ \\
\hline 14 & Maintenance \& Rehabilitation & EPOXY PVT MK LINE 4 & FOOT & 10560.00 & $\$ 1,406.93$ \\
\hline 15 & Maintenance \& Rehabilitation & EPOXY PVT MK LINE 6 & FOOT & 2112.00 & $\$ 381.37$ \\
\hline 16 & Maintenance \& Rehabilitation & EPOXY PVT MK LINE 4 & FOOT & 2112.00 & $\$ 209.38$ \\
\hline 17 & Maintenance \& Rehabilitation & $\begin{array}{l}\text { BITUMINOUS MATERIALS } \\
\text { (PRIME COAT) }\end{array}$ & GAL & 234.67 & $\$ 158.62$ \\
\hline 18 & Maintenance \& Rehabilitation & $\begin{array}{l}\text { BITUMINOUS MATERIALS } \\
\text { (PRIME COAT) }\end{array}$ & GAL & 234.67 & $\$ 111.26$ \\
\hline 19 & Maintenance \& Rehabilitation & $\begin{array}{l}\text { BITUMINOUS MATERIALS } \\
\text { (PRIME COAT) }\end{array}$ & GAL & 234.67 & $\$ 78.03$ \\
\hline 20 & Maintenance \& Rehabilitation & $\begin{array}{l}\text { BITUMINOUS MATERIALS } \\
\text { (PRIME COAT) }\end{array}$ & GAL & 234.67 & $\$ 58.06$ \\
\hline 21 & Maintenance \& Rehabilitation & $\begin{array}{l}\text { BITUMINOUS MATERIALS } \\
\text { (PRIME COAT) }\end{array}$ & GAL & 46.93 & $\$ 8.64$ \\
\hline 22 & Material \& Construction & $\begin{array}{c}\text { HOT-MIX ASPHALT SURFACE } \\
\text { REMOVAL }\end{array}$ & SQ YD & 14080.00 & $\$ 0.00$ \\
\hline 23 & Maintenance \& Rehabilitation & $\begin{array}{c}\text { HOT-MIX ASPHALT REMOVAL OVER } \\
\text { PATCHES, 2" }\end{array}$ & SQ YD & 14080.00 & $\$ 0.00$ \\
\hline 24 & Maintenance \& Rehabilitation & $\begin{array}{l}\text { HOT-MIX ASPHALT REMOVAL OVER } \\
\text { PATCHES, 2" }\end{array}$ & SQ YD & 14080.00 & $\$ 0.00$ \\
\hline 25 & Maintenance \& Rehabilitation & $\begin{array}{l}\text { HOT-MIX ASPHALT REMOVAL OVER } \\
\text { PATCHES, } 2 "\end{array}$ & SQ YD & 14080.00 & $\$ 0.00$ \\
\hline 26 & Maintenance \& Rehabilitation & $\begin{array}{l}\text { HOT-MIX ASPHALT REMOVAL OVER } \\
\text { PATCHES, } 2 "\end{array}$ & SQ YD & 14080.00 & $\$ 0.00$ \\
\hline 27 & Maintenance \& Rehabilitation & $\begin{array}{c}\text { HOT-MIX ASPHALT REMOVAL OVER } \\
\text { PATCHES, 2" }\end{array}$ & SQ YD & 2816.00 & $\$ 0.00$ \\
\hline
\end{tabular}


Table D.45. Fuel Cost for Case B-5\% Penetration

\begin{tabular}{|c|c|c|c|c|c|c|}
\hline \multirow[b]{2}{*}{ Year } & \multicolumn{2}{|c|}{ Passenger } & \multicolumn{2}{|c|}{ Medium Truck } & \multicolumn{2}{|c|}{ Large Truck } \\
\hline & Fuel (gal) & Present Cost (\$) & Fuel (gal) & Present Cost (\$) & Fuel (gal) & Present Cost (\$) \\
\hline 0 & 192886.0 & 496483.0 & 14073.5 & 38561.2 & 70585.1 & 193024.7 \\
\hline 1 & 195044.2 & 487415.8 & 14208.8 & 37797.9 & 71282.0 & 189253.0 \\
\hline 2 & 197268.4 & 478615.4 & 14349.1 & 37059.4 & 72008.0 & 185611.9 \\
\hline 3 & 199534.7 & 470013.5 & 14492.4 & 36339.2 & 72750.5 & 182064.0 \\
\hline 4 & 201841.2 & 461598.7 & 14638.0 & 35635.4 & 73506.8 & 178598.8 \\
\hline 5 & 204187.2 & 453363.0 & 14785.9 & 34947.0 & 74275.6 & 175210.5 \\
\hline 6 & 206411.5 & 444953.1 & 14932.8 & 34266.3 & 75028.5 & 171831.5 \\
\hline 7 & 208657.0 & 436692.9 & 15081.5 & 33599.4 & 75789.8 & 168519.5 \\
\hline 8 & 210938.3 & 428609.1 & 15232.0 & 32946.3 & 76561.9 & 165277.9 \\
\hline 9 & 213255.7 & 420696.9 & 15384.4 & 32306.7 & 77344.7 & 162104.5 \\
\hline 10 & 215609.5 & 412951.7 & 15538.7 & 31680.3 & 78138.1 & 158997.4 \\
\hline 11 & 218000.0 & 405369.2 & 15694.8 & 31066.7 & 78942.1 & 155954.9 \\
\hline 12 & 220427.7 & 397945.1 & 15852.8 & 30465.5 & 79756.9 & 152975.3 \\
\hline 13 & 222893.1 & 390675.7 & 16012.8 & 29876.6 & 80582.5 & 150057.1 \\
\hline 14 & 225419.8 & 383596.4 & 16175.0 & 29300.3 & 81422.9 & 147205.9 \\
\hline 15 & 223934.7 & 369970.1 & 16291.6 & 28651.9 & 81710.0 & 143422.2 \\
\hline 16 & 226691.5 & 363616.3 & 16454.4 & 28095.3 & 82567.9 & 140706.9 \\
\hline 17 & 229315.7 & 357112.1 & 16618.7 & 27549.4 & 83421.1 & 138020.3 \\
\hline 18 & 231990.7 & 350755.2 & 16786.3 & 27016.7 & 84293.0 & 135400.9 \\
\hline 19 & 234715.2 & 344538.4 & 16956.6 & 26496.0 & 85180.9 & 132841.8 \\
\hline 20 & 237371.1 & 338288.4 & 17127.3 & 25983.2 & 86063.2 & 130308.5 \\
\hline 21 & 239988.7 & 332057.1 & 17298.8 & 25479.0 & 86944.6 & 127808.8 \\
\hline 22 & 242651.3 & 325962.3 & 17472.6 & 24985.4 & 87839.1 & 125362.8 \\
\hline 23 & 245359.2 & 319999.9 & 17648.6 & 24502.0 & 88746.6 & 122969.0 \\
\hline 24 & 248112.8 & 314166.2 & 17826.9 & 24028.7 & 89667.1 & 120625.6 \\
\hline 25 & 250912.5 & 308457.5 & 18007.4 & 23565.0 & 90600.6 & 118331.4 \\
\hline 26 & 253978.5 & 303132.7 & 18194.1 & 23115.9 & 91585.0 & 116133.1 \\
\hline 27 & 252335.2 & 292399.4 & 18320.5 & 22598.6 & 91886.0 & 113121.2 \\
\hline 28 & 255272.0 & 287186.9 & 18501.7 & 22157.3 & 92827.7 & 110952.0 \\
\hline 29 & 258229.3 & 282052.3 & 18687.3 & 21727.8 & 93791.7 & 108839.0 \\
\hline 30 & 261252.4 & 277043.0 & 18876.7 & 21308.7 & 94777.5 & 106779.6 \\
\hline 31 & 264338.1 & 272150.7 & 19069.2 & 20899.0 & 95782.1 & 104768.3 \\
\hline 32 & 267447.1 & 267331.6 & 19263.9 & 20497.5 & 96797.5 & 102795.1 \\
\hline 33 & 270424.4 & 262434.7 & 19457.8 & 20100.9 & 97796.4 & 100831.0 \\
\hline 34 & 273457.7 & 257648.8 & 19654.4 & 19712.6 & 98810.9 & 98909.7 \\
\hline 35 & 276546.9 & 252970.4 & 19853.6 & 19332.4 & 99840.8 & 97029.7 \\
\hline 36 & 279692.5 & 248395.9 & 20055.4 & 18960.1 & 100886.0 & 95189.9 \\
\hline 37 & 282894.8 & 243922.2 & 20259.8 & 18595.4 & 101946.7 & 93389.0 \\
\hline 38 & 286216.5 & 239598.3 & 20467.9 & 18239.3 & 103033.4 & 91635.4 \\
\hline 39 & 284337.6 & 231092.7 & 20606.8 & 17828.2 & 103352.6 & 89242.0 \\
\hline 40 & 287821.8 & 227111.1 & 20815.0 & 17483.8 & 104448.2 & 87561.2 \\
\hline 41 & 291205.8 & 223088.6 & 21025.6 & 17146.3 & 105545.9 & 85904.3 \\
\hline 42 & 294668.1 & 219166.1 & 21240.4 & 16816.9 & 106668.2 & 84289.0 \\
\hline 43 & 298205.9 & 215337.3 & 21458.7 & 16494.9 & 107812.0 & 82711.6 \\
\hline 44 & 301711.1 & 211522.8 & 21678.3 & 16178.4 & 108957.6 & 81155.8 \\
\hline 45 & 305136.9 & 207693.7 & 21898.4 & 15866.7 & 110096.4 & 79615.5 \\
\hline 46 & 308631.1 & 203953.4 & 22121.5 & 15561.5 & 111253.6 & 78109.1 \\
\hline 47 & 312194.0 & 200299.0 & 22347.6 & 15262.6 & 112429.0 & 76635.2 \\
\hline 48 & 316160.4 & 196935.6 & 22582.9 & 14974.1 & 113680.3 & 75231.3 \\
\hline
\end{tabular}




\begin{tabular}{|rrr|rr|rr|}
\cline { 2 - 7 } & \multicolumn{2}{c|}{ Passenger } & \multicolumn{2}{c|}{ Medium Truck } & \multicolumn{2}{c|}{ Large Truck } \\
\hline Year & Fuel (gal) & Present Cost (\$) & Fuel (gal) & Present Cost (\$) & Fuel (gal) & Present Cost (\$) \\
\hline 49 & 314085.6 & 189944.9 & 22732.0 & 14633.9 & 114011.4 & 73252.8 \\
\hline 50 & 317784.1 & 186584.1 & 22959.9 & 14350.2 & 115199.3 & 71860.2 \\
\hline 51 & 321525.8 & 183282.5 & 23193.0 & 14073.7 & 116414.5 & 70503.1 \\
\hline 52 & 325366.4 & 180069.7 & 23430.9 & 13803.9 & 117658.4 & 69181.0 \\
\hline 53 & 329300.0 & 176938.6 & 23672.7 & 13540.1 & 118927.5 & 67890.5 \\
\hline 54 & 333276.9 & 173859.6 & 23917.5 & 13281.7 & 120212.1 & 66625.1 \\
\hline 55 & 337103.7 & 170734.0 & 24161.5 & 13026.4 & 121478.1 & 65365.8 \\
\hline 56 & 341013.6 & 167683.7 & 24409.0 & 12776.5 & 122765.7 & 64134.6 \\
\hline 57 & 345006.6 & 164706.0 & 24659.9 & 12531.9 & 124074.6 & 62930.4 \\
\hline 58 & 349169.0 & 161837.9 & 24915.9 & 12293.2 & 125419.6 & 61759.8 \\
\hline 59 & 346945.9 & 156123.8 & 25079.5 & 12013.5 & 125785.4 & 60135.9 \\
\hline 60 & 351280.2 & 153470.2 & 25336.5 & 11783.2 & 127144.0 & 59015.0 \\
\hline
\end{tabular}

Table D.46. Pay Items for Case B-10\% Penetration

\begin{tabular}{|c|c|c|c|c|c|}
\hline Number & Stage & Description & Unit & Quantity & Present Cost (\$) \\
\hline 1 & Material \& Construction & $\begin{array}{c}\text { HOT-MIX ASPHALT SURFACE } \\
\text { COURSE }\end{array}$ & TON & 1531.00 & $\$ 202,967.08$ \\
\hline 2 & Maintenance \& Rehabilitation & $\begin{array}{c}\text { HOT-MIX ASPHALT REMOVAL } \\
\text { OVER PATCHES, 2" }\end{array}$ & SQ YD & 14080.00 & $\$ 149,534.27$ \\
\hline 3 & Maintenance \& Rehabilitation & $\begin{array}{c}\text { HOT-MIX ASPHALT SURFACE } \\
\text { COURSE REPLACEMENT } \\
\text { OVER PATCHES }\end{array}$ & TON & 1531.20 & $\$ 106,697.26$ \\
\hline 4 & Maintenance \& Rehabilitation & $\begin{array}{l}\text { HOT-MIX ASPHALT REMOVAL } \\
\text { OVER PATCHES, 2" }\end{array}$ & SQ YD & 14080.00 & $\$ 101,825.56$ \\
\hline 5 & Maintenance \& Rehabilitation & $\begin{array}{c}\text { HOT-MIX ASPHALT SURFACE } \\
\text { COURSE REPLACEMENT } \\
\text { OVER PATCHES }\end{array}$ & TON & 1531.20 & $\$ 72,655.64$ \\
\hline 6 & Maintenance \& Rehabilitation & $\begin{array}{l}\text { HOT-MIX ASPHALT REMOVAL } \\
\text { OVER PATCHES, 2" }\end{array}$ & SQ YD & 14080.00 & $\$ 71,418.40$ \\
\hline 7 & Maintenance \& Rehabilitation & $\begin{array}{l}\text { HOT-MIX ASPHALT REMOVAL } \\
\text { OVER PATCHES, 2" }\end{array}$ & SQ YD & 14080.00 & $\$ 53,142.00$ \\
\hline 8 & Maintenance \& Rehabilitation & $\begin{array}{l}\text { HOT-MIX ASPHALT SURFACE } \\
\text { COURSE REPLACEMENT } \\
\text { OVER PATCHES }\end{array}$ & TON & 1531.20 & $\$ 50,959.20$ \\
\hline 9 & Material \& Construction & $\begin{array}{c}\text { HOT-MIX ASPHALT SURFACE } \\
\text { REMOVAL }\end{array}$ & SQ YD & 14080.00 & $\$ 43,628.32$ \\
\hline 10 & Maintenance \& Rehabilitation & $\begin{array}{c}\text { HOT-MIX ASPHALT SURFACE } \\
\text { COURSE REPLACEMENT } \\
\text { OVER PATCHES }\end{array}$ & TON & 1531.20 & $\$ 37,918.43$ \\
\hline 11 & Maintenance \& Rehabilitation & $\begin{array}{l}\text { HOT-MIX ASPHALT REMOVAL } \\
\text { OVER PATCHES, 2" }\end{array}$ & SQ YD & 2816.00 & $\$ 8,145.78$ \\
\hline 12 & Maintenance \& Rehabilitation & EPOXY PVT MK LINE 6 & FOOT & 10560.00 & $\$ 7,000.84$ \\
\hline 13 & Maintenance \& Rehabilitation & $\begin{array}{c}\text { HOT-MIX ASPHALT SURFACE } \\
\text { COURSE REPLACEMENT } \\
\text { OVER PATCHES }\end{array}$ & TON & 306.24 & $\$ 5,812.26$ \\
\hline 14 & Maintenance \& Rehabilitation & EPOXY PVT MK LINE 6 & FOOT & 10560.00 & $\$ 4,767.23$ \\
\hline 15 & Maintenance \& Rehabilitation & EPOXY PVT MK LINE 4 & FOOT & 10560.00 & $\$ 3,843.60$ \\
\hline 16 & Maintenance \& Rehabilitation & EPOXY PVT MK LINE 6 & FOOT & 10560.00 & $\$ 3,343.64$ \\
\hline 17 & Maintenance \& Rehabilitation & EPOXY PVT MK LINE 4 & FOOT & 10560.00 & $\$ 2,617.30$ \\
\hline
\end{tabular}




\begin{tabular}{|c|c|c|c|c|c|}
\hline Number & Stage & Description & Unit & Quantity & Present Cost (\$) \\
\hline 1 & Material \& Construction & $\begin{array}{c}\text { HOT-MIX ASPHALT SURFACE } \\
\text { COURSE }\end{array}$ & TON & 1531.00 & $\$ 202,967.08$ \\
\hline 18 & Maintenance \& Rehabilitation & EPOXY PVT MK LINE 6 & FOOT & 10560.00 & $\$ 2,487.98$ \\
\hline 19 & Maintenance \& Rehabilitation & EPOXY PVT MK LINE 4 & FOOT & 10560.00 & $\$ 1,835.72$ \\
\hline 20 & Maintenance \& Rehabilitation & EPOXY PVT MK LINE 4 & FOOT & 10560.00 & $\$ 1,365.95$ \\
\hline 21 & Maintenance \& Rehabilitation & EPOXY PVT MK LINE 6 & FOOT & 2112.00 & $\$ 381.37$ \\
\hline 22 & Maintenance \& Rehabilitation & EPOXY PVT MK LINE 4 & FOOT & 2112.00 & $\$ 209.38$ \\
\hline 23 & Maintenance \& Rehabilitation & $\begin{array}{l}\text { BITUMINOUS MATERIALS } \\
\text { (PRIME COAT) }\end{array}$ & GAL & 234.67 & $\$ 158.62$ \\
\hline 24 & Maintenance \& Rehabilitation & $\begin{array}{l}\text { BITUMINOUS MATERIALS } \\
\text { (PRIME COAT) }\end{array}$ & GAL & 234.67 & $\$ 108.02$ \\
\hline 25 & Maintenance \& Rehabilitation & $\begin{array}{c}\text { BITUMINOUS MATERIALS } \\
\text { (PRIME COAT) }\end{array}$ & GAL & 234.67 & $\$ 75.76$ \\
\hline 26 & Maintenance \& Rehabilitation & $\begin{array}{l}\text { BITUMINOUS MATERIALS } \\
\text { (PRIME COAT) }\end{array}$ & GAL & 234.67 & $\$ 56.37$ \\
\hline 27 & Maintenance \& Rehabilitation & $\begin{array}{l}\text { BITUMINOUS MATERIALS } \\
\text { (PRIME COAT) }\end{array}$ & GAL & 46.93 & $\$ 8.64$ \\
\hline
\end{tabular}

Table D.47. Fuel Cost for Case B-10\% Penetration

\begin{tabular}{|c|c|c|c|c|c|c|}
\hline & \multicolumn{2}{|c|}{ Passenger } & \multicolumn{2}{|c|}{ Medium Truck } & \multicolumn{2}{|c|}{ Large Truck } \\
\hline Year & Fuel (gal) & Present Cost (\$) & Fuel (gal) & Present Cost (\$) & Fuel (gal) & Present Cost (\$) \\
\hline 0 & 192927.3 & 496589.2 & 14074.3 & 38547.0 & 70592.5 & 192585.2 \\
\hline 1 & 194896.6 & 487046.8 & 14206.1 & 37774.7 & 71256.8 & 188735.3 \\
\hline 2 & 196911.1 & 477748.6 & 14342.6 & 37026.7 & 71946.5 & 185011.8 \\
\hline 3 & 198963.9 & 468669.0 & 14481.9 & 36297.5 & 72652.1 & 181384.9 \\
\hline 4 & 201053.0 & 459796.2 & 14623.6 & 35585.1 & 73370.9 & 177844.0 \\
\hline 5 & 203177.6 & 451121.4 & 14767.3 & 34888.3 & 74101.5 & 174383.4 \\
\hline 6 & 205337.3 & 442637.5 & 14913.1 & 34206.5 & 74843.2 & 170998.9 \\
\hline 7 & 207532.1 & 434338.5 & 15060.8 & 33539.1 & 75595.7 & 167687.7 \\
\hline 8 & 209761.9 & 426218.8 & 15210.4 & 32885.6 & 76358.9 & 164447.2 \\
\hline 9 & 212027.2 & 418273.4 & 15361.8 & 32245.6 & 77132.7 & 161275.2 \\
\hline 10 & 214328.1 & 410497.6 & 15515.1 & 31618.9 & 77916.9 & 158169.9 \\
\hline 11 & 216665.1 & 402886.9 & 15670.3 & 31004.9 & 78711.7 & 155129.5 \\
\hline 12 & 219038.5 & 395437.2 & 15827.3 & 30403.5 & 79517.1 & 152152.3 \\
\hline 13 & 221448.9 & 388144.4 & 15986.2 & 29814.4 & 80333.2 & 149236.7 \\
\hline 14 & 223896.7 & 381004.6 & 16147.0 & 29237.2 & 81160.0 & 146381.3 \\
\hline 15 & 223990.2 & 370061.8 & 16292.7 & 28641.6 & 81719.8 & 143097.9 \\
\hline 16 & 226296.7 & 362983.1 & 16447.1 & 28071.0 & 82499.9 & 140256.3 \\
\hline 17 & 228659.2 & 356089.8 & 16606.6 & 27517.7 & 83307.9 & 137504.8 \\
\hline 18 & 231070.7 & 349364.3 & 16769.4 & 26978.0 & 84134.3 & 134824.1 \\
\hline 19 & 233528.6 & 342796.6 & 16934.8 & 26450.7 & 84976.2 & 132207.0 \\
\hline 20 & 236031.9 & 336379.8 & 17102.7 & 25934.8 & 85832.1 & 129649.2 \\
\hline 21 & 238580.2 & 330108.2 & 17272.9 & 25430.1 & 86701.5 & 127147.9 \\
\hline 22 & 241173.3 & 323976.8 & 17445.4 & 24935.9 & 87584.0 & 124701.1 \\
\hline 23 & 243811.3 & 317981.1 & 17620.1 & 24452.1 & 88479.5 & 122306.8 \\
\hline 24 & 246494.5 & 312117.0 & 17797.1 & 23978.4 & 89387.8 & 119963.5 \\
\hline 25 & 249223.3 & 306380.9 & 17976.3 & 23514.4 & 90309.0 & 117669.7 \\
\hline 26 & 251998.2 & 300769.2 & 18157.7 & 23059.9 & 91243.1 & 115424.1 \\
\hline 27 & 254819.8 & 295278.4 & 18341.4 & 22614.7 & 92190.2 & 113225.5 \\
\hline 28 & 254923.2 & 286794.5 & 18502.0 & 22148.3 & 92801.5 & 110656.6 \\
\hline
\end{tabular}




\begin{tabular}{|c|c|c|c|c|c|c|}
\hline & \multicolumn{2}{|c|}{ Passenger } & \multicolumn{2}{|c|}{ Medium Truck } & \multicolumn{2}{|c|}{ Large Truck } \\
\hline Year & Fuel (gal) & Present Cost (\$) & Fuel (gal) & Present Cost (\$) & Fuel (gal) & Present Cost (\$) \\
\hline 29 & 257563.3 & 281324.9 & 18679.1 & 21709.0 & 93696.7 & 108469.8 \\
\hline 30 & 260275.3 & 276006.9 & 18861.5 & 21282.6 & 94623.0 & 106351.7 \\
\hline 31 & 263049.5 & 270824.0 & 19047.7 & 20866.6 & 95570.6 & 104288.1 \\
\hline 32 & 265882.3 & 265767.5 & 19236.9 & 20460.1 & 96536.3 & 102273.7 \\
\hline 33 & 268772.3 & 260831.3 & 19429.0 & 20062.5 & 97518.7 & 100305.3 \\
\hline 34 & 271718.6 & 256010.3 & 19623.8 & 19673.4 & 98517.2 & 98380.9 \\
\hline 35 & 274721.1 & 251300.2 & 19821.2 & 19292.6 & 99531.4 & 96498.7 \\
\hline 36 & 277779.8 & 246697.3 & 20021.3 & 18919.7 & 100561.0 & 94657.3 \\
\hline 37 & 280895.2 & 242198.0 & 20223.9 & 18554.6 & 101606.1 & 92855.4 \\
\hline 38 & 284067.5 & 237799.4 & 20429.2 & 18197.1 & 102666.7 & 91091.8 \\
\hline 39 & 287297.6 & 233498.4 & 20637.1 & 17846.8 & 103742.8 & 89365.7 \\
\hline 40 & 287303.9 & 226702.5 & 20812.2 & 17474.0 & 104392.8 & 87306.4 \\
\hline 41 & 290331.5 & 222418.9 & 21013.5 & 17129.2 & 105414.9 & 85593.4 \\
\hline 42 & 293440.6 & 218253.1 & 21220.6 & 16794.2 & 106470.4 & 83932.4 \\
\hline 43 & 296624.1 & 214195.0 & 21431.8 & 16467.3 & 107549.9 & 82314.0 \\
\hline 44 & 299878.8 & 210238.2 & 21646.4 & 16147.8 & 108650.3 & 80734.2 \\
\hline 45 & 303203.4 & 206377.6 & 21864.3 & 15835.2 & 109770.2 & 79190.6 \\
\hline 46 & 306597.2 & 202609.3 & 22085.4 & 15529.5 & 110909.0 & 77681.7 \\
\hline 47 & 310060.0 & 198929.8 & 22309.5 & 15230.1 & 112066.3 & 76206.1 \\
\hline 48 & 313592.1 & 195335.9 & 22536.6 & 14937.1 & 113242.0 & 74762.8 \\
\hline 49 & 317193.9 & 191824.7 & 22766.8 & 14650.2 & 114436.1 & 73350.6 \\
\hline 50 & 317327.7 & 186316.1 & 22958.3 & 14343.1 & 115154.5 & 71661.2 \\
\hline 51 & 320670.4 & 182794.9 & 23181.3 & 14060.6 & 116286.7 & 70258.0 \\
\hline 52 & 324120.0 & 179379.9 & 23410.8 & 13786.2 & 117457.4 & 68898.4 \\
\hline 53 & 327662.9 & 176058.9 & 23644.8 & 13518.4 & 118655.8 & 67574.1 \\
\hline 54 & 331293.7 & 172825.1 & 23882.8 & 13256.8 & 119878.6 & 66282.1 \\
\hline 55 & 335010.0 & 169673.5 & 24124.5 & 13000.9 & 121124.2 & 65020.2 \\
\hline 56 & 338810.4 & 166600.3 & 24369.8 & 12750.6 & 122391.8 & 63787.0 \\
\hline 57 & 342694.5 & 163602.1 & 24618.5 & 12505.6 & 123681.1 & 62581.5 \\
\hline 58 & 346662.4 & 160676.1 & 24870.8 & 12265.8 & 124991.9 & 61402.7 \\
\hline 59 & 347026.4 & 156160.0 & 25081.0 & 12009.2 & 125799.5 & 59999.4 \\
\hline 60 & 350664.3 & 153201.0 & 25325.3 & 11772.9 & 127037.9 & 58825.3 \\
\hline
\end{tabular}


Table D.48. Pay Items for Case B-20\% Penetration

\begin{tabular}{|c|c|c|c|c|c|}
\hline Number & Stage & Description & Unit & Quantity & Present Cost (\$) \\
\hline 1 & Material \& Construction & $\begin{array}{c}\text { HOT-MIX ASPHALT SURFACE } \\
\text { COURSE }\end{array}$ & TON & 1531.00 & $\$ 179,417.81$ \\
\hline 2 & Maintenance \& Rehabilitation & $\begin{array}{c}\text { HOT-MIX ASPHALT SURFACE } \\
\text { COURSE REPLACEMENT } \\
\text { OVER PATCHES }\end{array}$ & TON & 1530.92 & $\$ 118,609.99$ \\
\hline 3 & Maintenance \& Rehabilitation & $\begin{array}{c}\text { HOT-MIX ASPHALT SURFACE } \\
\text { COURSE REPLACEMENT } \\
\text { OVER PATCHES }\end{array}$ & TON & 1530.92 & $\$ 80,767.63$ \\
\hline 4 & Maintenance \& Rehabilitation & $\begin{array}{c}\text { HOT-MIX ASPHALT SURFACE } \\
\text { COURSE REPLACEMENT } \\
\text { OVER PATCHES }\end{array}$ & TON & 1530.92 & $\$ 58,348.25$ \\
\hline 5 & Maintenance \& Rehabilitation & $\begin{array}{c}\text { HOT-MIX ASPHALT SURFACE } \\
\text { COURSE REPLACEMENT } \\
\text { OVER PATCHES }\end{array}$ & TON & 1530.92 & $\$ 43,416.58$ \\
\hline 6 & Maintenance \& Rehabilitation & $\begin{array}{c}\text { HOT-MIX ASPHALT SURFACE } \\
\text { COURSE REPLACEMENT } \\
\text { OVER PATCHES }\end{array}$ & TON & 459.28 & $\$ 9,691.80$ \\
\hline 7 & Maintenance \& Rehabilitation & EPOXY PVT MK LINE 6 & FOOT & 10560.00 & $\$ 7,210.86$ \\
\hline 8 & Maintenance \& Rehabilitation & EPOXY PVT MK LINE 6 & FOOT & 10560.00 & $\$ 4,910.25$ \\
\hline 9 & Maintenance \& Rehabilitation & EPOXY PVT MK LINE 4 & FOOT & 10560.00 & $\$ 3,958.91$ \\
\hline 10 & Maintenance \& Rehabilitation & EPOXY PVT MK LINE 6 & FOOT & 10560.00 & $\$ 3,547.27$ \\
\hline 11 & Maintenance \& Rehabilitation & EPOXY PVT MK LINE 4 & FOOT & 10560.00 & $\$ 2,695.82$ \\
\hline 12 & Maintenance \& Rehabilitation & EPOXY PVT MK LINE 6 & FOOT & 10560.00 & $\$ 2,639.50$ \\
\hline 13 & Maintenance \& Rehabilitation & EPOXY PVT MK LINE 4 & FOOT & 10560.00 & $\$ 1,947.52$ \\
\hline 14 & Maintenance \& Rehabilitation & EPOXY PVT MK LINE 4 & FOOT & 10560.00 & $\$ 1,449.14$ \\
\hline 15 & Maintenance \& Rehabilitation & EPOXY PVT MK LINE 6 & FOOT & 3168.00 & $\$ 589.21$ \\
\hline 16 & Maintenance \& Rehabilitation & EPOXY PVT MK LINE 4 & FOOT & 3168.00 & $\$ 323.49$ \\
\hline 17 & Maintenance \& Rehabilitation & $\begin{array}{l}\text { BITUMINOUS MATERIALS } \\
\text { (PRIME COAT) }\end{array}$ & GAL & 234.67 & $\$ 163.38$ \\
\hline 18 & Maintenance \& Rehabilitation & $\begin{array}{l}\text { BITUMINOUS MATERIALS } \\
\text { (PRIME COAT) }\end{array}$ & GAL & 234.67 & $\$ 111.26$ \\
\hline 19 & Maintenance \& Rehabilitation & $\begin{array}{l}\text { BITUMINOUS MATERIALS } \\
\text { (PRIME COAT) }\end{array}$ & GAL & 234.67 & $\$ 80.37$ \\
\hline 20 & Maintenance \& Rehabilitation & $\begin{array}{c}\text { BITUMINOUS MATERIALS } \\
\text { (PRIME COAT) }\end{array}$ & GAL & 234.67 & $\$ 59.81$ \\
\hline 21 & Maintenance \& Rehabilitation & $\begin{array}{c}\text { BITUMINOUS MATERIALS } \\
\text { (PRIME COAT) }\end{array}$ & GAL & 70.40 & $\$ 13.35$ \\
\hline 22 & Material \& Construction & $\begin{array}{c}\text { HOT-MIX ASPHALT SURFACE } \\
\text { REMOVAL }\end{array}$ & SQ YD & 14080.00 & $\$ 0.00$ \\
\hline 23 & Maintenance \& Rehabilitation & $\begin{array}{c}\text { HOT-MIX ASPHALT REMOVAL } \\
\text { OVER PATCHES, } 2 "\end{array}$ & SQ YD & 14080.00 & $\$ 0.00$ \\
\hline 24 & Maintenance \& Rehabilitation & $\begin{array}{c}\text { HOT-MIX ASPHALT REMOVAL } \\
\text { OVER PATCHES, } 2 "\end{array}$ & SQ YD & 14080.00 & $\$ 0.00$ \\
\hline 25 & Maintenance \& Rehabilitation & $\begin{array}{c}\text { HOT-MIX ASPHALT REMOVAL } \\
\text { OVER PATCHES, 2" }\end{array}$ & SQ YD & 14080.00 & $\$ 0.00$ \\
\hline 26 & Maintenance \& Rehabilitation & $\begin{array}{c}\text { HOT-MIX ASPHALT REMOVAL } \\
\text { OVER PATCHES, } 2 "\end{array}$ & SQ YD & 14080.00 & $\$ 0.00$ \\
\hline 27 & Maintenance \& Rehabilitation & $\begin{array}{c}\text { HOT-MIX ASPHALT REMOVAL } \\
\text { OVER PATCHES, 2" }\end{array}$ & SQ YD & 4224.00 & $\$ 0.00$ \\
\hline
\end{tabular}


Table D.49. Fuel Cost for Case B-20\% Penetration

\begin{tabular}{|c|c|c|c|c|c|c|}
\hline & \multicolumn{2}{|c|}{ Passenger } & \multicolumn{2}{|c|}{ Medium Truck } & \multicolumn{2}{|c|}{ Large Truck } \\
\hline Year & Fuel (gal) & Present Cost (\$) & Fuel (gal) & Present Cost (\$) & Fuel (gal) & Present Cost (\$) \\
\hline 0 & 192886.0 & 496483.0 & 14073.6 & 38512.4 & 70585.8 & 191647.7 \\
\hline 1 & 195045.4 & 487418.6 & 14208.9 & 37750.1 & 71282.9 & 187903.3 \\
\hline 2 & 197271.7 & 478623.5 & 14349.3 & 37012.6 & 72009.2 & 184289.1 \\
\hline 3 & 199541.0 & 470028.4 & 14492.6 & 36293.5 & 72752.2 & 180767.8 \\
\hline 4 & 201851.2 & 461621.6 & 14638.3 & 35590.8 & 73509.2 & 177328.7 \\
\hline 5 & 204201.5 & 453394.9 & 14786.3 & 34903.3 & 74278.7 & 173966.1 \\
\hline 6 & 206430.8 & 444994.6 & 14933.3 & 34223.7 & 75032.5 & 170613.0 \\
\hline 7 & 208681.8 & 436744.8 & 15082.0 & 33557.8 & 75794.8 & 167326.5 \\
\hline 8 & 210969.3 & 428672.0 & 15232.7 & 32905.8 & 76567.9 & 164110.0 \\
\hline 9 & 213293.4 & 420771.3 & 15385.2 & 32267.3 & 77351.8 & 160961.4 \\
\hline 10 & 215654.5 & 413038.0 & 15539.6 & 31641.9 & 78146.5 & 157878.6 \\
\hline 11 & 218053.0 & 405467.7 & 15695.9 & 31029.2 & 78951.9 & 154860.0 \\
\hline 12 & 220489.3 & 398056.3 & 15854.1 & 30429.1 & 79768.1 & 151904.0 \\
\hline 13 & 223183.1 & 391184.0 & 16018.2 & 29848.7 & 80633.2 & 149078.9 \\
\hline 14 & 221717.5 & 377296.3 & 16133.3 & 29187.5 & 80916.2 & 145244.9 \\
\hline 15 & 224253.6 & 370497.0 & 16290.9 & 28614.1 & 81731.9 & 142435.9 \\
\hline 16 & 226831.1 & 363840.2 & 16453.1 & 28057.4 & 82572.9 & 139710.2 \\
\hline 17 & 229462.9 & 357341.4 & 16618.7 & 27514.3 & 83433.1 & 137054.1 \\
\hline 18 & 232146.2 & 350990.4 & 16787.1 & 26983.6 & 84309.7 & 134460.1 \\
\hline 19 & 234863.3 & 344755.7 & 16957.7 & 26463.9 & 85198.2 & 131919.7 \\
\hline 20 & 237444.8 & 338393.4 & 17127.3 & 25950.0 & 86069.1 & 129386.4 \\
\hline 21 & 240072.0 & 332172.4 & 17299.2 & 25447.1 & 86953.1 & 126908.2 \\
\hline 22 & 242745.1 & 326088.3 & 17473.3 & 24954.5 & 87850.2 & 124483.0 \\
\hline 23 & 245464.3 & 320137.0 & 17649.6 & 24472.2 & 88760.3 & 122109.3 \\
\hline 24 & 248230.0 & 314314.6 & 17828.2 & 23999.9 & 89683.3 & 119785.6 \\
\hline 25 & 251042.6 & 308617.5 & 18009.0 & 23537.1 & 90619.4 & 117510.6 \\
\hline 26 & 253954.6 & 303104.1 & 18193.0 & 23085.1 & 91577.5 & 115294.2 \\
\hline 27 & 252335.2 & 292399.4 & 18320.7 & 22569.9 & 91886.7 & 112313.9 \\
\hline 28 & 255403.6 & 287335.0 & 18504.2 & 22132.1 & 92851.1 & 110187.2 \\
\hline 29 & 258384.1 & 282221.4 & 18690.3 & 21703.6 & 93819.1 & 108093.1 \\
\hline 30 & 261429.1 & 277230.4 & 18880.1 & 21285.4 & 94808.7 & 106051.7 \\
\hline 31 & 264536.5 & 272355.0 & 19073.0 & 20876.5 & 95817.0 & 104057.8 \\
\hline 32 & 267610.6 & 267495.1 & 19267.0 & 20474.7 & 96826.3 & 102091.3 \\
\hline 33 & 270609.9 & 262614.6 & 19461.4 & 20078.9 & 97829.0 & 100144.2 \\
\hline 34 & 273665.7 & 257844.8 & 19658.4 & 19691.4 & 98847.4 & 98239.5 \\
\hline 35 & 276778.3 & 253182.0 & 19858.0 & 19312.0 & 99881.4 & 96375.8 \\
\hline 36 & 279948.1 & 248622.9 & 20060.2 & 18940.5 & 100930.8 & 94551.8 \\
\hline 37 & 283382.1 & 244342.4 & 20268.9 & 18580.0 & 102031.5 & 92799.0 \\
\hline 38 & 281522.4 & 235668.8 & 20405.8 & 18160.7 & 102344.5 & 90372.5 \\
\hline 39 & 284870.5 & 231525.8 & 20610.0 & 17808.2 & 103411.4 & 88655.0 \\
\hline 40 & 288209.3 & 227416.9 & 20818.3 & 17464.3 & 104496.0 & 86975.5 \\
\hline 41 & 291629.2 & 223413.0 & 21030.7 & 17128.6 & 105605.6 & 85338.9 \\
\hline 42 & 295126.1 & 219506.7 & 21246.8 & 16800.6 & 106737.0 & 83741.0 \\
\hline 43 & 298634.9 & 215647.1 & 21464.9 & 16478.7 & 107877.8 & 82170.9 \\
\hline 44 & 302024.7 & 211742.6 & 21682.7 & 16161.1 & 109004.9 & 80611.0 \\
\hline 45 & 305483.8 & 207929.8 & 21903.6 & 15850.2 & 110150.5 & 79085.6 \\
\hline 46 & 309012.1 & 204205.2 & 22127.5 & 15545.8 & 111314.3 & 77593.4 \\
\hline 47 & 313029.7 & 200835.1 & 22362.1 & 15253.1 & 112568.8 & 76182.4 \\
\hline 48 & 310975.9 & 193706.2 & 22510.0 & 14906.7 & 112897.8 & 74179.7 \\
\hline
\end{tabular}




\begin{tabular}{|c|c|c|c|c|c|c|}
\hline & \multicolumn{2}{|c|}{ Passenger } & \multicolumn{2}{|c|}{ Medium Truck } & \multicolumn{2}{|c|}{ Large Truck } \\
\hline Year & Fuel (gal) & Present Cost (\$) & Fuel (gal) & Present Cost (\$) & Fuel (gal) & Present Cost (\$) \\
\hline 49 & 314583.5 & 190246.0 & 22734.5 & 14616.9 & 114064.2 & 72763.2 \\
\hline 50 & 318282.0 & 186876.4 & 22965.2 & 14335.2 & 115266.1 & 71388.3 \\
\hline 51 & 322082.0 & 183599.6 & 23200.6 & 14060.3 & 116497.1 & 70049.2 \\
\hline 52 & 325976.5 & 180407.4 & 23440.1 & 13791.7 & 117753.5 & 68742.4 \\
\hline 53 & 329939.2 & 177282.0 & 23682.8 & 13528.7 & 119029.6 & 67463.4 \\
\hline 54 & 333732.0 & 174097.0 & 23924.5 & 13268.6 & 120283.8 & 66188.6 \\
\hline 55 & 337608.5 & 170989.6 & 24169.6 & 13014.2 & 121559.4 & 64942.3 \\
\hline 56 & 341568.8 & 167956.7 & 24418.2 & 12765.1 & 122856.5 & 63723.5 \\
\hline 57 & 345699.4 & 165036.7 & 24671.8 & 12522.0 & 124189.7 & 62538.9 \\
\hline 58 & 343510.8 & 159215.4 & 24834.2 & 12237.3 & 124555.2 & 60896.1 \\
\hline 59 & 347808.7 & 156512.1 & 25088.8 & 12002.7 & 125901.2 & 59761.3 \\
\hline 60 & 351984.8 & 153777.9 & 25345.7 & 11772.4 & 127246.6 & 58640.7 \\
\hline
\end{tabular}

Table D.50. Pay Items for Case B-50\% Penetration

\begin{tabular}{|c|c|c|c|c|c|}
\hline Number & Stage & Description & Unit & Quantity & Present Cost (\$) \\
\hline 1 & Material \& Construction & $\begin{array}{c}\text { HOT-MIX ASPHALT SURFACE } \\
\text { COURSE }\end{array}$ & TON & 1531.00 & $\$ 179,417.81$ \\
\hline 2 & Maintenance \& Rehabilitation & $\begin{array}{c}\text { HOT-MIX ASPHALT SURFACE } \\
\text { COURSE REPLACEMENT OVER } \\
\text { PATCHES }\end{array}$ & TON & 1530.92 & $\$ 122,168.29$ \\
\hline 3 & Maintenance \& Rehabilitation & $\begin{array}{c}\text { HOT-MIX ASPHALT SURFACE } \\
\text { COURSE REPLACEMENT OVER } \\
\text { PATCHES }\end{array}$ & TON & 1530.92 & $\$ 83,190.66$ \\
\hline 4 & Maintenance \& Rehabilitation & $\begin{array}{c}\text { HOT-MIX ASPHALT SURFACE } \\
\text { COURSE REPLACEMENT OVER } \\
\text { PATCHES }\end{array}$ & TON & 1530.92 & $\$ 60,098.70$ \\
\hline 5 & Maintenance \& Rehabilitation & $\begin{array}{c}\text { HOT-MIX ASPHALT SURFACE } \\
\text { COURSE REPLACEMENT OVER } \\
\text { PATCHES }\end{array}$ & TON & 1530.92 & $\$ 44,719.08$ \\
\hline 6 & Maintenance \& Rehabilitation & $\begin{array}{c}\text { HOT-MIX ASPHALT SURFACE } \\
\text { COURSE REPLACEMENT OVER } \\
\text { PATCHES }\end{array}$ & TON & 857.31 & $\$ 19,193.13$ \\
\hline 7 & Maintenance \& Rehabilitation & EPOXY PVT MK LINE 6 & FOOT & 10560.00 & $\$ 7,427.19$ \\
\hline 8 & Maintenance \& Rehabilitation & EPOXY PVT MK LINE 6 & FOOT & 10560.00 & $\$ 5,057.56$ \\
\hline 9 & Maintenance \& Rehabilitation & EPOXY PVT MK LINE 4 & FOOT & 10560.00 & $\$ 4,077.67$ \\
\hline 10 & Maintenance \& Rehabilitation & EPOXY PVT MK LINE 6 & FOOT & 10560.00 & $\$ 3,653.69$ \\
\hline 11 & Maintenance \& Rehabilitation & EPOXY PVT MK LINE 4 & FOOT & 10560.00 & $\$ 2,776.70$ \\
\hline 12 & Maintenance \& Rehabilitation & EPOXY PVT MK LINE 6 & FOOT & 10560.00 & $\$ 2,718.69$ \\
\hline 13 & Maintenance \& Rehabilitation & EPOXY PVT MK LINE 4 & FOOT & 10560.00 & $\$ 2,005.95$ \\
\hline 14 & Maintenance \& Rehabilitation & EPOXY PVT MK LINE 4 & FOOT & 10560.00 & $\$ 1,492.61$ \\
\hline 15 & Maintenance \& Rehabilitation & EPOXY PVT MK LINE 6 & FOOT & 5913.60 & $\$ 1,166.84$ \\
\hline 16 & Maintenance \& Rehabilitation & EPOXY PVT MK LINE 4 & FOOT & 5913.60 & $\$ 640.62$ \\
\hline 17 & Maintenance \& Rehabilitation & $\begin{array}{l}\text { BITUMINOUS MATERIALS } \\
\text { (PRIME COAT) }\end{array}$ & GAL & 234.67 & $\$ 168.28$ \\
\hline 18 & Maintenance \& Rehabilitation & $\begin{array}{l}\text { BITUMINOUS MATERIALS } \\
\text { (PRIME COAT) }\end{array}$ & GAL & 234.67 & $\$ 114.59$ \\
\hline 19 & Maintenance \& Rehabilitation & $\begin{array}{c}\text { BITUMINOUS MATERIALS } \\
\text { (PRIME COAT) }\end{array}$ & GAL & 234.67 & $\$ 82.79$ \\
\hline
\end{tabular}




\begin{tabular}{|c|c|c|c|c|c|}
\hline Number & Stage & Description & Unit & Quantity & Present Cost (\$) \\
\hline 20 & Maintenance \& Rehabilitation & $\begin{array}{l}\text { BITUMINOUS MATERIALS } \\
\text { (PRIME COAT) }\end{array}$ & GAL & 234.67 & $\$ 61.60$ \\
\hline 21 & Maintenance \& Rehabilitation & $\begin{array}{l}\text { BITUMINOUS MATERIALS } \\
\text { (PRIME COAT) }\end{array}$ & GAL & 131.41 & $\$ 26.44$ \\
\hline 22 & Material \& Construction & $\begin{array}{l}\text { HOT-MIX ASPHALT SURFACE } \\
\text { REMOVAL }\end{array}$ & SQ YD & 14080.00 & $\$ 0.00$ \\
\hline 23 & Maintenance \& Rehabilitation & $\begin{array}{l}\text { HOT-MIX ASPHALT REMOVAL } \\
\text { OVER PATCHES, } 2 "\end{array}$ & SQ YD & 14080.00 & $\$ 0.00$ \\
\hline 24 & Maintenance \& Rehabilitation & $\begin{array}{l}\text { HOT-MIX ASPHALT REMOVAL } \\
\text { OVER PATCHES, } 2 "\end{array}$ & SQ YD & 14080.00 & $\$ 0.00$ \\
\hline 25 & Maintenance \& Rehabilitation & $\begin{array}{l}\text { HOT-MIX ASPHALT REMOVAL } \\
\text { OVER PATCHES, } 2 "\end{array}$ & SQ YD & 14080.00 & $\$ 0.00$ \\
\hline 26 & Maintenance \& Rehabilitation & $\begin{array}{c}\text { HOT-MIX ASPHALT REMOVAL } \\
\text { OVER PATCHES, } 2 "\end{array}$ & SQ YD & 14080.00 & $\$ 0.00$ \\
\hline 27 & Maintenance \& Rehabilitation & $\begin{array}{c}\text { HOT-MIX ASPHALT REMOVAL } \\
\text { OVER PATCHES, } 2 "\end{array}$ & SQ YD & 7884.80 & $\$ 0.00$ \\
\hline
\end{tabular}

Table D.51. Fuel Cost for Case B-50\% Penetration

\begin{tabular}{|c|c|c|c|c|c|c|}
\hline & \multicolumn{2}{|c|}{ Passenger } & \multicolumn{2}{|c|}{ Medium Truck } & \multicolumn{2}{|c|}{ Large Truck } \\
\hline Year & Fuel (gal) & Present Cost (\$) & Fuel (gal) & Present Cost (\$) & Fuel (gal) & Present Cost (\$) \\
\hline 0 & 192886.0 & 496483.0 & 14073.8 & 38414.5 & 70586.6 & 188892.0 \\
\hline 1 & 195047.7 & 487424.3 & 14209.1 & 37654.3 & 71284.0 & 185202.4 \\
\hline 2 & 197278.5 & 478640.1 & 14349.6 & 36918.8 & 72011.1 & 181642.1 \\
\hline 3 & 199553.9 & 470058.9 & 14493.0 & 36201.8 & 72755.2 & 178173.9 \\
\hline 4 & 201871.7 & 461668.4 & 14638.9 & 35501.2 & 73513.5 & 174787.1 \\
\hline 5 & 204230.8 & 453459.9 & 14787.0 & 34815.9 & 74284.5 & 171476.2 \\
\hline 6 & 206470.2 & 445079.5 & 14934.2 & 34138.4 & 75040.0 & 168174.8 \\
\hline 7 & 208732.5 & 436850.9 & 15083.1 & 33474.6 & 75804.2 & 164939.4 \\
\hline 8 & 211032.6 & 428800.6 & 15234.0 & 32824.6 & 76579.5 & 161773.1 \\
\hline 9 & 213370.5 & 420923.3 & 15386.8 & 32188.2 & 77365.8 & 158673.9 \\
\hline 10 & 215746.6 & 413214.3 & 15541.4 & 31564.8 & 78163.1 & 155639.9 \\
\hline 11 & 218161.3 & 405669.1 & 15698.0 & 30954.2 & 78971.3 & 152669.2 \\
\hline 12 & 220615.0 & 398283.3 & 15856.6 & 30356.1 & 79790.6 & 149760.2 \\
\hline 13 & 223151.9 & 391129.3 & 16043.5 & 29819.4 & 80757.4 & 147160.1 \\
\hline 14 & 221717.5 & 377296.3 & 16126.8 & 29101.1 & 80883.1 & 143096.3 \\
\hline 15 & 224397.5 & 370734.8 & 16289.7 & 28539.0 & 81737.7 & 140396.3 \\
\hline 16 & 227001.2 & 364113.1 & 16453.6 & 27986.6 & 82589.0 & 137726.6 \\
\hline 17 & 229658.4 & 357645.8 & 16620.3 & 27446.7 & 83456.8 & 135120.2 \\
\hline 18 & 232367.4 & 351324.9 & 16789.5 & 26918.6 & 84339.7 & 132572.5 \\
\hline 19 & 235044.3 & 345021.5 & 16959.7 & 26399.4 & 85222.7 & 130058.7 \\
\hline 20 & 237652.8 & 338689.8 & 17130.0 & 25887.8 & 86099.2 & 127569.2 \\
\hline 21 & 240308.1 & 332499.1 & 17302.5 & 25387.0 & 86988.8 & 125133.4 \\
\hline 22 & 243010.7 & 326445.0 & 17477.3 & 24896.6 & 87891.6 & 122749.6 \\
\hline 23 & 245760.7 & 320523.6 & 17654.3 & 24416.2 & 88807.5 & 120416.3 \\
\hline 24 & 248558.8 & 314730.9 & 17833.6 & 23945.8 & 89736.6 & 118132.0 \\
\hline 25 & 251458.2 & 309128.4 & 18016.0 & 23486.2 & 90688.0 & 115907.3 \\
\hline 26 & 249836.8 & 298189.5 & 18142.3 & 22962.0 & 90992.3 & 112908.9 \\
\hline 27 & 252882.9 & 293034.0 & 18324.2 & 22516.6 & 91948.2 & 110771.9 \\
\hline
\end{tabular}




\begin{tabular}{|c|c|c|c|c|c|c|}
\hline 28 & 255842.4 & 287828.6 & 18508.5 & 22080.7 & 92907.8 & 108668.0 \\
\hline 29 & 258868.1 & 282750.1 & 18696.6 & 21655.4 & 93889.4 & 106617.5 \\
\hline 30 & 261957.6 & 277790.8 & 18887.8 & 21239.7 & 94889.8 & 104615.1 \\
\hline 31 & 265016.0 & 272848.7 & 19080.2 & 20831.1 & 95891.6 & 102640.4 \\
\hline 32 & 268002.3 & 267886.6 & 19272.9 & 20428.7 & 96887.2 & 100685.5 \\
\hline 33 & 271046.5 & 263038.3 & 19468.3 & 20034.7 & 97898.7 & 98773.4 \\
\hline 34 & 274148.7 & 258299.9 & 19666.3 & 19649.0 & 98925.8 & 96902.6 \\
\hline 35 & 277309.4 & 253667.8 & 19866.9 & 19271.3 & 99968.7 & 95072.0 \\
\hline 36 & 280577.6 & 249182.0 & 20071.0 & 18902.3 & 101035.6 & 93288.0 \\
\hline 37 & 278735.0 & 240335.5 & 20206.8 & 18475.9 & 101346.6 & 90849.7 \\
\hline 38 & 282221.4 & 236254.0 & 20412.1 & 18119.9 & 102432.2 & 89148.4 \\
\hline 39 & 285562.4 & 232088.1 & 20618.9 & 17770.4 & 103511.9 & 87464.1 \\
\hline 40 & 288983.2 & 228027.5 & 20829.9 & 17429.4 & 104616.4 & 85822.7 \\
\hline 41 & 292481.2 & 224065.7 & 21044.4 & 17096.0 & 105742.6 & 84220.0 \\
\hline 42 & 295929.3 & 220104.2 & 21259.9 & 16768.0 & 106867.6 & 82636.9 \\
\hline 43 & 299323.6 & 216144.4 & 21476.3 & 16445.3 & 107990.0 & 81072.7 \\
\hline 44 & 302788.1 & 212277.8 & 21695.6 & 16129.4 & 109131.0 & 79543.0 \\
\hline 45 & 306323.3 & 208501.2 & 21918.1 & 15820.2 & 110290.4 & 78046.7 \\
\hline 46 & 309929.6 & 204811.5 & 22143.5 & 15517.4 & 111468.3 & 76582.7 \\
\hline 47 & 307896.9 & 197542.0 & 22290.1 & 15165.2 & 111795.4 & 74570.3 \\
\hline 48 & 311922.7 & 194296.0 & 22520.8 & 14875.8 & 113028.3 & 73196.8 \\
\hline 49 & 315655.7 & 190894.5 & 22750.5 & 14589.8 & 114230.4 & 71820.6 \\
\hline 50 & 319484.7 & 187582.6 & 22984.7 & 14310.7 & 115460.6 & 70479.7 \\
\hline 51 & 323406.1 & 184354.4 & 23223.0 & 14037.9 & 116715.7 & 69170.7 \\
\hline 52 & 327187.2 & 181077.4 & 23460.7 & 13768.6 & 117954.5 & 67868.8 \\
\hline 53 & 331007.1 & 177855.8 & 23701.1 & 13504.6 & 119207.3 & 66591.9 \\
\hline 54 & 334911.7 & 174712.4 & 23945.0 & 13246.2 & 120481.7 & 65343.5 \\
\hline 55 & 338967.4 & 171677.8 & 24193.6 & 12993.8 & 121789.1 & 64128.7 \\
\hline 56 & 336742.3 & 165583.4 & 24350.9 & 12697.4 & 122130.8 & 62435.6 \\
\hline 57 & 341048.5 & 162816.3 & 24602.0 & 12454.7 & 123465.7 & 61279.6 \\
\hline 58 & 345168.7 & 159983.8 & 24854.2 & 12215.9 & 124788.7 & 60132.3 \\
\hline 59 & 349403.6 & 157229.8 & 25111.5 & 11982.9 & 126143.6 & 59014.7 \\
\hline 60 & 353748.5 & 154548.5 & 25373.4 & 11755.2 & 127527.0 & 57924.2 \\
\hline
\end{tabular}

Table D.52. Pay Items for Case B-100\% Penetration

\begin{tabular}{|c|c|c|c|c|c|}
\hline Number & Stage & Description & Unit & Quantity & Present Cost (\$) \\
\hline 1 & Material \& Construction & $\begin{array}{c}\text { HOT-MIX ASPHALT SURFACE } \\
\text { COURSE }\end{array}$ & TON & 1531.00 & $\$ 179,417.81$ \\
\hline 2 & Maintenance \& Rehabilitation & $\begin{array}{c}\text { HOT-MIX ASPHALT SURFACE } \\
\text { COURSE REPLACEMENT } \\
\text { OVER PATCHES }\end{array}$ & TON & 1530.92 & $\$ 122,168.29$ \\
\hline 3 & Maintenance \& Rehabilitation & $\begin{array}{l}\text { HOT-MIX ASPHALT SURFACE } \\
\text { COURSE REPLACEMENT } \\
\text { OVER PATCHES }\end{array}$ & TON & 1530.92 & $\$ 88,256.97$ \\
\hline 4 & Maintenance \& Rehabilitation & $\begin{array}{c}\text { HOT-MIX ASPHALT SURFACE } \\
\text { COURSE REPLACEMENT } \\
\text { OVER PATCHES }\end{array}$ & TON & 1530.92 & $\$ 63,758.71$ \\
\hline 5 & Maintenance \& Rehabilitation & $\begin{array}{l}\text { HOT-MIX ASPHALT SURFACE } \\
\text { COURSE REPLACEMENT } \\
\text { OVER PATCHES }\end{array}$ & TON & 1530.92 & $\$ 48,865.74$ \\
\hline
\end{tabular}




\begin{tabular}{|c|c|c|c|c|c|}
\hline Number & Stage & Description & Unit & Quantity & Present Cost (\$) \\
\hline 6 & Maintenance \& Rehabilitation & $\begin{array}{c}\text { HOT-MIX ASPHALT SURFACE } \\
\text { COURSE REPLACEMENT } \\
\text { OVER PATCHES }\end{array}$ & TON & 1316.59 & $\$ 32,208.31$ \\
\hline 7 & Maintenance \& Rehabilitation & EPOXY PVT MK LINE 6 & FOOT & 10560.00 & $\$ 7,427.19$ \\
\hline 8 & Maintenance \& Rehabilitation & EPOXY PVT MK LINE 6 & FOOT & 10560.00 & $\$ 5,365.56$ \\
\hline 9 & Maintenance \& Rehabilitation & EPOXY PVT MK LINE 4 & FOOT & 10560.00 & $\$ 4,077.67$ \\
\hline 10 & Maintenance \& Rehabilitation & EPOXY PVT MK LINE 6 & FOOT & 10560.00 & $\$ 3,876.20$ \\
\hline 11 & Maintenance \& Rehabilitation & EPOXY PVT MK LINE 6 & FOOT & 10560.00 & $\$ 2,970.78$ \\
\hline 12 & Maintenance \& Rehabilitation & EPOXY PVT MK LINE 4 & FOOT & 10560.00 & $\$ 2,945.80$ \\
\hline 13 & Maintenance \& Rehabilitation & EPOXY PVT MK LINE 4 & FOOT & 10560.00 & $\$ 2,128.11$ \\
\hline 14 & Maintenance \& Rehabilitation & EPOXY PVT MK LINE 6 & FOOT & 9081.60 & $\$ 1,958.10$ \\
\hline 15 & Maintenance \& Rehabilitation & EPOXY PVT MK LINE 4 & FOOT & 10560.00 & $\$ 1,631.02$ \\
\hline 16 & Maintenance \& Rehabilitation & EPOXY PVT MK LINE 4 & FOOT & 9081.60 & $\$ 1,075.03$ \\
\hline 17 & Maintenance \& Rehabilitation & $\begin{array}{l}\text { BITUMINOUS MATERIALS } \\
\text { (PRIME COAT) }\end{array}$ & GAL & 234.67 & $\$ 168.28$ \\
\hline 18 & Maintenance \& Rehabilitation & $\begin{array}{l}\text { BITUMINOUS MATERIALS } \\
\text { (PRIME COAT) }\end{array}$ & GAL & 234.67 & $\$ 121.57$ \\
\hline 19 & Maintenance \& Rehabilitation & $\begin{array}{l}\text { BITUMINOUS MATERIALS } \\
\text { (PRIME COAT) }\end{array}$ & GAL & 234.67 & $\$ 87.83$ \\
\hline 20 & Maintenance \& Rehabilitation & $\begin{array}{l}\text { BITUMINOUS MATERIALS } \\
\text { (PRIME COAT) }\end{array}$ & GAL & 234.67 & $\$ 67.31$ \\
\hline 21 & Maintenance \& Rehabilitation & $\begin{array}{l}\text { BITUMINOUS MATERIALS } \\
\text { (PRIME COAT) }\end{array}$ & GAL & 201.81 & $\$ 44.37$ \\
\hline
\end{tabular}

Table D.53. Fuel Cost for Case B-100\% Penetration

\begin{tabular}{|c|c|c|c|c|c|c|}
\hline & \multicolumn{2}{|c|}{ Passenger } & \multicolumn{2}{|c|}{ Medium Truck } & \multicolumn{2}{|c|}{ Large Truck } \\
\hline Year & Fuel (gal) & Present Cost (\$) & Fuel (gal) & Present Cost (\$) & Fuel (gal) & Present Cost (\$) \\
\hline 0 & 192886.0 & 496483.0 & 14073.8 & 38250.6 & 70586.5 & 184295.5 \\
\hline 1 & 195051.6 & 487434.3 & 14209.2 & 37493.8 & 71284.7 & 180697.4 \\
\hline 2 & 197290.3 & 478668.7 & 14349.8 & 36761.9 & 72013.1 & 177227.0 \\
\hline 3 & 199576.3 & 470111.6 & 14493.4 & 36048.4 & 72759.0 & 173847.4 \\
\hline 4 & 201907.0 & 461749.2 & 14639.5 & 35351.3 & 73519.5 & 170548.0 \\
\hline 5 & 204281.5 & 453572.3 & 14787.9 & 34669.5 & 74293.2 & 167323.2 \\
\hline 6 & 206538.2 & 445226.2 & 14935.4 & 33995.6 & 75051.7 & 164108.2 \\
\hline 7 & 208820.2 & 437034.3 & 15084.7 & 33335.3 & 75819.3 & 160957.9 \\
\hline 8 & 211141.9 & 429022.7 & 15236.0 & 32688.9 & 76598.3 & 157875.5 \\
\hline 9 & 213503.6 & 421185.9 & 15389.2 & 32056.0 & 77388.7 & 154858.8 \\
\hline 10 & 215905.6 & 413518.8 & 15544.4 & 31436.1 & 78190.5 & 151905.9 \\
\hline 11 & 218348.3 & 406016.8 & 15701.5 & 30829.0 & 79003.5 & 149015.1 \\
\hline 12 & 220977.5 & 398937.6 & 15863.2 & 30239.3 & 79853.1 & 146230.6 \\
\hline 13 & 219522.3 & 384767.5 & 15976.7 & 29568.5 & 80130.4 & 142464.4 \\
\hline 14 & 222111.8 & 377967.3 & 16134.0 & 28990.0 & 80951.2 & 139731.8 \\
\hline 15 & 224691.0 & 371219.6 & 16295.1 & 28426.7 & 81788.3 & 137064.8 \\
\hline 16 & 227327.5 & 364636.5 & 16459.6 & 27877.3 & 82645.3 & 134466.9 \\
\hline 17 & 230019.1 & 358207.5 & 16626.9 & 27340.5 & 83519.0 & 131930.6 \\
\hline 18 & 232715.0 & 351850.3 & 16795.9 & 26814.0 & 84399.7 & 129438.6 \\
\hline 19 & 235313.4 & 345416.5 & 16964.6 & 26294.5 & 85269.1 & 126963.1 \\
\hline 20 & 237961.1 & 339129.1 & 17135.6 & 25785.9 & 86152.4 & 124542.0 \\
\hline 21 & 240658.2 & 332983.4 & 17308.9 & 25288.1 & 87049.3 & 122173.3 \\
\hline 22 & 243405.1 & 326974.9 & 17484.5 & 24800.6 & 87959.7 & 119855.5 \\
\hline
\end{tabular}




\begin{tabular}{|c|c|c|c|c|c|c|}
\hline & \multicolumn{2}{|c|}{ Passenger } & \multicolumn{2}{|c|}{ Medium Truck } & \multicolumn{2}{|c|}{ Large Truck } \\
\hline Year & Fuel (gal) & Present Cost (\$) & Fuel (gal) & Present Cost (\$) & Fuel (gal) & Present Cost (\$) \\
\hline 23 & 246500.3 & 321488.1 & 17667.9 & 24330.8 & 88935.2 & 117655.1 \\
\hline 24 & 244914.1 & 310115.9 & 17790.6 & 23786.3 & 89228.3 & 114604.7 \\
\hline 25 & 247737.6 & 304554.5 & 17965.8 & 23320.8 & 90136.7 & 112399.4 \\
\hline 26 & 250623.8 & 299128.7 & 18146.1 & 22868.8 & 91074.5 & 110261.0 \\
\hline 27 & 253582.7 & 293844.9 & 18330.3 & 22428.1 & 92035.1 & 108178.7 \\
\hline 28 & 256609.7 & 288691.8 & 18517.6 & 21997.4 & 93015.4 & 106146.4 \\
\hline 29 & 259684.4 & 283641.7 & 18707.6 & 21575.8 & 94010.5 & 104157.4 \\
\hline 30 & 262619.5 & 278492.8 & 18896.7 & 21159.1 & 94987.6 & 102174.7 \\
\hline 31 & 265615.1 & 273465.4 & 19088.4 & 20751.2 & 95981.0 & 100236.2 \\
\hline 32 & 268671.0 & 268555.1 & 19282.7 & 20351.9 & 96990.4 & 98340.1 \\
\hline 33 & 271787.6 & 263757.6 & 19479.7 & 19961.0 & 98015.7 & 96485.1 \\
\hline 34 & 275030.4 & 259130.6 & 19680.5 & 19579.4 & 99068.3 & 94680.8 \\
\hline 35 & 273242.9 & 249948.0 & 19814.5 & 19138.5 & 99378.7 & 92211.1 \\
\hline 36 & 276621.4 & 245668.5 & 20014.8 & 18768.9 & 100435.5 & 90477.4 \\
\hline 37 & 279906.1 & 241345.2 & 20217.7 & 18406.9 & 101495.1 & 88768.9 \\
\hline 38 & 283274.5 & 237135.6 & 20424.7 & 18053.8 & 102580.2 & 87104.8 \\
\hline 39 & 286723.4 & 233031.7 & 20635.3 & 17708.7 & 103687.4 & 85480.6 \\
\hline 40 & 290148.3 & 228946.9 & 20847.4 & 17369.6 & 104797.8 & 83879.6 \\
\hline 41 & 293504.2 & 224849.4 & 21059.9 & 17035.7 & 105902.8 & 82295.2 \\
\hline 42 & 296933.0 & 220850.7 & 21275.6 & 16708.8 & 107026.9 & 80746.3 \\
\hline 43 & 300785.4 & 217200.0 & 21500.7 & 16393.8 & 108230.2 & 79275.8 \\
\hline 44 & 298841.7 & 209511.1 & 21643.2 & 16021.8 & 108550.8 & 77194.8 \\
\hline 45 & 302380.4 & 205817.5 & 21860.1 & 15711.0 & 109682.8 & 75728.0 \\
\hline 46 & 305973.0 & 202196.9 & 22082.4 & 15408.5 & 110843.6 & 74300.5 \\
\hline 47 & 309670.4 & 198679.9 & 22309.3 & 15113.5 & 112034.0 & 72911.0 \\
\hline 48 & 313465.9 & 195257.2 & 22540.3 & 14825.2 & 113250.0 & 71555.8 \\
\hline 49 & 317311.4 & 191895.8 & 22774.2 & 14542.8 & 114482.5 & 70227.6 \\
\hline 50 & 321022.8 & 188485.7 & 23007.6 & 14263.9 & 115698.9 & 68906.6 \\
\hline 51 & 324821.7 & 185161.3 & 23244.4 & 13991.0 & 116937.2 & 67615.7 \\
\hline 52 & 328906.1 & 182028.7 & 23488.4 & 13726.0 & 118231.5 & 66372.9 \\
\hline 53 & 326838.8 & 175616.1 & 23643.3 & 13414.2 & 118582.3 & 64630.9 \\
\hline 54 & 330882.9 & 172610.8 & 23884.4 & 13156.2 & 119853.5 & 63421.1 \\
\hline 55 & 334878.6 & 169607.0 & 24129.0 & 12903.9 & 121136.4 & 62233.0 \\
\hline 56 & 338995.0 & 166691.1 & 24378.8 & 12657.7 & 122452.1 & 61076.6 \\
\hline 57 & 343225.8 & 163855.8 & 24633.1 & 12417.2 & 123796.9 & 59948.9 \\
\hline 58 & 347469.6 & 161050.3 & 24889.8 & 12181.2 & 125152.2 & 58840.0 \\
\hline 59 & 351623.0 & 158228.5 & 25146.9 & 11948.6 & 126499.6 & 57741.2 \\
\hline 60 & 355879.6 & 155479.5 & 25408.0 & 11721.0 & 127872.1 & 56667.7 \\
\hline
\end{tabular}

